Sandra Meireis

\title{
Mikro-Utopien der Architektur
}


Sandra Meireis

Mikro-Utopien der Architektur

Architektur Denken 12 


\section{Architektur Denken}

Architekturtheorie und Ästhetik

Herausgeber: Jörg H. Gleiter, Berlin

Beirat: Nathalie Bredella, Berlin

Tim Kammasch, Bern

Dietrich Neumann, Providence 
Sandra Meireis

\section{Mikro-Utopien der Architektur}

Das utopische Moment

architektonischer Minimaltechniken

[transcript] 
Diese Publikation wurde aus dem Open-Access-Publikationsfonds der Technischen Universität Berlin unterstützt und ebendort zugleich als Dissertation im Jahr 2020 u. d. T. Mikrotopoi der Architektur genehmigt.

Bibliografische Information der Deutschen Nationalbibliothek Die Deutsche Nationalbibliothek verzeichnet diese Publikation in der Deutschen Nationalbibliografie; detaillierte bibliografische Daten sind im Internet über https://portal.dnb.de/ abrufbar.

Dieses Werk ist lizenziert unter der Creative Commons Attribution 4.0 Lizenz (BY). Diese Lizenz erlaubt unter Voraussetzung der Namensnennung des Urhebers die Bearbeitung, Vervielfältigung und Verbreitung des Materials in jedem Format oder Medium für beliebige Zwecke, auch kommerziell.

https://creativecommons.org/licenses/by/4.0/deed.de

Die Bedingungen der Creative-Commons-Lizenz gelten nur für Originalmaterial. Die Wiederverwendung von Material aus anderen Quellen (gekennzeichnet mit Quellenangabe) wie z.B. Schaubilder, Abbildungen, Fotos und Textauszüge erfordert ggf. weitere Nutzungsgenehmigungen durch den jeweiligen Rechteinhaber.

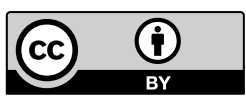

Erschienen $2021 \mathrm{im}$ transcript Verlag, Bielefeld

(c) Sandra Meireis

Gestaltung und Satz: Philipp Heinlein, Berlin

Druck: Majuskel Medienproduktion $\mathrm{GmbH}$, Wetzlar

ISBN (Print): 978-3-8376-5197-3

ISBN (PDF): 978-3-8394-5197-7

https://doi.org/10.14361/9783839451977

Gedruckt auf alterungsbeständigem Papier mit chlorfrei gebleichtem Zellstoff. Besuchen Sie uns im Internet: www.transcript-verlag.de Unsere aktuelle Vorschau finden Sie unter:

www.transcript-verlag.de/vorschau-download 
Für

Ella Pauline

\&

alle Geschöpfe

Deiner Generation 


\section{Inhalt}

8 Vorwort

10 Einführung

12 Das Themenfeld

18 Zur Quellenlage

21 Zur Methode der Arbeit

23 Zum Aufbau des Buches

26 Mikro-Utopos. Mikro-Utopoi. Mikro-Utopie(n)

29 Etymologische Herleitung

32 Geschichtsphilosophischer Kontext

38 Auflösung der Dichotomie Zentrum und Peripherie

42 Utopie in der Philosophie:

Zur Konstituierung politischer Vorstellungskraft

45 Klassischer Utopiebegriff

56 Geschichtsphilosophische Wende zur Praxis

61 Intentionaler Utopiebegriff

76 Exkurs: Macht und Herrschaft

84 Utopie in der Architektur:

Zur Konstituierung räumlicher Vorstellungskraft

87 Idealstadt und Stadtutopie

100 Architekturutopien der Moderne: Mensch und Technik

115 Utopie in der Postmoderne: Krise und Kritik 
122 Exkurs: Macht und Boden

132 Mikro-Utopien der Architektur:

Ästhetische Implikationen

135 Ästhetik architektonischer Minimaltechniken

146 Soziale Wende in der Architektur

154 Autonomie und Heteronomie in der Ästhetik

170 Exkurs: Macht und Geschlecht

178 Mikro-Utopien der Architektur:

Politische Implikationen

181 Politik architektonischer Minimaltechniken

196 Lokalismus und Postwachstum

205 Kulturelle Partikularität und partikulare Erzählungen

218 Zusammenfassung

224 Utopie und soziale Realität-

Nachwort von Jörg H. Gleiter

234 Anmerkungen

294 Literaturverzeichnis

324 Abbildungsverzeichnis 


\section{Vorwort}

Utopisches Denken ist eine kulturanthropologische Konstante, in der sowohl kritisches als auch idealisches Potential steckt. Die Versprachlichung einer Kritik setzt immer eine leidvolle bzw. als beklagenswert empfundene Erfahrung voraus, die entweder dem*der Kritiker*in selbst widerfahren ist, oder die er*sie im Schicksal anderer mitempfindet. Ohne diese ,Quelle der Empörung“

„,...] kann das Schwungrad der Kritik nicht in Gang kommen. Allerdings ist es ein weiter Weg vom Anblick des Leids bis zur artikulierten Kritik. Der Kritiker benötigt dazu eine theoretische Grundlage und eine argumentative Rhetorik. Nur so kann er sich zu Wort melden und das individuelle Leid in allgemeinwohlorientierte Begrifflichkeiten fassen."I

Von einer alltagssprachlichen Verwendung des Utopiebegriffs, d.h. einer ,phantastische[n] Lehre von einer idealen Gesellschaftsordnung ohne reale Grundlage; Hirngespinst, Schwärmerei“"2 habe ich mich im Verlaufe des Arbeitsprozesses gänzlich verabschiedet.

Ich bezweifle, dass menschengleichwürdiges Leben ohne utopische Intention jemals möglich war, möglich ist, oder möglich sein wird. Meine utopische Überzeugung ist unbedingt (im klassischen Sinne) humanistisch, jedoch nicht vorrangig anthropozentrisch motiviert.

Das Buch wurde vor Bekanntwerden des Ausbruchs von SARS-CoV-2 verfasst. Die Corona-Pandemie sensibilisiert die kollektive Wahrnehmung für die seit langer Zeit schon bestehende und sich immer konkreter abzeichnende sozialökologisch missliche planetare Lage. Mithin haben globalgesellschaftliche Fragestellungen — auch gerade auf der Ebene der Architektur und Stadt, für 
die das unmittelbare physische Miteinander von zentraler Bedeutung ist — neue Brisanz erlangt. Die Aktualisierung einer kritischen Geschichte und politischen Theorie der Architektur und Stadt ist seither noch dringlicher geworden, d.h. das Thema Utopie hat an Relevanz noch hinzugewonnen. Wie wollen wir auf und mit dem Planet Erde leben? Was bleibt uns zu hoffen? 
Einführung 
You assigned me to protect our lantern

to be intentional about the light

Utopia it's not elsewhere

Bird species never seen or heard before the first flute from the first fauna

Utopia is not elsewhere it's here

My instinct has been shouting at me for years saying let's get out of here toxic tumour bulging under the earth here need to purify the air here.

Björk (2017)

Utopia.

Ich bin. Wir sind.

Ernst Bloch (I964 [zuerst I9I8/23])

Geist der Utopie, S. I I. 


\section{Das Themenfeld}

Ausgangslage Um das Jahr 2000 dominierten zwei Phänomene die einschlägigen, deutschsprachigen Fachzeitschriften und Feuilletons in Architektur und Städtebau. Einerseits wurde von ikonischen Bauten berichtet, die globusumspannend errichtet wurden und teils beispiellose städtische Formationen hervorbrachten, z. B. Dubai-Stadt in den Vereinigten Arabischen Emiraten. Andererseits füllte die Berliner Debatte um die Kritische Rekonstruktion die nationalen Blätter; ein Thema das bereits seit der Internationalen Bauausstellung (IBA) I984/87 und nach dem Mauerfall verstärkt diskutiert wurde.

Bewahrt man eine kritische Distanz zu beiden Entwicklungen, ergibt sich Folgendes: Auf der einen Seite geht die globale Architekturavantgarde leichthin einen Schulterschluss mit den neuesten, digitalen Technologien ein. Auf der anderen Seite stehen die städtischen Traditionalisten, die Neuerungen vorwiegend im Sinne des Bewahrens einsetzen. Beiden Entwicklungen gemeinsam ist-auf lokaler und globaler Ebene-die Suche nach einer identitätsstiftenden Architektursprache. Und beide Richtungen setzen in unterschiedlicher Weise architektonisch fort, was sich bereits seit Mitte der I980er Jahre in der politischen Rhetorik als ,neoliberale Alternativlosigkeit" durchgesetzt hat: ein im Kern liegendes konservatives Werte- und Wirtschaftssystem.

Im Schatten dieser Entwicklungen, im Zuge der deutschen Wiedervereinigung und der Debatte um schrumpfende Städte keimte allerdings etwas auf, das zunächst kaum als architektonisches Phänomen wahrgenommen wurde. Temporär angelegte und scheinbar folgenlose urbane Interventionen entstehen auf spielerische Weise in liminalen Räumen, d.h. am Rande des gesellschaft- 
lichen Geschehens, sowohl örtlich als auch im Diskurs, z. B. in Zwischennutzungsprojekten auf (meist städtischen) Brachflächen.

Solche Projekte zeichnen sich weitgehend durch das Fehlen klassischer Zuschreibungen aus, die bis heute als Referenz dienen, wenn es um die qualitative Bestimmung von Architektur geht: firmitas (Festigkeit), utilitas (Zweckmäßigkeit/Nützlichkeit) und venustas (Anmut/Schönheit), so die Vitruvianische Trias. Hier sollte jedoch festgehalten werden, dass das Fehlen dieser Zuschreibungen nur dann zutrifft, wenn man sich eng an der inhaltlichen Auslegung von Vitruvs ästhetischen Grundbegriffen orientiert: Demnach bezieht sich die Kategorie Festigkeit auf den festen Untergrund der Fundamente, die sorgfältige Baukonstruktion und Auswahl der Baustoffe; die Kategorie Zweckmäßigkeit bezieht sich auf die fehlerfreie Anordnung der Räume hinsichtlich ihrer Benutzung; und die Kategorie Anmut bezieht sich auf das angenehme, gefällige Aussehen, wobei die Proportion bzw. Symmetrie der Bauglieder eine übergeordnete Rolle spielt. ${ }^{I}$

Im Fehlen dieser klassischen Zuschreibungen liegt aber zugleich das kritische Potential der in der vorliegenden Arbeit im Fokus stehenden ästhetischen Praktiken und somit, wie im Folgenden argumentiert wird, ihr utopisches Moment begründet.

Die Beiläufigkeit dieser kritisch-ästhetischen Praxis ist von eminent politischer Natur; das betrifft sowohl die sinnliche als auch die diskursive Ebene des Ästhetischen. Mikro-Utopien entstehen durch architektonische Minimaltechniken. ${ }^{2}$

Erkenntnisinteresse In den I990er und 2000er Jahren konnte die Kommodifizierung ${ }^{3}$ des städtischen Raums zunehmend zum bestimmenden Faktor seiner Gestaltung und Organisation werden. Das ist eine Folge des verbreiteten Anstiegs wirtschaftsliberaler Stadtpolitik, die auch die Raum- und Kulturproduktion durchdringt. In diesem Zusammenhang ist oftmals die Rede von einem „Ausverkauf der Städte“, worin sich ein Unbehagen gegenüber der Entwicklung artikuliert, dass das komplexe Gebilde Stadt an seinem Warenwert gemessen wird. In dieser Zeit schien die gesellschaftspolitische Dimension von Architektur anderen Fragestellungen nachrangig zu sein. Ein offener Austausch über kritische, sozialpolitische Themen schien deshalb nur noch in Verbindung mit informellen Praktiken, die mit Hilfe von architektonischen Minimaltechniken Eingang in die Gestaltung der Stadt fanden, 
möglich. Da dies zunächst nur eine Annahme sein konnte, erwuchs das Forschungsinteresse an jener neuen Architekturströmung, aus der Frage, ob Projekte, die einer kritischen Architekturpraxis zugerechnet werden können, zu einer ,Re-politisierung urbanen Denkens" beitragen würden. Aber was soll das heißen?

Auch Technikoptimismus (Technik-Firmitas), Orientierung an Altbewährtem (Gebrauch-Utilitas) und die Suche nach der guten Proportion (Ästhetik - Venustas) unterliegen Prozessen politischer Willensbildung, erst einmal dahingestellt welcher Überzeugung sie jeweils entspringen. Obwohl die Begründungszusammenhänge sich ändern, bilden die klassischen Themen der Architektur, hier mit den Vitruvianischen Grundbegriffen gleichgesetzt, weiterhin die Grundlage des kritischen bzw. politischen Urteilens. Letztlich war damit aber die Anerkennung einer als Fehlstelle empfundenen, mit politischem Optimismus geführten Debatte im Architekturdiskurs formuliert und die Relevanz für weiterführende Überlegungen im Rahmen der vorliegenden Arbeit gegeben.

Forschungsfrage und -hypothese Die dargelegten Vorüberlegungen und Vermutungen führten zu folgender Forschungsfrage:

> Zeigt sich in der gegenwärtigen kritischen Architekturpraxis eine veränderte Erscheinungsform utopischen Denkens und Handelns?

Und zu folgender Hypothese:

> Ja, in der Architektur zeigt sich eine Wiederkehr der Utopie als Mikro-Utopien. Die Utopie-als geschichtsphilosophisches Modell-unterliegt gesellschaftlichen Wandlungen, d.h. heute reflektiert sie die spätmoderne Tendenz der kulturellen Partikularisierung.

Zentrale Begriffe Mikro-Utopie(n) ist die titelgebende Wortschöpfung. Ausgehend vom Utopiebegriff entsteht die Ableitung MikroUtopie bzw. Mikro-Utopos. Etymologisch aus dem Griechischen hergeleitet bedeutet U-tópos „Nicht-Ort“ (Ou-tópos); die Bedeutungsebene ,guter Ort“ (Eu-tópos) erschließt sich erst im anglophonen Sprachgebrauch (mit Thomas Morus' Utopia). Entsprechend dem Präfix mikro- (Gr. klein, eng) und dem Wortstamm -tópos (Altgr. Ort, Erzählung; Pl. -topoi) lassen sich Mikro-Utopoi bzw. Mikro-Utopien etwa als ,kleine gute Orte“ oder ,gute Kleinsterzählungen“ frei übersetzen. Im jeweiligen Mikro-Utopos wird 
keine umfassende Utopie im Sinne eines Staatsentwurfs entwickelt, sondern es werden lediglich Momente, d. h. spezielle sozialpolitische, ökologische und/oder ökonomische Aspekte von Zukunftsentwürfen erprobt.

Architektonische Minimaltechniken bezeichnet die Entstehungsbedingungen von Mikro-Utopien im Feld der Architektur, d.h. die Umstände (Kontext, Formgebung und Methodik) unter denen kritisch-ästhetische Architekturprojekte hergestellt werden. Es galt Konnotationen zu vermeiden, die bisher kursierende Begriffskonstruktionen in unterschiedlichen Fachbereichen hervorgerufen hätten; außerdem rückt damit die Architektur im Gegensatz zum Städtischen in den Fokus.

Kulturelle Partikularität fokussiert den geschichtsphilosophischen Blick auf das Geschehen im Kleinen. Im Anschluss an das postmoderne Abwenden von den großen, universellen Erzählungen bildet sich eine herrschaftskritische Weltperspektive heraus. Auf diese pluralistische Ausdifferenzierung reagiert auch die Utopie als geschichtsphilosophisches Denkmodell.

Verknüpfung von Utopie und Architektur In der Geschichte der Utopie nehmen Architektur und Städtebau einen zentralen Stellenwert ein. Stadtplanerische Entwicklungen gehen Hand in Hand mit Vorstellungen über ihr Gemeinwesen. Seit Anbeginn der Sesshaftwerdung des Menschen wird im Nachdenken über Gesellschaft die politische mit der räumlichen Ordnung verknüpft_— so auch im Politisch-spekulativen. Man könnte auch sagen: Utopie ist ohne Architektur nicht denkbar.

Die Idealstadt gilt als Abbild einer bestehenden politischen Ordnung, die Utopie als Entwurf einer kommenden politischen Ordnung. Die Verknüpfung von Architektur und Utopie wird in Umbruchzeiten, wenn die Frage „Wie wollen wir leben?“ Dringlichkeit annimmt, umso stärker wahrgenommen. Dies kann zur Ausgangsbedingung utopischen Denkens werden.

Die ihrem Wesen nach, umstrittene Natur des Utopiekonzepts und die wechselhafte Geschichte utopischen Denkens kann zurückgeführt werden auf das Paradoxon, das wesentlich bereits in Morus' Begriffsbildung Utopia (I5I6) begründet liegt: Ist der gute Ort (eu-tópos) per definitionem ein Nicht-Ort (ou-tópos)? Im Wortstamm selbst steckt also bereits die räumliche Dimension der Zukunft, wie auch immer diese aussieht. 
In der Utopiegeschichte entwickeln sich zwei Hauptlinien: anarchistische (herrschaftsfreie) Landgemeinschaften (Arkadien, Garten Eden) und archistische (herrschaftsbezogene) Stadtgesellschaften (Utopien, Jenseits von Eden); letztere steht hier im Fokus.

Die Idealstädte der Renaissance gelten als das ursprüngliche archistische Utopiemodell. Sie stellen ein an geometrischen Grundfiguren ausgerichtetes ,sekundäres System“ dar, ein Artefakt der Ratio, das dem Chaos der Natur entzogen und menschlicher Kontrolle unterworfen ist.

Wenn man die Ursprungsidee der Stadt als symbolische Repräsentation des Universums versteht, d.h. dass Stadtpläne nicht auf der Zufälligkeit praktischer Erwägungen beruhen, sondern in kosmologischen Vorstellungen wurzeln, kann sogar davon ausgegangen werden, ,daß die Stadt selbst die erste Utopie war." ${ }^{4}$ Der geordnete Mikrokosmos der Stadt wurde als ein Abbild makrokosmischer, transzendentaler Ordnungen verstanden. ${ }^{5}$

In der Figur des Hippodamos von Milet, einem Staatstheoretiker und Städteplaner der griechischen Antike aus dem 5. Jahrhundert v. Chr., vereinen sich bereits zwei wesentliche Aspekte: die Suche nach der besten Staatsverfassung und die stadtplanerische Arbeit. Seine staatstheoretischen Überlegungen korrespondieren aber nicht unmittelbar mit seiner urbanistisch-praktischen Tätigkeit. Hippodamos äußerte sich lediglich im Rahmen seiner Staatstheorie zur Einteilung des Stadtterritoriums. ${ }^{6}$ Hippodamos' Schrift ist zwar verloren gegangen, aber in der Kritik von Aristoteles, der die scheinbar miteinander korrespondierende soziologische und räumliche Dreiteilung infrage stellt, überliefert:

„,[Hippodamos] jedenfalls unternahm es als erster der nicht politisch Tätigen, sich über die beste Staatsverfassung zu äußern. Er richtete einen Staat ein [...], den er in drei Teile [aus Handwerkern, Bauern und Waffentragenden] aufteilte. [...] Und das Land unterteilte er in drei Teile, in ein geheiligtes, ein öffentliches und ein privates."7

Noch bevor die Utopie sich schließlich in der Renaissance mit Morus' Utopia und Tommaso Campanellas Civitas solis (Lat. Sonnenstaat, I602) explizit als literarische Gattung entwickelte, erschuf der Architekt Antonio di Pietro Averlino alias Filarete in der ersten Hälfte des I 5. Jahrhunderts die Idealstadt Sforzinda. Er begründete damit ein Urmodell für die Architektur- und Utopiege- 
schichte. Später entstandene Raum-Utopiemodelle werden dazu, annähernd oder abgrenzend, in Bezug gesetzt, z. B. die Stadtutopien der Industrialisierung, die technischen und sozialen Utopien der Moderne, die Sonderform der Heterotopie in der Postmoderne oder die Mikro-Utopien der Globalisierungsmoderne. 


\section{Zur Quellenlage}

Die zyklische Wiederkehr des Utopischen lässt sich zeitdiagnostisch erklären: Die utopische Phantasie wird seit jeher durch den Wunsch nach der Beseitigung von Missständen veranlasst. In Krisenzeiten ist der Traum vom guten Leben zentral. Utopisch denken bedeutet letztlich die Krisenhaftigkeit einer Situation anzuerkennen. So lässt sich die gegenwärtige Entwicklung in eine historische Reihe von Umbruch- und Übergangssituationen aufnehmen, in denen Utopien besonders häufig entstanden sind und intensiv bearbeitet wurden: Dazu zählt Platons Politeia, verfasst in einer Zeit als das Großreich Alexanders erwuchs; die Idealstädte der Renaissance begleiten den Übergang von der mittelalterlichen Feudal- zur späteren Bürgergesellschaft; oder Stadtutopien, die zu Beginn der industriellen Revolution den Entstehungsweg des Industrieproletariats säumen. ${ }^{8}$ Und nun heute, im Zuge der Digitalen Revolution, die ganze Gesellschaften vor ungeklärte Zukunftsfragen stellt, scheinen utopische Konzepte erneut brisante Relevanz zu erlangen. ${ }^{9}$

Auf das letzte größere Hoch-im Glaube an utopische Modelle um I968 - , folgte das letzte größere Tief-mit dem Zusammenbruch der kommunistischen Regime I989/9I, gepaart mit dem Eintritt in die „Postmoderne“ und damit dem Wandel des kollektiven Zeitbewusstseins - , in dem sich utopische Energien vorübergehend erschöpften. ${ }^{\text {Io }}$

In aktuellen kulturellen Diskursen weicht die Skepsis allmählich. Die Wiederkehr der Utopie ist zu einer denkbaren Notwendigkeit geworden, wenn die weltweit wahrgenommene und sich zuspitzende Krisensituation-der Klimawandel und die soziale Frage als Folgen des neoliberalen Wirtschaftens bzw. einer marktfundamentalistischen Weltordnung - eine positive Wendung erfah- 
ren soll. Ein systemisches Umdenken ist nötig, wenn sich der Mensch ein Überleben auf der Erde im heutigen Sinne-transhumanistische Tendenzen sind in der vorliegenden Arbeit unterrepräsentiert-sichern will. Es sei vorweggenommen, dass die Verknüpfung beider Bereiche weder abschließend, noch erschöpfend behandelt werden kann.

Quellenlage in der Utopieforschung Trotz ihrer literarischen Tradition — „mit geringer poetischer Potenz"II — ist die Utopie keine explizit literarische Gattung. ${ }^{\text {I2 }}$ Die Buchutopie, z. B. Marge Piercys Er, Sie und Es, I99I und die nicht-literarische (mündliche) Gruppenutopie, z. B. ökologisch oder feministisch motivierte Bewegungen führen eine intime Beziehung, sie entstehen zuweilen in Resonanz zueinander. Die Unterschiede und Zusammenhänge dieser Utopietypen sind fließend. ${ }^{13}$ Erweitert um die konkrete Verräumlichung, z. B. die Freistadt Christiania in Kopenhagen/Dänemark, die Experimentalstadt Arcosanti in der Wüste Arizonas/USA oder die ,universelle Stadt“ Auroville im südindischen Bundesstaat Tamil Nadu und gleichzeitig Abstand nehmend von disziplinären Grenzziehungen, lässt sich resümieren, dass die Utopie eine Gattung der politischen Philosophie bzw. Theorie ist, ob nun verschriftlicht, mündlich, gezeichnet oder gebaut. Das skizziert bereits die unüberschaubare Fülle des über die letzten Jahrhunderte entstandenen und bis heute bekannten Materials.

Auf der einen Seite stehen also die utopischen Primärquellen und ihre Autor*innen, auf der anderen Seite hat sich zur Mitte des I9. Jahrhunderts mit dem Staatswissenschaftler Robert von Mohl die Utopieforschung als eigenständiger Wissenschaftszweig entwickelt.

Da für die vorliegende Arbeit zunächst insbesondere die historische Vertiefung des Utopiebegriffs ausschlaggebend ist-um dann in Abgrenzung dazu die veränderte Erscheinungsform des Utopischen bis in die Gegenwart zu verfolgen - wird vornehmlich vom aktuellen Stand der Utopieforschung, die auf den einzelnen Primärquellen basiert, ausgegangen. Im historischen Überblick wird dem umfangreichen Werk des Politologen und Utopieforschers Richard Saage eine zentrale Stellung eingeräumt; für die weitere Argumentation ist der intentionale, also sozialpsychologische Utopiebegriff von besonderem Interesse, der durch zent- 
rale Autoren der kritischen Theorie und anhand von Analysen der neueren Utopieforschung eingeführt wird.

Quellenlage in der Architekturforschung Wenn in der Disziplin der Architektur von utopischen Modellen die Rede ist, dann geschieht dies meist in Rekurs auf die Renaissance und die klassische Moderne. In der Renaissance stehen idealstädtische Modelle im Fokus, in der Moderne stehen neue Wohn- und Siedlungsmodelle, insbesondere der I920er und I960-70er Jahre, im Fokus.

Im aktuellen Architekturdiskurs erlangten sozialpolitische Fragestellungen in den letzten Jahren wieder Aufwind, womit eine Rückkehr des Interesses am Utopischen einhergeht. ${ }^{I 4}$ Gibt es gegenwärtig Utopien und wie zeigen sie sich? Konnte die Utopie einen neuen Platz bzw. Ort in der Gegenwart finden? Entsteht sie am Rande der kollektiven Wahrnehmung? Das ist im Anschluss an den jüngeren Utopiediskurs $\mathrm{zu}$ vermuten: Abstandnehmend von den in die Zukunft verlegten Zeit-Utopien, z. B. Louis-Sébastien Merciers L'An 2440 (Frz. Das Jahr 244O, I77I), ist die Tendenz erkennbar wieder zum Geltungsanspruch der älteren Raum-Utopien zurückzukehren; sprich, die Utopie wieder in die Gegenwart zu holen, ähnlich wie bei Morus, dessen ferne Insel Utopia allerdings für die meisten Menschen unerreichbar blieb. Im Unterschied dazu hat der Geltungsanspruch der heutigen Raum-Utopien eher

„den Status eines regulativen Prinzips, das immer nur annäherungsweise verwirklicht werden kann und nicht mehr auf eine revolutionäre Totalrevision der sozio-politischen Wirklichkeit abzielt."15

Der zugrundeliegende Hauptuntersuchungsgegenstand, MikroUtopien, die durch architektonische Minimaltechniken entstehen, wurde im Kontext der Utopie bisher nicht erforscht. Die realisierten Modellprojekte und dazugehörige Dokumentationen bilden die primäre Quellenbasis, um die Argumentation, die Utopie sei in die Gegenwart zurückgekehrt, darzulegen. 


\section{Zur Methode der Arbeit}

Am Anfang der Forschungsarbeit stand die empirische Beobachtung der alltäglichen Lebenswelt, in größeren europäischen Städten, wodurch das originäre Interesse an zeitgenössischen kritischen Architekturpraktiken geweckt wurde. Nach der Sichtung entsprechender Quellen wurde klar, dass die architekturwissenschaftliche Beschäftigung mit dem genannten Gegenstand entweder ihre historische Entwicklung umkreist, z. B. Fest- und Ausstellungsarchitekturen, sich auf materialtechnische Fragen konzentriert, z. B. innovative Pavillonstrukturen, oder mit einem sozialpolitischen Schwerpunkt unter der Sammelbezeichnung „kritische Raumpraxis bzw. -produktion“ lediglich dokumentarisch zusammengeführt wird. Ihr theoretischer Kontext wurde bislang vor allem durch kultur- und sozialwissenschaftliche Begriffe und Theorien geprägt, z. B. durch den Begriff und die Praxis der Aneignung (Michel de Certeau) oder die Akteur-Netzwerk-Theorie (Bruno Latour). Die Praktizierenden selbst verfolgen — näherungsweise bis explizit - eine anti-utopische Rhetorik, das ist, speziell für ein postmodern geprägtes Denken, geradezu idiosynkratisch.

Durch die hermeneutische Beschäftigung eröffneten sich auf der Ebene des Politischen größere Zusammenhänge. Anschließend erschloss sich, durch den Einbezug informierter Zufallsfunde, das weite Feld des Utopischen und damit die Utopieforschung.

Infolgedessen gesellte sich das Konzept der Utopie-als gleichberechtigter Untersuchungsgegenstand — neben die zunächst im Fokus stehende kritisch-ästhetische Architekturpraxis. Nach eingehender Beschäftigung mit der Begriffsgeschichte der Utopie verdichtete sich die Argumentation dahingehend, dass mindestens „utopische Momente“ in den meisten dieser Projekte stecken; und 
weiterhin durch diese Erkenntnis sogar von einer Veränderung der Erscheinungsform des Utopischen ausgegangen bzw. diese neu gedacht werden kann.

Die wissenschaftliche Begründung eines Mikro-Utopos weist also über das Feld der Architektur selbst hinaus. Die Zusammenfassung der gewonnenen Einzelerkenntnisse und ihre Übertragbarkeit über den Kerngegenstand (architektonische Minimaltechniken) auf ein erweitertes Feld (Geschichtsphilosophie) — unter ein allgemeines „Gesetz"16 (Mikro-Utopie), d. h. die geschichtsphilosophische Aktualisierung des Utopiemodells—schien damit gewährleistet. 


\section{Zum Aufbau des Buches}

Zuerst wird das neue Begriffskonzept Mikro-Utopos. MikroUtopoi. Mikro-Utopie(n) als dialektische Zusammenführung von Architektur und Utopie erläutert. Diese ,guten Kleinsterzählungen“ werden zusammengenommen als ,mikrohistorisch angelegte Alltagsgeschichte"I7, die seit den I980er Jahren der Makro- bzw. Strukturgeschichte kritisch gegenübergestellt wird, verstanden. Der Begriff Mikro-Utopie verweist demnach auf seine geschichtsphilosophische Dimension und Einbettung.

Im Kapitel Utopie in der Philosophie leitet ein historisch-kritischer Überblick in die wichtigsten Definitionen und Wendepunkte der Utopieforschung ein. Die utopischen Erscheinungsformen und Inhalte ändern sich entsprechend ihres Erscheinungsortes und -zeitpunktes; aber es kristallisiert sich eine Konstante heraus: Gleichbleibend ist der inhärent dialektische Charakter des Utopiekonzepts. Dies geschieht auf unterschiedliche Weise, z. B. wird die Kritik am Bestehenden durch den Entwurf eines Ideals (Gegenbild) oder im negativen Umkreisen des idealen Desiderats geübt. Damit erfüllt die Utopie, obwohl veränderlich, eine zentrale gesellschaftliche Funktion.

Im Kapitel Utopie in der Architektur wird die Parallelentwicklung der Architekturutopie zur Architektur- und Städtebaugeschichte und -theorie dargestellt; erläutert anhand der Idealstadt der Renaissance, gefolgt von einer definitorischen Abgrenzung zur Stadtutopie im I9. Jahrhundert und der heterogenen Entwicklung der Utopie im Architekturdiskurs des 20. Jahrhunderts. Trotz ihrer starken Verflechtung ändert sich der Stellenwert von Architektur und Städtebau in der Utopiegattung kontinuierlich, ebenso umgekehrt. Mal sind sie sich jeweils gegenseitig von symbolischer 
Natur, mal werden sie jeweils gegenseitig zur konstitutiven Disziplin. Ihre Gewichtungen verschieben sich, Richtungswechsel inbegriffen.

Im Kapitel Mikro-Utopien der Architektur: Ästhetische Implikationen werden die architektonischen Minimaltechniken eingeführt. Sie sind in den vergangenen Jahren verstärkt in das öffentliche Interesse gerückt und können einer sozialen Wende in der Architektur zugerechnet werden. Dieses neue ästhetische Phänomen reflektiert die gesellschaftliche Beschaffenheit; sie verleiht ihr eine konkret-spekulative Form. Dabei spielen der Kontext (Ort und Zeit), die Formgebung (Material und Konstruktion) und die Methodik (Organisation und Performanz) eine besondere Rolle; diese werden beschrieben und in den ästhetischen Diskurs eingeordnet, wozu Theorien und Konzepte in Architektur und Kunst der I990er, I960er und I930er Jahre in besonderer Weise beitragen.

Im Kapitel Mikro-Utopien der Architektur: Politische Implikationen wird die Ästhetik architektonischer Minimaltechniken um ihre politischen Implikationen erweitert, d.h. die Vorgehensweisen bezüglich Kontext, Formgebung und Methodik bilden aktuelle politische Debatten ab und werfen offene Fragen hinsichtlich der gesellschaftlichen, d.h. wachstumskritischen und digitalen Transformation auf. Hier wird klar, dass man es dabei in konkreter Ortsbezogenheit mit neuen utopischen Modellen zu tun hat. 

Mikro-Utopos.

Mikro-Utopoi.

Mikro-Utopie(n) 
[Es] sind die großen Menschen in der Geschichte, deren eigene partikuläre Zwecke das Substanzielle enthalten, welches Wille des Weltgeistes ist.

G. W. F. Hegel (I955 [zuerst I 822-3 I])

Vorlesungen über die Philosophie der Weltgeschichte, Bd. I, S. 90 [Hervorh. d. Verf.].

In der [bürgerlich]-individualistischen Gesellschaft [...] verwirklicht nicht nur das Allgemeine sich durchs Zusammenspiel der Einzelnen hindurch, sondern die Gesellschaft ist wesentlich die Substanz des Individuums.

Theodor W. Adorno (2003 [zuerst I95I])

Minima Moralia. Reflexionen aus dem beschädigten Leben, S. I6.

Small facts [can] speak to large issues.

Clifford Geertz ( I973)

Thick Description, S. 23. 
Etymologische Herleitung: Mikro-Utopie ist eine Begriffsneubildung bzw. Wortschöpfung, die in der Tradition utopischer Konzeptionen steht. Darüber können gegenwärtige architektonische Handlungsweisen als utopische Praktiken neu bestimmt werden. Das Präfix mikro- bezieht sich auf ihre Dimension und der Wortstamm -u-tópos bezieht sich auf das dialektische Wesen (Kritik und Ideal) dieser neuen utopischen Praxis.

Geschichtsphilosophischer Kontext: Der Neologismus MikroUtopie verweist zudem auf seine geschichtsphilosophische Dimension und Einbettung; das Konzept der Mikrogeschichte wird seit den I980er Jahren der Makro- bzw. Strukturgeschichte kritisch gegenübergestellt. Darüber lässt sich die doppelt konnotierte Arbeitshypothese erschließen: Erstens, die Utopie tritt gegenwärtig in Form von Mikro-Utopien in Erscheinung und zweitens, das Konzept der Utopie unterliegt der Partikularisierungstendenz der Spätmoderne.

Auflösung der Dichotomie Zentrum und Peripherie: Aus dem Zusammenspiel verschiedener Argumentationsebenen ergibt sich eine stabile Grundlage für die Theoriebildung der Mikro-Utopie. Das Phänomen der Auflösung der Dichotomie Zentrum und Peripherie wird anhand zweier Ansatzpunkte dargelegt: der Geschichtsschreibung von unten und der Philosophie kritischer Praxis. 


\section{Etymologische Herleitung}

Im Verlaufe der Arbeit kommen verschiedene Begriffsabwandlungen zum Einsatz: Mikro-Utopos, Mikro-Utopoi, MikroUtopie(n).

Die Einzelerscheinung Mikro-Utopos entfaltet erst in der Pluralform ihre volle Bedeutung für die vorgestellte Hypothese, denn ihr vielzähliges Auftreten ist entscheidend: Mikro-Utopoi bzw. (titelprägend) Mikro-Utopien bedeutet frei übersetzt soviel wie ,kleine gute Orte“ oder „gute Kleinsterzählungen“.

Mikro-Utopie, im Singular, bezeichnet das abstrakte, übergeordnete Konzept. Man könnte also sagen, die Mikro-Utopie ist die Gattung bzw. Lehre der konkret und vielfältig in Erscheinung tretenden Mikro-Utopoi. Im Feld der Architektur und des Städtebaus entsteht ein Mikro-Utopos durch architektonische Minimaltechniken.

Mikro-Utopos, -Utopoi, -Utopie(n) Die traditionelle Begriffsbildung dient als Ausgangspunkt zur Herleitung der Begriffsneubildung Mikro-Utopie, d.h. ausgehend vom $U$-topie-Begriff entsteht die Ableitung Mikro-U-topie(n):
mikro
Gr. klein, eng;
ou/eu
Gr. kein, ohne/gut;
tópos (Pl. topoi)
Altgr. Ort, Erzählung.

Mikro-Utopie ist eine neue Wortschöpfung, die sich in die Tradition zahlreicher Spielarten des Utopiebegriffs - insbesondere seit Morus' Urschrift Utopia - einreiht, im Deutschen lässt sich etwa jene Begriffsfolge aufstellen: 


\author{
$U$ topie Thomas Morus, I5I6 \\ Dys topie John Stuart Mill, I868 \\ Hetero topie Michel Foucault, I966 \\ ... topie \\ $A$ topie Helmut Willke, 200 I \\ Retro topie Zygmunt Bauman, 2017 \\ Mikro- $U$ topie Sandra Meireis, 20I6/I9
}

Das variierende Präfix bezeichnet die unterschiedlich angelegten Seinsweisen des jeweiligen Begriffskonzepts, während der Wortstamm -topie als wertneutrale und unveränderte Bezeichnung bestehen bleibt.

Räumliche Dimension der Dialektik (Wortstamm -tópos) Im Folgenden geht es um den begriffsgeschichtlichen Zusammenhang von politischem und räumlichem Denken, dargelegt anhand des Wortstammes -tópos.

Die Architektur und die Utopie sind nicht nur auf historischphilosophischer Ebene eng verknüpft, die Verknüpfung ist auch etymologisch interessant. Man kann die Utopie als ,dialektisches Übungsgespräch“ verstehen und zwar als Auseinandersetzung der Gesellschaft mit sich selbst. Auf das Vorgegebene wird mit einer Gegenposition (Kritik) reagiert. Das Wort Tópos hat

,als philosophischer Terminus im nicht-physikalischen Sinne [...] seinen Ursprung in der Aristotelischen Argumentationslehre: Als ,Topoi' bezeichnet Aristoteles diejenigen allgemeinen sprachlich-sachlichen Gesetzmäßigkeiten, die in [der] Dialektik [...] die methodische Konstruktion von Argumenten zur Erreichung vorgegebener Argumentationsziele ermöglichen." "I

Aristoteles versteht unter Dialektik die Kunst der zwingenden Argumentation in Frage und Antwort. Die Voraussetzung für den Einsatz der Topoi besteht dann darin, dass dem Argumentierenden sein Argumentationsziel klar vor Augen steht. Denn in einem dialektischen Übungsgespräch war dem Fragenden stets die Aufgabe gestellt, die vom Antwortenden anfangs eingenommene Position zu widerlegen, so dass als Argumentationsziel für den Fragenden von Anfang an das kontradiktorische Gegenteil der Position des Antwortenden feststeht. ${ }^{2}$ 
„Von hier aus klärt sich auch die dem Aristotelischen ToposBegriff zugrundliegende bildliche Vorstellung: Der Topos ist der (strategisch günstig gelegene) Ort, von dem aus im dialektischen Übungsgespräch der Angriff auf die gegnerische Position zu führen ist." 3

Mit diesem kurzen Rekurs auf die antike Vorgeschichte des Begriffs Tópos und seine ,stets durchscheinende spatiale Hintergrundmetaphorik eines festen Standpunkts, von dem aus ein Angriff erfolgt" ${ }^{4}$ sei verdeutlicht, dass der dialektischen Übung eine räumliche Dimension zugrunde liegt, die bereits im Wortstamm der U-topie enthalten ist. Der dialektische Raum bzw. Ort ist also seit der Antike durch seine agonale, argumentative Methode (Topik) bestimmt. Mit anderen Worten: Der Dialektik liegt eine Verräumlichung des Denkens zugrunde, die wiederum als zentrale Ausgangsbedingung der Utopie verstanden werden kann. Davon ausgehend lässt sich folgende Reihe aufspannen: Topik > räumliche Dimension der Dialektik > Utopie.

Übertragen auf den aktuellen, hier relevanten Architekturdiskurs heißt das, dass in Reaktion auf lokale Defizite oder Missverhältnisse temporäre Kleinstorte unterschiedlicher Wesensart entstehen, Mikro-Utopien, die durch architektonische Minimaltechniken errichtet werden.

Dementsprechend wird eine konkrete lebensweltliche Situation zur kritischen Ausgangsbedingung für das Nachdenken oder den Disput über „,bessere (Zukunfts-)Modelle“. Im weltlichen Hier und Jetzt werden unwirtliche Nicht-Orte (ou-topoi), z. B. innerstädtische Brachflächen, kurzfristig zu guten Orten (eu-topoi) umgestaltet. Utopische Experimente entwickeln sich aus der gelebten Gegenwart heraus und nisten sich unter Umständen in ihr ein. 


\section{Geschichtsphilosophischer Kontext}

Um die These, die Wiederkehr der Utopie als Mikro-Utopien unterliege der spätmodernen Partikularisierungstendenz, überblickshaft erfassen zu können, folgt ein kurzer Abriss zur historischen Veränderung der Utopie. Damit sei die Anpassung der politisch-spekulativen Theorie, der Utopie, an die veränderten Seinsbedingungen der Gesellschaftsgeschichte - von der Raum-Utopie zur MikroUtopie — dargestellt. Anschließend folgt die Einordnung der MikroUtopie in die Entwicklung der Mikrogeschichte.

Raum-Utopie, Zeit-Utopie, Heterotopie, Mikro-Utopie Unterschiedliche Utopiekonzepte haben immer schon parallel zueinander oder in Mischformen unscharf getrennt voneinander existiert; sie sind Teil der Menschheitsgeschichte. Lediglich ihre begriffliche Konzeptionierung fand zu unterschiedlichen Zeiten statt. Die Konzepte bleiben namenlos bzw. unbenannt bis zu jenem spezifischen Zeitpunkt, der ihre Benennungslücke spürbar macht und so eine Wortneuschöpfung veranlasst. Mit der Erschließung begrifflicher Lücken kann die Definition des Neubenannten beginnen.

Als Anhaltspunkt kann man sich eine Veränderung des Utopiemodells (in vier Schritten) vorstellen: Raum-Utopie I5I6, ZeitUtopie I77I, Heterotopie I967, Mikro-Utopie 2016/I9:

Die Raum-Utopie um I 500: Am Beginn der Neuzeit hatten die Menschen den Planet Erde bereits als Kugel entdeckt, jedoch noch nicht erschlossen. Die Utopie fand in der Vorstellung des Autors, im Beispiel von Morus' Utopia (I5I6) auf unbekanntem Terrain, einer unerreichbaren Ozeaninsel, gleichzeitig mit dem tatsächlichen Geschehen auf der Erde einen Ort bzw. Platz. Morus' Insel beherbergt insgesamt 54 Städte. Es ist ein Inselstaatmodell über 
das sich ein Netzwerk städtischer Entitäten spannt. Kennt man die Hauptstadt Amaurotum (Lat. Stadt im Nebel, in Anspielung auf Morus' Heimstatt London), kann man sich ein Bild von den anderen Städten machen, denn sie sind stadtplanerisch und gesellschaftsorganisatorisch jeweils gleichsam aufgebaut. Morus erfand damit die literarische Gattungsform der geschlossenen RaumUtopie.

Die Zeit-Utopie um I800: Im Entdeckungszeitalter war die Erde geografisch weitgehend erschlossen. Die Utopie weicht in die Zukunft aus. Im Beispiel von Merciers Das Jahr 2440 (I77I) wird ein Szenario der Stadt Paris um etwa 670 Jahre in die Zukunft verlegt. Mercier erfand damit die Zeit-Utopie. Er führt die Leser*innen mit Hilfe einer Zeitmaschine in das Neu-Paris des 25. Jahrhunderts. Die Stadtstruktur ist im Wesentlichen unverändert, das verkehrsbefreite Straßenbild von Fußgänger*innen gesäumt und die Häuser tragen Dachgärten. An den Schulen und Universitäten werden die Grundsätze der aufklärerischen Philosophie gelehrt, die christliche Religion ist zugunsten eines Wissenschaftskultes abgeschafft, es gibt eine einzige Bürgerklasse und das politische System ist eine Mischung aus Demokratie und aufgeklärtem Absolutismus. ${ }^{5}$

Die Heterotopie um 1970: Im Weltraumzeitalter erhielt die Weltgesellschaft erstmals einen ganzheitlichen Blick, aus extraterrestrischer Perspektive, auf den eigenen Planet als Teil des Universums, auf globale Zusammenhänge und die Unscheinbarkeit der menschlichen Existenz. Es ist eine Phase der Bewusstwerdung über die Einzigartigkeit und Fragilität der Erde, womit auch die Ökologie-Bewegung angestoßen wurde.

Mit der Möglichkeit des Ausweichens auf andere Planeten rücken schließlich Raum-Utopien (inklusive des Alls) wieder ins Zentrum gesellschaftlicher Alternativentwürfe. In dieser Zeit ersann der Soziologe und Philosoph Michel Foucault die Heterotopie (I966) als utopische Sonderform. Als Paradebeispiel eines heterotopischen Ortes gilt das Schiff (auf dem Meer; denkbar ist aber auch das Raumschiff); per definitionem führen diese Orte eine Parallelexistenz zur gesellschaftlichen Wirklichkeit, eingekapselt in ihr.

Die Mikro-Utopie seit den I990er Jahren: Die spätmoderne Informations- bzw. Wissensgesellschaft lässt sich, im Unterschied zur Agrar- oder Industriegesellschaft, mit der pluralen Ausdiffe- 
renzierung des Besonderen umschreiben. Obwohl unterschiedliche Maßstäbe weiterhin Bestand haben, dominiert heute die Sicht- und Erzählweise des Singulären bzw. Partikulären. Dementsprechend findet auch ein kultureller Prozess der Partikularisierung und Pluralisierung der Utopie statt, d.h. Mikro-Utopien (Begriffsschöpfung d. Verf. von 20I6) treten in lokalen Örtlichkeiten (partikular) global in Erscheinung (plural). Im fortgeschrittenen Netzwerkzeitalter verteilen sich Mikro-Utopien gleichmäßig über den gesamten Globus.

Der Soziologe Andreas Reckwitz imaginiert ein ähnliches Szenario und schreibt in seinem Buch Die Gesellschaft der Singularitäten (2017), dass es Prozesse der Kulturalisierung und Singularisierung in verschiedenen Konstellationen in der gesamten Gesellschaftsgeschichte schon immer gegeben habe. Er argumentiert, dass diese aber in der Spätmoderne eine neue Quantität und Qualität erlangten:

„Um die Explosion des Besonderen zu veranschaulichen, kann man sich mit einem Bild behelfen und an die Satellitenbilder von Earth's City Lights der NASA denken, die Kontinente bei Nacht zeigen und auf denen sich die Großstädte in ihrer nächtlichen Beleuchtung hell abheben. Würde man entsprechende Aufnahmen aus den Jahren O, I200, I800, I900, I950, I980 und 20 IO machen, wären dann gewiss auch einzelne Punkte und Pfade zu sehen - die alten Riten und Magier, die Kirchen und Hofgesellschaften, die romantischen Gemeinschaften und bürgerlichen Theater, die Kinos und Stars — , aber ab I980 würde man einer Helligkeitsexplosion gewahr: eine Ausdehnung immer aufdringlicher strahlender Singularitäten. Gewiss, nicht alles ist erleuchtet, denn der Hintergrund der Logik des Allgemeinen existiert weiter. Aber die bisherige Ausnahme hat sich zur Regel verkehrt_zur Gesellschaft der Singularitäten."6

In der Konzeptionierung der Utopie kommt es zu einer Verschiebung der Dominanten: Sie hat sich von einer staatstheoretischen Totalperspektive (geschlossen-statische Raum-Utopie) zu einem partikularen Alltagsphänomen (offen-dynamische Raum-Utopie) hin entwickelt. 
Entwicklung der Mikrogeschichte (Präfix mikro-) Im Folgenden wird das aktuelle Weltbild — die kulturelle Erzählweise der Partikularisierung — an ein Geschichtsverständnis der jüngeren Dekaden geknüpft. Die Argumentation lautet, dass die Verkleinerung und Vervielfältigung des Utopischen, Mikro-Utopoi, als Teilphänomen einer geschichtsphilosophischen Entwicklung gedeutet werden kann, die sich seit den I970er Jahren abzeichnete und schließlich in den I99oer Jahren — nach dem Fall des Eisernen Vorhangs — voll entfaltete. In der sogenannten Mikro- oder Alltagsgeschichte etabliert sich eine Erzählweise kleiner Narrative. Eine Zeit, die bekanntermaßen mit Jean-François Lyotards Ausspruch vom ,Ende der großen Erzählungen“ ( I979) und Francis Fukuyamas Bericht vom „Ende der Geschichte“ ( I989) postmodern geprägt wurde.

Dem Text Alltagsgeschichte, Mikro-Historie, historische Anthropologie (1998) des Historikers Alf Lüdtke zufolge, argumentieren Vertreter*innen der Mikro-Historie, dass Begriffe wie der einer Gesamtgeschichte fragwürdig geworden seien; dies gelte sowohl methodisch, d.h. wie lässt sich das „Gesamt“ definieren?, als auch inhaltlich angesichts der globalen Entwicklungen, z. B. im Respekt gegenüber der Eigenlogik indigener Kulturen. Es sei dringlich geworden,

„, eine Vorstellung von Geschichte zu dekonstruieren, die vom Konzept eines einheitlichen Prozesses der Zivilisation oder der Modernisierung angeleitet sei. Diese erweise sich als strikt eurozentrisch und verharre im Horizont , bürgerlicher' Gesellschaft."7

Die Entstehung der Mikrogeschichte lässt sich demzufolge als geschichtswissenschaftliches und politisches Projekt der I9809oer Jahre verstehen. Dies geschieht im Zuge der Erweiterung der klassischen Politik- bzw. Ereignisgeschichtsschreibung um ein sozialgeschichtliches Herangehen. Die spezifische Entwicklung der Mikrogeschichte ist auf den Zeitgeist erneuerungswilliger Protagonist*innen zurückzuführen. Ohne auf einzelne Denker*innen und Denkschulen, sprich genaue Entwicklungslinien, Differenzierungen und Herausbildungen des mikrogeschichtlichen Ansatzes - im Rahmen der vorliegenden Arbeit-einzugehen, ${ }^{8}$ seien hier wichtige Aspekte herausgegriffen, die zu einem vertieften Verständnis der Einordnung der Mikro-Utopie 
in die Mikrogeschichte_-das Präfix der Begriffe legt es bereits nahe-beitragen.

Die Qualität dieses Ansatzes liegt im mikrohistorischen Blick begründet, der eine lokale Konfiguration heraushebt und diese groß vor dem Auge der Forscher*in erscheinen lässt. ${ }^{9}$ Mikrohistorische Verfahren ${ }^{\text {Io }}$ können damit zu einem entscheidenden sozialgeschichtlichen Erkenntnisgewinn beitragen. Denn die Wechselbeziehung kultureller, sozialer und politisch-herrschaftlicher Momente gerät gerade dann — als lebensgeschichtlicher Zusammenhang — in den Blick, wenn historische Besonderheiten und Einzelheiten möglichst vielseitig und genau durchleuchtet werden. ${ }^{\text {II }}$

Die Mikrohistoriker Carlo Ginzburg und Carlo Poni führen in ihrem Text Was ist Mikrogeschichte? (1985) aus, dass gerade die Dokumentation des ,außergewöhnlich Normalen“"I2 von entscheidender Bedeutung ist. Denn dort kommen gelebte Erfahrungen der konkreten alltäglichen Lebenswelt zum Tragen, die anderen historiographischen Ansätzen unzugänglich bleiben. Mit Hilfe von

„Spuren, Indizien und Fehlleistungen [einer verborgenen Wirklichkeit], die die Oberfläche der Quellenüberlieferung stören und desorganisieren [...] lässt sich die tiefere, unsichtbare Ebene der sozialen Spielregeln erreichen."I3

Die mikrohistorische Analyse untersucht - in freudomarxistischer Prägung - die gelebten Erfahrungen, letztlich, um die zugrundeliegenden, unsichtbaren und unbewussten Strukturen erkennen zu können. ${ }^{\mathrm{I}}$

Genau diese Annahme, also dass die Konzentration auf ein begrenztes Beobachtungsfeld, z. B. ein Dorf, ein Stadtteil, eine soziale Gruppe, ein oder mehrere Individuen oder auch ein MikroUtopos, eine qualitative Erweiterung der historischen Erkenntnismöglichkeiten ${ }^{15}$ ergebe, wird von Kritiker*innen des mikrohistorischen Ansatzes infrage gestellt. Sie argumentieren, dass Einzelbetrachtungen alltäglicher Sonderfälle keinen Schluss über makrogeschichtliche Entwicklungen zuließen und seien damit nicht von Belang. Anders gewendet: Die Theoriefähigkeit von Alltagsgeschichte sei nicht gewährleistet.

Ohne dieser Aussage zuzustimmen, wird damit jedoch auf die größte Herausforderung, aber auch auf ,den größten potentiellen Reichtum der Mikro-Historie" "I6 hingewiesen: Die Analyse der Verhältnisse zwischen den betreffenden Gemeinschaften und 
der Außenwelt bildet die Schnittstelle zwischen einer lokalen Alltagsgeschichte und einer globalen Geschichtsperspektive. ${ }^{17}$ Denn obwohl es nicht möglich ist, die in einem ,mikroskopischen“ Bereich gewonnen Ergebnisse automatisch in einen ,makroskopischen" Bereich zu übertagen (und umgekehrt), sei darauf verwiesen, dass genau an dieser Schnittstelle ein Prozess der Theoriebildung stattfindet. Die Ableitung von Einzelerkenntnissen hin $\mathrm{zu}$ allgemeinen Gesetzen verläuft genau hier.

Übertragen auf die vorliegende Arbeit heißt das: Erst durch die Untersuchung partikularer Architekturphänomene (I. Hypothesenhälfte: plurale Mikro-Utopien) wurde eine makrohistorische Synthese (2. Hypothesenhälfte: Partikularität des Utopiemodells) möglich.

Die Betrachtung einzelner Fallbeispiele erreicht in der vorliegenden Arbeit nicht die Tiefe klassischer Mikrostudien; dies anzustreben war nicht zielführend. Ausschlaggebend ist hier indes die Vielheit der Mikro-Utopoi. Dadurch wird die Breite bzw. Ähnlichkeit des außergewöhnlich Normalen-Serialitätsprinzip ${ }^{18}$ — in seinem globalen Vorkommen aufgezeigt und hervorgehoben, sowohl auf ästhetischer als auch auf politischer Ebene. 


\section{Auflösung der Dichotomie Zentrum und Peripherie}

Im Ansatz der Mikrohistorie geht es auch um eine Abwendung vom postmodernen Geschichtsfragment, hin zu der Entwicklung einer konsistent kritischen Linie. ${ }^{19}$ So schreibt der Historiker Hans Medick, dass die Mikro-Historie ( 1994) einen methodischen Ausweg versuche

„,jenseits der Konzepte einer makrohistorischen Synthesenhistorie, aber auch jenseits der (zu) häufig als unausweichlich angesehenen Einbindungen historischen Forschens, Interpretierens und Darstellens in den Zustand postmoderner ,Fragmentarisierung ' und seiner Abwendung von globalen Sinneinheiten und Zusammenhängen. “20

Die vorliegende Arbeit ist als Beitrag zu einer Geschichtsschreibung von unten $\mathrm{zu}$ verstehen. Im alltäglichen Geschehen entstehen alternative Szenarien gemeinschaftlichen Lebens, Utopien von unten. Damit richten sich die Handlungen minoritärer, d.h. untergeordneter Gruppen oder „,subalterner Klassen“ gegen das Axiom großer Heroen und anonymer Strukturen, die Geschichte machen. ${ }^{2 \mathrm{I}}$ In einer Geschichte von unten setzt die gesellschaftliche Vorstellungskraft_-das utopische Bewusstsein-im Kleinen an und macht, vermittelt durch das Alltägliche, die Komplexität des Globalen begreifbar. Die ,positivistische Bescheidenheit“"22 des mikrogeschichtlichen Ansatzes steht demnach nicht im Widerspruch zur großen Denkfigur der Utopie. ${ }^{23}$

Bereits die politische Aktivistin und Denkerin Rosa Luxemburg legt die Betonung auf die Handlungstat und -kraft der*des Einzelnen und kehrt die Marx'sche These (I8. Brumaire, I852) syntaktisch um, die besagt, dass die Menschen zwar ihre eigene 
Geschichte machen, aber nicht aus freien Stücken und betont, dass die Menschen ihre Geschichte zwar nicht aus freien Stücken machen, aber sie machen sie selbst. ${ }^{24}$

Während das Streben der Menschen bzw. der revolutionären Arbeiterklasse bei Karl Marx an das geschichtlich Mögliche bzw. an die objektiven gesellschaftlichen Bedingungen ihres Tuns gebunden ist, d.h. sie müssen ihr Leben ,,unter [den] unmittelbar vorgefundenen, gegebenen und überlieferten Umständen“25 einrichten, stellt Luxemburg die Handlungsmacht der Menschen bzw. der deutschen Arbeiter*innen in den Vordergrund und legt (mit Ferdinand Lassalle, ein Wortführer der frühen deutschen Arbeiterbewegung) Nachdruck auf die ,befruchtende Initiative, auf die revolutionäre Energie und Entschlossenheit" ${ }^{26}$, womit das Leben eine selbstwählbare Alternative bereithält.

Das ist auch eine Weltauffassung, die der Philosophie der Praxis von Antonio Gramsci zugrunde liegt. Ihm scheint eine neue Lebensweise und Zivilisation möglich, in der alle Menschen ihr Denken und Fühlen auf den höchsten Stand der gesellschaftlichen Entwicklung bringen können. Dazu gehört die Überwindung der weltgeschichtlichen Unterscheidung von Kopf- und Handarbeit und die Selbstermächtigung zur Mitgestaltung des gemeinsamen Lebens. Wenn die Individuen sich selbst regieren, wird auch das Verhältnis von Führenden und Geführten, von Regierenden und Regierten aufgebrochen, es werde dann keine Hegemonie, d.h. Vorherrschaft einer Führung, mehr geben. ${ }^{27}$ Gramsci schreibt, dass

„, [d]ie Philosophie der Praxis [...] nicht darauf [zielt], die in der Geschichte und in der Gesellschaft bestehenden Widersprüche friedlich zu lösen, sondern ist im Gegenteil die Theorie der Widersprüche selbst; sie ist nicht das Regierungsinstrument herrschender Gruppen, um den Konsens zu haben und die Hegemonie über subalterne Klassen auszuüben; sie ist der Ausdruck dieser subalternen Klassen, die sich selbst zur Kunst des Regierens erziehen wollen und die daran interessiert sind, alle Wahrheiten zu kennen, auch die unerfreulichen $[\ldots] .{ }^{* 28}$

Kulturell und soziopolitisch marginalisierte Gruppen und Themen behaupten ihren Platz in der Gesellschaft oftmals in sogenannten dritten Räumen, Wegen und Narrativen, d.h. die Emanzipation von Minoritäten findet überwiegend in kleineren, sozialen Zwischen- 
räumen, z. B. in Mikro-Utopoi, ihren Ausgangspunkt; ebenso die sich mithin herausbildenden Theorien, z. B. in queerfeministischen oder postkolonialen Ansätzen, die der gesellschaftlichen Kolonisierung durch die traditionell patriarchale, christlich-westliche Hegemonie entgegentreten.

Im Weiteren stehen also räumliche Konfigurationen, durch die das Neue die Welt betreten kann, im Fokus. In diesem Sinne lassen sich Mikro-Utopien auch als „Ent-grenzungen“ lesen und sind

„für diejenigen, die im Feld des ,Normalen ' beheimatet sind, bedrohlich, denn sie machen das exkludierte Andere nicht nur sichtbar, sondern eröffnen ihm Widerstandsräume, in denen gegendiskursive Praktiken entwickelt werden können. Der paradiesische Nicht-Ort eröffnet somit Praktiken des Unmöglichen und erhebt das vormals Nichtige zum kritisch Seienden." 29

Andere Kulturen nehmen Einfluss auf die alte Welt; die Dichotomie Zentrum und Peripherie hat begonnen sich aufzulösen, jedenfalls ist eine solche Wandlung im gegenwärtigen kulturhegemonialen Diskurs zu verzeichnen. Mit der Überwindung des eurozentrischen Denkens öffnet sich auch eine andere Geschichtsschreibung. ${ }^{30}$ Noch Ende der I96oer Jahre schreibt Foucault,

„, [a]ls habe man dort, wo man daran gewöhnt war, nach Ursprüngen zu suchen, unbegrenzt [...] Traditionen zu rekonstruieren, [...] Teleologien zu entwerfen [...], eine eigenartige Abneigung verspürt, den Unterschied zu denken, Abweichungen und Dispersionen zu beschreiben, die vergewissernde Form des Identischen aufzulösen. [...] Als hätten wir Angst, das Andere in der Zeit unseres eigenen Denkens zu denken."31

Das Verhältnis zwischen dem auf was man hofft und die veränderten Bedingungen, die nötig sind um diese Hoffnungen zu realisieren, wird sowohl in den Künsten als auch in der politischen Praxis verhandelt.

Die US-amerikanische Bürgerrechtlerin und kritische Humanwissenschaftlerin Angela Davis sieht die zentrale Bedeutung des Wortes Utopie eher im negierenden no-place (Raum für/der Negation) als im entwerfenden better-place (Ort für/der Imagination) beheimatet; denn dies erinnere Gesellschaften daran, dass sie die Gegenwart als Überschneidung zwischen Vergangenheit 
und Zukunft selbst produzieren und kritisch hinterfragen können. Die bestehenden gesellschaftlichen Rahmenbedingungen müssen zuerst aufgeschlüsselt werden, um Zukünfte überhaupt denken zu können, d.h. die Arbeit der Imagination besteht zunächst in der Anstrengung gegebene „Relationalitäten“ zu erkunden. ${ }^{32}$

Die vorliegende Arbeit nimmt sowohl im lokalen als auch im globalen Kontext auf hegemoniale bzw. minoritäre Gefälle Bezug. 


\section{Utopie in der Philosophie: Zur Konstituierung politischer Vorstellungskraft}


Während der Untergang des Ideologischen nur für bestimmte Schichten eine Krise darstellt und die durch Ideologieenthüllung entstehende Sachlichkeit für die Gesamtheit immer eine Selbsterklärung bedeutet, würde das völlige Verschwinden des Utopischen die Gestalt der gesamten Menschwerdung transformieren.

Das Verschwinden der Utopie bringt eine statische Sachlichkeit zustande, in der der Mensch selbst zur Sache wird.

Karl Mannheim ( I969 [zuerst I929])

Ideologie und Utopie, S. 225. 
Klassischer Utopiebegriff: Ein makrohistorischer Überblick leitet in die wichtigsten Wendepunkte der Utopiegeschichte ein. Dieser Darstellung liegt zunächst der klassische Utopiebegriff zugrunde. Die Inhalte utopischer Schriften prägen sich epochenspezifisch aus; vorherrschende Themen der jeweiligen Zeit spiegeln sich in ihnen wider. Das Konzept der Utopie kann bis heute als Resonanzphänomen der Realgesellschaft verstanden werden.

Geschichtsphilosophische Wende: Im I8. Jahrhundert transformierte sich das Geschichtsverständnis der damaligen Gesellschaft. Die Zukunft verwandelte sich zu einer durch den Menschen gestaltbaren Größenordnung. Die Idee von Fortschritt bildet sich auch im utopischen Denken ab, das damit eine Wende zur Praxis erfährt. Dieser lebensweltlichen Hinwendung ist ein eigener Abschnitt gewidmet, denn hier werden die Grundlagen für eine Verknüpfung von Geschichtsphilosophie und Sozialpsychologie gelegt, d.h. Gesellschafts- und Individualgeschichte fließen zusammen.

Intentionaler Utopiebegriff: Trotz der unterschiedlich ausgeprägten Utopiekonzepte kristallisiert sich eine Konstante heraus: die Funktion der Utopie für das (individuelle) menschliche Bewusstsein. Der bis hierhin verfolgte klassische Utopiebegriff erfährt eine Aufweitung hin zum intentionalen Utopiebegriff, der eingeführt und anhand spezieller Theoriekonzeptionen näher erläutert wird. Dies dient als Hinführung zur zweiten Einzelthese der Arbeit, in der für eine Rehabilitierung des Utopiebegriffs - der Mikro-Utopie — plädiert wird. 


\section{Klassischer Utopiebegriff}

Der Begriff und das Konzept der Utopie ist vielgestaltig und von so langer Tradition, dass eine allumfassende Definition weder möglich noch zielführend ist. Für den argumentativen Fortgang der Arbeit ist es jedoch unausweichlich eine eindeutige Ausgangsbasis zu schaffen und damit den Utopiebegriff zunächst definitorisch einzugrenzen. Zugunsten eines klaren historischen Überblicks wird im Folgenden erst einmal von der Geschichte des ,klassischen Utopiebegriffs“ ausgegangen, der explizit die politischen Utopien der Neuzeit in der Literatur einkreist. In der internationalen Utopieforschung herrscht Konsens darüber, dass die Utopie als eigenständige (literarische) Gattung ihren Anfang bei Morus' begriffsbildender Schrift Utopia nimmt. ${ }^{\mathrm{I}}$

Im Folgenden wird insbesondere das umfangreiche deutschsprachige Werk des Politologen und Utopieforschers Richard Saage berücksichtigt, denn er stellt den klassischen Utopiebegriff ins Zentrum seiner Untersuchungen, im Unterschied zu den beiden anderen vielbeachteten Utopiebegriffen: intentional und totalitär. Der totalitäre Utopiebegriff ist im 20. Jahrhundert durch den Nationalsozialismus und Stalinismus in Verruf geraten-prominent kritisiert von Hannah Arendt und Karl Popper. Wohingegen der intentionale Utopiebegriff für die vorliegende Arbeit eine besondere Rolle spielt.

Der klassische Utopiebegriff birgt drei entscheidende Vorzüge:

I) Aus dem engen Bezug auf das ursprünglich von Morus entwickelte Muster ergeben sich klare Kriterien zur Definierung des Gegenstands und damit zur Abgrenzung von anderen Phänomenen, wie z. B. Paradiesvorstellungen, Goldenes Zeitalter, Traumassoziationen, chiliastische Heilserwartungen, religiöse 
Eschatologien, Mythen, individualistisches Vertragsdenken, Antizipationen technischer Art (Science-Fiction), oder die sozialwissenschaftliche Prognostik (Marxismus, Futurologie).

2) Das klassische Konzept berücksichtigt die Kontinuität und den Wandel seines Gegenstands, weil die politische Utopie (immer) ein Phänomen des Reagierens und Antizipierens ist.

3) Die utopische Fiktion wird nicht auf Größen wie „Revolution“ oder „Totalitarismus“ zurückgeführt, d.h. die wissenschaftliche Verwendbarkeit ist durch den Wegfall reduktionistischer Zuordnungen gesichert. ${ }^{2}$

Die Eingrenzung auf den klassischen Utopiebegriff macht es möglich explizit nach den Ursachen der Ausprägung der jeweiligen (politischen) Utopie zu fragen. Dies geht Hand in Hand mit einer zeitdiagnostischen Analyse des gesellschaftlichen Entwicklungsstandes der jeweiligen Epoche. ${ }^{3}$

Die Entwicklung der klassischen Utopie vollzieht sich vor dem Hintergrund von Platons Politeia (Gr. Bürgerschaft, Verfassung, meist übersetzt als Staat, 387-367 v. Chr.). ${ }^{4}$ Es ist ein Werk in zehn Büchern, das oft als analytische Folie herangezogen wird, wenn es um die Weiterentwicklung und Unterscheidung neuerer Utopien geht.

Platon fokussiert in seinen fiktiven Dialogen, in denen er sich mit der Beschaffenheit des Idealstaates beschäftigt, das sind Politeia, Timaios, Kritias und Nomoi, auf die Beschreibung der Sozialordnung des Gemeinwesens. Städtebauliche Anlagen, z.B. Wehranlagen, spielen dabei eine untergeordnete Rolle. Der gesamte Gesellschaftsaufbau ist vornehmlich darauf ausgerichtet Bürgerkriege — also die universelle Bedrohung — zu verhindern.

In der Politeia steht die Frage nach der Gerechtigkeit und worin diese bestehe an erster Stelle; sowohl im Staat, als auch innerhalb der menschlichen Seele-Platons Konzept ist also von allegorischem Charakter. Er fährt fort die Ordnung seines Drei-StändeStaates (Herrscher-, Wehr- und Nährstand) darzulegen, dessen biologische und gesellschaftliche Grundsicherung im Kern auf zwei Maßnahmen beruht, die gegenseitiges Wohlwollen begünstigen sollen: die Besitzlosigkeit der Eliten (Gütergemeinschaft) und die Abschaffung der Familie, ersetzt durch Kinder- und Frauengemeinschaften. ${ }^{5}$ Außerdem soll der Herrscherstatus den Philosophen vorbehalten sein, denn nur diese könnten gleichbleibende Ideen im Prozess der Veränderung erfassen und dabei die Idee des Guten 
erkennen; wie dargelegt in seinen drei aufeinander aufbauenden Gleichnissen, dem Sonnen-, Linien- und Höhlengleichnis. Durch die Bändigung der gefährlichsten Triebe, dem Geld-, Macht- und Geschlechtstrieb, soll der Ausbruch eines Bürgerkriegs verhindert werden.

Morus' Grundlegung: Utopia ${ }^{6}$ Der Begriff Utopie wird seit der Prägung durch die Schrift Utopia meist als eine nicht auf Realisierbarkeit zielende Idealvorstellung vom besseren Leben definiert. Morus, ihr Verfasser, englischer Staatsmann, humanistischer Gelehrter und nach eigener Angabe „Bürger und Vicecomes [Vertreter in Rechtssachen, Lordkanzler] der weltbekannten britischen Hauptstadt London"7 erschuf darin die strukturellen Grundlagen für die literarische Gattung der Utopie; worin auch die „Programmschrift eines zukünftigen Ministers"8 erkannt werden kann.

Die Schrift steht seit ihrem Erscheinen in direkter Traditionslinie zu Platons idealem Stadtstaat; namentliche Mehrfachnennungen im Text bestätigen das. ${ }^{9}$ Die Lektüre von wiederentdeckten Schriftstellern der Antike erweckte am beginnenden I6. Jahrhundert die Begeisterung insbesondere von jungen Menschen, die ihren intellektuellen Horizont dadurch erweiterten. Der Soziologe Norbert Elias beschreibt das humanistische Studium der Antike als ein Generationenerlebnis dieser Zeit,

„,[d]enn das , neue Wissen“, die Vertiefung in eine Gedankenwelt, die weniger theologisch vorbestimmt war als die der scholastischen Philosophie [...], bedeutete für Menschen nicht etwa lediglich eine Ausweitung ihres Buchwissens. Sie eröffnete ihnen zu gleicher Zeit auch einen neuen, wirklichkeitsnäheren Zugang zu den Problemen ihrer eigenen Zeit. Das ist die Mischung, der man in Morus' Utopia begegnet: Gelehrtes Wissen wirklichkeitsnah angewandt." "10

Utopia gehört zu den frühesten Zeugnissen des in der Renaissance erwachenden menschlichen Bewusstseins selbst etwas tun zu können, um Not und Elend zu verringern und das nicht etwa um den Willen Gottes, sondern um den Willen der Menschen; verstanden als säkulare Form des Gewissens. ${ }^{\text {I }}$

Auf dieser Entwicklungsstufe waren die Menschen bereits in der Lage, Erfahrungen verschiedener Gruppen-gemeint als 
Abstraktionsleistung, enthoben einer wir-zentrierten Perspektive - zu vergleichen und allmählich synthetische Begriffe, wie den Utopie- und Staatsbegriff zu entwickeln.

Morus' Schrift wurde zuerst in der Universitätsstadt Leuven, im heutigen Belgien, auf Latein publiziert. Sie gliedert sich in zwei Teile bzw. Bücher, die beide überschrieben sind mit: „Bericht des (vortrefflichen Herrn) Raphael Hythlodaeus über die beste Staatsverfassung“".

Im ersten Buch der Schrift Utopia - konzipiert als einführende Rahmenhandlung - berichtet ein weitgereister Erzähler namens Raphael Hythlodaeus dem späteren Herausgeber der Schrift Morus, bei einem Treffen in der damaligen Weltmetropole Antwerpen, über seinen vorangegangenen mehrmonatigen England-Aufenthalt und beklagt die dortigen Zustände: Zentral in der Kritik steht dabei vor allem die Ausbeutung des Volkes durch Hof und Adel. Er hebt besonders die Lust der Könige an der Kriegführung, die Privilegien der Adligen und die private Verfügung von Eigentum hervor, u. a. die breite Umwidmung von Allmenden zu Schafsweiden für die Wollgewinnung. ${ }^{\mathrm{I} 2}$

Im zweiten Buch der Schrift Utopia schildert Hythlodaeus dann seine Reiseerfahrungen (mit dem Entdecker Amerigo Vespucci) auf der Insel Utopia. In seinem Bericht erscheint das dortige Geschehen als strahlendes Gegenbild zur mangelhaft empfundenen gesellschaftlichen und staatlichen Wirklichkeit Englands. Die wichtigsten Errungenschaften einer perfekten Organisation des idealen Inselstaates fasst er in sechs Lehrbereiche zusammen: (I) Topographie von Land und Leuten; (2) gesellschaftliche Verhältnisse und Gliederung des sozialen Aufbaus; (3) Moralsystem, Erziehung, Bildung und Wissenschaft; (4) Gesetzgebung und Rechtswesen; (5) Außenpolitik und Militärwesen; und (6) Religionswesen.

Von herausragender Bedeutung ist die Eigentumsordnung: Die Utopier*innen kennen kein Privateigentum, die Grundlage ihres Systems ist das Prinzip des Güterkommunismus. ${ }^{\mathrm{I3}}$

Morus' strukturelle Grundlagen für die Fiktion idealer Gemeinwesen lassen sich in drei Analyseebenen aufgliedern. Die erste Ebene bildet die beschreibende Zeitdiagnose bzw. Sozialkritik, auf die das utopische Denken reagiert bzw. wovon es sich absetzt (vgl. Utopia, I. Buch). Denn 
„ohne die Gegenüberstellung mit dem, was kritikwürdig erscheint, verlöre die politische Utopie ihren emanzipatorischen Impetus und damit ein wesentliches Element ihrer Identität."I4

Auf der zweiten Ebene kommen in der Regel Aussagen über das Gemeinwohlideal selbst und dessen Auswirkungen auf das äußere Erscheinungsbild-Architektur, Stadt- und Siedlungsplanung — zum Tragen.

Die dritte Ebene enthält schließlich präzise Informationen über die sozialen Voraussetzungen des besten Gemeinwesens und das Muster seiner politischen Verfassung, sie stellt die sozial-normative Seite der politischen Utopie dar ${ }^{15}$ (beide vgl. Utopia, 2. Buch).

Morus' Werk ist außerdem auf verschiedenen Erzählebenen dialektisch angelegt. Im Gesamtaufbau der Schrift stehen die beiden großen Abschnitte für das Gegensatzpaar Kritik (Buch I) und Ideal (Buch 2), das den strukturellen Kern der utopischen Konstruktion bildet.

Auch der Nachname des weitgereisten Erzählers ist dialektisch erdacht. Hythlodaeus lässt sich-mit komisch-narrativer Note-aus dem Griechischen frei übersetzen als derjenige, der ,fachmännisch Unsinn redet“ (hythlos, Gr. Unsinn, leeres Geschwätz; daios, Gr. erfahren, auch feindlich). Der Philosoph Ernst Bloch übersetzt den Namen als „Schaumredner“ und der Literaturwissenschaftler Wolfgang Biesterfeld erkennt darin einen, bei dem man sich zwischen ,Wahrheitsliebe oder Flunkerfreude“ entscheiden kann. ${ }^{16}$ Berücksichtigt man darüber hinaus seinen Vornamen Raphael, dann ergibt sich insgesamt ein positives Bild, denn dieser lässt sich aus dem Hebräischen als ,heilender Gott/ Mächtiger" übertragen.

Auf der rhetorischen Ebene nutzte Morus verschiedene literarische Kniffe, um

, seinen höchst unorthodoxen, wenn nicht geradezu ketzerischen Vorstellungen von dem besten Staatszustand durch die Drucklegung eine gewisse Verbreitung zu sichern, ohne sich allzu großen Gefahren auszusetzen." ${ }^{17}$

Die Dialogform ist seit der griechischen Antike ein bekanntes rhetorisches Stilmittel, z. B. die Einbeziehung fiktiver Personen bei Platon oder später bei Filarete. Der Einsatz dieser stilistischen 
Figur dient zur Entkräftung der Argumente des Gegners und zur Belebung des sonst vorherrschenden Monologs. ${ }^{18}$

Morus' ganz eigene literarische Erfindung ist hingegen der fiktive Inselstaat, in dem alles zum Besten und in verfügbarer Weise eingerichtet ist. Der kollektiv erschaffene Staat gilt-im Zeitalter der Entdeckungen, insbesondere aus Perspektive der Insellage des Vereinigten Königreichs - als Modell eines vorbildlichen Staates. ${ }^{19}$ Es ist ein Gemeinschaftswerk, das von der Urbevölkerung in Zusammenarbeit mit den Neuankömmlingen unter der Leitung von Hythlodaeus neu errichtet wurde. Zur Herstellung dieses Inselstaates wurde Erde vom Festland abgetragen, d. h. es ist eine künstliche Insel und damit eine kulturelle Konstruktion.

Utopie im Wandel der Zeit Die Utopie ist-Morus folgend, allgemein gefasst-eine stark reaktive und gleichzeitig antizipierende Gattung. Aus einer fiktiven Reaktion auf soziokulturelle Fehlentwicklungen ihres je spezifischen Entstehungsortes und -zeitpunktes, werden im Vorgriff auf die Zukunft-Defizite der Herkunftsgesellschaft vermeidend - gesellschaftliche Alternativen dargelegt. Analysiert man diese wiederum, lassen sich Auskünfte über die jeweiligen Verhältnisse und Vorstellungen der Herkunftsgesellschaft rückschließen. In der historisch-kritischen Analyse utopischer Konzeptionen nehmen deshalb Fragen nach dem Wie (utopische Erscheinungsform) und Warum (gesellschaftlicher Ausgangspunkt) eine besondere Stellung ein.

Oft werden im Zuge der utopischen Denktradition zwei weitere Werke - chronologisch nach Platon und vor Morus - als wegbereitend angeführt. Zentrale Aspekte dieser Schriften sollen auch hier, selbst in aller Kürze, nicht unerwähnt bleiben: Die Utopie wird mit dem Werk De civitate Dei (Lat. Vom Gottesstaat, 4I 2-426 n. Chr., speziell Buch I5-I8) des frühmittelalterlichen Kirchenvaters und Philosophen Aurelius Augustinus zur Geschichtsphilosophie avant la lettre. Er unterscheidet darin zwischen einem irdischen Staat (Civitas Terrena) und einem Gottesstaat (Civitas Dei) und setzt sich damit der Auffassung entgegen, dass der Fall Roms den göttlichen Heilsplan infrage stelle. Im jüdischen und christlichen Verständnis von Geschichte gibt es einen Anfang und ein Ende (mit dem Ziel der Erlösung); seit Augustinus wird dies gegenüber dem zyklischen Denken der Antike als Sinn und Zweck der Geschichte kontrastiv herausgestellt. ${ }^{20}$ 
Die spätmittelalterliche Schriftstellerin und Philosophin Christine de Pizan verfasste etwa tausend Jahre später Le Livre de la Cité des Dames (Frz. Das Buch von der Stadt der Frauen, I405). Ihr Verdienst ist es, als Erste überhaupt einen säkularen utopischen Entwurf vorgelegt $\mathrm{zu}$ haben, dessen fundamentale Kritik an der Ausgrenzung von Frauen aus dem Bildungswesen und der gesellschaftlichen Macht ansetzt. Sie greift damit ein leitendes Thema des Utopiediskurses auf, das seit der Antike einen zentralen Stellenwert im Nachdenken über friedfertige politische Gemeinwesen einnimmt: Die Struktur der Geschlechterverhältnisse. ${ }^{2 \mathrm{I}}$

Im Folgenden werden richtungsweisende Werke der Utopiegeschichte mit zeitlich korrespondierenden Ereignissen der westlichen Universalgeschichte zusammengeführt. Diese periodisierende Überblicksdarstellung bereitet die Grundlage für die weiterführende Argumentation, in der für einen Anschluss der Mikro-Utopie an den intentionalen Utopiebegriff plädiert wird. Die tabellarische Darstellung (Tab. I) dient zunächst als Orientierungshilfe und wird anschließend erläutert:

Tabelle 1: Utopiehistorische Perioden und Phasen in Korrespondenz mit Geschichtszeichen ${ }^{22}$ der Neuzeit

Periode (A) Erfindung der Gattung (Morus I 5I6)

bis zur praktischen Wende (Mercier I77I):

- Phase (A.I)

Luthers Thesenanschlag I5I7 ... Westfälischer Friede I648

- Phase (A.2)

Westfälischer Friede ... Französische Revolution I789;

Periode (B) Praktische Wende bis zur Gegenwart:

- Phase (B.I)

Französische Revolution ... Erster Weltkrieg I9I 8

- Phase (B.2)

Erster Weltkrieg ... Ende Kalter Krieg I99I

- Phase (B.3) ( I967-)I97I-I 989/9I-200 I-2008-20 I I-20 I 9/20.. 3 
Insgesamt ergeben sich zwei große geschichtliche Abschnitte. Die erste Periode ( $A$ ) beginnt bei Morus' gattungsbildender Schrift und endet mit Merciers Zeit-Utopie, die mit einer utopiehistorischen Wende zur Praxis gleichgesetzt wird, d.h. einen lediglich kontemplativen Praxisbezug überschreitet. Zeitgeschichtlich umfasst dies die Epochen der Reformation und Aufklärung; vom Thesenanschlag Martin Luthers (ein Zeitgenosse und Gegenspieler von Morus), über den Westfälischen Frieden, der den Dreißigjährigen Krieg in Deutschland beendete und das völkerrechtliche Konzept souveräner Nationalstaaten begründete, bis hin zur Französischen Revolution.

Infolgedessen setzt die zweite Periode $(B)$ bei Mercier an und besteht bis heute fort. Zeitgeschichtlich umfasst diese Periode das I9. und 20. Jahrhundert, die geprägt sind vom Aufstieg und der Entwicklung der Industrialisierung; von der Französischen Revolution, über den Ersten und Zweiten Weltkrieg zum Ende des Kalten Krieges, bis hin zu den jüngsten, globalgeschichtlich bedeutsamen Geschehnissen im ersten Viertel des 2 I. Jahrhunderts.

Im Folgenden werden diese beiden Perioden detaillierter ausgeführt. Frühneuzeitliche Utopien bis zur Mitte des I7. Jahrhunderts lassen sich im Wesentlichen mit Morus' Utopia, inbegriffen ihrer inselartigen Abgeschlossenheit und der Gründung und Herrschaft durch den König Utopos vergleichen; denn in ihnen ist

„ die ideale Gesellschaftsordnung Ausfluß des Verfassungsentwurfs eines weisen Gründungsvaters [...]. “24

Ihr utopischer Geltungsanspruch zielt auf das herrschende soziopolitische System als Ganzes ab. Es wird eine konkrete innerweltliche Kritik vorgenommen, jedoch in Abwesenheit von Religionsskepsis. Das Gemeineigentum wird zur Grundlage der Gesamtgesellschaft und die Kategorie Arbeit erfährt eine maßgebliche Aufwertung. Dies ist als radikale gesellschaftliche Ausweitung utopischen Denkens zu verstehen, denn zuvor wurde Gleichheit nur innerhalb der herrschenden Eliten ersonnen, z. B. bei Platon und Erlösungshoffnungen waren transzendental orientiert, z. B. bei Augustinus. ${ }^{25}$

In der Renaissance und der Reformation erscheint also die „Utopia als Leviathan“26, d. h. als staatstheoretische Schrift, obwohl noch stark christlich geprägt. Der Sozialphilosoph und Leiter des Frankfurter Instituts für Sozialforschung Max Horkheimer schreibt dazu: 
„Bei Morus und Campanella war die Religion das Gefäß, das die Forderung der Gerechtigkeit im Angesicht des realen Elends unverfälscht bewahrte; sie wollten die heilige Gemeinschaft auf Erden verwirklichen, welche die Gesetze der freien Konkurrenz durch die Gebote Christi zu ersetzen hätte."“27

Die Notwendigkeit des Überblicks und dem damit einhergehenden Verzicht auf Einzelheiten lassen die Beschreibungen hier teils holzschnittartig ausfallen. Die utopischen Erzählungen werden erst lebendig, wenn ihr jeweiliger Detailreichtum zur Entfaltung kommt. Dazu muss auf die Originaltexte verwiesen werden. ${ }^{28}$

Die anschließende Entwicklung der politischen Utopie zwischen Absolutismus und Aufklärung wird von Saage als kritische Fortsetzung der Tradition der Renaissance-Utopien dargestellt. Die kritische Beurteilung des Gegenwärtigen verwandelt sich in ihnen hin zu einer dezidierten Ablehnung der absolutistischen Herrschaft, der Rolle des Adels und der katholischen Kirche.

Gleichbleibend aufrechterhalten wird die zentrale Forderung nach Gemeinbesitz. Dieser soll zur Harmonisierung gesellschaftlicher Interessen dienen. Damit ist das Privateigentum als Kernproblem erneut ausgemacht und eine radikale Zeitkritik am Absolutismus unter König Ludwig XIV. vollzogen. ${ }^{29}$

In dieser Zeit vollzieht sich auch eine bedeutsame Weiterentwicklung utopischer Schriften; zwei Pole bilden sich deutlicher heraus: Auf der einen Seite entwickeln sich explizit archistische bzw. etatistische Utopien, in denen die Regulierung des gesellschaftlichen Zusammenlebens institutionell verankert ist-heute würde man etwa von staatlicher Herrschaft sprechen. Auf der anderen Seite entwickeln sich explizit harmonische Anarchien, die auf der Freiheit und Selbstbestimmung des Individuums gründen.

Diese bereits in der Antike vorhandenen utopischen Pole-archistisch und anarchistisch — entwickeln sich bezeichnenderweise in einem Zeitalter weiter, das geprägt ist von der Entstehung bürgerlicher Nationalstaaten. ${ }^{30}$

$\mathrm{Ab}$ der Mitte des I8. Jahrhunderts lässt sich dann insbesondere in Frankreich die Entwicklung der Utopie vom regulativen Prinzip zum revolutionären Instrument beobachten. Der Sozialphilosoph Hans Freyer schreibt dazu, dass die Utopie als

„Zeitkritik aus beiläufiger Randbemerkung oder positiver Opposition zur vernichtenden Waffe gegen das Bestehende 
wird, bis [sie] schließlich [...] eines der geistigen Mittel wird, mit denen Frankreich zur Revolution reif gemacht wird.“3I

Und der Historiker Thomas Nipperdey kommentiert die Funktion der Utopie in jener Zeit so, dass sie

„, die Zukunft als Raum menschlicher Sinnerfüllung und als Raum planenden autonomen Handelns vorzustellen und zu eröffnen; [...] und die Totalität der politischen Welt und die Abhängigkeit der Personalität von den Institutionen zu erschließen [erlaubte]. Damit ist die Utopie seit 1789 in die Struktur des politischen Handelns eingegangen. “32

Die Veränderung der Utopie von einer praxisbezogenen Kontemplation hin zu einer aktiven gesellschaftlichen, die konkrete Lebenswelt berücksichtigende Betätigung steht für eine entscheidende Wende in der Gesamtgeschichte der Utopie. ${ }^{33}$

Das I9. Jahrhundert ist geprägt vom Zusammenbruch der vergleichsweise statisch gegliederten feudalistischen Ständegesellschaft und einer wissenschaftlich-technischen Dynamisierung der gesellschaftlichen Prozesse. Der technische Fortschritt und die damit verbundene neue soziale Frage, der Umgang mit den neuen Klassen der Industriegesellschaft, die Bourgeoisie und das Proletariat, sind das Fundament auf dem ,,die politische Utopie als ,Technischer Staat" in der industriellen Revolution"34 entsteht. Obwohl die allgemeine Versorgung der Bevölkerung mit Konsumgütern zur realistischen Perspektive geworden ist, wird nun die seit Menschengedenken bestehende Ungleichheit (Verteilung der Produktionsmittel) zum epochenspezifischen Merkmal, verstärkt durch Strukturdefekte der kapitalistischen Industrialisierungsprozesse. ${ }^{35}$

Ein idealisierter Glaube an den technischen Fortschritt avancierte zum normativen Fundament der Gesellschaft und sollte der Erwirtschaftung gesellschaftlichen Reichtums Vorschub leisten, mit dem Effekt den Zerfall der Gesellschaft in sich bekämpfende Klassen den Boden zu entziehen.

Der unbedingte Glaube an die Technik wird dann allerdings durch den Ersten Weltkrieg vorübergehend erschüttert. Dies spiegelt sich auch in der Entstehung dystopischer Literatur in der ersten Hälfte des 20. Jahrhunderts wider. In ihr werden ernste Bedenken gegenüber dem schrankenlosen Fortschritt gehegt und es wird vor den düsteren Folgen eines technischen Totalitarismus gewarnt. ${ }^{36}$ Die Umkehr von einem gesellschaftlichen Wunschbild hin zu 
einem Furchtbild wird zuweilen mit dem Nullpunkt der klassischen Utopietradition gleichgesetzt. Daran anschließend und mit dem Zerfall der kommunistischen Regime, ist auch das letzte größere Tief der Utopie, das bisweilen mit dem Ende der klassischen utopischen Denktradition gleichgesetzt wird, zu verstehen. 


\section{Geschichtsphilosophische Wende zur Praxis}

Die Erneuerung des utopischen Diskurses nimmt ihren Anfang am Ausgang des I8. Jahrhunderts mit einer Hinwendung zur lebensweltlichen Praxis. Bisher wurde die Utopie an einem fernen Ort, in zeitlicher Übereinstimmung mit der Realität (synchron) ersonnen, jetzt wird sie am gleichen Ort in die Zukunft (diachron) entworfen. Die fiktive Entdeckung transformiert sich zur Zukunftsvision. Das kommt einer ,kopernikanischen Wende“37 in der Utopiegeschichte gleich. Der Übergang von der Raum-Utopie zur Zeit-Utopie wird gewöhnlich mit Merciers Jahr 2440 ( I77I) gleichgesetzt. Der Historiker Reinhart Koselleck erkennt darin eine „Einverwandlung der Utopie in die Geschichtsphilosophie“, denn Merciers Werk sei eher den „Fortschrittsphilosophemen“ als verräumlichten Gegenwelten zuzuordnen, deren theoretisches Fundament die ,Verzeitlichung der [bisher statisch und räumlich gedachten] Perfectio-Ideale“ bildet, d.h. nun konnte der Weg zur irdischen Vollkommenheit als geschichtlicher Verlauf in die Zukunft gedacht werden. ${ }^{38}$

Im neuzeitlichen Geschichtsbewusstsein wird nicht mehr von der Präexistenz zukünftiger Dinge ausgegangen, sondern die neue Vorstellung vom Gang des Menschen durch die Zeiten setzt jetzt die Existenz eines Zeitraumes voraus, in den der aus der Gegenwart kommende Mensch aktiv eintritt. Damit war im neuzeitlichen Weltbild die Idee der Zukunft als eines leeren zeitlichen Raums geboren, der sich nun mit beliebigen Ereignissen und Vorstellungen füllen ließ.39

Die Zeitatmosphäre um die Französische Revolution suggerierte also, dass der Verlauf der Geschichte umgelenkt werden könne, und Utopie (gewisser Art) implementiert werden könne- 
mit anderen Worten, dass abstrakten Idealen eine Gestalt in der Gesellschaft verliehen werden könnte, angetrieben von bewusstem menschlichen Handeln. ${ }^{40}$ Man nahm die Revolution als eine Urszene des gesellschaftsbegründenden Handelns wahr. ${ }^{4 \mathrm{I}}$ Dies erklärt auch den Anstieg des Optimismus und Aktivismus von Sozialutopien im I9. Jahrhundert.

Nipperdey schreibt, dass der Wandel der Utopie zur Prognose erst nach der Französischen Revolution deutlich wird und dass sich

„, [e]in Zukunftsentwurf [...] jetzt nicht mehr an einer übergeschichtlichen Vernunft orientieren [kann], er legitimiert sich nur noch aus der Hinwendung zur Erfahrung, nur so kann der Boden politisch-sozialer Argumentation nach vorn gewonnen werden. Das Handeln wird in den sozialen Bedingtheiten verankert. [...] [A] us der Utopie als Leitbild wird die sich als Wissenschaft verstehende Prognose. Aus der Geschichte als Revolution wird die Geschichte als Evolution."42

Die utopischen Frühsozialisten stehen genau zwischen diesen Positionen. Prognose und Leitbild greifen bei ihnen ineinander, werden aber nicht identisch. Die Französische Revolution hat

„, die geschlossene Welt aufgebrochen, die politische Zukunft als Raum planender Selbstgesetzgebung eröffnet. Die Theorie ist praktisch geworden."43

Die wissenschaftlich-technische Entfaltung der „Produktivkräfte“ sollte zur Triebkraft des Fortschritts werden. Die entsprechende materialistische Grundannahme war, dass die Gestaltung der gesellschaftlichen Verhältnisse in Analogie zur wissenschaftlich-technischen Beherrschung der Natur möglich sei, v. a. in den Schriften der frühen Sozialutopisten Claude-Henri de Saint-Simon, Charles Fourier, Robert Owen und Étienne Cabet. Der Glaube an die Totalrevision der gesellschaftlichen Wirklichkeit gründete nun auf der Tendenz einer Verwissenschaftlichung der Utopie. ${ }^{44}$ Das spezifische Zusammenspiel von naturwissenschaftlichen Erkenntnissen und romantischen Visionen menschlicher Gesellschaften prägt die Schriften der Frühsozialisten. Sie übertrugen materielle Kräfte aus den Naturwissenschaften, z. B. Isaac Newtons Gravitations- bzw. Bewegungsgesetze auf die menschliche Sphäre und konzeptionierten das Soziale so, dass es den Leidenschaften, Sympathien und Affekten des Menschen Rechnung trug. Aber nicht der Mensch 
selbst, ob als Individuum oder universales Gattungswesen, stand im Zentrum ihres Interesses, sondern insgesamt konstituierte die Pluralität dieser Kräfte das eigentliche Subjekt ihrer Anschauung. ${ }^{45}$ Der frühsozialistische Philosoph Saint-Simon gilt als prophetischer Denker des Industriezeitalters und verfasste dazu die erste wissenschaftliche Abhandlung. Er prophezeite, dass das Goldene Zeitalter nicht in der Vergangenheit, sondern in der Zukunft liege und dass es durch die Vervollkommnung der sozialen Ordnung verwirklicht werden würde. ${ }^{46}$

Auch andere utopische Denker dieser Zeit, z. B. Edward Bellamy, William Morris und Theodor Hertzka waren davon überzeugt, dass sich die Gesellschaftsordnung auf die nächste Stufe hinbewege und diese sei-geschichtsphilosophisch begründet — die Verwirklichung des utopischen Gemeinwesens. ${ }^{47}$

Die primäre Frage des alten utopischen Denkens (vor der praktischen Wende) lautet demnach: Was muss auf der Welt verbessert werden und wie? Die primäre Frage des neuen utopischen Denkens (nach der praktischen Wende) lautet demnach: Wer kann diese Veränderungen herbeiführen und wann $?^{48}$

Die Gesellschaftstheoretiker und Ökonomen Karl Marx und Friedrich Engels radikalisierten die Ideen der Frühsozialisten, d.h. sie knüpften an ihre utopischen Vordenker im Glauben an die wissenschaftliche Befreiung an, lehnten ihre abstrakten, ahistorischen Postulate jedoch strikt ab. Auf Grundlage von Georg Wilhelm Friedrich Hegels dialektischem Idealismus prägten sie ihre historisch-materialistische Gesellschaftstheorie.

Zum Glauben an die Wissenschaft sei aus Marx' frühem Aufsatz Zur Kritik der Hegelschen Rechtsphilosophie. Einleitung ( I844) zitiert, in dem er zum ersten Mal das Proletariat als die gesellschaftliche Klasse darstellt, die die allgemein menschliche Emanzipation verwirklichen solle, und die gesellschaftliche Kraft des sozialen Fortschritts verkörpere.

„Wie die Philosophie im Proletariat ihre materiellen, so findet das Proletariat in der Philosophie seine geistigen Waffen."49

Darin begründet Marx die These von den proletarischen Massen als der materiellen Kraft, die imstande sei die Gesellschaft umzugestalten. Im Prozess der gesellschaftlichen Umgestaltung wiederum spiele diese fortschrittliche Theorie als geistige Waffe im Kampf eine herausragende Rolle. Die Erkenntnis von der welthistori- 
schen Rolle der Arbeiterklasse als utopische Trägerschicht bildete den Ausgangspunkt für die Entwicklung des Frühsozialismus von der Utopie zur Wissenschaft. Engels legt das weitestgehend in seiner Schrift Die Entwicklung des Sozialismus von der Utopie zur Wissenschaft ( I880) dar; ausgehend von einer Kritik an Ergebnissen der Französischen Revolution.

Die Frühsozialisten stellten der unvollkommenen Wirklichkeit nur einen theoretischen Idealzustand gegenüber, ohne konkrete Entwicklungsmöglichkeiten aufzuzeigen. An die Stelle ihres Utopismus sollte eine genaue Analyse der Gesellschaft und ihrer Entwicklungsgesetze treten, die wissenschaftliche Aussagen über die Zukunft gesellschaftlicher Ordnungen ermöglichen würde. $5^{5}$

Zum Verständnis der Marx'schen Abgrenzung von den utopischen Sozialisten - allen voran Saint-Simon und Fourier - formuliert Ernst Bloch später, dass diese zwar „Ahnungen vorhandener Tendenzen erforschten“ doch letztlich die abstrakte Ergründung einer von Geschichte und Gegenwart unabhängigen Phantasie siegte.

„Die Traumlaterne scheint bei abstrakten Utopisten in einen leeren Raum [...]. [H]ier kam der Gedanke nicht zur Wirklichkeit, weil die damalige Wirklichkeit nicht zum Gedanken kam."5I

Bei den Sozialutopisten nahm also das „Gemälde des Zukunftsstaates“ den allermeisten Raum ein, wodurch, so Bloch,

„,zwar das Ziel bunt und lebhaft gehalten [wurde], doch der

Weg zu ihm, soweit er in den gegebenen Verhältnissen liegen konnte, blieb versteckt." 52

Mit Marx drehte sich das Verhältnis von Ideal und Kritik um, denn er

„, setzte mehr als neun Zehntels seines Schrifttums an die kritische Analyse des Jetzt, und einen verhältnismäßig geringeren Platz räumte er Bezeichnungen der Zukunft ein. “53

Marx und Engels begründeten die Antizipationen des Utopischen zwar durch die Ökonomie, allerdings deuteten sie die humanen Verhältnisse durch die Vergesellschaftung der Produktionsmittel kaum an. Sie sprechen allgemein vom „Reich der Freiheit“ 
(Engels) und prägen den Begriff der „,klassenlosen Gesellschaft“ (Marx). Und noch einmal Bloch:

„Marxens ganzes Werk [dient] der Zukunft [...], ja [kann] überhaupt nur im Horizont der Zukunft begriffen werden [...], jedoch nicht als einer utopisch-abstrakt ausgemalten. Sondern als einer, die in und aus der Vergangenheit wie Gegenwart, aus den wirkenden, weiterwirkenden Tendenzen also, historisch-materialistisch erleuchtet wird, um so erst eine wissend-gestaltbare zu sein. [...] Marxismus ist nicht keine Antizipation (utopische Funktion), sondern das Novum einer prozeßhaft-konkreten. [...] Utopie in diesem nicht mehr abstrakten Sinn ist derart das gleiche wie realistische Antizipation des Guten; [...]." ${ }^{\text {54 }}$ 


\section{Intentionaler Utopiebegriff}

Die bis hierhin verfolgte „begrenzte“ historische Lesart kann durch eine ,aufweitende“ funktionale Lesart der Utopie komplementiert werden, denn der Utopie wohnt eine anthropologische Funktion inne, die im Gegensatz zur historisierenden und ideologisierenden sozialgeschichtlichen Exegese steht. 55

Als Analyseinstrument sei eine Differenzierung — die im Anschluss erläutert wird — vorangestellt:

- Utopische Form (a): Literatur (Roman, wissenschaftliche Abhandlung), Architektur und Stadtplanung (Zeichnung, Modell, Film, Realexperiment), soziale Bewegungen, Sozialtheorie.

- Utopischer Inhalt (b): doppelt bedingt durch die Realgesellschaft

(b. I) Kritik bezogen auf die je gegenwärtige Gesellschaft;

(b.2) Ideal bestimmt durch Antizipationsmöglichkeiten und -grenzen der je gegenwärtigen Gesellschaft.

- Utopische Funktion (c): auf zwei Wirkebenen

(c.I) je gegenwärtige Gesellschaft

(c.2) je gegenwärtiges Individuum.

Wurde ein „,utopisches Objekt“ (a) identifiziert und in den gesellschaftlichen Kontext (b) gestellt, lässt sich analysieren, ob und welche soziale Grund- bzw. Bewusstseinsfunktion (c) sich der Utopie zuordnen lässt.

Erläuternd lässt sich sagen, dass die formale (a) und inhaltliche (b.I und b.2) Ausprägung der Utopie je veränderlich, d.h. unmittelbar zeitgebunden ist, wohingegen sich ihre soziale Grundfunktion (c.I und c.2) durch eine relativ höhere Stabilität auszeichnet. 
Auf der ersten funktionalen Wirkebene (c. I: gesellschaftlich) bleibt die Utopie ein träge-veränderliches Resonanzphänomen. Ihre gesellschaftliche Funktionsweise lässt sich periodisch, wie zuvor dargelegt, unterscheiden: In der Renaissance diente die Utopie vorwiegend als Kritik an der Realität (Ideal als Negation); in der Aufklärung diente die Utopie als revolutionäres Element in der Realität (Durchgangsstufe zum Ideal); und in der Moderne wurde die Utopie zur Ideologie (Realisierung des Ideals).

Auf der zweiten funktionalen Wirkebene (c.2: individuell) kommt der intentionale Utopiebegriff ins Spiel. Die Funktion, die die Utopie im individuellen Bewusstsein erfüllt ist eine wenig veränderliche Grundkonstante; ihre mentale Funktionsweise ist relativ stabil.

Der letzte Abschnitt dieses Kapitels ist-unter der Bezeichnung ,,intentionaler Utopiebegriff“ — der sozialen Grundfunktion der Utopie gewidmet. Das Potential dieses Begriffs steckt in der Rehabilitierung des Utopiediskurses - im Allgemeinen - basierend auf der Grundidee der Sozialutopie. Die Untersuchung des Hauptgegenstandes der vorliegenden Arbeit (architektonische Minimaltechniken bzw. Mikro-Utopoi) —im Besonderen-kann hier angeknüpft werden.

Elias, der u. a. für eine sozialpsychologische Lesart räumlicher Strukturen bekannt ist, hat darauf hingewiesen, dass eine komplementäre Herangehensweise zur historisch-kritischen Perspektive von zentraler Bedeutung für die Utopieforschung ist. Eine vielfach zitierte Stelle aus seinem Aufsatz Thomas Morus' Staatskritik. Mit Überlegungen zur Bestimmung des Begriffs Utopie (1982) lautet:

,[E]ine Utopie ist ein Phantasiebild einer Gesellschaft, das Lösungsvorschläge für [...] ungelöste Probleme der jeweiligen Ursprungsgesellschaft enthält, und zwar Lösungsvorschläge, die entweder anzeigen, welche Änderungen der bestehenden Gesellschaft die Verfasser oder Träger einer solchen Utopie herbeiwünschen [Wunschgebilde] oder welche Änderungen sie fürchten [Furchtgebilde] und vielleicht manchmal beide zugleich." 56

Elias fährt fort, dass alle Bemühungen um die Erforschung von Utopien auf unsicherem Boden stünden, wenn man es unterlässt, sich Klarheit über diese (zentralen) Funktionen zu verschaffen, 
direkt oder indirekt. Eine Kenntnis über diese Funktionen macht es auch einfacher, die Frage zu beantworten,

„, an welches Publikum ein Mensch — oder Menschen — sich durch das Ausdenken einer Utopie zu wenden sucht. [...] Zu den wesentlichen Aufgaben der Utopieforschung gehört also die Beantwortung der Frage nach der Funktion der Utopie als Mitteilung an wen?"57

Unter Bezugnahme auf dieses Zitat ergänzt der Soziologe Richard Kilminster in seinem Aufsatz Zur Utopiediskussion aus soziologischer Sicht (1982), dass Elias mit seinem Fokus auf

, die gesellschaftliche Funktionsbestimmung von Utopien [...] den Utopiebegriff sowohl von abwertenden bzw. überschwenglichen Assoziationen als auch von der Verrechnung auf bestimmte politische Gruppen befreien [will]. “58

Der Gesellschaftstheoretiker Alexander Neupert-Doppler geht noch einen Schritt weiter und rückt die Analyse des funktionalen bzw. intentionalen Utopiebegriffs ins Zentrum seiner Forschung. In seinem Buch Utopie. Vom Roman zur Denkfigur (2015) und in einem jüngst gehaltenen Vortrag Utopiebewusstsein (2016) konstatiert er, dass die Einteilung der Utopie in Aspekte der Form, des Inhalts und der Funktion nicht zielführend sei; unter kritischer Bezugnahme auf die Soziologin und Utopieforscherin Ruth Levitas, die jene kategoriale Trias Form-Inhalt-Funktion in ihrem Buch The Concept of Utopia ( I990) vorlegte.

Neupert-Doppler plädiert dafür, dass die gesellschaftliche Funktion der Utopie wieder eingehender erforscht werden müsse, gefolgt von einer neuen Begriffsbildung - z. B. im Konzept der Mikro-Utopie, wie in der vorliegenden Arbeit vorgeschlagen und ausgeführt.

Er begründet dies mit einer notwendigen Rehabilitierung eines humanistischen Ansatzes von Utopie, in der die Grundidee der Sozialutopie - das Erreichen ,individuellen Glücks durch die vernünftige Einrichtung von Gesellschaft" — wieder aufgegriffen würde. 59

In diesem Zusammenhang wird in der Utopieforschung explizit auf drei Autoren verwiesen, deren Werke eine eigene Traditionslinie begründen und die als Grundlage zur weiteren Forschung aufschlussreich sind: Gustav Landauer, Ernst Bloch und 
Karl Mannheim; hier erweitert um das Schaffen von Theodor W. Adorno und Max Horkheimer. Im Wesentlichen basiert die intentionale Argumentationslinie, ausgehend vom Individualisierungsprozess der Neuzeit, auf Landauers Utopiebegriff mit anarchistischer Stoßrichtung (Intention). In der Rückschau wird diese Linie von Mannheim wissenssoziologisch weiterentwickelt (Motivation), von Bloch popularisiert (Konkretion), und von Adorno und Horkheimer negativ umkreist (Negation). ${ }^{60}$

Am intentionalen Utopiebegriff ist allgemein gefasst entscheidend, dass er die

„Statik ,endzeitlicher Idealvorstellungen“ durchbrochen und das Utopische zugleich dynamisiert [hat]. Erst dieser Neuakzentuierung, die eine Wende von der bloßen Denkbemühung zu einer die Geschichte durchziehenden und Theorie und Praxis vermittelnden Denkhaltung bewirkte, sei die Erneuerung des utopischen Diskurses [...] zu verdanken. “61

Der intentionale Utopiebegriff ist ein „Plädoyer für einen gegenstandsunabhängigen Utopiebegriff“62 — die „Ersetzung einer starren und endgültigen Welt durch eine sich permanent erneuernde $^{\text {“63 }}$ — dessen Identität dann nicht in

,, irgendwelchen Ähnlichkeiten positiver Zukunftsbilder [liegt] [...], sondern in der kritischen Negation der bestehenden Gegenwart im Namen einer glücklicheren Zukunft, die noch so verschieden ausgemalt sein mag. Deshalb kann sich die utopische Intention auch dort ausdrücken, wo auf Zukunftsbilder verzichtet wird." 64

Die Betonung liegt aber eher auf dem Bilderverzicht, im Sinne der Endgültigkeit, als im Verzicht auf Zukunft generell. NeupertDoppler findet aktuelle Perspektiven des Utopischen vor allem in sozialen Bewegungen wieder und Levitas weist der Architektur eine besondere Rolle in der Weiterentwicklung utopischer Konzeptionen zu. ${ }^{65}$ Die These der Mikro-Utopien knüpft an beide Aspekte an und aktualisiert die intentionale Linie aus architekturtheoretischer Perspektive.

Landauer: u-topische Verkettung in Die Revolution Die Neuakzentuierung des Utopiebegriffs nimmt ihren Anfang bei Landauers Schrift Die Revolution (1905/07), in der er die Weltgeschichte als 
Abfolge von stabilen (Topien) und revolutionären Phasen (Utopien) deutet:

,Die relative Stabilität der Topie ändert sich graduell, bis der Punkt des labilen Gleichgewichts erreicht ist. Diese Änderungen in der Bestandssicherheit der Topie werden erzeugt durch die U t o p i e. [...] Unter Utopie verstehen wir ein Gemenge individueller Bestrebungen und Willenstendenzen, die immer heterogen und einzeln vorhanden sind, aber in einem Moment der Krise sich durch die Form des begeisterten Rausches zu einer Gesamtheit und zu einer Mitlebensform vereinigen und organisieren: zu der Tendenz nämlich, eine tadellos funktionierende Topie zu gestalten, die keinerlei Schädlichkeiten und Ungerechtigkeiten mehr in sich schließt. Auf die Utopie folgt dann eine Topie, die sich von der früheren Topie in wesentlichen Punkten unterscheidet, aber eben eine ist." 66

Die Geschichtsphilosophie vereint sich hier mit der Sozialpsychologie. ${ }^{67}$ Landauer ist von der kommenden Entwicklung selbstständiger Individuen, die sich in Gemeinschaften freiwillig zusammenschließen, überzeugt. Als Alternative zum politischen System seiner Zeit werden sich, so Landauer, kleine, unabhängige und trotzdem untereinander vernetzte Gesellschaften im Geiste Novalis', d.h. im Sinne einer Romantisierung des praktischen Lebens, herausbilden. ${ }^{68}$

„, Das Eingehen kooperativer Verhältnisse ist Landauers Ziel, die Gründung sozialistischer Siedlungen sein Weg“, 69

den er aber nicht als Utopie verstanden wissen will. ${ }^{70}$

Landauers Denkungsweise, eine Utopie der Praxis, schließt damit an den anarchistischen Siedlungssozialismus bzw. genossenschaftlichen Frühsozialismus an.

Der Architekt Bruno Taut nahm später konkret Bezug auf diese Vorstellungen Landauers und entwickelte zeichnerisch ein System vernetzter Runddörfer, das Stadt und Land optimal verbinden sollte. $^{71}$

Dies ist bezeichnend für all diejenigen, die um I900 Gesellschaftsmodelle vorlegten, um sie in die Tat umzusetzen, erklärt der Begriffshistoriker Ulrich Dierse. Sie wehrten sich einerseits dagegen mit den Verfassern von utopischen Staatsromanen oder 
Schwärmern verwechselt zu werden, andererseits bemühten sie sich darum die starre Entgegensetzung von Utopie und Wirklichkeit aufzulösen. Zur langsamen Rehabilitierung der Utopie gehöre eben auch der

„Entwurf einer neuen Form der U.[topie], in der das Ideal in einer stufenweisen Entwicklung erreicht werden soll, die also nicht mehr, static but kinetic' sein wird [H. G. Wells, I905]. Und dazu gehört das Zugeständnis an den Utopisten, daß er , seine Ideale [...] verwirklichen“ will [A. Voigt, I906]. In sich differenzierte U.[topie]-Begriffe entstehen, die im 20. Jh. die Kritik an historisch abstrakten oder ideologischen U.[topie]n mit dem positiven Anliegen einer U.[topie] als Kritik des Gegebenen verbinden." 72

Dementsprechend lehnt Landauer den orthodoxen Marxismus und dessen Adaption durch die deutsche Sozialdemokratie seiner Zeit entschieden ab. ${ }^{73}$ Die Marx'sche Auffassung, dass das Sein das Bewusstsein bestimme sei ein ebensolcher Irrtum, wie Marx' Mehrwerttheorie, Staatsbezogenheit und teleologische Geschichtsphilosophie. So spottet Landauer in Aufruf zum Sozialismus (I9I I):

„Alte Weiber prophezeien aus dem Kaffeesatz. Karl Marx prophezeite aus dem Dampf."74

„Es liegt in der Tatsächlichkeit und so im Begriff der Revolution, daß sie wie ein Gesundfieber zwischen zwei Siechtümern ist; ginge nicht die Mattigkeit voraus und folgte nicht die Ermattung, so wäre sie gar nicht." 75

Bloch: Konkretion in Das Prinzip Hoffnung Im Unterschied zu Landauers Wechselspiel von Topien und Utopien - als „Intention und Option gegen den Marxismus“ gestellt—versteht Bloch die Utopie als einheitliche Tendenz und ergänzt sie ,,als subjektiven Faktor marxistisch. "76 Die Geschichte des Utopischen wird oftmals in eine Vielzahl historisch gebundener Utopien aufgelöst, nicht so bei Bloch. Bei ihm lösen sie sich nicht gegenseitig ab, sondern sind Vorgriffe auf ein einziges noch unklares und geschichtstranszendentes Menschheitsziel. Da keine Utopie das Ziel selbst bezeichnet, will Bloch die utopische Tradition ordnen und konstruiert sie so, 
dass sie auf ein außenstehendes Ziel der Geschichte zuläuft—von Moses über Morus und Münzer bis Marx. ${ }^{77}$

Auch in Blochs Philosophie, wie bei Landauer, ist die Erkenntnis einer „offenen Geschichte“ zentral, also dem utopischen Denken immanent, denn der subjektive ist mit dem objektiven Faktor im Welt- und Geschichtsprozess dialektisch verschränkt. ${ }^{78}$ Sie stehen in Wechselwirkung miteinander.

Der Philosoph Hans Heinz Holz formuliert in seinem Buch Logos Spermatikos (1975), dass bei Bloch

„,eine ontologisch so tief, anthropologisch so breit angelegte Phänomenologie des utopischen Bewußtseins [...] ihre Bestätigung in der Sphäre des objektiven Geistes suchen [muß]. Werden die Hoffnung als die zentrale Funktion des Gemüts, die Zukunft als die bestimmende Zeitdimension, die Möglichkeit als die Grundkategorie des Seins, die Antizipation als die entscheidende Leistung des Denkens herausgestellt, so hat sich diese Konzeption auch in den historischen Bewußtseinsgestalten zu erweisen." 79

Blochs früher Geist der Utopie (I918/23), ein Werk aus Sturm und Drang, ${ }^{80}$ erfährt in seinem dreibändigen Hauptwerk Das Prinzip Hoffnung ( 1959), ,über den Zwischenbegriff der , utopischen Intention“"8I eine enzyklopädische Aufweitung. In fünf Teilen legt er seine Philosophie der Hoffnung vor einem ,konkret-utopischen Horizont $^{* 82}$ dar.

Von besonderem Interesse für die vorliegende Arbeit sind dabei der zweite Teil: „Grundlegung: Das antizipierende Bewußtsein“ und der vierte Teil: „Konstruktion: Grundrisse einer besseren Welt".

Das Konzept des „Noch-Nicht“83 spielt—im Anschluss an Marx - eine elementare Rolle in Blochs Werk. Es geht ihm um eine Reform des Bewusstseins durch Analyse desselben, ob religiös oder politisch.

„Es wird sich dann zeigen, daß die Welt längst den Traum von einer Sache besitzt, von der sie nur das Bewußtsein besitzen muß, um sie wirklich zu besitzen." ${ }^{84}$

Auf der Grundlage des Noch-Nicht verdichten und verschränken sich zentrale Begriffe der Bloch“schen Philosophie. Der Zustand des Noch-Nicht-Seins gliedert sich auf in das Noch-Nicht- 
Bewusste des Subjekts, d. h. in der menschlichen Seele, und das Noch-Nicht-Gewordene des Objekts, d.h. in der Welt.

Zum Verständnis dieser Grundlegung sollte man aber ihre Entstehung während des Zweiten Weltkrieges, d.h. eine Zeit in der Mangel und Verlust den Alltag prägten, nicht aus den Augen verlieren. $^{85}$ Bloch selbst ist Zeuge dieser entbehrungsreichen, „dürftigen Zeit", 86 in der die materielle Not (Nicht-Haben), die Sehnsucht nach einem erfüllten Leben und Vertreibung aus dem gewohnten Leben (Nicht-Sein), den Willen nach Heimat nährt.

Vergleiche zur heutigen Zeit lassen sich nur frei assoziieren. Vielleicht ließe sich am ehesten auf ein Gefühl der Orientierungslosigkeit in einer Gesellschaft des Überflusses referenzieren, das, je nachdem wo man ansetzt, durchaus Züge sozialökologischer Entfremdung hervorruft.

Letztlich geht es darum, die jeweilige Ausgangssituation als Auslöser für einen noch unbestimmten Wunsch nach Verbesserung zu verstehen, als Hoffnung, die sich nicht auf bloßes Träumen beschränkt, sondern aktiv in die Welt hinausgreift, ,um in ihr das Ultimum menschlichen Strebens $\mathrm{zu}$ suchen oder $\mathrm{zu}$ verwirklichen." ${ }^{\text {"87 }}$

Bei Bloch entspricht die ,utopische Funktion“ ganz der elementaren Grundfunktion des Geistes, die sich in Erwartung eines Besseren, in Antizipation und Phantasie äußert. ${ }^{88}$ Doch er unterscheidet:

„Pures wishful thinking diskreditierte seit alters die Utopien, sowohl politisch-praktisch wie in der ganzen übrigen Anmeldung von Wünschbarkeiten; gleich als wäre jede Utopie eine abstrakte. Und ohne Zweifel ist die utopische Funktion im abstrakten Utopisieren erst unreif vorhanden, das heißt, noch überwiegend ohne solides Subjekt dahinter und ohne Bezug aufs Real-Mögliche. Folglich ist sie leicht Abwegen verfallen, ohne Kontakt mit der wirklichen Tendenz nach Vorwärts, ins Bessere. "89

Bloch ordnet der utopischen Funktion also eine Vermittlerrolle zwischen Ideal und Realität zu. Diese muss sich an „der Linie konkreter Vermittlung mit materieller Ideal-Tendenz in der Welt“" bewähren. Bewährung heißt aber nicht Belehrung und Berichtigung durch bloße Tatsachen, im Gegenteil, es gehöre zum Wesen des Idealischen in einem gespannten Verhältnis zur bloß fakti- 
schen Gewordenheit zu stehen. Das Idealische hat aber durchaus Anschluss an den Prozess der Welt, ,wenn es etwas taugt“.$^{90}$

Ein fragmentarischer Ausdruck des Wünschens kann sich demnach potentiell zu einer vollständigen Artikulation des Wollens hin entwickeln. Eine abstrakte Utopie als fantastische Spekulation, z. B. der imaginierte ,gute Nicht-Ort“ in Morus'scher Tradition, kann sich potentiell zur konkreten Utopie als Praxis des sozialen und politischen Strebens nach einer besseren Welt - die Verwirklichung des Glücks im Diesseits der Menschheit-hin entwickeln..$^{91}$

Diesen Prozess bezeichnet Bloch mit dem „Kombinat Docta spes“:92 Eine an der objektiv-realen Möglichkeit berichtigte, „,begriffene Hoffnung“,93 eine „marxistische Tendenzkunde“, die keineswegs auf Probleme der besten Gesellschaftsverfassung beschränkt ist, sondern sämtliche Gegenstandswelten der menschlichen Arbeitswelt für sich hat — nicht minder in Technik und Architektur, in Malerei, Dichtung und Musik, in Moral wie Religion; ${ }^{94}$

„ethische Ideale als Vorbilder, ästhetische als Vor-scheine, die auf ein möglicherweise Realwerdendes deuten."95

Bloch beschreibt zwei „Grundelemente der marxistisch erkannten Wirklichkeit" und sieht in beiden die (prozesshaft-)konkrete Utopie als ihre wichtigste Theorie-Praxis:

- Tendenz als „Spannung des verhindert Fälligen“ und

- Latenz als „Korrelat der noch nicht verwirklichten objektivrealen Möglichkeiten in der Welt. “ 96

Blochs Leistung, die Befreiung des Utopiebegriffs ,aus seiner ursprünglichen, eingeschränkten Bedeutung einer romanhaften Staats- oder Sozialutopie“"97 ist gleichsam das zentrale Augenmerk seiner Kritiker*innen. Die begriffliche Befreiung wird als begriffliche Ausuferung angeprangert. Die Kritik an seinem ,unersättlichen" ${ }^{\circ 8}$ Utopiebegriff trifft das eigentliche Potential seiner Philosophie zwar im Kern - eben die Befreiung der Utopie aus ihrer begrenzten Bedeutung — kann es aber nicht dekonstruieren.

Ein Widerspruch, der nicht aufzulösen ist, obwohl der Versuch der Auflösung Entscheidendes zu Tage bringt: Wollte man die Überdehnung des Bloch'schen Utopiebegriffs vom kleinen Tagtraum zur klassenlosen Gesellschaft umgehen, konzentriere man sich:

1. Möglichkeit: auf seinen „Abriß der Sozialutopien“, der erstmals I946 erschien und später als Kernstück des vierten Teils in 
Das Prinzip Hoffnung aufgenommen wurde, denn Sozialutopien seien das „Stammhaus“99 der Utopien. Darin schildert er in kurzen Zügen die historische Abfolge sozialutopischer Entwürfe, von der Antike bis zum Beginn des 20. Jahrhunderts. ${ }^{\text {Ioo }}$ Damit wäre man aber wieder zurück bei der ,eingeschränkten Bedeutung“ des Utopiebegriffs, den Bloch schließlich befreite.

2. Möglichkeit: Im Zentrum steht bei Bloch die konkrete menschliche Praxis als eigentliche Dimension. ${ }^{\text {Ior }}$ Die mitarbeitende Prozesshaltung ${ }^{\mathrm{IO2}}$ gegenüber der Unfertigkeit der Welt, die Partizipation des schaffenden Menschen (Teilhabe) verbinden sich mit seinem aristotelischen Materiebegriff (Hylemorphismus), der Materie und Form als zwei Prinzipen in derselben Sache eint. ${ }^{\text {I03 }}$

Die Herausforderung Blochs Gedanken zu aktualisieren steckt für die Theoriebildung der Mikro-Utopie zweifellos in der zweiten Möglichkeit, denn

„Denken, das kann man bei Bloch lernen, setzt im Kleinen an, auch in kleinen Geschichten: so soll das utopische Potential [...] Anreiz sein, , die großen Fragestrecken selber zu durchmessen"."I04

Oder in den Worten des Schriftstellers Navid Kermani ausgedrückt:

„,Bloch ist veraltet. Aber der Befund spricht nicht gegen ihn, er spricht gegen uns."I05

Mannheim: Motivation in Ideologie und Utopie Es sind drei Aspekte die Karl Mannheims Wissenssoziologie für die vorliegende Arbeit besonders aktuell und spannend erscheinen lassen: Erstens, die Rückbindung des Denkens und damit der Erkenntnis an die soziale Realität, d.h. auch an den sozialen Raum. Zweitens, die Berücksichtigung und Begrüßung von pluralen Denkstilen und ihr Zusammenprall. Und drittens, die differenzierte Verkettung von Utopie und Ideologie.

$\mathrm{Zu}$ I) Mannheim versuchte den ,spezifischen Zusammenhang zwischen den wirklichen sozialen Interessengruppen und ihren Ideen und Denkweisen aufzuspüren." Iо6 Die Bedeutung des Denkens ist im alltäglichen Handeln des Menschen situationsgebunden und daher kein Ergebnis einer abstrakten Subjekt-ObjektBeziehung. ${ }^{107}$ 
$\mathrm{Zu}$ 2) Gemeinschaft ist auch unter den Bedingungen der Moderne möglich und zwar nicht als Gemeinschaft einer Gruppe von Menschen, die sich auf einen Mythos, eine Nation oder eine Ideologie gründet, sondern eine, die sich im intellektuellen Diskurs erst herstellt: die ,sozial freischwebende Intelligenz" als utopische Trägerschicht ${ }^{108}$; im Kontrast dazu steht Marx' Idee von der Rolle des Proletariats als utopische Trägerschicht. Daraus ergibt sich auch eine Pluralität von Utopien, die sich weder ablösen noch zerstören müssen, sondern durch einen intellektuellen Überblick in Relation gebracht werden sollen ${ }^{109}$ und Wahrheitsansprüchen bzw. Letztbegründungen entgegensteht. Darin steckt Mannheims ,,allgemeine Fassung des totalen Ideologiebegriffs" - im Anschluss an Marx - , der von dem Politikwissenschaftler Wilhelm Hofmann als die „eigentliche Geburtsstunde der Wissenssoziologie“" "Io ausgemacht wird. Dabei wird eine Selbstanwendung des Ideologieverdachts vollzogen, d.h. dass man nicht davor zurückschreckt ,auch den eigenen Standort, als ideologisch zu sehen. "II I

$\mathrm{Zu}$ 3) Durch Mannheims Differenzierung von Ideologie und Utopie ergeben sich wesentliche Blickrichtungen für die weitere Argumentation der vorliegenden Arbeit. Zunächst einmal, vereinfacht ausgedrückt, sind

„, Ideologien [...] Ideenkomplexe, die sich um die Aufrechterhaltung der bestehenden Ordnung bemühen [Herrscherphilosophie], und Utopien [...] Ideenkomplexe, die auf eine diese Ordnung ändernde Aktion zielen [Oppositionspolitik]. “II2

Für beide, Ideologie und Utopie, gilt, dass sie zwei Formen von seinstranszendentem Bewusstsein darstellen. Das Denken steigt zwar aus dem gesellschaftlichen Sein auf, übersteigt es aber gleichzeitig. Utopien sind tendenziell vorwärtsgewandt orientiert bzw. transzendieren das Sein nach vorne. Ideologien sind als Ausdruck von Legitimationsstrategien herrschender Gruppen tendenziell rückwärtsgewandt orientiert; dabei können

„, herrschende Gruppen in ihrem Denken so intensiv mit ihren Interessen an eine Situation gebunden sein [...], daß sie schließlich die Fähigkeit verlieren, bestimmte Tatsachen zu sehen, die sie in ihrem Herrschaftsbewußtsein verstören könnten. In dem Wort ,Ideologie' ist implizit die Einsicht enthalten, daß in bestimmten Situationen das kollektive Unbe- 
wußte gewisser Gruppen sowohl diesen selbst wie anderen die wirkliche Lage der Gesellschaft verdunkelt und damit stabilisierend wirkt." "II3

Die Ideologie verändert sich aber innerhalb ihrer historischen Entwicklung, d. h. für Mannheims Gegenwart, dass sie nicht nur bei der eigenen Standortbestimmung haltmacht, sondern dass sie auch versucht den jeweiligen politischen Gegner zu vernichten. ${ }^{\text {II4 }}$

Demgegenüber strukturieren Utopien das Denken von unterdrückten Gruppen, die

,, geistig so stark an der Zerstörung und Umformung einer gegebenen Gesellschaft interessiert sind, daß sie unwissentlich nur jene Elemente der Situation sehen, die diese zu negieren suchen. Ihr Denken ist nicht fähig, einen bestehenden Zustand der Gesellschaft korrekt zu erkennen; sie befassen sich keineswegs mit dem, was wirklich existiert, suchen vielmehr in ihrem Denken bereits die Veränderung des Bestehenden vorwegzunehmen. Ihr Denken zielt nie auf eine Situationsdiagnose ab; es kann nur als eine Anweisung zum Handeln genutzt werden. Im utopischen Bewußtsein verdeckt das von Wunschvorstellungen und dem Willen zum Handeln beherrschte kollektive Unbewußte bestimmte Aspekte der Realität. Es kehrt sich von allem ab, was den Glauben erschüttern oder den Wunsch nach einer Veränderung der Dinge lähmen würde." "II5

Weil hier jene These durchklingt, die sich bei Thomas Hobbes und Carl Schmitt findet und zwar, dass ,,der Souverän so lange Souverän ist, wie er seine Herrschaft behaupten kann", wurde Mannheims Ideologiebegriff von der kritischen „Linken“ hinterfragt und zurückgewiesen, schreibt der Politikwissenschaftler Andreas Heyer. ${ }^{116}$

Es könne ,von ,wirklicher Utopie“ [...] nach Mannheim erst dann gesprochen werden, wenn es der die Utopie tragenden Schicht gelingt, die Herrschaft zu übernehmen bzw. zumindest die ,Realität' an zentralen Stellen zu verändern. "II7 Daraus leitet sich — zusammenfallend und überspitzt dargestellt — ab, dass

„Utopie für Mannheim nicht mehr und nicht weniger darstellt als den positiven Kern der Ideologie, der am Kriterium der Verwirklichung erst im Nachhinein feststellbar ist." "II8 
Dennoch, utopische Vorstellungen tragen von vornherein ein ideologisches Moment in sich, denn die institutionelle Verwirklichung bleibt meist hinter ihrem Ideal zurück, d. h. sobald ein regelerzeugendes, politisches Handeln in eine regelverwendende Verwaltungsstruktur übergeht, verliert es unter Umständen seine gestalterische Kraft. ${ }^{\text {I } 9}$ Der utopische Kern des Denkens kann also entweder durch politisches Handeln verwirklicht werden oder ,,zerschellt an der Realität“،. Mannheim stellt aber heraus,

„, dass eine Welt ohne utopische Überschüsse ein Maß an Nüchternheit und Sachlichkeit verlangen müsste, das dann in den Verlust politischen Wollens überhaupt münden würde."I20

Eine der „vornehmsten Aufgaben der Wissenssoziologie“ ist es, dem Handelnden - über das Marx'sche Diktum von Sein und Bewusstsein hinaus-den Zusammenhang von (utopischem) Denken und Sein so durchsichtig wie möglich zu machen. Die Wissenssoziologie fungiert damit selbst als Utopie. ${ }^{\text {I2I }}$

Horkheimer/Adorno: Negation in der Kritischen Theorie Neben dem Staatstheoretiker Niccolò Machiavelli, dem Vertragstheoretiker Thomas Hobbes und dem Zivilisationsphilosophen Giambattista Vico stehen die frühen Utopisten Morus und Campanella für die „Anfänge der bürgerlichen Geschichtsphilosophie“ in Max Horkheimers gleichnamigem Buch (I930). Horkheimer kritisiert, dass sowohl Hobbes als auch die Utopisten von den geschichtlichen Bedingtheiten abstrahierten und die vorgestellte Gesellschaft auf den freien Willensakt der Bürger*innen gründeten. Und weiter,

„, [d]ie Utopie verkenn[e], daß der geschichtliche Entwicklungsstand, von dem aus sie zum Entwurf ihres Nirgendlandes gedrängt wird, materielle Bedingungen seines Werdens, Bestehens und Vergehens hat, die man genau kennen muß und an denen man selbst anzusetzen hat, wenn man etwas zustande bringen will. [...] Für sie ist die Änderung des Bestehenden nicht an die mühsame und opferreiche Umwandlung der Grundlagen der Gesellschaft geknüpft, sondern in den Kopf der Subjekte verlegt."I22

Horkheimers Formulierung von der mühsamen und opferreichen Umwandlung der Grundlagen der Gesellschaft spiegelt sich im großen Projekt der $\mathrm{K} / \mathrm{kritischen}$ Theorie wider. Ihre Annäherung 
an die Grundbedingungen des Menschseins geschieht in genau umgekehrter Weise wie diejenige der Utopisten. Die zeitgenössische Gesellschaft wird eingehend erforscht, inbegriffen ihrer guten und schlechten Momente als verschiedene Seiten des gleichen Zustandes, basierend auf den gleichen Bedingungen. Kritische Theoretiker*innen ziehen die geduldige Arbeit an der Wirklichkeit der Zeichnung eines gesellschaftlichen Idealbildes vor. Dazu schreibt der Philosoph Burghart Schmidt, dass

,[d]ie marxistische Kritik an den Utopien [...] von der ,Kritischen Theorie' dahin gesteigert [wurde], daß an der Utopie nur noch für wahr zu halten sei, was in ihrem Gegenwurf das Gewordene verneint. Utopische Intention sei einzig zu retten in die kritische Intention gegenüber der Gesellschaft, sonst werde sie allemal zur Ideologie. Oder anders: Nur wer der Utopie sich enthält, vermag ihre antiideologische Intention zu retten." "I23

Horkheimer erkennt in den bis ins Einzelne bestimmten, vollkommenen Gesellschaftsvorstellungen der Utopisten die Überheblichkeit von der Annahme einer ,,absoluten Allgemeinvernunft“. Dies, also die Annahme einer absoluten Vernunft, könne auch ins Gegenteil umschlagen und die bestehende Gesellschaft verklären, indem sie ihre Kategorien als für immer gültig ausgebe. ${ }^{\text {I24 }}$ In der Rückschau auf die totalitären politischen Entwicklungen im 20. Jahrhundert ist dies, einem Kassandraruf gleichkommend, leicht als Warnung zu verstehen.

Die antizipierte Entwicklung technischer Totalitarismen im 20. Jahrhundert zeigt sich u. a. im Erscheinen dystopischer Schriften, z. B. in Aldous Huxleys negativer Utopie Schöne neue Welt (I932); ein Buch, das auch als Nullstunde der klassischen Utopietradition verstanden wird. Darin vollzieht sich-entsprechend dem Geschichtsverständnis von Fortschritt durch Technik - ein Zusammenfall der Gegenwart mit der Zukunft, in dem die Mündigkeit der Menschen (Praxis im Dasein) dem Fortschritt der Technik (Ideal im Außerhalb) untergeordnet wird, so kritisieren Horkheimer und Adorno die ideologische Befangenheit von Huxleys Romankonzeption, in der überhaupt kein Raum für eine mögliche gesellschaftliche Selbstermächtigung geschaffen bzw. gelassen wird. Adorno diagnostiziert: 
„Je mehr das gesellschaftliche Dasein, kraft seiner Allgewalt und Geschlossenheit, den Desillusionierten zur Ideologie seiner selbst wird, um so mehr brandmarkt es den als Sünder, dessen Gedanken dagegen freveln, daß das was ist, eben darum auch recht hat."

Eben das unterscheidet auch die Dystopie von der Utopie. In dystopischen Entwürfen werden vorherrschende Ideologien ausgepinselt bzw. weitergesponnen, während utopische Szenarien vorherrschenden Ideologien kritisch gegenüberstehen bzw. ein Umdenken einleiten.

Das gesamte kritische Schaffen von Horkheimer und Adorno kreist im Grunde um die Suche nach einem Ausweg aus dem beschädigten Leben. ${ }^{\mathrm{I} 26}$ Dies tun sie ex negativo: Sie umgrenzen den positiven Raum, bewahren ihn, indem sie ihn nicht beschreiben. ${ }^{127}$ Das Umgrenzen des positiven Raums geschieht als Negation des Bestehenden, in der Kritik, die sich in der Regel besonders in krisenhaften Situationen herauskristallisiert. Der objektive Zweck der Negation ist das Bessere. Es gilt also etwas Positives herzustellen, ungeachtet dessen wie konturiert es sich schon benennen lässt. ${ }^{\text {I } 28}$

In den vier vorgestellten Theorien kommen jeweils Inhalte zur Sprache, die im weiteren Verlauf der Arbeit jeweils eine entscheidende Rolle spielen: Landauers Verknüpfung von Geschichtsphilosophie und Sozialpsychologie ist als Vorbote der Mikrogeschichte zu erkennen. Mannheims Rückbindung der Utopie an die soziale Realität weist auf ihr ideologisches Kippmoment hin. Blochs Denken, das im Kleinen ansetzt, aber große Kreise zieht, bindet die gesellschaftliche Vorstellungskraft zurück an das individuelle Bewusstsein. Und schließlich Adorno und Horkheimer, die in ihrer kritischen Reflexion zwar auf fixierte Bilder verzichten, aber nicht auf Zukunft generell. 
Exkurs:

Macht und Herrschaft 
Die drei Exkurse orientieren sich an Urthemen gesellschaftsutopischen Denkens: Macht-, Eigentums- und Geschlechterverhältnisse. Da sowohl Eigentums- als auch Geschlechterverhältnisse von Machtstrukturen geprägt sind, dient das Thema Macht als durchgängige Konstante. Die Exkurse sind entsprechend benannt und strukturiert:

Im Exkurs Macht und Herrschaft geht es um eine grundlegende Begriffsklärung, denn Macht ist einer der am dauerhaftest umstrittenen Begriffe der Gesellschaftstheorie. Obwohl der Begriff allgegenwärtig verwendet wird, offenbart sich bei genauerer Betrachtung eine Vieldeutigkeit der damit bezeichneten Phänomene und teils sogar konträren inhaltlichen Ausprägungen. Macht und Herrschaft sind zentrale Kategorien der Gesellschaftswissenschaften, sie unterscheiden sich.

Im Exkurs Macht und Boden wird dargelegt, dass sich Eigentumsverhältnisse historisch in eine platonische Linie (Prinzip Gütergemeinschaft) und eine aristotelische Linie (Prinzip Privateigentum) unterscheiden. Im aktuellen Architekturdiskurs wird dies als dringliche Boden- und Wohnungsfrage kritisch besprochen, wobei neue Formen der Gemeingüterschaft eine besondere Rolle spielen.

Im Exkurs Macht und Geschlecht wird das Thema Geschlechterverhältnisse anhand von Beispielen aus der antiken, spätmittelalterlichen und neuzeitlichen Literatur punktuell beleuchtet. In drei unterschiedlichen mythologischen Erzählungen erlangen jeweils weibliche Protagonistinnen (raum-)politische Machtpositionen, die sie durch kollektives, strategisches Vorgehen auf unterschiedliche Weise herbeiführen. 
Wenige Jahre bevor Morus das Wort Utopia ersann, verfasste der Staatstheoretiker Machiavelli bereits eine der frühesten Utopiekritiken. An der Schwelle zur Neuzeit setzt er in seiner Schrift Principe (Ital. Fürst, I 5I3) einen Kontrapunkt zum utopischen Denken mit folgenden Worten:

„Da aber meine Absicht darauf gerichtet ist, etwas für den, der Verständnis hat, Nützliches zu schreiben, so scheint es mir, die Dinge so darzustellen, wie sie in Wirklichkeit liegen, als bloßen Phantasien über sie zu folgen.

Gar viele haben ja Republiken und Monarchien erdacht, dergleichen niemals gesehen worden, oder in der Wirklichkeit begründet gewesen sind. Aber es besteht ein so großer Unterschied zwischen dem, was das Leben ist und dem, was es sein sollte, daß der, der das Erste vernachlässigt und sich nur nach dem letzten richtet, sich eher dem Untergang schafft als die Rettung. "I

In Machiavellis Position steckt die Argumentationsbasis jeder realpolitisch orientierten Utopiekritik. ${ }^{2}$ Er war davon überzeugt, dass das Wohlergehen des gesellschaftlichen Ganzen vom freien Spiel der wirtschaftlichen Kräfte abhinge und dies nur durch eine mächtige Staatsgewalt zu sichern sei. Seine leidenschaftliche Verkündigung des starken Staates begründet sich im Glauben an die Möglichkeit des geistigen und moralischen bzw. kulturellen Fortschritts, dessen Entstehung aber materiell verursacht werde.

Für Machiavelli gehört die Politik zur vornehmsten Aufgabe eines Denkers, allerdings nur dann, wenn der Staat die Bedingung für die bürgerliche Kraftentwicklung des Einzelnen und der Gesamtheit darstellt. ${ }^{3}$ Bei Machiavelli entspricht die Machttheorie einer Staatstheorie. In seiner Schrift Discorsi (Ital. Diskurse, I 5 I3I9) erneuert er das republikanische Denken und verleiht ihm eine praktische Gestalt von Regierungsführung; er lehrt darin, dass

„, die Menschen nur aus Not etwas Gutes tun. Sobald ihnen aber freie Wahl bleibt und sie tun können, was sie wollen, gerät alles drunter und drüber. Darum sagt man, Hunger und Armut machen die Menschen arbeitsam und Gesetze machen sie gut."4

In der Renaissance vollzieht sich ein Übergang von einem organischen Begriff der Republik als Gemeinwesen hin zu einer 
eigenständigen Philosophie des Republikanismus.5 Gleichzeitig erscheint der Begriff Staat im europäischen Vokabular zuerst im Italienischen als lo stato. Darin reflektiert sich auch die merkliche Wandlung der Organisation der europäischen Staaten in dieser Periode, d.h. die Machtchancen der Fürsten vergrößerten sich, sie wurden zu ,Zentralherren“ im europäischen Staatsbildungsprozess. Das Aufkommen von der neuzeitlichen Utopieliteratur und den Idealstadtkonzepten steht, soziologisch betrachtet, damit in engem Zusammenhang. ${ }^{6}$

Auch die Verquickung von Macht und Architektur vollzieht sich dazu parallel in der italienischen Renaissance. ${ }^{7}$ Die auf Alberti zurückgehende Trennung des architektonischen Entwurfs von der Bauausführung erscheint bei Filarete als

„Wunschbild eines enormen sozialen Prestigegewinns für
den Architekten [...]. Der Architekt ist Wissenschaftler
und Humanist, er speist an der Tafel des Herzogs, der
seine architektonischen Ideen respektiert und sie in
die—-fiktive — Realität umsetzen lässt."8

Sowohl Macht als auch Herrschaft sind immer als soziale Verhältnisse zu denken und zu verstehen. Der Soziologe Max Weber verortet die Herausbildung des Unterschieds von Macht und Herrschaft, worauf sich die Soziologie seither bezieht, auch in der frühen Neuzeit, d.h. zu Beginn des I6. Jahrhunderts. Er bindet Herrschaft an Legitimität zurück und will sie so von der Macht als soziologisch amorpher Kategorie geschieden wissen. Nach Weber heißt

„,Herrschaft‘ [...] die Chance [...], für spezifische (oder: für alle) Befehle bei einer angebbaren Gruppe von Menschen Gehorsam zu finden. Nicht also jede Art von Chance, ,Macht“ und ,Einfluß` auf andere Menschen auszuüben. Herrschaft (,Autorität') in diesem Sinn kann im Einzelfall auf den verschiedensten Motiven der Fügsamkeit: von dumpfer Gewöhnung angefangen bis zu rein zweckrationalen Erwägungen, beruhen. Ein bestimmtes Minimum an Gehorchen wollen, also: Interesse (äußerem oder innerem) am Gehorchen, gehört zu jedem echten Herrschaftsverhältnis."9

Herrschaft setzt also, im Gegensatz zur Macht, Legitimität voraus, die durch die Akzeptanz der Herrschenden von den Beherrschten 
sichergestellt wird. Herrschaft ist nah am negativen bzw. institutionalisierten Machtbegriff, z. B. einer politischen oder wirtschaftlichen Machtausübung über die Menschen-erst einmal dahingestellt, ob mit guten oder schlechten Absichten, ausgeführt von einem Subjekt oder bedingt durch ein entsubjektiviertes System, z. B. dem Staat als übergreifende Ordnungsinstanz. Das soziale (Herrschafts-)Verhältnis ist demnach zwar wechselseitig, aber von stark asymmetrischen Beziehungen zwischen den Akteuren bestimmt.

In der (radikalen) Herrschaftskritik der Kritischen Theorie wird-in der Tradition von Marx und Engels-der historische Charakter von Herrschaft betont. Die Herrschaftsverhältnisse werden dabei an bestimmte Gesellschaftsverhältnisse, d.h. Klassenverhältnisse und die Ungleichverteilung gesellschaftlicher Arbeit gekoppelt. Da Herrschaftsverhältnisse menschengemachte Verhältnisse sind, müsste sich die Herrschaft auch vom Menschen überwinden lassen. Die ,,in Herrschaftsstrukturen eingelagerten strukturellen Ungleichheitsverhältnisse“ und ihre ,negativen Folgen für die Mehrzahl der Herrschaftsunterworfenen“ kann dann dazu führen, ,den Legitimitätsanspruch von Herrschaft zu bestreiten und für die Abschaffung bzw. Überwindung von Herrschaft zu plädieren." Io

Im Zustand der Moderne, so Adorno, ist ein erdrückendes Übergewicht von-an sich doch selbstgeschaffen-über die Menschen bestimmende Machtverhältnisse (technische Rationalität) zu beobachten, die dafür verantwortlich sind, dass Gesellschaft, als den ,eigentlichen Zielen des menschlichen Zusammenlebens entfremdete Ver-gesellschaftung, auf jeden einzelnen primär als Nichtidentisches, als Zwang "stößt."II

„Mit der totalen Vergesellschaftung wird das Programm der Aufklärung obsolet, weil es keinen Bezugspunkt mehr gibt, von dem aus zwischen Wahrheit und Schein unterschieden werden könnte. Das gesellschaftliche Bewußtsein wird notwendig eindimensional, die Gesellschaft verschwindet hinter einem ,technologischen Schleier'."I2

Die Erfahrung von Unterdrückung bzw. erzwungener Unterordnung kann aber auch als Antrieb zur Selbstbefreiung bzw. -ermächtigung dienen, so ließe sich die dialektische Ausführung Hegels über die Selbständigkeit und Unselbständigkeit des Selbstbewusst- 
seins in seiner Parabel über Herrschaft und Knechtschaft ${ }^{13}$ interpretieren. In der Folge gab auch die Kritische Theorie der Versuchung, sich abzustumpfen und ans Gegebene zu gewöhnen-obwohl sie kaum an Änderung zum Besseren glaubte —, nicht nach.

„Empfindsam bleiben war eine gleichsam utopische Haltung — die Sinne für ein Glück geschärft zu halten, das nicht kommen wird, jedoch uns im Bereitsein für es vor den ärgsten Verrohungen schützt.

Politisch und nervlich gründet die ästhetische, die ,empfindliche“ Theorie in einer aus Leid, Verachtung und Wut gemischten Vorwurfshaltung gegen alles, was [herrschaftliche] Macht hat."I4

Ganz allgemein wird mit dem Begriff Macht die Fähigkeit eigene Interessen zu verwirklichen bezeichnet; das ist eine Definition, die sowohl einen instrumentellen (eingesetzte Fähigkeit) als auch einen strukturellen (soziokulturelle Bedingtheit der Handlungsfähigkeit) Aspekt einschließt.

Eine noch umfassendere Vorstellung bzw. Definition von Macht lautet: Die Fähigkeit von Akteuren, Dinge in der Welt zu erreichen. Das klingt sehr allgemein, damit soll aber die Vorstellung vom Erzielen und Wirken in der Welt ausgedrückt werden, ohne von vornherein zu präzisieren, um welche Wirkungen es sich handelt:

„Mächtig sein bedeutet in der Lage sein, mit Bezug auf ein irgendwie geartetes Ziel oder einen Zweck umfangreiche Wirkungen zu erreichen." ${ }^{15}$

Grundlegend ist in vieler Hinsicht die Unterscheidung von power to und power over. Im ersten Fall steht die Möglichkeit bzw. Fähigkeit eines Akteurs, etwas zu tun, was er*sie ansonsten nicht getan oder gekonnt hätte im Vordergrund. Im letzten Fall be- oder verhindert ein Akteur Handlungen oder Verhaltensweisen anderer Personen. Es lässt sich also unterscheiden zwischen einem positiven Machtkonzept, dass die förderlichen Fähigkeiten betont, alleine oder zusammen mit anderen bestimmte Ziele zu erreichen und einem negativen Machtkonzept, bei dem eine präventive Machtausübung betont wird, die wesentlich Kontrolle über andere anstrebt. ${ }^{16}$

Machtverhältnisse sind nie einfache Vektoren der Herrschaft oder der ,sozialen Kontrolle“, sondern auch Vermittler des mögli- 
chen Widerspruchs oder sogar der Emanzipation. Um eine allzu totale Vorstellung von Macht zu umgehen, wie im Anschluss an Foucault naheliegt, der Macht als durchdringende Dimension aller sozialen Beziehungen theoretisiert, ${ }^{17}$ muss auch das Widerständige in Betracht gezogen, d. h. Foucault um Gramsci rückwirkend ergänzt werden.

Die post-Foucault'sche Betonung der Machtstreuung führte vom staatszentrierten Verständnis der Macht (Armeen, Notstandsgesetze, Polizeimächte) weg. Gramscis Begriff der Hegemonieder eher den Konsens und Prozesse der moralischen Überzeugung betont, die notwendig seien, um die Beteiligung an einer bestimmten Ordnung zu sichern, - eignet sich hingegen dazu zentrale Orte der Macht, wie die Staatspolitik, mitzudenken. Er nimmt zwar an, wie Foucault, dass die Gesellschaft von Macht durchdrungen ist, fasst sie jedoch als Raum des Widerspruchs bzw. Feld des Kampfes auf. Gramscis Begriff der Hegemonie erlaubt zu sehen wie verschiedene Quellen und Orte der Macht zum Zusammenwirken organisiert werden können.

Beide beeinflussten die neue Entwicklung der Beziehung zwischen Politik und Gesellschaft auf herausragende Weise. Gramsci kehrte jedoch zurück zur Besonderheit der Politik als Prozess einer hegemonialen Konstruktion mit einem bestimmten Verhältnis sowohl zur staatsbezogenen Handlung als auch zu den mikropolitischen Zusammenhängen, die Foucault insbesondere betonte.

Setzt man den Machtbegriff als zentralen Begriff der intellektuellen Geschichte der Gegenwart ein, dann kommt man nicht umhin die Veränderung des Begriffes des Politischen zu thematisieren.

Im 20. Jahrhundert nahm die feministische Kritik entscheidenden Einfluss auf die Erweiterung des institutionellen Politikbegriffs und erschloss Bereiche, wie z. B. die Familie, die Sexualität, die Fortpflanzung oder den Körper im Allgemeinen als hochpolitische Felder. Diese Kritik hat auch Annahmen über das Individuum als rational handelndes Wesen, ob nun als Subjekt oder Objekt politischer Initiativen, infrage gestellt. Das bedeutet, dass die Menschen nicht außerhalb ihrer jeweiligen Lebenswelt bzw. der sie prägenden gesellschaftlichen Strukturen verstanden werden können.

Die poststrukturalistische Einsicht, dass Macht selbst Formen der Subjektivität produziert, statt nur auf bereits verfasste auto- 
nome Individuen $\mathrm{zu}$ wirken, stellt eine beunruhigende Herausforderung für das Verständnis der Fragen des Handelns, der Erfahrung und des Bewusstseins dar. ${ }^{18}$ 


\section{Utopie in der Architektur: Zur Konstituierung räumlicher Vorstellungskraft}


[W]ir [sollten] jene Sache für die beste halten [...], welche an sich derart beschaffen ist, daß sie nur verschlechtert werden kann.

Sokrates zit. nach Leon Battista Alberti (I99I [Lat. um I450]) Zehn Bücher über die Baukunst, S. I 83 .

Wenn die Geschichte des Denkens der Ort der ununterbrochenen Kontinuitäten bleiben könnte, [...] wäre sie für die Souveränität des Bewußtseins ein privilegierter Schutz.

Michel Foucault (20I8 [Frz. I969])

Archäologie des Wissens, S. 23. 
Idealstadt und Stadtutopie: $\mathrm{Zu}$ den Grundlagen des Utopiebegriffs in der Architektur gehört die Erkenntnis, dass die Geschichte der Utopie mit der Geschichte der Stadt und damit der Geschichte der Architektur eng verbunden ist. Die historische Idealstadt lässt sich von neueren Stadtutopien unterscheiden. Idealstädte sind von einem statischen, an der Antike orientierten Geschichtsverständnis geprägt. Sie erreichen ihre Blüte in der Renaissance. Der technische Fortschritt der industriellen Entwicklung suggeriert hingegen eine Veränderbarkeit der gesellschaftlichen Verhältnisse; dieses Verständnis liegt den Stadtutopien zugrunde.

Architekturutopien der Moderne: Im 20. Jahrhundert entwickelt sich die Architekturutopie heterogen. In der Moderne lassen sich humanistische von technizistischen Utopieansätzen unterscheiden. Im historischen Verlauf - vor dem jeweiligen sozialgeschichtlichen Hintergrund - tritt ein Verschiebungsprozess hervor. Es stellt sich heraus, dass eine Trennung von technischen und sozialen Fragestellungen Ideologien Vorschub leistet.

Utopie in der Postmoderne: Im Übergang zur Postmoderne wird die klassische Geschichtsschreibung aufgebrochen. In dieser Zeit ist oftmals vom Ende der Utopie, vom Ende der Geschichte und vom Ende der großen Erzählungen von Freiheit und Aufklärung die Rede. Das ist aber eher als eine Stimmungslage — Krise und Kritik als Haltung - in Abgrenzung zur Moderne zu verstehen. Dazu sind spezielle Aspekte in den Werken von Michel Foucault und Manfredo Tafuri aufschlussreich. 


\section{Idealstadt und Stadtutopie}

Städte sind mehr als zufällige, d.h. geographisch und ökonomisch vorbestimmte Anhäufungen menschlicher Behausungen. Sie werden seit jeher als spirituelle und politische Einheiten höherer Ordnung verstanden. ${ }^{\mathrm{I}}$

Die Form einer Stadt (urbs, Lat. Stadtgestalt) und die Form ihrer Gesellschaftsordnung (civitas, Lat. Bürgerschaft, Gemeinwesen) stehen in direktem Zusammenhang; die räumliche Organisation ist Ausdruck der politischen Idee der Stadt. Sie führen aber mitnichten ein widerspruchsfreies Verhältnis, das meist Ergebnis einer langen und komplexen Entwicklung ist.

Die Reflexion darüber bildet einen wesentlichen Bestandteil philosophischer Auseinandersetzungen in der Architektur- und Utopiegeschichte. Architektonische und städtebauliche Darstellungen sind utopischen Erzählstrategien immer schon inhärent.

Als Grundlage für die folgenden Überlegungen dient eine Auswahl kanonischer Referenzen der Architektur- und Stadtgeschichte. In entsprechenden Standardwerken setzt die Chronologie — auf unterschiedliche Weise — im Altertum an: In jüdischer Tradition mit Darstellungen der Stadt Jerusalem, z. B. des Madaba Mosaiks; in römischer Tradition mit Schemazeichnungen von Stadtanlagen des Architekten und Theoretikers Marcus Vitruvius Pollio alias Vitruv; oder wie folgt, in griechischer Tradition mit dem städtebaulichen System des Hippodamos von Milet. ${ }^{2}$

Ideale Stadtstaaten in Antike und Renaissance Das Hippodamische System, eine Stadtaufteilung sich rechtwinklig kreuzender Straßenzüge, ist nicht die Erfindung seines Namensgebers. Es entstammt den vorderasiatischen Hochkulturen des Altertums, d.h. 
den hethitischen, assyrischen und babylonischen Städten. Aber Hippodamos popularisierte es als städtebauliches System. Er kam mit dem Straßensystem von Milet, das bereits im 6. Jahrhundert v. Chr. rasterförmig angelegt wurde, im Zuge der Wiedererrichtung der Stadt im frühen 5. Jahrhundert v. Chr., nach der Zerstörung durch die Persischen Kriege, in Berührung. Er übernimmt die Grundprinzipien für seine eigene Planung in Piräus, der Hafenstadt Athens. ${ }^{3}$ Das Hippodamische System als urbanistischer Entwurf zählt, dem Kontext seiner Überlieferung nach, zu den griechischen Staatsutopien. Es ist aber nicht davon auszugehen, dass Hippodamos mit seiner funktionellen Differenzierung, d. h. einer Aufteilung in heilige, öffentliche und private Zonen, eine Besiedlung nach den drei Ständen vorgesehen hat, wie in der Kritik von Aristoteles zu lesen ist.

Die geometrische Regelmäßigkeit des städtebaulichen Grundrasters lässt auch keinen Schluss darüber zu, dass das System Ausdruck einer demokratischen Gesinnung war. ${ }^{4}$

Wahrscheinlich ist, schreibt die Archäologin Ulrike Muss, dass die Stadt in ein Raster eingeteilt wurde zum Vorteil der Messbarkeit der sich daraus ergebenden Grundstücke.

„So wie das Zer- und Verteilen des Opferfleisches in gleiche und ungleiche Teile den Teilnehmern ihre soziale Position verdeutlichte, so ermöglichte auch die Aufteilung der Stadt nach den hippodamischen Prinzipien die Feststellung von Gleichheit bzw. Ungleichheit innerhalb der Bürger[schaft]. "5

Platon geht - ein Jahrhundert später-in seinen Dialogen, die sich der Reflexion der idealen Stadtgesellschaft widmen, kaum auf die konkrete Stadtgestalt ein. ${ }^{6}$ Wenige vage Einzelheiten zu Merkmalen der städtischen Umwelt sind nur in seiner Spätschrift Nomoi (Gr. Gesetze, Rechtsstaatlichkeit) zu finden, die er der realen antiken griechischen Stadt entnimmt. In der Politeia, dem ältesten Dialog mit dem größten Wirkungsradius, entwirft er seine Vorstellung eines idealen Staates - ohne Hinweise auf eine räumliche Gestalt — zuerst. Er behält viele Institutionen der bestehenden Stadt bei. Zugunsten von Integrität und Einheit des Stadtstaates nimmt er allerdings eine Verbesserung ihrer idealen Dimension vor, das bedeutete eine zahlenmäßige Begrenzung der dort lebenden Menschen. Bei einer Angabe von 5040 Wahlberechtigten ergibt sich eine Gesamtanzahl von ca. 25.00o Personen.7 Das ist bezeichnend, 
denn darin zeigt sich, dass der geographische Raum der Antike noch von den Poleis (Pl. Polis, Altgr. Stadt, Staat) als vorherrschende politische Einheiten - ca. 700 an der Zahl—bestimmt war; wobei eine Polis durchaus mehrere „Städte“ umfassen konnte.

Weder Philosophen noch Stadtplaner konnten sich eine Gesellschaft über die Grenzen der Polis hinausgehend, d. h. eine Gemeinschaft von vielen Nationen oder Kulturen vorstellen. Der Territorialstaat, ein Flächenstaat im heutigen Sinne, hatte sich noch nicht entwickelt. Der entscheidende Unterschied des Stadtstaats liegt darin, dass dort die Herrschaft über Personen - heute würde man von Biopolitik sprechen — und eben nicht über Territorien ausgeübt wird. Innerhalb eines Stadtstaates schien z. B. die Abschaffung der Ehe und des Privateigentums politisch denkbar, Sklaverei und Klassenschranken wurden aber aufrechterhalten. Die Beseitigung des Krieges, eine Institution zur Verteidigung gegenüber den „Barbaren“, d. h. den Fremden, insbesondere die Bedrohung durch das Persische Reich, schien allerdings nicht im Entferntesten vorstellbar. ${ }^{8}$

Auch in der italienischen Renaissance war der Stadtstaat die prägende Staatsform. Die antiken Schriften erfuhren in der Renaissance neue Aufmerksamkeit. Während die Form des idealen Gemeinwesens bislang nur textlich beschrieben wurde, sollten in der Renaissance räumliche Vorstellungen auch zeichnerisch konkretisiert werden. ${ }^{9}$

Im Timaios berichtet Platon über die Entstehung der Welt und warum der Demiurg, der Schöpfergott als Baumeister des Universums, den „Leib der Welt“ in Kugelgestalt erschuf. Er erklärt, dass dem, das

„, bestimmt war, alles Lebende in sich zu umfassen, [...] wohl die Gestalt angemessen sein [dürfte], welche alle irgend vorhandenen Gestalten in sich schließt; darum verlieh er ihm die kugelige, vom Mittelpunkte aus nach allen Endpunkten gleich weit abstehende kreisförmige Gestalt, die vollkommenste und sich selbst ähnlichste aller Gestalten [...]." "Io

Die humanistisch gelehrten Architekten der Renaissance könnten daraus geschlossen haben, dass die zutreffendste Analogie zum kugelförmigen Leib der Welt, als Sinnbild des ihr innewohnenden Urhebers, am besten durch einen kreisförmigen Stadtgrundriss verkörpert würde. Sie erkannten das innovatorische Potential der 
Antike und überführten es in säkulare Neuerungen. Die ideale Form für das Zentrum eines Idealstaates ist demnach der Kreis als der Spiegel einer kosmischen, also harmonischen Ordnung. ${ }^{\text {I }}$

Die auf tabula rasa errichteten Idealstädte der Renaissance mussten-vor dem Hintergrund des chaotisch gewachsenen mittelalterlichen Stadtmusters - einen kaum zu unterschätzenden Eindruck auf die Zeitgenossen gemacht haben; der radikale Bruch mit den alten Strukturen erschien unweigerlich modernisierend. Das heißt, die Idealstadt war als architektonisches Thema bereits ein halbes Jahrhundert vor Morus' gattungsbildender Schrift etabliert. ${ }^{\mathrm{I2}}$

Im selben historischen und sogar personellen Umfeld der italienischen Renaissance, aus dem die ersten Idealstadtentwürfe emportraten, tritt auch die Architekturtheorie in Erscheinung; ${ }^{13}$ namentlich durch den Florentiner Universalgelehrten Leon Battista Alberti und Filarete als Architekt und Künstlerpersönlichkeit. Alberti gilt als Vordenker von Utopie und Stadtplanung und nach heutigem Verständnis als erster moderner Architekt überhaupt. ${ }^{14}$ Er verfasste sein Traktat De re aedificatoria (Lat. Über die Baukunst, um I450, I485 erschienen), in römischer Tradition stehend, in klassischer Form. Das Geleitwort des Traktats ist an Lorenzo Medici gerichtet, dessen Macht Alberti diente.

Kurze Zeit später verfasste Filarete seine Schrift Trattato d'architettura (Ital./Volg. Architekturtraktat, ca. I46I-64). Er führte, mit politischen Ambitionen in griechischer Tradition stehend, die Dialogform als neues Stilmittel in das Traktatgenre ein. Bis dahin war der Dialog als literarische Form im Wesentlichen moralphilosophischen und pädagogischen Themen vorbehalten; der kunsttheoretische Dialog ist also eine Transferleistung Filaretes und eine Mitteilung an seinen Dienstherrn, den Fürsten Francesco I. Sforza, Herzog von Mailand. Der Kunsthistoriker Andreas Tönnesmann schreibt dazu, dass

„, [w]eder bei Platon noch bei den italienischen Humanisten

[...] bis dahin Fürst und Fachmann, Macht und Expertise in ähnlicher Unbefangenheit als Gesprächspartner zusammengefunden [hatten]. "I5

Mit „Sforzinda“ ersann Filarete die erste durchgeplante und illustrierte Idealstadt der Renaissance, deren fiktive bauliche Umsetzung in die unmittelbare Gegenwart - Grundsteinlegung: I5. April 


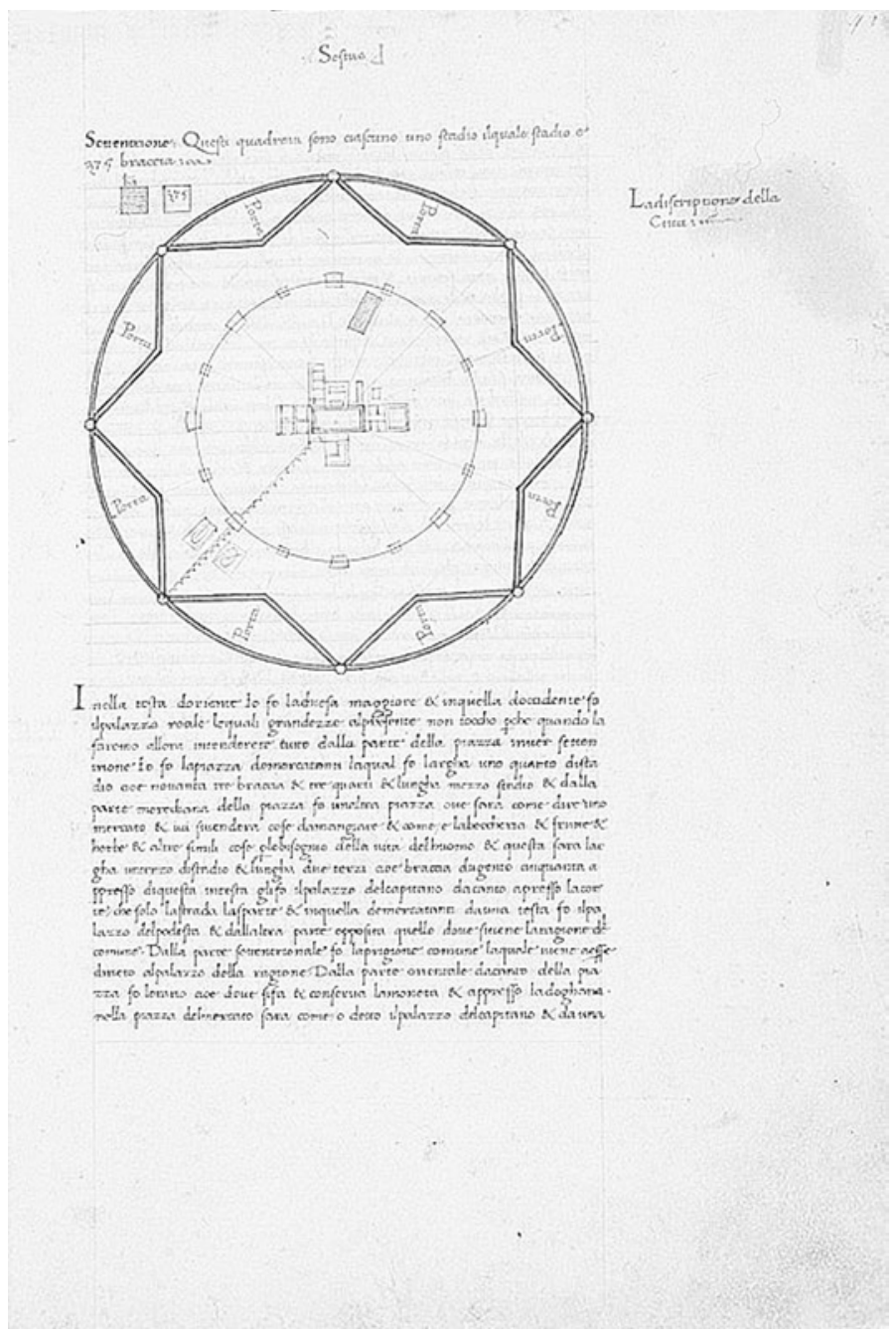

1 Stadtanlage von Sforzinda aus Filaretes Architekturtraktat, Florenz, Bibl. Naz., Cod. Magl. II, I, 140 fol. 43 f.

I460 - verlegt wird. Im dialogisierten Text des Traktats wird auf die dazugehörigen Zeichnungen immer wieder Bezug genommen (Abb. I). Dabei reflektiert der Architekt über die Form und Einteilung der Stadt und ihre Lage in der Landschaft. So gewinnt Filaretes Entwurf eine Autonomie bzw. Priorität gegenüber dem Text und ist damit nicht nur als Illustration für die Leser*in, sondern 
als unmittelbarer Niederschlag der Erfindung des Architekten zu verstehen, schreibt der Kunsthistoriker Hanno-Walter Kruft. Sforzinda sollte zu der paradigmatischen Stadt für viele zukünftige utopische Schriften bzw. Entwürfe avancieren. ${ }^{16}$

Die Idealstadt kann als der paradoxe Realisierungsversuch einer Utopie verstanden werden, wobei die Stadtgestalt ihr sichtbares Abbild ist, konstatiert Kruft in seinem Buch Städte in Utopia (I989). Der prägnanteste ästhetische Wesenszug der Idealstadt ist insbesondere in den regelmäßigen Stadtanlagen zu sehen. Sie ist für gewöhnlich kreis- oder sternförmig, oder auf andere Weise symmetrisch angelegt und bildet mithin eine eher monotone Umwelt aus. Dies schlägt sich auch auf die späteren literarischen Utopievorstellungen nieder, wozu Saage interpretiert, dass der

„,geometrische Grundriss ,Utopias“, des ,Sonnenstaates“ und der ,Christianapolis` eine überraschungslos gewordene Welt [symbolisiert], deren absolute Transparenz individuelle Abweichung nicht duldet."I7

Idealstädte sollten aber nicht nur anhand ihrer physischen, visuellen oder praktischen Kriterien beurteilt werden, denn sie hinterließen deshalb nachhaltigen Eindruck, weil ihre gedankliche Grundlage kosmischer und metaphysischer Natur ist, so der Kunsthistoriker Colin Rowe. ${ }^{18}$ Von einer Idealstadt ist auch nur dann zu sprechen, wenn ,Utopie, ästhetische Reflexion und urbanistische Umsetzung [...] zusammentreten, "I9 also Utopie und Wirklichkeit sich in der realisierten Idealstadt berühren, so die Kruft'sche Definition. Die Regelmäßigkeit der Planung, ein formales Kriterium, ist für eine Idealstadt also nicht konstituierend. Es muss ein nachvollziehbarer architekturtheoretisch oder urbanistisch begründeter Reflexionsvorgang vorliegen, der die geforderte Äquivalenz zwischen Utopie und Idealstadtform in der Umsetzung rechtfertigt. ${ }^{20}$

Auf idealstädtische Entwürfe-im Sinne entscheidender architekturtheoretischer Entwicklungen-wird hier nur fluchtpunktartig verwiesen, weil es vorzugsweise darum geht auf übergeordnete, d.h. von der Antike übernommene Prinzipien aufmerksam zu machen: In der Renaissance findet das stadtstaatlich organisierte Gemeinwesen zu seiner baulichen Struktur. Zur weiterführenden Beschäftigung mit idealstädtischen Realisierungen in Renaissance und Barock muss auf Standardwerke der Stadtgeschichte verwiesen werden. ${ }^{2 \mathrm{I}}$ 
Es lässt sich resümieren, dass die Idealstadt, ob imaginiert oder materialisiert, einer Zeit knapper Ressourcen entspringt, in der eine gleichbleibend stabile Weltsicht-ein „geschlossen-statisches“ Weltbild — vorherrschte und die Lehre von der ewigen Wiederkehr des Gleichen galt. ${ }^{22}$ Eine Aussicht auf Veränderung bestand in idealstädtischen Konzeptionen nicht, in ihr wurden bestehende Machtverhältnisse demonstriert und manifestiert. Das klassische Idealstadtdenken reicht also bis in die Antike zurück und kommt erst mit der Französischen Revolution vollends zum Erliegen. ${ }^{23}$

Die Stadtutopie hingegen, ob imaginiert oder materialisiert, entspringt einer Zeit des beginnenden materiellen Überflusses im Zuge des technischen Fortschritts der industriellen Revolution. Das Stadtleben beginnt sich als neues Modell durchzusetzen. Eine neue Weltsicht-ein „offen-dynamisches“ Weltbild-entwickelt sich und weil damit Veränderung vorstellbar wird, kann sich sozialkritisches Denken herausbilden. ${ }^{24}$

Neuere Modelle, z. B. die Siedlungsexperimente der utopischen Sozialisten oder die spätere Gartenstadtidee können nicht in die Idealstadttradition gestellt werden. Sie konstituieren sich durch ihre Haltung zur modernen Naturwissenschaft und Technik, eine dem antiken Denken fremde Welt. Das Paradigma der ewigen Wiederkehr des Gleichen wurde ebenso obsolet wie das Primat der überschaubaren und statischen Größe der Idealstadt. ${ }^{25}$

Zum Ausgang des I 8. Jahrhunderts ergibt sich also auch in der Geschichte der Architektur und Stadt ein historischer Einschnitt, parallel mit der Wende zur Praxis in der Geschichte der Utopie. Die praktische Wende ist auch hier als Verzeitlichung der Utopie zu verstehen, sie konkretisiert sich in der zukünftigen Welt.

Die Theorie wird praktisch, oder anders formuliert, die Theorie taucht in die Praxis als ,offene Utopie“"26 ein.

Revolutionsarchitektur im Übergang Im Übergang von der Idealstadt zur Stadtutopie entsteht ein architekturgeschichtliches Sonderphänomen, die sogenannte Revolutionsarchitektur. ${ }^{27}$ Aufgrund ihrer klaren Formensprache, die über ihre jeweilige Funktion Auskunft gibt, ist sie auch unter der Bezeichnung „Architecture parlante“ (Frz. sprechende Architektur) bekannt geworden. Insbesondere die Entwürfe der Architekten Claude-Nicolas Ledoux und Étienne-Louis Boullée werden oftmals zuerst mit utopischen 


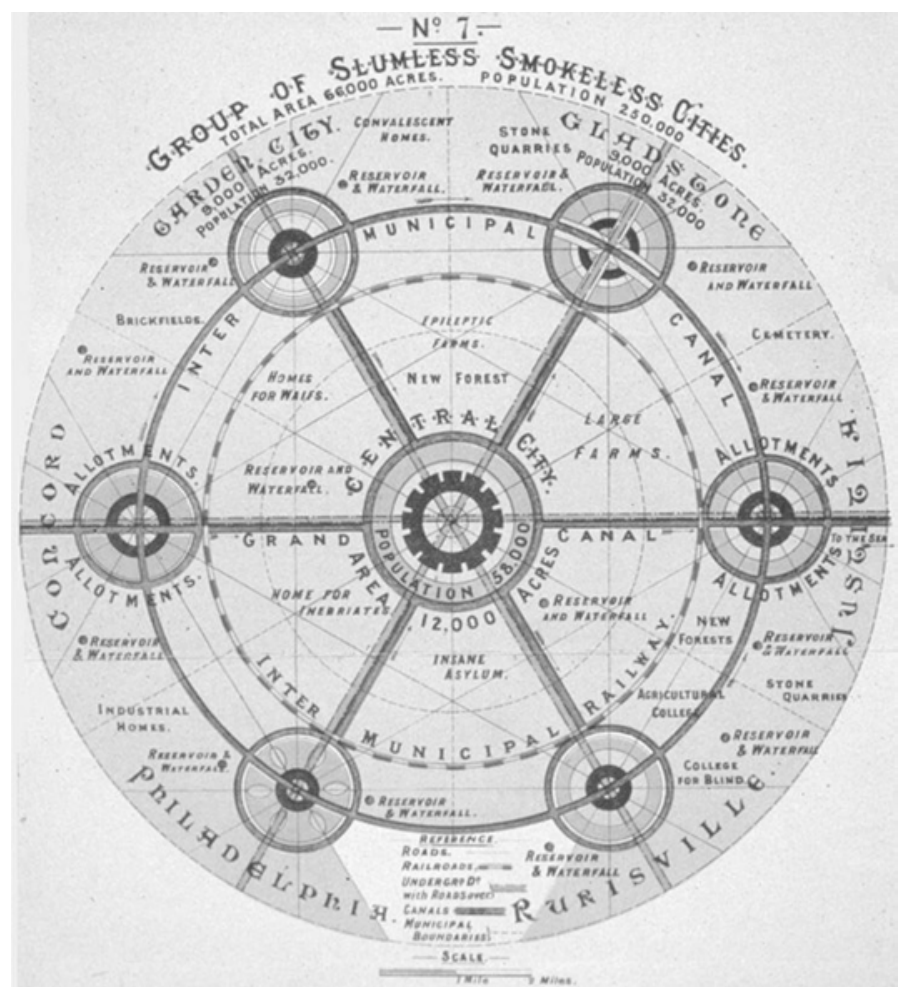

2 Gartenstadt, Ebenezer Howard, Diagramm Nr. 7, 1898

Architekturvisionen des I8. Jahrhunderts in Verbindung gebracht und sollen deshalb an dieser Stelle Erwähnung finden.

Ledoux entwirft seine utopische Vision der Stadt Chaux ( $773-85$ ) auf erzählerische Weise. ${ }^{28}$ Sein ausgeprägt symbolischer Umgang mit dem architektonischen Formenvokabular lässt Rückschlüsse auf den jeweiligen Berufs- oder Familienstand der Bewohnerschaft zu; z. B. wird das Haus des Reifenmachers in der Ansicht von großen konzentrischen Kreisen dominiert oder das Haus des Holzfällers gleicht einem geschichteten Holzstapel in Form einer stumpfen Pyramide. Ledoux bettet seine körperhaften Architekturentwürfe in perspektivisch dargestellte, szenische Landschaftsambientes ein, die das Werk der Natur und das der Menschen in ihrer Polarität programmatisch vor Augen führen. ${ }^{29}$ 


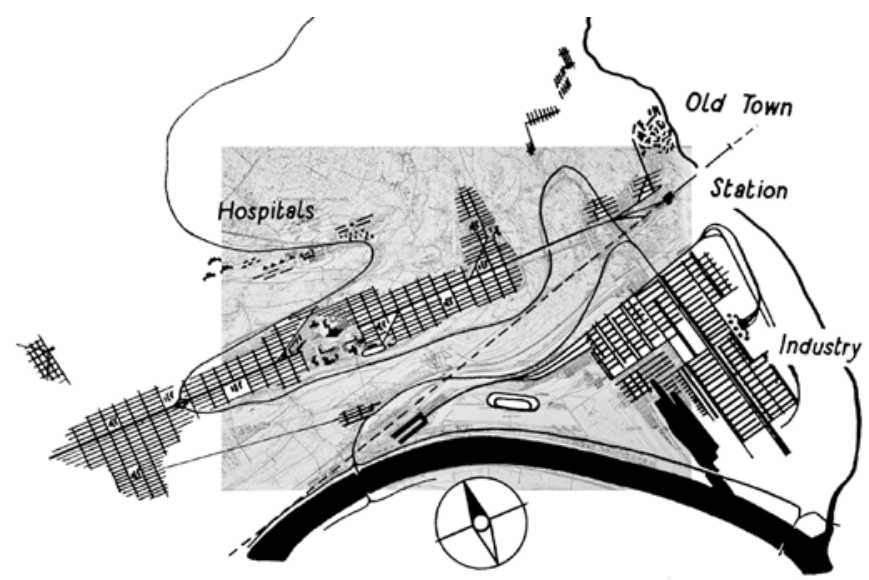

3 Ideale Industriestadt, Tony Garnier, funktionelle Zonen, 1917

Bis dahin stand die architektonische Phantasie im Dienst der literarischen Utopie und orientierte sich an der zeitgenössischen Praxis und Theorie des Bauens. Nun bricht sie,

„, in dem Augenblick, in dem sie sich der Bevormundung durch das literarische Medium entledigt, mit Macht aus diesen Grenzen aus. Die radikale Innovation, in der literarisch verfaßten Utopie ein Merkmal mehr der staatstheoretischen Spekulation als der baulichen Belange, wird nun, mit der Emanzipation des Architekten zum Utopisten, ein Signum auch der Bauprojekte. “30

Die ,gigantischen architektonischen Träume“ dieser Architekten, weithin bekannt ist v. a. Boullées Kenotaph für Isaac Newton ( 1784), zeugen vom Realismus der Aufklärung, schreibt der Architekturhistoriker Manfredo Tafuri. Der überdimensionale Maßstab, die geometrische Reinheit und der prunkvolle Primitivismus haben eine konkrete Bedeutung: Sie sind kaum als unrealisierbare Träume $\mathrm{zu}$ verstehen, sondern gelten als experimentelle Modelle einer neuen Entwurfsmethode. ${ }^{3 \mathrm{I}} \mathrm{Zu}$ jener Zeit erhob man die Geometrie, das relevanteste mathematische Teilgebiet für räumliches Denken, in der Architektur zum Analogon der menschlichen Vernunft. Die Radikalität dieser Architekten liegt damit im Kerngebiet der Archi- 
tektur selbst begründet, d.h. im Vorgang des Entwerfens wird eine autonome Formensprache gewonnen.

Die Radikalität des frühsozialistischen Gesellschaftstheoretikers Charles Fourier hingegen zeigt sich in seinem Konzept für eine ,neue sozietäre Ordnung. “32 Das Geschichts- und Menschenbild hat sich verändert. Der Maßstab guten Lebens liegt nun nicht mehr im gesellschaftlichen Egalitarismus und dessen Bewahrung durch die Unveränderlichkeit des Systems begründet, sondern die Hoffnung auf Metamorphose und Besserung gründet sich jetzt in der Unterschiedlichkeit der Menschen.

Die von außen auferlegte Zwanghaftigkeit früherer Utopien, ob platonisch oder königlich, wird durch einen individualistischen Ansatz ersetzt, ${ }^{33}$ basierend auf freiwilliger Anstrengung, freien Vereinigungen und gegenseitiger Hilfe. Die rationale Allgemeinvernunft weicht libidinösen Individualbedürfnissen. Fouriers Vision des sozialen und individuellen Glücks, der guten menschlichen Ordnung, zeigt sich in einem gesellschaftlichen Zusammenleben, das von leidenschaftlicher Anziehung bestimmt wird. ${ }^{34}$ Obwohl die Arbeitsorganisation weiterhin das gesellschaftliche Zentrum bildet, werden die Handlungen der Menschen nun nicht mehr von ihrer wirtschaftlichen Vorteilhaftigkeit diktiert.

In der Beschreibung von Leben und Liebe dieser Gemeinschaften ähnelt kein Tag dem anderen, besonders derjenigen, deren psychologische Natur beständige Veränderung anstrebt, wie z. B. bei den Menschen des „Schmetterlingstyps.“35 Die Zusammenfassung verschiedenster psychologischer Typen - Fouriers „Temperamente" - unter einem Dach, bildete nun die Grundlage für eine glückliche Gemeinschaft. Gelang dies nicht, so fehle die „Mannigfaltigkeit der Beziehungen, die für die totale Selbstverwirklichung im Zustand der Harmonie" notwendig wäre. ${ }^{36}$ In seiner Schrift Théorie des quatre mouvements (et des destinées générales. Le nouveau monde amoureux) (Frz. Theorie der vier Bewegungen, I808) entwickelte Fourier die Grundlagen seiner genossenschaftlichen Gemeinschaften. Seine Theorie besagt, dass nicht allein die materielle, sondern auch die organische, animalische und soziale Bewegung dem Gesetz der Attraktion bzw. zwölf Leidenschaften unterworfen ist. ${ }^{37}$

Die Bevölkerungszahl einer Phalanx (oder Phalange) richtet sich nach der 
,mathematisch-psychologischen Theorie des Zusammenklangs der Kontraste [...] von 8io Temperamenten [im Falle der größten Produktionsauslastung ist die doppelte Mitgliederanzahl vorgesehen], die die volle Entfaltung des sozialen Mechanismus in jeder Phalange ermöglichen. "38

Diese werden wiederum in produktions- und wohngenossenschaftliche Gemeinschaftshäuser zusammengefasst. Ein Phalansterium (oder Phalanstère), eine Hybridform aus Palast, Kirche, Wohnhaus und Werkstätte, bildet dann das Grundelement einer Stadt. In Fouriers Vorstellung von einem harmonischen Gemeinschaftsleben wird der Rückzug ins Private auf ein Minimum beschränkt, d.h. eine Differenzierung in private und öffentliche Bereiche entfällt. Er ersinnt verbindungsräumliche Passagen - überdacht, geheizt, ventiliert und geprägt von Zirkulation, Bewegung und Kommunikation ${ }^{39}$ - , die als Übergangszonen zwischen den unterschiedlichen Nutzungen dienen.

Allerdings zeigt die Widersprüchlichkeit der theoretischen und architektonischen Darstellungen utopischer Gesellschaftsmodelle dieser Zeit, dass das nachrevolutionäre Frankreich um die Jahrhundertwende noch von Auseinandersetzungen um die politische Herrschaft geprägt war. Fouriers Ausführungen über das Leben in den Phalanstères ist mit seinen architektonischen Ideen, die sich stilistisch noch stark an der absolutistischen Machtarchitektur von Ludwig XIV. orientieren, kaum vereinbar. ${ }^{40}$ Ein „Abklatsch von Versailles“ diente als „Prototyp für die proletarische Zukunft“. Doch diese ,prosaische[n] und wenig anregende[n] [architektonischen] Aussagen“ wirkten in einem ,Zeitalter evolutionärer Hoffnung und demokratischen Aufschwungs“" wenig überzeugend. ${ }^{4}$

Fouriers Betrachtung der richtigen Gesellschaft in Analogie zu ästhetischen Sachverhalten spielt sich auf einer anderen Ebene ab: Die neue Kunst, „l'art social“, bestehe darin, das Zusammenspiel der Leidenschaften nicht mehr dem Zufall zu überlassen, sondern ihre richtigen Proportionen zu finden und sie so zu kombinieren, dass ein soziales Kunstwerk entsteht. ${ }^{42}$

In den I96oer Jahren wurde Fouriers Theorie der vier Bewegungen ins Deutsche übertragen, herausgegeben und versehen mit einem Vorwort von Theodor W. Adorno, in dem er schreibt, dass keiner sich dem Vorwurf des Utopismus schutzloser darbietet als Fourier; ,,bei keinem aber auch ist die Anfälligkeit der Doktrin so sehr gezeitigt vom Willen, die Vorstellung des besseren Zustands 
zu konkretisieren." 43 In der darauffolgenden Einleitung beschreibt die Literaturwissenschaftlerin und Soziologin Elisabeth Lenk die Grundstruktur Fourier'schen Denkens als dialektische Einheit eines unbestechlich kritischen Blicks verschmolzen mit grenzenlosem Optimismus. Fourier war überzeugt, dass das erste Phalanstère eine derartige Anziehungskraft ausüben werde, dass innerhalb weniger Jahre mit einer Verbreitung des Prinzips der leidenschaftlichen Serien zu rechnen sei. Die soziale Metamorphose könne sich vollziehen, ohne dass ein einziger gewaltsamer Handstreich geführt zu werden brauche. ${ }^{44}$

Stadtutopien der Industrialisierung Zwei Klassiker des neuen stadtutopischen Denkens, die Garten- und Industriestadt, sind als Reaktion auf die Verslumung der industrialisierten Innenstädte zu verstehen: Um I900 lässt der Stadtplaner Ebenezer Howard die Gartenstadt als neues städtebauliches Leitbild entstehen. Mit seinem Werk To-morrow. A Peaceful Path to Real Reform (Engl. Gartenstädte von morgen, I898) stieß er die internationale Gartenstadtbewegung an. Diese Bewegung darf aber nicht als Flucht zurück in die arkadische, also ursprüngliche Natur verstanden werden, so wie es die oberen Schichten der italienischen Renaissance um I500 unternahmen, um sich den — zu ihren Ungunsten - verändernden stadtgesellschaftlich-ökonomischen Bedingungen zu entziehen. ${ }^{45}$ Der periphere Grünraum wird hier als Gegengewicht zu den veränderten Lebensbedingungen in den verrußten Industriestädten für die Arbeiterklasse imaginiert. ${ }^{6}$ Für Howard besteht die „wesentliche Eigentümlichkeit des Planes“ darin, dass alle Bodenrenten, die auf dem jährlichen Ertragswert des Landes basieren, an das Trust-Kollegium, d.h. die Verwaltenden, zu zahlen sind. Diese händigen den Überschuss (nach den nötigen Abzügen) an den Hauptverwaltungsrat der Stadtgemeinde aus, der wiederum den Überschuss zur Schaffung und Instandhaltung aller öffentlichen Anlagen, wie Straßen, Schulen, Parks, verwendet. Der Zweck dieses Landerwerbs besteht darin, der Industriebevölkerung, den Unternehmern und Handwerkern aller Art, sowie den Landwirten, ein höheres Maß von Gesundheit und Wohlbehagen zu bieten in Form einer Gartenstadt, der eine Möglichkeit auf Veränderung und Wachstum eingeschrieben ist (Abb. 2). 
„,Das Mittel für diesen Zweck ist eine gesunde, natürliche und wirtschaftliche Vereinigung von Stadt- und Landleben und zwar auf Grund und Boden, der sich im Gemeindeeigentum befindet." 47

Der Architekt Tony Garnier schlägt mit seiner ,,idealen Industriestadt" eine andere Richtung ein. Er entwickelt seine funktionell zonierte, durch Grüngürtel unterteilte Planstadt (Abb. 3) umfassend zeichnerisch; zusammengeführt im Buch Une Cité industrielle. Étude pour la construction des villes (Frz. Die ideale Industriestadt, I9I7). ${ }^{48}$ Die Darstellungen zeugen, unter Einbezug landschaftlicher Charakteristika Frankreichs, von einem glorifizierenden Realismus. ${ }^{49}$ Garnier integrierte den neuesten Stand der Technik, z. B. armierten Beton und Elektrizität, was dazu beitrug ein Bild der Architektur (Wohnbauten, ,,schlicht, standardisiert und schmucklos") zu erzeugen, das humane Lebensbedingungen zum obersten Prinzip erhob. ${ }^{5}$ Obwohl die hygienischen Bedingungen seit jeher ein Motor von gesellschaftlichen Entwicklungen waren, lässt sich bei Garnier eine Umsetzung des — als modernistische Forderung bekannt gewordenen - Rufs nach einem harmonischen Leben in Licht, Luft und Sonne erkennen. ${ }^{5}$ 


\section{Architekturutopien der Moderne: Mensch und Technik}

Die Programmatik der architektonischen und städtebaulichen Moderne wird oftmals als einheitliche, utopisch-motivierte Entwicklung des „,neuen Bauens“ für den ,neuen Menschen“52 wahrgenommen. Für den Architekturhistoriker Sigfried Giedion sind es die Architekturschaffenden und für den Wissenssoziologen Karl Mannheim sind es die Utopieschaffenden, die den - oft unbewussten - Wünschen ihrer Herkunftsgesellschaft Gestalt verleihen. Die ,soziale Imagination“ sei das entscheidende Bindeglied zwischen der Fähigkeit von Architekt*innen bzw. Utopist*innen, die menschliche Umwelt zu gestalten und der entsprechenden utopischen Mentalität, die für die Pflege dieser Fähigkeit notwendig ist. ${ }^{53}$

Die Stadtsoziologin Mechthild Schumpp geht noch einen Schritt weiter und schreibt, dass durch den Bezug auf konkrete utopische Intentionen nachgewiesen werden kann, dass das Auseinanderklaffen der technischen von der politisch-sozialen Dimension einer Humanisierung der städtischen Umwelt im Wege steht und damit der Ausbildung von Ideologien Vorschub geleistet wird. ${ }^{54}$

Im Folgenden wird eine differenzierende Betrachtung utopischer Motivationen vorgeschlagen.

Zunächst folgt eine Übersichtstabelle (Tab. 2), die mit „,humanistische und technizistische Programme im 20. Jahrhundert" überschrieben ist; darin wird eine Auswahl von Architekturutopien, in die städtebauliche Überlegungen unweigerlich miteinfließen, vorgeschlagen. Ob dann jeweils ein politisch-sozialer oder technischer Zukunftsanspruch im Vordergrund steht, d. h. expliziert, oder implizit formuliert ist und wo die Grenze dieser Differenzierung verläuft, bleibt im Einzelfall zu erörtern. ${ }^{55}$ 

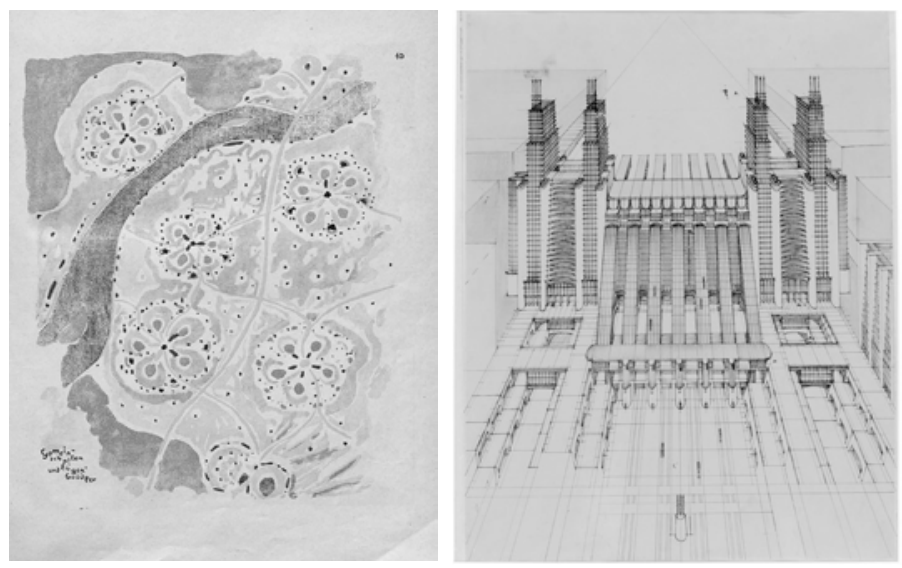

4 Links: Die Auflösung der Städte, Bruno Taut, 1920; Zeichnung Nr. 10: Gemeinschaften und Eigenbrötler — aus 5000m Höhe. Ein humanistischer Ansatz: heteronomes Gewebe, weiche diagrammatische Darstellung von kleinen miteinander verwobenen Einheiten (funktional und ästhetisch), sozial, Aufbau von unten, ländlich, dezentral.

5 Rechts: La Città Nuova, Stazione, Antonio Sant'Elia, 1914. Ein technizistischer Ansatz: autonome Maschine, harte positivistische Darstellung einer großen mechanischen Entität (funktional und ästhetisch), technisch, Steuerung von oben, städtisch, zentral.

Die einordnenden Notizen sollen als „Umgrenzungen und Einengungen" ${ }^{66}$ zu einer differenzierenden Betrachtung beitragen.

Im Anschluss wird eine Auswahl der ,,architekturutopischen Programme“ ausführlicher erläutert.

In Deutschland war das frühe 20. Jahrhundert durch die Umbruchsituation vom Kaiserreich zur Weimarer Republik bestimmt, d.h. eine autoritär geprägte und Demokratie-unerfahrene Gesellschaft rang mit wirtschaftlichem Niedergang, starker Inflation und Massenarmut. Trotzdem lässt sich in dieser Zeit, auch über deutsche Grenzen hinweg, von einer ,allgemeinen Aufbruchstimmung“ sprechen. 57

Die Suche nach neuen Gesellschaftsmodellen wurde auf unterschiedlichen Wegen beschritten, d.h. die Hoffnung auf Zukunft 
Tabelle 2: Humanistische und technizistische Programme im 20. Jahrhundert

\begin{tabular}{l|l} 
Humanistisch & Technizistisch \\
\hline $\begin{array}{l}\text { Bruno Taut: Arbeitsrat für } \\
\text { Kunst, I9 8, Gläserne Kette, } \\
\text { I9I9 }\end{array}$ & \\
\hline $\begin{array}{l}\text { Bauhaus (Weimar-Dessau- } \\
\text { Berlin), I9I9-33 }\end{array}$ & \\
\hline & $\begin{array}{l}\text { Le Corbusier: La Ville } \\
\text { Radieuse, I924/33 }\end{array}$ \\
\hline & $\begin{array}{l}\text { Ludwig Hilberseimer: } \\
\text { Hochhausstadt, I924 }\end{array}$ \\
\hline
\end{tabular}

Russ. Konstruktivismus: Architektenvereinigung OSA, I925 Frank Lloyd Wright: Broadacre City, I932/35

\begin{tabular}{l|l}
\hline & $\begin{array}{l}\text { Charta von Athen: } \\
\text { I933/43 (CIAM, I928-59) }\end{array}$ \\
\hline $\begin{array}{l}\text { Statement on Habitat; The } \\
\text { Doorn Manifesto: Smithsons }\end{array}$ & \\
I954/60 (Team I0, I953-8I) & \\
\hline
\end{tabular}

Richard B. Fuller: Raumschiff Erde, I968

Cedric Price: Non-Plan, I969

Frei Otto: IL-Mitteilungen, I969-95

\begin{tabular}{l|l}
\hline & $\begin{array}{l}\text { Urbane Megastrukturen: } \\
\text { z. B. Superstudio, I960-70er }\end{array}$ \\
\hline $\begin{array}{l}\text { Renée Gailhoustet: Spinoza } \\
\text { Complex, Paris d'Ivry, I96o- } \\
\text { 8oer }\end{array}$ & \\
\hline Lina Bo Bardi: São Paolo, & \\
I96o-9oer & \\
\hline & Smart City, seit 2000 \\
\hline Mikro-Utopien, seit 2000 &
\end{tabular}


Notiz

Maschinistischer Urbanismus

"Überpolitischer Sozialismus"

Humanisierung der Industrialisierung

durch eine Sozialreform der Künste

Ästhetisierter Technizismus

"Groszstadt" als (Auto)Modellstadt

"Social condensers" im Zeitalter der Massen

Nordamerikanische Agrarutopie

Utilitaristischer Funktionalismus

Humanistischer Funktionalismus bzw.

architektonisch-anthropologischer

Strukturalismus

Humanistischer Technizismus

Urbanistisch-technizistischer Strukturalismus

Urbanistische Gemeinschaftsarchitektur;

wohnen im innerstädtischen Naturraum

Architektonische Stadtlandschaft,

"Stones against Diamonds" 
polarisierte sich in zwei Denkrichtungen: der Glaube an einen gesellschaftlichen Fortschritt durch Technik stand dem Glauben an einen gemeinschaftlichen Fortschritt durch Lebensreformen gegenüber.

Für den argumentativen Fortgang der Arbeit liegt es nahe, den Architekten Bruno Taut als zentrale Figur an der Schwelle zur klassischen Moderne hervorzuheben. Seine humanistischen Überzeugungen spiegeln sich in unterschiedlichen Facetten seines Schaffens wider, z. B. in seiner Rolle innerhalb der expressionistischen Künstlergemeinschaft Gläserne Kette und im Arbeitsrat für Kunst; in seinem (durch Walter Gropius vermittelten) Einfluss auf das Bauhaus; $5^{8}$ in seiner architektonisch-zeichnerischen Umsetzung der Ideenbilder von Kropotkin und Landauer;59 und erwähnenswert ist nicht zuletzt sein Japanaufenthalt, der ihn dazu anregte in der Tradition des japanischen Hauses eine „Urgeschichte der Moderne" zu erkennen. ${ }^{60}$

Schon um I900 imaginierte die Gläserne Kette-im Austausch mit dem ,pankosmischen“ Literaten und Zeichner Paul Scheerbart-eine vom Gemeinschaftsgedanken durchdrungene zukünftige Welt, deren Kristallbauten eine neue Zivilisation, ganz im Einklang mit dem Universum, einleiten und glorifizieren sollte. Bloch kommentiert Tauts ,gebautes Reich der Freiheit“" so:

„, Der Kristall ist der Rahmen, ja der Horizont der Ruhe, aber das Ornament des menschlichen Lebensbaums ist der einzig wirkliche Inhalt dieser umschließenden Ruhe und Klarheit. Die bessere Welt, welche der große Baustil ausprägt und antizipierend abbildet, besteht so ganz unmythisch, als reale Aufgabe vivis ex lapidibus, aus den Steinen des Lebens.“6I

Nach dem Ersten Weltkrieg konkretisiert Taut seine Vorstellungen. Er übersetzt Landauers Idee einer ,Gesellschaft [...], in der ländliche Kommunen eine harmonische Verbindung von Freiheit und Ordnung, Autonomie und Unabhängigkeit gewährleisteten“ in räumliche Strukturen, genauer in ein Netz aus Runddörfern zur Verschmelzung von Stadt und Land (Abb. 4). ${ }^{62}$

Die Wege von Taut und Landauer kreuzten sich während der kurzen Münchner Räterepublik, d.h. in einem Moment der Geschichte, in dem in Europa alles möglich schien: neue Staaten, Organisationen und Parteien wurden gegründet. Der neue Völkerbund sollte künftige Kriege verhindern. Das Frauenwahlrecht 
wurde eingeführt. Und man stritt über Rätesysteme und die parlamentarische Demokratie. ${ }^{63}$

Taut und Landauer waren davon überzeugt, dass die neue Ära der Menschheitsgeschichte ihren Ausdruck in der Architektur finden müsse. Ihre Vorstellungen betten sich in die historische Kontinuität ,,antiurbaner Ideologien“ ein — ausgehend von der Überzeugung einer notwendigen „Auflösung der Städte“ aus der zweiten Hälfte des I 8. Jahrhunderts - worin sich

„, eine tiefe Sehnsucht nach der , organischen Gemeinschaft

[Ferdinand] Tönnies aus[drückt] [...], die alle außenstehenden Organisationen ablehnt, nach der Gemeinde der Subjekte, die die Angst der großstädtischen Entfremdung nicht kennt."64

Im Gegensatz dazu stehen die Visionen der italienischen Futuristen Filippo Tommaso Marinetti und Antonio Sant'Elia. Der Literat Marinetti verfasste das Manifest des Futurismus bereits im Jahr 1909. Eine Erweiterung der Bewegung um das Manifest der futuristischen Architektur sollte wenige Zeit später durch die Zeichnungsserie La Città Nuova (Ital. Die neue Stadt, I9I4) (Abb. 5) der beiden Architekten Sant'Elia und Mario Chiattone angestoßen werden.

In der „,neuen Stadt“ ist „Maschine Geist oder Geist Maschine“ und ,die Schwungkraft der Geschichte zum Anzeiger des Schicksals geworden“; statische Vorstellungen seien völlig verschwunden. ${ }^{65}$ Auch für sie galt es, eine Architektur zu bestimmen, die ,ganz und gar auf den besonderen Bedingungen des modernen Lebens“ beruht,

„,mit einem neuen [...] Verhältnis für die Existenz und den ästhetischen Wert, der von uns empfunden wird. [...] Sie muß so neu sein wie unsere Geisteshaltung. [...] Wir müssen die futuristische Stadt erfinden und erbauen — sie muß einer großen lärmenden Werft gleichen und in allen Teilen flink, beweglich, dynamisch sein; das futuristische Haus muß wie eine riesige Maschine sein." ${ }^{\circ 6}$

Sie hegten also vor Anbruch des Ersten Weltkrieges noch eine hoffnungsgeladene Begeisterung für den technologischen Fortschritt. Freudetrunken, kriegsverherrlichend und naiv-, wie ganz Europa"67_ zogen sie in das Urtrauma des gerade erst angebro- 
chenen Jahrhunderts hinein, um ihm schließlich zum Opfer zu fallen.

Hoffnung auf das Neue Bauen Der Zusammenbruch der gewohnten Weltordnung nach dem Ersten Weltkrieg hinterließ eine gewisse Ratlosigkeit. Man könnte auch sagen, es fand sich zunächst einmal keine Gesellschaft vor, die ein neues Bild von Architektur und Stadt hätte prägen können. Im Umkehrschluss verstanden deshalb viele zeitgenössische Architekt*innen das neue Bauen als Schlüsselfunktion, um eine neue Gesellschaft herzustellen. ${ }^{68}$

„Baukunst oder Revolution?“, diese Frage stellte sich zu Beginn der I920er Jahre der Architekt Charles-Édouard JeanneretGris alias Le Corbusier; und kommt sogleich zu dem Schluss: „Die Revolution läßt sich vermeiden."69 Er sei Architekt und hüte sich davor, das Gebiet der Technik zu verlassen; er lasse sich nicht dazu verleiten Politik zu machen, denn man revolutioniere nicht durch Revolution, sondern dadurch Problemlösungen anzubringen. ${ }^{70}$

Er war in jener Zeit - neben Walter Gropius, Ludwig Mies v. d. Rohe und selbst Frank L. Wright—nicht der Einzige, der so dachte, berichtet der Architekturhistoriker Julius Posener in seinen Vorlesungen zur Geschichte der Neuen Architektur (I98I). Für Le Corbusier seien ,die sozialen Probleme [...] in erster Linie technische Probleme“ gewesen. „Soziale Probleme“ könnten durch die Lösung „technischer “, d.h. ,,architektonischer Probleme“ behoben werden; er war davon überzeugt, dass „Architektur eine Gesellschaft zu verändern imstande sei“71, womit er eine in der architektonischen Moderne weit verbreitete Hoffnung explizierte. In einem I929 gehaltenen Vortrag mit dem Titel „Die Technik als Grundlage des Lyrismus eröffnet eine neue Epoche der Architektur"72 wird deutlich, dass für Le Corbusier die Sprache der neuen Technik, also ihre Ästhetik, die Grundlage für eine neue Architektur bilde, d.h. die Gestaltung des modernen Lebensraums eine neue Gesellschaft hervorbringen könne.

Im Glauben an die Elite der bedeutenden Einzelnen, d. h. große Geschäftsleute oder Technokraten, ${ }^{73}$ genügte es ihm einstweilen,

„,wenn er einen jener Kapitäne des Kapitalismus dazu bewegen konnte, einen seiner Pläne zu verwirklichen. Er hat zweifellos das soziale Problem nicht gesehen, nicht über sehr allgemeine Reformen hinaus, wie den Abbau der verslumten Städte und 
ihren Ersatz durch lichte, geräumige neue. [...] Hätte er [das soziale Problem] gesehen, hätte er dann noch den Mut gehabt, zu entwerfen?"74

Le Corbusier verfolgte mit seinen städtebaulichen Lösungsvorschlägen, z. B. mit der frühen Konzeptstudie La Ville Radieuse ( I924, I933 veröffentlicht), keineswegs Veränderungen der ökonomischen oder politischen Lage, die für die miserablen Lebensbedingungen der Arbeiter*innen und Angestellten verantwortlich zu machen waren. Anstatt — durch architektonische Lösungen - einen Interessenausgleich für eine gerechtere Gesellschaft $\mathrm{zu}$ verfolgen, beförderte er mit seinen Ideen eher die Fixierung einer neuen, sich nun in drei Klassen manifestierenden, Feudalstruktur. ${ }^{75}$

Er widmete die Konzeptstudie La Ville Radieuse den „Autoritäten“. Der zugrundeliegende Plan ist als stadtplanerisches Äquivalent bzw. Metapher der arbeitsteiligen Fertigung in den Fabriken zu verstehen und der städtische Verkehrsstrom mithin als gesellschaftliches „Fließband.“76 Die moderne Architektur diene in erster Linie der Organisation von Produktionszyklen und der dazugehörigen Distribution und Konsumtion. Der Architekt sei „Organisator und kein Gestalter mehr von Objekten“, er gehöre zur Avantgarde von der die ,geistige Initiative“ der civilisation machiniste ausginge. Mit seinem appel aux industriels wendet sich Le Corbusier einerseits direkt an die unternehmerisch Tätigen und mit der Gründung der CIAM (Congrès internationaux d'architecture moderne) ${ }^{77}$ versuchte er andererseits ,,auf politischer Ebene eine Autorität zu schaffen, die die Bau- und Stadtplanung mit den Programmen für die Reorganisation der Gesellschaft verbinden soll." "78

Dieser Erfolg sollte ihm beschieden sein, denn die Statuten der CIAM kamen ab den I930-40er Jahren zunehmend zu internationalem Einfluss. Die Ergebnisse des bekanntesten und folgenreichsten Kongresses, CIAM 4: Die funktionale Stadt (I933), mündeten zehn Jahre später in der Veröffentlichung der Charta von Athen (I943), die die Entflechtung städtischer „Funktionen“ propagierte und damit folgenreich zur Leitbilddebatte der aufgelockerten, funktionalen Stadt beitrug.

In den späten I940er Jahren sollte die gesellschaftlich-utilitaristische Tendenz der städtischen und architektonischen Moderne zum Ausgangspunkt für eine kritische Reaktion der nachfolgenden Generation werden. Die Protagonist*innen des Team io begegneten der rationalen Funktionslogik der ersten CIAM-Generation 


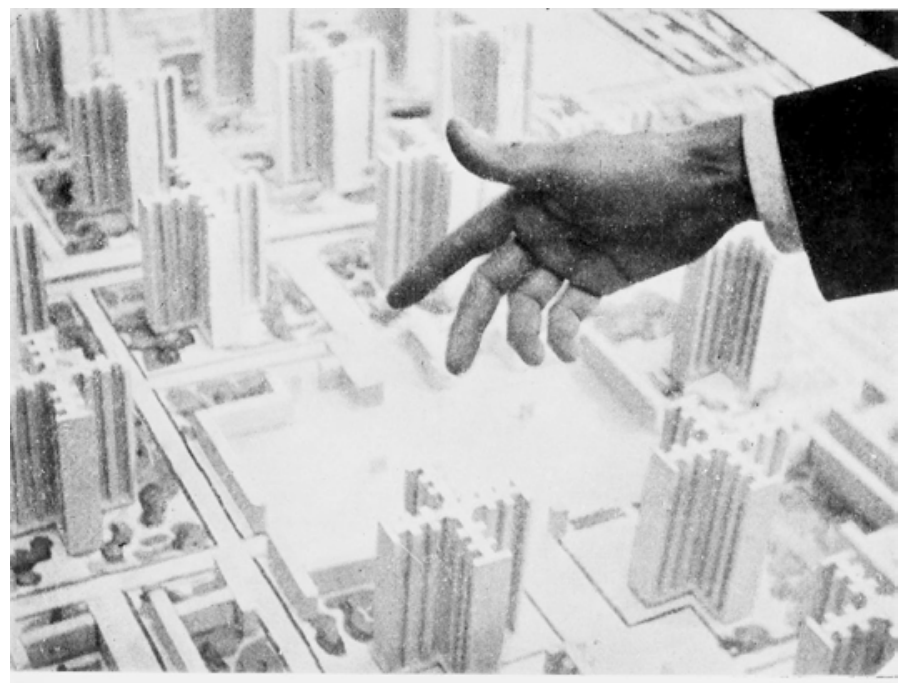

\section{UNE NOUYELLE VILLE REMPLACE UNE ANCIENNE VILLE}

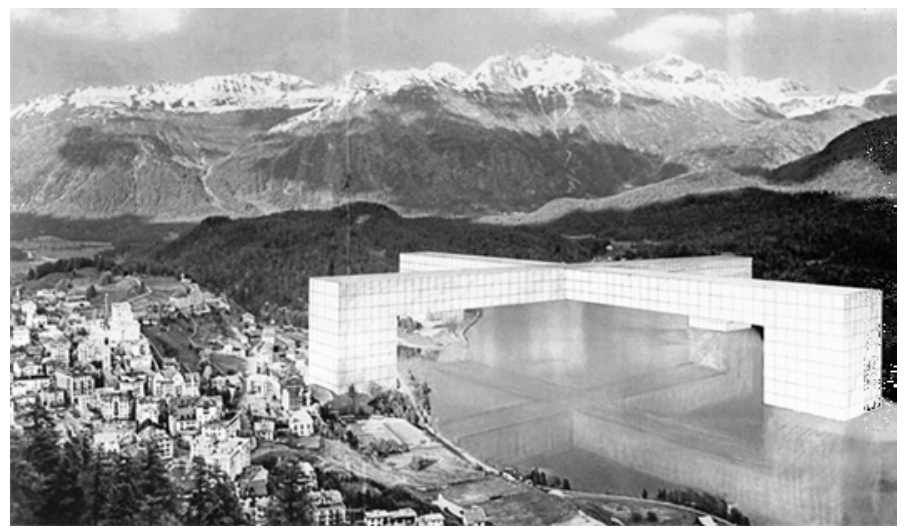

6 Oben: Plan Voisin Paris, Le Corbusier, 1925; eine Konkretisierung der Konzeptstudie Ville Radieuse, 1924

7 Unten: Monumento Continuo: St. Moritz rivisitata, Superstudio, 1969; eine kritische Utopie bzw. Gegen-Utopie 


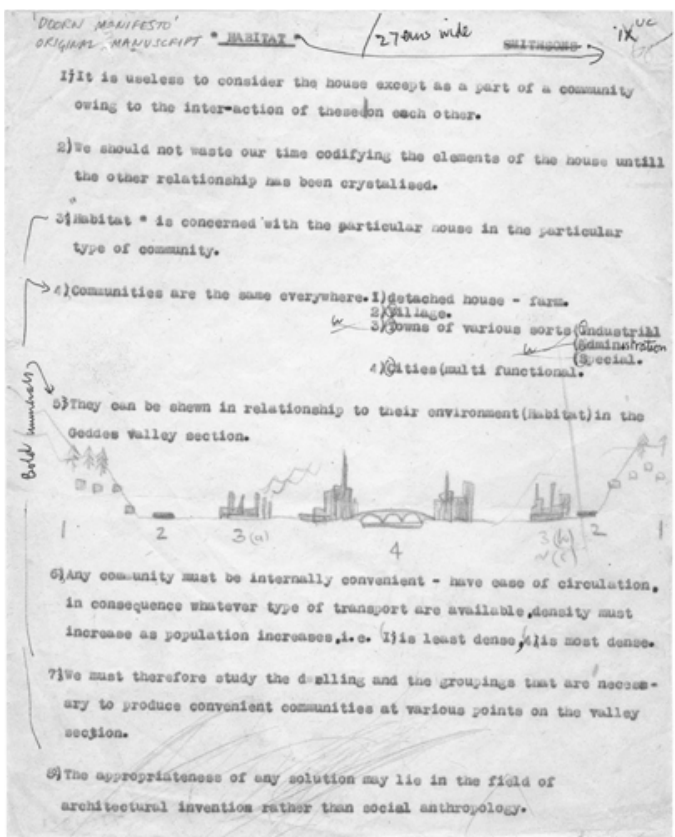

8 Doorn Manifesto, Alison \& Peter Smithson, Manuskript, 1954

Abschrift:

3) Habitat is concerned with the particular house in the particular type of community.

4) Communities are the same everywhere: 1: Detached house-farm, 2: Village, 3: Towns of various sorts (industrial, admin., special.), 4: Cities (multi functional).

5) They can be shown in relationship to their environment (Habitat) in the Geddes valley section.

[Valley section sketch]

6) Any community must be internally convenient - have ease of circulation, in consequence whatever type of transport are [!] available, density must increase as population increases, i. e. 1) is least dense, 4) is most dense.

7) We must therefore study the dwelling and the groupings that are necessary to produce convenient communities at various points on the valley section. 
mit Skepsis und widmeten sich selbst verstärkt dem „Komplex menschlicher Beziehungen.“ In dieser Übergangsphase, die formalästhetisch noch von der klassischen Moderne geprägt war, zeichnen sich aber bereits neuformierende Organisationshierarchien ab. Die Architekt*innen des Team io werden zu Vorboten eines planungstheoretischen, an den Nutzer*innen orientierten Paradigmenwechsels, der sich im Laufe der I96oer Jahre durchsetzen sollte. ${ }^{79}$

In der zweischneidigen Entwicklung der I960-70er Jahre tritt die Differenzierung humanistischer und technizistischer Utopien besonders deutlich hervor. Auf der einen Seite kommen, in der Folge der CIAM, humanistisch geprägte Ideen in architektonischstrukturalistisch angelegten Entwürfen zur Entfaltung, z. B. die Umsetzung von Aldo van Eycks „Philosophie der Türschwelle“ in den fließenden Übergängen, Kommunikationszonen und Zwischenräumen seines Amsterdamer Waisenhauses (um I960); das Verständnis der Smithsons von der „Straße als sozialer Ort“ zeigt sich in den breiten Korridoren und Aufenthaltszonen ihrer neu gedachten Wohnbaustrukturen (um 1970); die Architektin und Stadtplanerin Renée Gailhoustet entwickelte zusammen mit dem Architekten Jean Renaudi einen Gestaltungsansatz urbanistischer Gemeinschaftsarchitektur, umgesetzt als innerstädtischer Naturraum und Wohnkomplex (Spinoza Complexe) in Paris d'Ivry (um I970); oder in den Entwürfen der italienisch-brasilianischen Architektin Lina Bo Bardi, die in den späten I96oer Jahren durch ihre phänomenologisch-szenische Entwurfsmethodik architektonischer Stadtlandschaften Bekanntheit erlangte und jüngst im Architekturdiskurs wieder stärker rezipiert wird.

Auf der anderen Seite entfalten sich parallel dazu technizistisch geprägte Ideen in urbanen Megastrukturen, die gewöhnlich zuerst mit utopischen Architekturvisionen der I96oer Jahre in Verbindung gebracht werden. Die dabei stark lösungsorientiert angelegte und suggestive Bildproduktion beförderte einen ,Diskurs durch das Bild“, der der Strahlkraft bzw. Prominenz dieser groß angelegten Architekturentwürfe durchaus zuträglich war, z. B. Archigrams Plug-in City, Arata Isozakis City in the Air oder die Raumstadtkonzepte von Yona Friedman und Eckhard Schulze-Fielitz. ${ }^{80}$

Im Vergleich zu den Megastrukturen der I920er Jahre, z. B. Le Corbusiers Plan Voisin (Abb. 6) oder der I96oer Jahre, z. B. Superstudios Monumento Continuo (Abb. 7) gerät die ,weiche“ Darstel- 
lung sozialer Strukturen leicht ins Hintertreffen, z. B. die Untersuchung unterschiedlicher Lebensräume und ihre Einbettung in die Landschaft im Doorn Manifesto der Smithsons (Abb. 8).

In direkter Gegenüberstellung wird deutlich, dass architektonische Strukturen einerseits ungeachtet der gegebenen Umstände implementiert (Problemlösung) und andererseits aus der Analyse des Gegebenen herausgedacht werden (Problemanalyse). Die Analyse des Gegebenen sollte aber insbesondere-mehr noch als die Suche nach schnellen Lösungen mit Hilfe neuester technischer Errungenschaften - als sozialutopische Forschungspraxis verstanden werden; so lässt sich auch die folgende Aussage Tafuris anwenden auf die historisch gewachsenen Raumstrukturen der Gegenwart:

„The ,weak power' of analysis [...] is proposed as one moment in a process that leaves the problems of the past living and unresolved, unsettling our present. ${ }^{68 \mathrm{I}}$

Die enttäuschte Hoffnung Die Rede vom Scheitern der modernen Architektur stimmt insofern, als dass durch technische Lösungsansätze sozialpolitische Problematiken nicht gelöst werden konnten. Wie auch? Genau genommen, ist also nicht die Architektur gescheitert, sondern es sind die fälschlicherweise mit ihr verbundenen Hoffnungen enttäuscht worden, weil kein zugrundeliegendes politisches Programm formuliert wurde. ${ }^{82}$ Es bleibt zu spekulieren, ob das Versprechen des ,neuen Bauens für eine neue Gesellschaft““ dadurch hätte eingelöst werden können. Die utopische Motivation der modernen Architektur liegt also hauptsächlich im Glauben an die technische Steuerung und kaum im sozialanalytischen Blick für politische Veränderungen begründet.

Das Bestreben, die Programmatik moderner Architektur durch den Einsatz technischer Mittel direkt und total auf Städte anzuwenden, verdeutlicht wie wenig (sozial)utopisch in der Praxis der Moderne eigentlich gehandelt wurde. In diesem Sinne ist auch Colin Rowes und Fred Koetters tautologische Fragestellung vom „Niedergang oder Untergang der Utopie“"83 zu verstehen.

Generell sei aber für die ,seltsame Schrumpfung des utopischen Bewußtseins" nicht die (angebliche) Nüchternheit der modernen Technik verantwortlich zu machen, konstatiert Adorno in einem Rundfunkgespräch mit Bloch ,über die Widersprüche 
der utopischen Sehnsucht“. Das abhandengekommene utopische Bewusstsein bezieht sich eher ,,auf den Gegensatz der einzelnen technischen Errungenschaften [...] zu dem gesellschaftlichen Ganzen [...] als etwas, das völlig anders sein könnte." Utopie betrifft die Vorstellung von einer Veränderung des Ganzen und diese sei in allen ,utopischen Errungenschaften“ grundsätzlich verschieden. ${ }^{84}$

An dieser Stelle bietet es sich an, auf den Unterschied zwischen Utopie und Prognostik hinzuweisen. In der Prognostik werden konkrete Bilder von Zukunftsszenarien, wie z. B. im Science-Fiction Genre, evoziert. Dabei geht es vor allem um technikimmanente Entwicklungsmöglichkeiten und die Antizipation ihrer Potentiale. Das heißt, ihr ,Rationalitätskriterium ist [...] der Stand von Wissenschaft und Technik selbst, nicht aber die weltimmanente Vernünftigkeit einer gelungenen gesellschaftlichen Konstruktion." Die Prognostik nimmt dabei eine zentrale Stellung ein, ,die für das Selbstverständnis der Utopie [...] von marginaler Bedeutung ist. ${ }^{\circ 85}$

Wohingegen auch die „Bilderlosigkeit der Utopie“ bzw. die Abstinenz der Utopie im Hinblick auf ihre Konkretisierung und Materialisierung - eine Forderung der Kritischen Theorie-, in der spätmodernen Gegenwart bedenklich erscheint. Denn abstrahiert man stadtsoziologische Überlegungen von ihrer räumlichmateriellen Verwirklichung, verfehlen sie den Gegenstand, auf den sie sich richten. Denn das soziale Geschehen ereignet sich in der räumlich-materiellen Umwelt, demzufolge ist ihre Erscheinungsform von nicht zu unterschätzender Bedeutung. ${ }^{86}$

Das ist allerdings im Bewusstsein darüber zu verstehen, dass das Beibehalten formaler räumlicher Konzepte unter Verlust der politischen Inhalte eines der prägnantesten Beispiele für Prozesse der ,Verdinglichung“ hervorbringt. Das bedeutet, dass die Abkopplung der (technischen) Form von den (sozialen) Inhalten eine „,gespenstige Gegenständlichkeit" erhält, die in ihrer strengen, scheinbar völlig geschlossenen und rationellen Eigengesetzlichkeit jede Spur ihres [Daseinsgrundes], der Beziehung zwischen Menschen verdeckt" ${ }^{* 87}$, so der marxistische Philosoph Georg Lukács.

Zum Schluss dieses Abschnitts sei auf eine architektonische Sonderposition im 20. Jahrhundert verwiesen, die „offene“ technische Formen mit sozialen Aspekten und mikro- mit makroutopi- 
schen Ideen verknüpft: Der Architekt Richard Buckminster Fuller entwickelte die Vision eines planetaren Ökosystems, dessen dynamisches Gleichgewicht ihm zufolge nur dann intelligent aufrechtzuerhalten sei, wenn der Selbstwahrnehmung des Menschen Vorrang gegenüber der Entwicklung adaptiver Technologien eingeräumt würde. ${ }^{88}$ In seinem Verständnis ist der Mensch denselben ,fundamentalen Designregeln“ wie alle anderen „lebendigen Systeme“ auf der ,außergewöhnlichen Konstruktion des Raumschiffs Erde“ unterworfen. Er versteht den blauen Planeten als integral konstruierte Maschine, ,die zum Zwecke dauerhafter Leistungsfähigkeit als Ganzes begriffen und bedient werden muss." Aber gerade in Ermangelung einer Bedienungsanleitung seien die Menschen dazu gezwungen ihren Intellekt zu gebrauchen als höchste Fähigkeit im Einsatz für wissenschaftliche Experimente und der Interpretation ihrer Ergebnisse. Gerade jene Ermangelung lehrt die Menschen $\mathrm{zu}$ antizipieren, welche Konsequenzen sich aus einer steigenden Anzahl von Alternativen ergeben, um das Überleben und Wachstum befriedigend zu erweitern - physisch und metaphysisch. ${ }^{89}$

Im utopischen Denken sollte der Verknüpfung von technischen und sozialen Aspekten besondere Aufmerksamkeit geschenkt werden, denn ihre strikte Trennung kann im äußersten Falle entweder zu Szenarien technischer Totalitarismen oder zu Szenarien sozialromantischer Weltflucht führen.

Der Prozess des technischen Fortschritts hat sich bis heute als ambivalent und zuweilen zerstörerisch erwiesen und kann damit nicht mehr als Modell für den historischen Prozess überhaupt dienen. Aber gerade die Reflexion dieser Ambivalenz stellt eine der dringlichsten Aufgaben für die Utopieforschung bzw. Geschichtsphilosophie dar. ${ }^{90}$ Im Nachdenken über gesellschaftspolitische Utopien sollte also der jeweils zeitgemäße Stand der Technik eine besondere Rolle spielen.

Wie kann das emanzipatorische Potential digitaler Technologien im sozialutopischen Denken heute eingesetzt werden?

Der Philosoph Christoph Menke spricht gegenwärtig von einer „,notwendigen Organisation von Neuerungsfähigkeiten“ und führt aus, dass wir alle z. B. Mit-Produzent*innen der Smartphonetechnologie seien, denn das Nutzer*innenverhalten wird für die technologische Anpassung und Weiterentwicklung der Geräte ausgewertet, d.h. aber auch, dass gesellschaftliche Kreativität zugunsten der kapitalistischen Mehrwertproduktion eingesetzt wird. ${ }^{\text {II }}$ 
Utopie in der Architektur

Es bleibt also die Frage, vor allem die Architektur und Stadt betreffend, wie die digital mit-arbeitende Prozesshaltung der Nutzer*innen eingesetzt werden kann, ohne den Marktinteressen unumwunden preisgegeben zu werden? 


\section{Utopie in der Postmoderne: Krise und Kritik}

Das „Phänomen Postmoderne“, als gesellschaftliche und kulturelle Epoche - in einer Zeit des Übergangs vom Fordismus zum deregulierten neuen Liberalismus - , lässt sich exemplarisch an der Architektur besprechen.92 Die Entwicklung der postmodernen Architektur vollzieht sich vor dem Hintergrund einer kritischen Revision der Theorie und Praxis der Architektur der Moderne. Beispielsweise tritt der Architekt Robert Venturi in seiner Schrift Komplexität und Widerspruch in der Architektur ( I966) für eine Komplexitätssteigerung, Widerspruchstoleranz und Mehrfachkodierung des architektonischen Formenvokabular ein; der Architekt Charles Jencks kritisiert in seinem Buch Die Sprache der postmodernen Architektur (1972) den Verlust der Sprachlichkeit, Geschichtlichkeit und Autonomie der modernen Architektur; und der Architekt Peter Eisenman entwickelt mit der Gestaltung seiner Houses-Serie ( I968-75) eine neoavantgardistische Dekonstruktion des modernen Formenvokabulars. Erwähnenswert ist in diesem Zusammenhang auch die im Jahr I980 erstmals stattfindende Architekturbiennale in Venedig mit dem Motto Die Gegenwart der Vergangenheit unter der Leitung des Architekten Paolo Portoghesi. Passend dazu stellt der Kulturtheoretiker Fredric Jameson einen Begründungszusammenhang her zwischen der postmodernen Kultur, die von Pastiche und Revivals, d. h. von der Nachahmung und Neukompilierung historischer Versatzstücke geprägt ist und gewissen politischen Tendenzen im Spätkapitalismus. 93

Der amerikanische Architekturhistoriker Reinhold Martin schreibt in seinem Buch Utopia's Ghost. Architecture and Postmodernism, Again (20Io), dass Utopie — als radikale Alternative zum Status quo, d. h. jenseits der gegebenen Zeichen- und Macht- 
strukturen - in der Postmoderne ,undenkbar“" wurde. Wenn überhaupt, kehrte die Utopie als ,,verdrängtes Thema“, im Rekurs auf Marx und Engels als „Gespenst“, wieder. ${ }^{94}$ Die Rede vom Ende der Utopie fängt also eine Stimmung jener Zeit ein, d.h. eine „Sinnkrise“ am Ende der Moderne als Zenit einer längeren Entwicklung, die zutreffender aber nur als eine vorübergehende Krise utopischen Denkens verstanden werden sollte-vor allem wenn das Konzept der Utopie als anthropologische Grundkonstante gedacht wird. ${ }^{95}$

Ähnliches vollzieht sich in den historiographischen Diskursen der Postmoderne. Die klassische Geschichtsschreibung, die Traditionen und Spuren folgt, wird dekonstruiert. Der mikrogeschichtliche Ansatz, der Ausschnitte und Grenzziehungen problematisiert, entwickelt sich. Die lineare Erzählweise der Moderne weicht einer notwendig werdenden Offenheit gegenüber dem Denken von Diskontinuitäten, d. h. der forschende Blick wird der Schwellen, Brüche, Einschnitte, Wechsel und Transformationen historischer Begebenheiten und Zuordnungen gewahr.

Die Werke von Michel Foucault und Manfredo Tafuri sind dazu weiterführend aufschlussreich. Foucault bezeichnet sein historisch-philosophisches Vorgehen als „Genealogie“, im Rekurs auf Friedrich Nietzsche, ein Begriff, der für einen kritisch-gegenwartsbezogenen und nicht-linearen Zugang zur Geschichte steht. Dabei geht es darum, die ,Erscheinungsbedingungen einer Singularität“ bzw. singulärer Ereignisse in ihren ,,vielfältigen bestimmenden Elementen ausfindig zu machen“ und sie dabei ,nicht als deren Produkt sondern als deren Effekt erscheinen zu lassen. Also eine Einsichtigmachung - die aber nicht in der Art einer SchlieBung vorgeht." $" 96$

Seine Genealogie kennt keine „Einheit der Geschichte“; denn es gibt in der Geschichte nichts zu ,erkennen“, nichts, was wir bereits wissen. „Denn Wissen dient nicht dem Verstehen, sondern dem Zerschneiden. “97 Daran knüpft Tafuri später an.

Foucault: Genealogie und Heterotopologie In seinem Buch Archäologie des Wissens (1969) schreibt Foucault, dass die Geschichte eines Begriffs — z. B. die Geschichte von der RaumUtopie zur Mikro-Utopie — nicht

„, die [Geschichte] seiner fortschreitenden Verfeinerung, seiner ständig wachsenden Rationalität, seines Abstraktionsanstiegs 
ist, sondern die [Geschichte] seiner verschiedenen Konstitutions- und Gültigkeitsfelder, die seiner aufeinander folgenden Gebrauchsregeln, der vielfältigen theoretischen Milieus, in denen sich seine Herausarbeitung vollzogen und vollendet hat." "98

Er bezieht sich dabei auf seinen Mentor, den Arzt und Wissenschaftshistoriker Georges Canguilhem, der eine Unterscheidung „Zwischen den mikroskopischen und den makroskopischen Abstufungen der Wissenschaftsgeschichte“ vornimmt. Auf diesen Abstufungen verteilen sich Ereignisse und ihre Folgen nicht gleichermaßen. Rücklaufende Neueinteilungen lassen jeweils mehrere Vergangenheiten, Verkettungsformen, Gewichtungshierarchien, Determinationsraster und Teleologien für ein und dieselbe Wissenschaft entsprechend den Veränderungen ihrer Gegenwart erscheinen.

„Infolgedessen ordnen sich die historischen Beschreibungen notwendig nach der Aktualität des Wissens, vervielfachen sie sich mit seinen Transformationen und hören ihrerseits nicht auf, mit sich selbst zu brechen [...]. "99

Im Vorwort seiner frühen Schrift Die Ordnung der Dinge (I966) nimmt Foucault-mit der Absicht vorrationale Ordnungssysteme (karikierend) zu illustrieren-bekanntlich auf den argentinischen Schriftsteller und Bibliothekar Jorge Luis Borges und dessen „,chinesische Enzyklopädie“ Bezug. Darin teilt Borges Tiere in unterschiedliche Klassen folgender Art ein, z. B. ,a) Tiere, die dem Kaiser gehören, b) einbalsamierte Tiere, c) gezähmte, [...] k) die mit einem ganz feinen Pinsel aus Kamelhaar gezeichnet sind, l) und so weiter, $[\ldots]^{\text {"IOo }}$ und bricht dabei mit vermeintlich gesetzten kategorialen Zuordnungen.

Diese Art der Klassifizierung überträgt Foucault ins Räumliche; ganz dem postmodernistischen Pluralitätspostulat entsprechend konzipiert er die Heterotopologie ${ }^{\mathrm{IOI}}$ als neue raumtheoretische Wissenschaft; eine postmoderne Raum-Utopie. Er sprengt damit einerseits traditionelle dualistische Denkgewohnheiten des Räumlichen (öffentlich/privat, innen/außen, kontrolliert/unkontrolliert) und andererseits traditionelle Denkgewohnheiten des Utopischen (Nicht-Ort/guter Ort). ${ }^{102}$

Foucault differenziert sechs Grundsätze der Heterotopie, des ,,anderen Ortes“: Heterotopien I) bilden eine Konstante aller 
menschlichen Gruppen, 2) variieren ihre Funktionsweise je nach Kultur- und Zeitraum, 3) besitzen die Fähigkeit, mehrere reale Räume, die eigentlich nicht miteinander verträglich sind, an einem einzigen Ort nebeneinander zu stellen, 4) funktionieren am besten, wenn ein absoluter Bruch mit der traditionellen Zeit vollzogen wird; sie sind nicht mehr auf die Ewigkeit, sondern vollkommen auf das Jetztzeitliche ausgerichtet. Diese Heterotopien können mit den flüchtigsten, vergänglichsten, prekärsten Aspekten der Zeit verbunden sein, z. B. in Gestalt des Festes. Grundsatz 5) lautet, dass Heterotopien immer ein System der Öffnung und Abschließung voraussetzen, das sie isoliert und gleichzeitig Zugang ermöglicht; und im letzten Grundsatz 6) heißt es schließlich, dass Heterotopien einen illusionären Raum schaffen, der den ganzen realen Raum als noch größere Illusion entlarvt. ${ }^{103}$

Er führt konkret den Friedhof, den Garten, das Museum oder das Freudenhaus als ,,andere Orte“ an, oder abgeschlossene Enklaven, wie z. B. ein Gefängnis oder ein Schiff; wobei ihm das Schiff als „Heterotopie par excellence“ gilt; so konstatiert er am Schluss des Textes, dass Gesellschaften ohne Schiff verloren sind, weil ihnen die Träume versiegen. ${ }^{104}$

Als weitere architektonische Beispiele kann man sich auch z. B. die Pariser Passagen in Walter Benjamins Beschreibung oder die Übergangszonen in Fouriers Phalanstères im I9. Jahrhundert ${ }^{105}$ vorstellen; oder als ,,anders gearteter“, mehrfachkodierter städtischer Kontext im 20. Jahrhundert z. B. das kulturell heterogen geprägte Musrara-Viertel in Jerusalem; vorstellbar sind auch die „temporär autonomen Zonen“ (T.A.Z.), ein Konzept des Schriftstellers Hakim Bey (I99I), z. B. der Ausnahmezustand eines StraBenprotests oder Karnevals.

Foucaults heterotopische Grundsätze wurden bis heute architektonisch und literarisch so vielgestaltig ausgedeutet, dass das Konzept der Heterotopie schnell an Schärfe verliert, versuchte man sich einen Überblick über die möglichen Erscheinungsformen des anderen, mehrfachkodierten Ortes zu verschaffen. ${ }^{\text {I06 }}$ Die Radikalität dieses Konzepts lässt sich am besten verstehen, wenn man Heterotopien als Orte der Spiegelung von Krisen- und Abweichungsszenarien der realen Welt begreift, um Nahe an Foucaults Beschreibung des ersten Grundsatzes zu bleiben. 
Tafuri: Ideologiekritik und Mikroanalyse Tafuris historisches Vorgehen lässt sich über Foucaults Heterotopie-Konzept, auf das er konkret Bezug nimmt, verstehen:

„Während Utopien trösten, weil sie Städte öffnen ,mit weiten Avenuen, wohl bepflanzte[n] Gärten', beunruhigen Heterotopien, unterminieren heimlich die Sprache, , weil sie im voraus die Syntax zerstören, und nicht nur die, die die Sätze konstruiert, sondern die weniger manifeste, die die Wörter und Sachen (die einen vor und neben den anderen) zusammenhalten läßt.“"'107

Tafuri bezieht sich in seinem historischen Vorgehen auch auf Foucaults Genealogie, wobei es um die Überwindung von Letztbegründungen geht. Das Ziel der Geschichte sei demnach nicht in einem hermeneutischen Prozess der Interpretation zu suchen, denn auch die

„, bis ins Kleinste analysierten Teile [können] als neue Einheiten [aufgeladen werden], die autonom und in sich selbst bedeutsam sind."108

Obwohl Tafuri in der marxistischen Tradition steht, liegt seine Originalität und Autonomie in der

„Weigerung, ein ,Zentrum“, eine endgültige dialektische Synthese wiederherzustellen; der Weg des Historikers führt nicht zur Gewissheit der Wahrheit, sondern zur Scheidung zwischen Bezeichnung und Bezeichnetem, zu den vielfältigen Bedeutungen der Realität."'o9

Tafuri versteht die Sprache der Theorie als Etwas, das in sich bereits eine „Vielfalt der Themen, des Wissens, der Institutionen“ umfasst. Geschichte müsse die Vielzahl der Sprachen und Themen berücksichtigen sowie die kontinuierlichen Grenzverschiebungen, die die Position einzelner Protagonist*innen und Sachverhalte ständig verändern. ${ }^{\text {II }}$ Ihm geht es erstmal nicht so sehr um die Analyse spezifischer Einzelereignisse, sondern seine Radikalität begründet sich in der ,skandalösen Einführung des Widerspruchs ins Herz der historischen Analyse. "III Es geht ihm vielmehr um

„, die Produktion von ,Bedeutungen“ durch , den ständigen Kampf zwischen der Analyse und ihren Objekten [...], um 
eine analytische Konstruktion, die nie endgültig und immer vorläufig ist; um ein Instrument der Dekonstruktion gesicherter Realitäten“" "II2

Tafuri versteht-anders als Foucault-den Akt der Dekonstruktion aber nur als vorläufiges Werkzeug, das zwangsläufig eine Form der „Rekonstruktion“ erfordere. In der Geschichtsschreibung müsse immer die Möglichkeit der Veränderung enthalten sein. ${ }^{113}$ Aus der Mehrdeutigkeit der gegebenen Realität heraus versucht der Kritiker, so Tafuri, eine logische Struktur und Bedeutung, als Vorbedingung zukünftiger Handlungen, die auf eine neue Arbeitshypothese gerichtet sind, zu entwickeln. Zu den primären Aufgaben eines Kritikers gehöre es die Fehler der Vergangenheit nachzuvollziehen und die Werte der Gegenwart zu verstehen. Es geht darum exakt zu diagnostizieren, ohne zu moralisieren. ${ }^{\text {II4 }}$

Sein ,historisches Projekt“ ist ein „Projekt der Krise“; es geht ihm um die „Überwindung der traditionellen, im Positivismus des I9. Jahrhunderts verwurzelten Beziehung zwischen einem ,Ursprung' und dem ,Ziel: einem Endpunkt, der alles erklärt, was eine bestimmte ,Wahrheit" ausmacht." "II5

Tafuri de/konstruiert die klassische Erzählung der Moderne in Kapitalismus und Architektur ( 1973) als ideologiekritische Genealogie und re/konstruiert mithin die Utopie der Moderne als Ideologie. Der rebellische Erneuerungsversuch der Architekturmoderne sei letztlich auch nur seinen historischen Umständen unterlegen. Das utopische Versprechen der Moderne wurde enttäuscht; die Utopie der Moderne kann als Ideologie, d. h. im Marx 'schen Sinne als falsches (kapitalistisches) Bewusstsein, entlarvt werden. ${ }^{\text {I }}{ }^{6}$ Für Tafuri steht die Krise der modernen Architektur exemplarisch für die Krise der Ideologie der ,neuen Welt““. ${ }^{117}$

Es lässt sich leicht über die Architektur selbst sprechen; über ihre Sprache, Technik, Institutionen und den historischen Kontext. All diese Themen besitzen jeweils eine Eigenlogik. Aber können all diese einzelnen Begriffe in eine kohärente Erzählung übersetzt werden? ${ }^{\text {I18 }}$ Was ist das Wesen der architektonischen Botschaft? Gibt es so etwas wie eine Sprache der Architektur? Oder besteht Architektur letztlich aus einer inkohärenten Menge von ,Techniken, die untereinander nicht kommunizieren können'? ${ }^{19}$

Mit dieser Aussage nimmt Tafuri Bezug auf Ginzburg, der Forschung als einen Vorgang beschreibt, bei dem ,nur einige Fragmente vorliegen, aus denen sich theoretisch mehr als eine Figur 
fügen lässt. [...] Die Tatsache, dass alles zusammenpasst, ist daher ein mehrdeutiges Zeichen: entweder liegt man völlig richtig oder völlig falsch“. ${ }^{\text {I20 }}$ Hier befinden wir uns erneut im Herzstück der Kritik an der Mikroanalyse bzw. -geschichte und der dialektische Kreis schließt sich.

Im enttäuschten Abwenden von der Deutung moderner Architektur, die sich immer mit etablierten Machtstrukturen verbündet, um verwirklicht werden zu können (Komplizenschaft), versteht Tafuri Geschichte als das politische Projekt. In seinem Spätwerk sondiert er schließlich krisenhaft-kritische Phasen (Einzelereignisse) der Architekturgeschichte der Renaissance — oftmals als ein „resignierter Rückzug ins Historische“ dargestellt. Sein Rückgriff auf spezifische Gegebenheiten der Architekturgeschichte ist aber nicht mit einem Rückzug ins Historische gleichzusetzen, sondern verdeutlicht die Relativität der Geschichtsschreibung-Mikrogeschichte als Ausweg und hochpolitisches Projekt. 
Exkurs:

Macht und Boden 
Die Begriffe Eigentum und Besitz werden alltagssprachlich oft austauschbar verwendet, aber sie unterscheiden sich. Während Eigentum definiert wird als die rechtliche Herrschaft (Herrschaftsrecht, de jure) über eine Sache, bezeichnet Besitz das tatsächliche Haben (Gewaltausübung, de facto) einer Sache.

Beim Eigentum ist das Individualinteresse gegenüber jeder anderen Person geschützt; man kann damit tun und lassen was man möchte, solange das Gesetz oder die Rechte Dritter nicht verletzt werden. ${ }^{1}$ In der deutschen Verfassung gibt es aber eine Einschränkung, d.h. eine Sozialpflichtigkeit beim Eigentum, die in Artikel I4 des Grundgesetzes (GG) festgelegt ist und in Absatz 2 bekanntermaßen lautet: „Eigentum verpflichtet. Sein Gebrauch soll zugleich dem Wohle der Allgemeinheit dienen." Das Allgemeinwohl steht dabei vor dem Einzelinteresse; eingebettet in das Sozialstaatsprinzip der Artikel 20 und 28 GG.

Anknüpfend an Art. I4 Abs. 2 GG stellen sich zwei grundlegende Fragen, die für die vorliegende Arbeit von besonderem Interesse sind:

— Erstens, wer ist die Allgemeinheit?

- Und zweitens, was ist das Gemeinwohl bzw. wie wird es definiert?

Die erste Frage lässt sich leicht beantworten: Die Allgemeinheit ist der jeweils betroffene Teil einer Bevölkerung, entsprechend der Sache. So haben auch Marx und Engels klargemacht, dass es sich beim Eigentum nicht so sehr um das Verhältnis einer Person zu einer Sache handele, sondern, dass das Eigentum in erster Linie als das Verhältnis einer Person zu anderen Personen im Hinblick auf die entsprechende Sache zu verstehen ist. ${ }^{2}$

Die zweite Frage - wie wird das Gemeinwohl definiert — lässt sich nicht so leicht beantworten. Aber auch hier findet sich eine 
(materialistische) Entsprechung bei Marx und Engels, die die betreffenden Sachen ganz allgemein als solche definieren, die im (jeweiligen) Wirtschaftsprozess eine entscheidende Rolle spielen, also Produktionsmittel und Produkte. Bei Fragen des Eigentums geht es Marx und Engels also weniger um philosophische bzw. ideelle oder juristische Fragestellungen, sondern vor allem um gesellschaftliche und wirtschaftliche Probleme, d. h. in ideologiekritischer Perspektive, darum, wie in einer Gesellschaft produziert wird und wie die Produkte verteilt werden. Unterschiedliche Wirtschaftsformen sind mit verschiedenen Eigentumsformen verbunden bzw. bringen diese erst hervor. ${ }^{3}$

Im vorliegenden Exkurs werden die gesellschaftlichen Eigentumsverhältnisse exemplarisch an das Thema der (städtischen) Bodennutzung (Raumordnung) geknüpft. Es ist erst einmal zweitrangig, ob das jeweilige Landstück eine Nutzung durch die konkrete Eigentümer*in oder Besitzer*in erfährt, denn dies ist eine für Außenstehende meist nicht ersichtliche juristische Frage. Hier soll die Klärung des Zugangs, der Nutzung und Kontrolle von Grund und Boden an erster Stelle stehen. Eigentumsverhältnisse sind dialektisch zu verstehen, wie bereits im Werk von JeanJacques Rousseau, ein Wegbereiter der Französischen Revolution, zu lesen ist, der das Eigentum - trotz aller Kritik daran - in Hinblick auf die Freiheit für unverzichtbar hielt. ${ }^{4}$

Seit einigen Jahren gibt es unzählige Initiativen, die den Boden als drängendes gesellschaftspolitisches Thema wiederentdecken, sowohl im regionalen Kontext von Stadt und Land, als auch globalperspektivisch. Dies gilt für die Bereiche Architektur und Kunst genauso wie für die Bereiche Wissenschaft und Realpolitik. ${ }^{5}$

Ein prominentes jüngeres Beispiel alternativer Stadtentwicklung ist die Neuerfindung Detroits im US-Bundesstaat Michigan. Die Stadt steht bereits seit den I960er Jahren und in verschärfter Weise seit der Weltwirtschaftskrise 2007/08 synonym für den Strukturwandel der Industrie. Der Niedergang der dortigen autoindustriellen Monokultur hinterlässt großflächig innerstädtisches Brachland, das allmählich durch neue Nutzungen bespielt wird, sowohl im kleinen als auch im großen Maßstab. Dort schließen sich zivilgesellschaftliche Initiativen z. T. mit architektonisch und/ oder künstlerisch motivierten Gruppen zusammen, auf der Suche nach einer Zukunft, die sich im Übergang vom Industrie- zum Digitalzeitalter erst noch räumlich formieren muss. Die Idee des 
Gemeineigentums, speziell der gemeinschaftlichen Bodennutzung spielt dabei aus pragmatischen Gründen eine wesentliche Rolle. Jene Prozesse, die Veränderungen anstoßen, werden radikal demokratisiert; die Beziehung zwischen Individuum und Gemeinschaft wird mit Hilfe von architektonischen Minimaltechniken operationalisiert, womit sich eine ästhetische Dimension in der politischen Ökonomie entfaltet. ${ }^{6}$

Auch im deutschen Architekturdiskurs wird die Bodenfrage jüngst als drängendes Thema besprochen. Die beiden im Jahr 2018 erschienen Archplus-Hefte The Property issue. Von der Bodenfrage und neuen Gemeingütern und An Atlas of Commoning. Orte des Gemeinschaffens greifen diesen Themenkomplex auf. Der Diskurs $\mathrm{zu}$ neuen Gemeingütern wird dort als kritische Reaktion auf den neoliberalen Exzess, in dem der Boden als legitimes Geschäftsmittel eingesetzt wird, dargestellt. In diesen Heften und in der internationalen Architekturszene steht der Architekt und Unternehmer Patrick Schumacher dafür exemplarisch an der rhetorischen Spitze der digitalen Architekturavantgarde. Er tritt unter dem Label „Parametrismus“ ungeniert für einen antisozial und technizistisch ausgerichteten Wettbewerb ein. Schumacher ist überzeugt, dass die besten Ergebnisse im Schulterschluss mit dem Kapital nur dann erzielt werden können, wenn Jede*r gegen Jede*n auf einem vollständig deregulierten Markt in freie Konkurrenz miteinander treten. Die offenherzige Propaganda eines solch anarchokapitalistischen Darwinismus ruft, kaum verwunderlich, Gegenstimmen auf den Diskursplan. So schreibt der Philosoph Wolfgang Scheppe, Marx folgend, dass die Landfläche als ,Raumpartikel der Erdoberfläche“ kein beliebig vermehrbarer Handelsartikel ist. Dies unterscheide sie von allen übrigen in einer marktwirtschaftlichen Wachstumsrationalität zirkulierenden Waren. Grund und Boden, samt ihrer Rohstoffe, seien keine Waren, die wegen ihres zu realisierenden Tauschwertes auf den Markt kommen. Sie sind als

„Prämisse und Unterbau jeder Architektur und jeden Wohnens die einzigen Produkte, die selbst nicht produziert wurden. Niemand stellte sie her. Sie können deshalb einem Eigentümer als dessen Grundbesitz nur gehören in der juristischen Form des gewaltsamen Ausschlusses aller anderen aus der Verfügung über eine Sache, die doch die gemeinsame irdische Existenzbedingung ausmacht: die räumliche Ausdehnung. 
Etwas, das wie die Luft zum Leben und wie die Bewegung zur Natur des Menschen gehört, etwas das in der Philosophie Immanuel Kants neben der Zeit als Bedingung von Empirie überhaupt im Stande eines transzendentalen Apriori erörtert wird, kann nur vermittels dieser Exklusion zum Handelsgut werden."7

Auch der Metropolenforscher Alain Thierstein erklärt die „Sorge um das Engagement und die qualitätsvolle und sorgsame Nutzung von Grund und Boden“ zum zentralen Prinzip des 2 I. Jahrhunderts. Der Boden ist eine strategische und lebenswichtige Ressource und in seiner Bedeutung als anthropologische Konstante bedrohter denn je. Als soziales und räumliches Wesen kann sich der Mensch ein Überleben auf der Erde nur in Kooperation und Austausch über Problemlösungen und Innovation mit anderen sichern. ${ }^{8}$ Raum sollte deshalb im Besitz der Gemeinschaft sein und entweder durch den Staat verwaltet werden oder einem Organisationsprinzip ,politischökonomischer Zusammenschlüsse [folgen], die Entscheidungsprozesse und Produktivität demokratisieren und den entstehenden gesellschaftlichen Mehrwert gerecht verteilen."9

Schaut man zurück in die Geschichte der Utopie, dann gilt Platon als der philosophische Stammvater der Gütergemeinschaft; das ist ein Hauptcharakteristikum seiner idealen Staaten. In der Politeia verfügen die beiden oberen Stände nicht über Privateigentum, die Philosophen und Krieger sind besitzlos. Das betrifft das Sacheigentum, aber auch die Zugehörigkeit der Kinder. Platon argumentiert, dass politische Führungseliten sich der Vernunft verpflichten müssten, losgelöst von individuellen Partikularinteressen. Dies führe zwangsläufig zum Guten an sich; inbegriffen persönlicher Freiheit, die demnach in seinem Staat nicht von vornherein gewährleistet werden müsse.

Die Abschaffung des Privateigentums ist der gemeinsame Nenner philosophischer Konstruktionen idealer Staaten in Antike und Renaissance. Auch Rousseau argumentiert Eigentumsbildung führe dazu, dass der Mensch den — von ihm als paradiesischen Ort verklärten - rechtsfreien Natur- bzw. Urzustand verlasse und macht im Privateigentum den Anfang aller Ungleichheit und Zerstörung aus.

Sie alle sind davon überzeugt, dass die Ursache der Ungleichheit zwischen den Menschen in den ökonomischen Verhältnissen 
liege und begründen damit die Ursache aller weiteren Übel: Wettbewerb, Neid, Eifersucht, Herrschaft, Gewalt, Tyrannei und Krieg.

Bei Morus und Campanella ist der Mensch nicht von Natur aus schlecht, wie bei der Konzeption der ,menschlichen Wolfsnatur“ des englischen Vertragstheoretikers Hobbes, sondern die gute Natur des Menschen werde erst durch die Verflechtung mit irdischen Institutionen, v. a. dem Eigentum, verdorben. ${ }^{\text {Io }}$ Ausgehend davon, dass das Privateigentum einen zerstörerischen Einfluss auf die Welt hat, ist die inselartige Abschottung vor äußeren Einflüssen für die Verfasser geschlossener Raum-Utopien, wie Platon, Morus, Campanella und für Autoren des I9. Jahrhunderts, aber auch für das realsozialistische Modell der UdSSR, von zentraler Bedeutung.

Manche Vertragstheoretiker des I7. Jahrhunderts, Z. B. Thomas Hobbes und John Locke, verfolgten eine ganz andere politische Linie und zwar pro Eigentum. Ihrer Überzeugung nach benötige der Mensch Privateigentum zur Selbstentfaltung. So argumentierte auch bereits Aristoteles, d. h. in Opposition zu Platons Ansatz der Gütergemeinschaft stehend.

Das utopische Moment im Denken vieler Vertragstheoretiker liegt in der Konstruktion eines lange vergangenen Anfangs, der grundlegende sozialpolitische Strukturen und Institutionen rechtfertigt, die als am besten für die Zukunft gelten. In den meisten Vertragstheorien nimmt das Privateigentum diesen Platz ein, denn es ist eine Bedingung für individuelle Freiheit, und individuelle Freiheit ist eine Bedingung für politische Freiheit. ${ }^{\text {I }}$

Der englische Philosoph John Locke entwirft in seiner Schrift Two Treatises of Government (Engl. Zwei Abhandlungen über Regierung, I689) die Grundlagen seines Gesellschaftsvertrags ausgehend davon, dass der Friede unter den Menschen im herrschaftslosen Naturzustand von Konflikten geprägt und damit gefährdet sei. Das Konzept der Schöpfung, als Gemeineigentum verstanden, konfligiere mit einem fundamentalen Recht im Naturzustand, dem Selbsterhaltungsrecht, dass das Recht auf Privateigentum — eben als Bedingung für individuelle Freiheit — nach sich zöge.

Nach Locke geschieht die Aufteilung der Natur nicht durch eine ohnehin aussichtslose Konsensfindung, sondern durch einen konkreten Rechtsgrund: die Arbeit. Die Natur wird durch menschliche Arbeit angeeignet; der bearbeitete Gegenstand (Grund und Boden) geht so in die Hände des Bearbeitenden als Eigentum über. 
Die Sozialstruktur des Naturzustandes ist demnach eine Gesellschaft von Kleineigentümern; ${ }^{12}$ das Konzept des Privateigentums ist im Naturzustand also bereits bekannt.

Die unhaltbaren Zustände der Herrschaftslosigkeit und die damit einhergehende Missachtung friedenssichernder Normen des Naturgesetzes seien dadurch aber nicht gebannt. Geburtsbedingte Unterschiede, z. B. Fleiß und Geschick, bedürften gegenseitigem Wohlwollen, das stünde aber im Widerspruch zur harmoniestörenden Wolfsnatur des Menschen. Durch den Abschluss eines Sozialvertrags könnte dieser Zustand jedoch überwunden werden. Das Prinzip der Eigenverantwortlichkeit bildet die Entstehungsgrundlage für die Institutionen des kommenden Gemeinwesens, denn ihr Hauptzweck ist der Schutz des bürgerlichen Eigentums, d.h. der Schutz ihrer Leiber, Leben, Freiheitsrechte und damit im engeren Sinne ihres Privateigentums. Locke nahm damit die liberale Idee vorweg, dass den bürgerlichen Freiheitsrechten Priorität zukomme und die politische Herrschaft den Zweck habe diese zu schützen. ${ }^{13}$

Kaum ein Jahrhundert später nahm auch der schottische Moralphilosoph und Begründer der klassischen Nationalökonomie Adam Smith an, dass bestehende Vermögensunterschiede zwar durch Glück, Fleiß und Geschick zustande kämen, aber durch den Handel ausgeglichen werden könnten, so seine Argumentation. Er verfährt nach dem Prinzip des Eigeninteresses freier Akteure: Das Privateigentum schaffe Anreiz zur bestmöglichen Verwertung des Ganzen, das belebe die Märkte und fördere en passant das Gemeinwohl. Die entscheidende Passage in seinem Werk An Inquiry into the Nature and Causes of the Wealth of Nations (Engl. Der Wohlstand der Nationen, I776) lautet:

„Wenn [...] jeder einzelne soviel wie nur möglich danach trachtet, sein Kapital zur Unterstützung der einheimischen Erwerbstätigkeit einzusetzen und dadurch diese so lenkt, daß ihr Ertrag den höchsten Wertzuwachs erwarten läßt, dann bemüht sich auch jeder einzelne ganz zwangsläufig, daß das Volkseinkommen im Jahr so groß wie möglich werden wird. Tatsächlich fördert er in der Regel nicht bewußt das Allgemeinwohl [...]. [Er] denkt [...] eigentlich nur an die eigene Sicherheit und [...] strebt [...] nach eigenem Gewinn. Und er wird in diesem, wie auch in vielen anderen Fällen von einer 
unsichtbaren Hand geleitet, um einen Zweck zu fördern, den zu erfüllen er in keiner Weise beabsichtigt hat."I4

Das ist eine Möglichkeit Unternehmer*innengeist auch als verantwortlichen Gesellschaftsauftrag zu verstehen. Aber die großen Probleme der industriellen Revolution im 19. Jahrhundert-Massenarmut und Ausbeutung des (bis auf seine Arbeitskraft) mittellosen Arbeiters durch den Kapitalisten — konnte Smith damit nicht lösen.

Die große Masse der Lohnarbeiter*innen, also die neue Klasse des Proletariats, entstand in England eben gerade durch die Beschneidung der Allmenderechte, d.h. der Einhegung von landwirtschaftlich genutztem Gemeindeland. Die sogenannten „Enclosures of the Commons" hatten ihren Höhepunkt im Zeitraum von I760-I820. Den zuvor kleinbäuerlich Tätigen wurde ihre Lebensgrundlage entzogen. ${ }^{15}$

Morus formulierte schon etwa 250 Jahre zuvor eine vergleichbare Kritik an der Umnutzung landwirtschaftlicher Flächen Englands. Diese wurden in Schafweideland zur Herstellung von Wolle für die aufkommenden Tuchmanufakturen transformiert und leisteten damit der gnadenlos ansteigenden Armut und Obdachlosigkeit unter der Bevölkerung Vorschub.

Marx formuliert im ersten Band von Das Kapital ( 1867), dass:

„die Expropriation der großen Volksmasse von Grund und

Boden [...] die Vorgeschichte des Kapitals [bildet]." ${ }^{\text {16 }}$

Die gemeinschaftliche Nutzung wird ausgehebelt. Der Zutritt (der Nichteigentümer*innen) zu dieser umzäunten Sphäre wird nur noch gegen ein Entgelt (Mietzins, Pacht oder Immobilienhandel) gewährt; es entsteht eine Eigentumsschranke des Grundeigentümers (Alleinrecht): die Erhebung eines Eintrittspreises für den Raum. Und Marx fährt in diesem Zusammenhang fort, dass

„[e]in Teil der Gesellschaft [...] hier von den andern einen Tribut für das Recht verlangt, die Erde bewohnen zu dürfen, wie überhaupt im Grundeigentum das Recht der Eigentümer eingeschlossen ist, den Erdkörper, die Eingeweide der Erde, die Luft und damit die Erhaltung und Entwicklung des Lebens zu exploitieren." ${ }^{17}$

Kurzum, die Produktion von Raum, genauer, die Änderung der Verfügungsgewalt über die Bodennutzung und den architektoni- 
schen Akt der Einschließung durch Hecken und Zäune bildet die Basis der kapitalistischen Akkumulation. Der landwirtschaftlich nutzbare Boden wird qua Exklusion zum Handelsgut, darin liegt der Ursprung des Kapitals im modernen Sinne. ${ }^{18}$

Gegenwärtig plädiert der französische Philosoph und Soziologe Bruno Latour in seinem Terrestrischen Manifest (20I8) dafür, die Energien, die bisher dem „Lokalen“ zugeflossen sind, auf das „Terrestrische“ hinzulenken. Das Lokale schließe sich zur Ausdifferenzierung $a b$, während sich das Terrestrische durch Öffnung ausdifferenziere, so Latour.

Das Lokale scheint eindeutig. Das Terrestrische kann man so interpretieren, dass er im Gegensatz zu den abstrakten Begriffen „global“ und/oder ,planetarisch“ mit dem Begriff ,terrestrisch“ einen konkreten Bezug zum tatsächlichen Boden des Planeten Erde (terra) herstellt. Dazu ein Zitat:

„Die Vorstellung des Bodens selbst verändert sich grundlegend.

Der erträumte Boden der Globalisierung beginnt, sich zu entziehen. [...] Mehr oder minder verschwommen entdecken wir, dass wir alle auf der Wanderung sind hin zu Territorien, die es neu zu entdecken und zu besetzen gilt."

In heutigen Globalisierungsprozessen treten Konflikte über den Boden in Sezessions- und Autonomiebestrebungen einzelner Regionen und Länder offen zu Tage. Die Erstarkung eines neu erwachten Nationalbewusstseins zeichnet sich z. B. im Ringen um die Unabhängigkeit der spanischen Provinz Katalonien oder im Austritt Großbritanniens aus der Europäischen Union ab. Dabei werden Identitätsfragen (Grenzziehungen) programmatisch ins Zentrum der — oft mit Angst angereicherten — politischen Rhetorik gerückt.

Tatsache ist, dass globale Wanderungsbewegungen (tendenziell vom ländlichen in den städtischen Raum und vom globalen Süden in den globalen Norden) die Gesellschaft vor neue Herausforderungen stellen. Aber anstatt ihnen mit langfristig in die Irre führender Ablehnung zu begegnen, können Themen der Verteilung, eben auch gerade des Grund und Bodens, einer zukunftsweisenden Auseinandersetzung mit diesem Komplex durchaus dienlich sein.

Illegitim ist, Latour folgend, nicht die Zughörigkeit zu einem Boden, sondern die Entwurzelung von ihm. Sich an ein Stück Erde zu binden und dafür Sorge zu tragen ist nur deshalb ,reaktionär“ geworden, weil es die von der Modernisierung aufgezwungene 
Flucht nach vorne scharf kontrastiert. Latour fährt fort, dass es an der Zeit sei ,die Bedeutsamkeit, die Legitimität, die Notwendigkeit der Zugehörigkeit zu einem Boden“ wieder zur Sprache zu bringen,

„aber ohne dass dies — und darin liegt die ganze Schwierigkeit - gleich wieder mit den Ingredienzien verwechselt wird, die dem LOKALEN beigemischt sind: ethnische Homogenität, Musealisierung, Historizismus, Nostalgie, falsche Authentizität. Es gibt ganz im Gegenteil nichts [...], das schöpferischer wäre und der gegenwärtigen Zeit mehr entsprechen würde, als darüber zu verhandeln, wie und wo wieder Bodenhaftung erzielt werden könnte. Verwechseln wir nicht die Rückkehr der Erde mit dem ,Zurück zur Natur' unseligen Andenkens. [...] Denn das Terrestrische hängt zwar an Erde und Boden, ist aber auch welthaft in dem Sinne, dass es sich mit keiner Grenze deckt und über alle Identitäten hinausweist.“20

Mit anderen Worten: Es geht um die Suche nach einem Gefühl der Zugehörigkeit und des Beschütztseins bei gleichzeitigem Verzicht auf territoriale Grenzziehungen im Namen der Identität, ob nun lokal/regional oder national/global. Im Prozess der Modernisierung wurden zwei sich ergänzende Bewegungen in Widerspruch zueinander gesetzt: ,sich an einen Boden binden einerseits [und] welthaft werden andererseits. "2I

Es gilt, diese heute wieder zusammenzudenken. Im Zusammenhang damit können die Mikro-Utopoi als zeitgenössische Testfelder verstanden werden, d.h. als neue raum-utopische Modelle, die der Forderung nachkommen (re)produktive Entscheidungsprozesse zu demokratisieren und gemeinwohlökonomische Zusammenschlüsse zu bilden, letztlich um ,gemeinsam herauszufinden, welches Territorium bewohnbar ist und mit wem wir es teilen wollen." ${ }^{22}$ 
Mikro-Utopien der

Architektur: Ästhetische Implikationen 
Aber etwas fehlt.

[...]

Aber etwas fehlt.

[...]

Aber etwas fehlt.

[Jim Mahoney im Gespräch mit Jack, Bill und Joe]

Bertolt Brecht (2017 [zuerst I929])

Aufstieg und Fall der Stadt Mahagonny, S. 23.

Freilich bietet durch ihre Absage an die Gesellschaft, die der Sublimierung durchs Formgesetz gleichkommt, autonome Kunst ebenso als Vehikel der Ideologie sich an: in der Distanz läßt sie die Gesellschaft, vor der ihr schaudert, auch unbehelligt.

Theodor W. Adorno (20I4 [zuerst I970])

Ästhetische Theorie, S. 335. 
Ästhetik architektonischer Minimaltechniken: Das ästhetische Wesen der Mikro-Utopoi, die durch architektonische Minimaltechniken entstehen, wird hier erfasst. Die sinnlich-ästhetischen Implikationen werden anhand von drei Funktionspaaren charakterisiert: Ort/Zeit, Materialität/Konstruktion und Organisation/Performanz. Die Produktions- und Rezeptionsbedingungen der Mikro-Utopoi werden beschrieben und ihre baulich-räumliche wird mit ihrer sozial-agilen Funktionsweise zusammengeführt. Es wird dargelegt, dass sich die kritisch-ästhetische Praxis als mikro-utopische Vorgehensweise verstehen lässt.

Soziale Wende in der Architektur: Die Präsenz des sozial engagierten, temporären Bauens hat sich sowohl im Zuge von städtischen Deindustrialisierungs- und Schrumpfungsprozessen, als auch durch eine neoliberale Stadtentwicklungspolitik ausgeweitet. Als Ausgangspunkt für ihr Entstehen werden zwei historische Entstehungsmodelle einander gegenübergestellt: der Ausnahmezustand des Mangels als Grund zur Bildung städtischer Solidargemeinschaften; der Ausnahmezustand des Überflusses als Grund für die Freiheit architektonischer Experimente.

Autonomie und Heteronomie in der Ästhetik: Der Diskurs um die Autonomie und Heteronomie (Eigengesetzlichkeit und Fremdbestimmung) der Kunst und Architekur ist ein zentraler Bestandteil der idealistisch-kritischen Ästhetik. Als Disziplinen folgen die Kunst und die Architektur zwar ihren je eigenen Gesetzen, stehen dabei aber-aus kritischer Perspektive immer nur-in einem ,relativ autonomen“ Verhältnis zur Gesellschaft. Zur Theoriebildung der Mikro-Utopoi werden architektur- und kunsttheoretische Positionen aus den I990er, I960/70er und I930er Jahren herangezogen. 


\section{Ästhetik architektonischer Minimaltechniken}

Die Wortkombination ,,architektonische Minimaltechniken“"I expliziert die spezifischen Entstehungsbedingungen von Mikro-Utopoi im Feld der Architektur. Die zum Einsatz kommenden architektonischen Minimaltechniken bestimmen die jeweilige Qualität der kritisch-ästhetischen Handlungspraxis (Tendenz) eines MikroUtopos. Es lässt sich zwischen drei Wirkungsebenen, die auf die Ästhetik Einfluss nehmen, unterscheiden:

- Kontext (Ort/Zeit), d.h. die örtlichen und zeitlichen Umstände unter denen temporäre Architekturprojekte hergestellt werden;

- Formgebung (Materialität/Konstruktion), d.h. die verwendeten Mittel und Werkzeuge, der Formfindungsprozess;

- Methodik (Organisation/Performanz), d.h. das organisatorische und kommunikative Vorgehen. ${ }^{2}$

Kontext: Leerraum und Transformationszeit Eine kritisch-ästhetische Architekturpraxis entwickelt sich meist aus der Logik der jeweiligen Umgebung. Typische Orte der Entstehung von MikroUtopoi können von formellem oder informellem Charakter sein. Formelle Orte sind programmatisch vorbestimmt und somit geschützte Orte, z. B. im Rahmen von Festivals, Ausstellungen oder Auftaktveranstaltungen, die sich städtischen, architektonischen und/oder künstlerischen Fragestellungen widmen. ${ }^{3}$ Informelle Orte sind programmatisch unbestimmt und somit ungeschützte Orte, z. B. Grenz- oder Resträume, wie innerstädtische Brachflächen oder Gebäudeleerstand.

Während formelle Orte durch den jeweiligen Veranstaltungsrahmen ästhetisch geprägt sind, treten bei informellen Orten stadtbildprägende Eigenschaften deutlicher hervor. Das sind z. B. in 


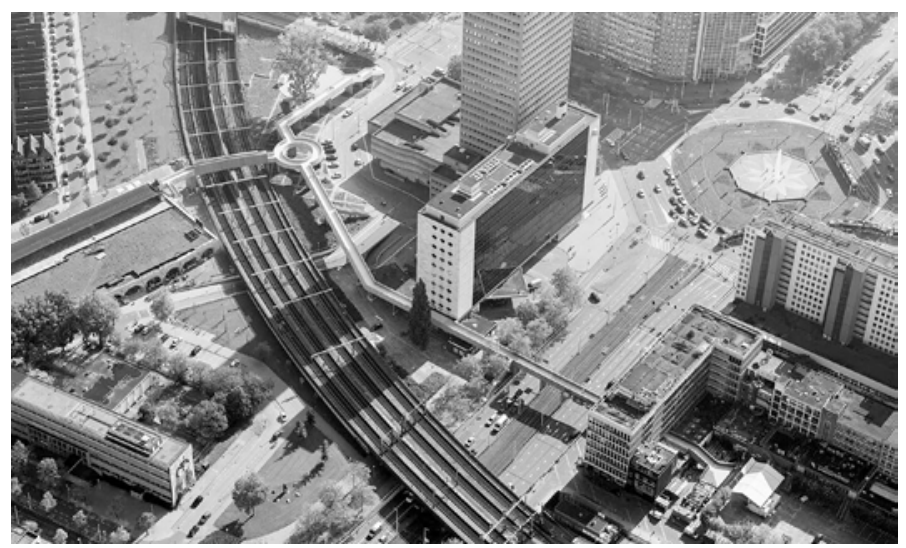

9 Luchtsingel Rotterdam, Zones Urbaines Sensible (ZUS), 2011-14

Berlin Brachflächen mit sandigem Erdboden, zumeist bewachsen mit Linden-, Ahorn- oder Birkenbäumen und daran oftmals angrenzende, hochaufragende Brandwände. Oder, das sind z. B. in London Brachflächen mit lehmigem Erdboden und bewachsen mit diversem Buschwerk vor dem Hintergrund dunkler Backsteinfassaden und gläsernen Firmenarchitekturen.

Auch unwirtliche Orte postmodern fragmentierter Stadtlandschaften z. B. unter Brückenabschnitten oder entlang lärmender Autoschneisen werden durch mobile bzw. temporäre Installationen kulturell bespielt und somit als vitale Räume neu erschlossen (Abb. I I bis I3). Solche Orte werden von den Projektbeteiligten internalisiert ${ }^{4}$ bzw. angeeignet, was so viel heißt wie

„, die Gleichzeitigkeit des Sich-Einfindens in Vorgefundenes, das dabei immer schon verändert und je Eigenes wird."5

Der Impuls für ein architektonisches Projekt erwächst meist aus dem Ort selbst, d.h. einer ortsinhärenten Problematik oder folgt einer vorgegebenen Thematik bzw. selbstgewählten Fragestellung, die ihre Entsprechung dann wiederum in einem konkreten Ort findet (Tab. 3). So lassen sich ungenutzte Orte vorübergehend beleben und/oder können sich auf längere Sicht etablieren und dabei helfen bereits bestehende Bedürfnisse sichtbar zu machen bzw. noch unbewusstes Begehren auszubilden. ${ }^{6}$ Das kann für Architekturvorhaben generell gelten, aber im kleinen Maßstab ist 


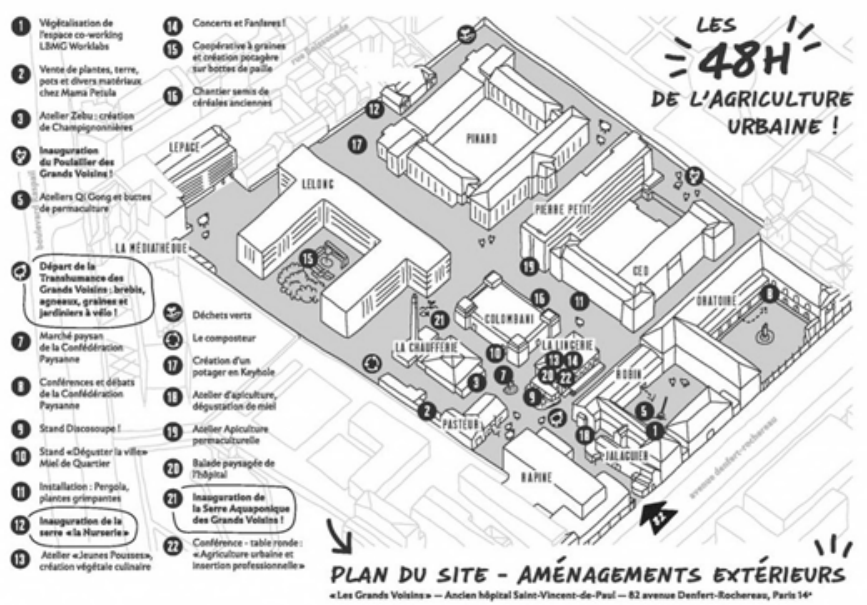

10 Les Grands Voisins Paris, Association Aurore + Yes We Camp + Plateau Urbain, 2015-20

die beschriebene Wirkungsweise für die Menschen unmittelbarer erlebbar.

Die Aneignung von Örtlichkeiten durch interventionistische Architekturen zieht nicht selten Konflikte um ihren Erhalt nach sich, z. B. wenn eine Bodenfläche zuerst nur als vorübergehendes Experimentierfeld in einem begrenzten Zeitfenster freigegeben wird, sich dann aber erfolgreich etabliert. In Debatten um ,,alternative Stadtgestaltung“ gilt der Relativismus der Zeitlichkeit deshalb als Schlüsselelement. ${ }^{7}$

Im Allgemeinen wird eine zeitliche Begrenzung zunächst als Potential für experimentelle Nutzungen wahrgenommen. Häufig stoßen temporäre Interventionen jedoch Impulse für weiterreichende Entwicklungen an. Sie wechseln zwar möglicherweise ihre Form und ihr Erscheinungsbild, werden aber von anderen Personen und Netzwerken oder in anderen Projekten weitergeführt. Sie nehmen einen über den Moment hinausreichenden Einfluss auf Personen, Prozesse und materielle Ergebnisse. Dabei steht die Wertschätzung von fluiden/liquiden Strukturen als impulsgebend für neue Stadtentwicklungen im Vordergrund. ${ }^{8}$

Es macht deshalb einen Unterschied, ob ein Endpunkt konkret terminiert ist oder unbestimmt bleibt. Das individuelle Zeiterleben wird zur Grundbedingung des Handelns in der Projektorganisation. 
Tabelle 3: Best practice-Projekte

Institutionalisierungsgrad Organisationsebene

Öffentlicher Raum Infrastrukturell

mit Genehmigung der öffent-

lichen Hand

Mit/ohne Zugangskontrolle

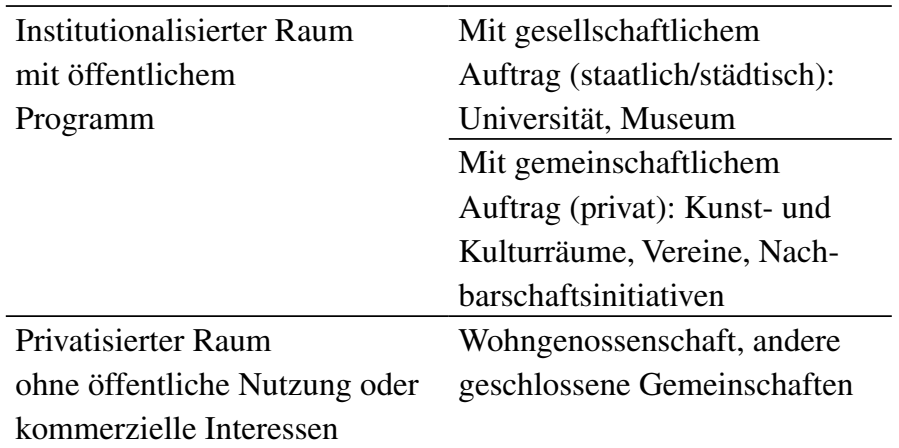

Ein vorbestimmtes Ende steckt den Rahmen eines Projekts klar ab. Bleibt das Ende aber offen, kann dies zum Auslöser von Unsicherheiten werden und polarisierende Effekte unter den Beteiligten erzeugen. Eröffnet sich für ein ursprünglich temporär angelegtes Projekt eine Möglichkeit der Verstetigung, bilden sich zwei Meinungspole heraus, hypothetisch: Gegner*innen und Befürworter*innen der Verstetigung.

Die Gegner*innen einer Verstetigung räumen der subversiven Kraft eines provisorischen Urbanismus Vorrang gegenüber langzeitlichen Planungen ein; sie sind im Falle einer Projektverstetigung besorgt über den Verlust der Glaubwürdigkeit ihrer eigenen Argumentation.

Die Befürworter*innen einer Verstetigung temporär angelegter Projekte hingegen, begreifen dies als Schritt hin zu einem progressiven Verständnis urbaner, demokratischer Kultur. Für sie führt die potentiell drohende Schließung zu einem Gefühl der ständigen Existenzgefährdung für das Projekt. 


\section{Beispiele}

Städtische Infrastrukturprojekte, z. B. Luchtsingel Rotterdam (Abb. 9); Stadtstrände oder Flussbäder, z. B. in Zürich und Basel; Radbahn Berlin (in Planung); generell autobefreite StraBenzüge

Städtisches Gemeingut, z. B. Tempelhofer Feld Berlin, Parklets

Stuttgart, urbane Landwirtschaftsprojekte; oder Festivalformate wie 72 HourUrbanAction

Alternative Lehrmethoden, z. B. Design Build Studios, Live project Initiativen (University of Sheffield/UK); oder Open University Formate, z. B. Floating University Campus

Arbeits- und Kulturareale, z. B. Les Grands Voisins Paris (Abb. Io), Ex-Rotaprint Berlin, E-Werk Luckenwalde, Baumwollspinnerei Leipzig, Wagenhallen/Container City Nordbahnhof Stuttgart

Außerhalb des (Immobilien-)Marktes, z. B. Mietshäuser Syndikat, Community Land Trusts (CLT)

Die jeweilige Qualität eines Mikro-Utopos hängt also mit den Voraussetzungsbedingungen seiner Entstehung zusammen, d.h. entscheidend ist der Umgang mit dem kulturell unbestimmten örtlichen und zeitlichen Kontext. Gerade das Unbestimmte übt eine gewisse Faszination aus, in der das imaginäre Denken leichter gewagt und realisiert werden kann. Die Kraft des Utopischen konkretisiert sich, d.h. imaginäre Nicht-Orte werden als gute Orte unmittelbar erlebbar.

Formgebung: Material as found und Formoffenheit Sobald die örtlichen und zeitlichen Rahmenbedingungen gemäß ihrer Funktion abgesteckt sind, können Entscheidungen über die Materialität und Konstruktion der Baustruktur getroffen werden. Der Umstand des Temporären prägt meist auch das ästhetische Erscheinungsbild. Dabei wird das Bauen von den Macher*innen als Prozess mit offenem Ausgang verstanden; vieles ist improvisiert, kleinmaßstäblich und damit von experimenteller Gestalt. In der Tradition des as found (oder trouvé) entstehen Architekturminiaturen - mal durch- 
lässiger, mal solider-, die aus vorgefundenen Materialien, d.h. tauschwertlosen Waren (Residuen) der Konsumgesellschaft entwickelt werden. Die Materialien werden zur Ausgangsbedingung der Formfindung, d.h. als gebrauchswertvolle Güter weiterverarbeitet.

Die Erbauer*innen verwenden bevorzugt leicht $\mathrm{zu}$ beschaffendes, einfach $\mathrm{zu}$ bearbeitendes und wenig kostenintensives Rohmaterial, dessen Reststoffverwertung (Re- und Upcycling) gleichsam als Bekenntnis zu einem ökologischen Bewusstsein verstanden wird. Zum Einsatz kommen z. B. gebrauchte Holz- und Kunststoffpaletten, ausrangierte Baugerüste, Kraftfahrzeugreifen, Wassertanks, Kanister und andere Behältnisse aus Glas oder Kunststoff, sowie alte Bauelemente (Fenster, Türen, Möbel, Industrietextilien) oder auch funktionsuntüchtige Elektrogeräte wie Kühlschränke, Röhrenbildschirme, etc. Oftmals werden auch Pflanzen eingesetzt, die neue Bilder und Narrative einer grünen, d.h. autofreien und ökologiebewusst gestalteten Stadt erzeugen, in der der öffentliche Raum dem Menschen und nicht mehr der Maschine vorbehalten ist.

Wenn ungenutzte oder deindustrialisierte Gebiete mit Hilfe von Selbstbautechniken nachverdichtet werden, dann haftet solchen Anordnungen alternativer Stadtgestaltung oft der ,negative Klang des Minderwertigen" 9 an. Eine experimentelle Architekturlandschaft kann aber auch gerade wegen dieses ,,authentischen“ Charakters - das romantische Image bzw. Klischee des Subkulturellen wird dabei von einer gewissen Melancholie des Vergänglichen gestützt - zum Markenzeichen werden oder sogar stilbildende Wirkung haben, denn ihre architektonische Ästhetik nimmt oft die Geschichte des Ortes auf und führt diese weiter.

Die (Stand-)Orte entwickeln sich unter Umständen zu einem veritablen Wirtschaftsfaktor. Als stadtplanerische und architektonische Experimentierfelder erlangten z. B. der Berliner Holzmarkt (Abb. I4), die Stuttgarter Wagenhallen oder der Berliner Prinzessinnengarten (Abb. I5) einen bedeutsamen gesellschaftlichen Status. Sie entsprangen subkulturellen Aktivitäten - oft als Nebenschauplätze größerer städtischer Umstrukturierungsmaßnahmen (etwa Media Spree oder Stuttgart 2 I) - und sind heute teils zu kommerzialisierten, touristischen Attraktionen geworden, die kulturelles Leben mit alternativen Wohnformen, Bildungsangeboten und städtischem Naturraum verbinden. 


\section{Ästhetik der begrenzten Zeitlichkeit}

zwischenräumlich, vergänglich, momenthaft, unfertig,

Raum-Zeit-Skizze

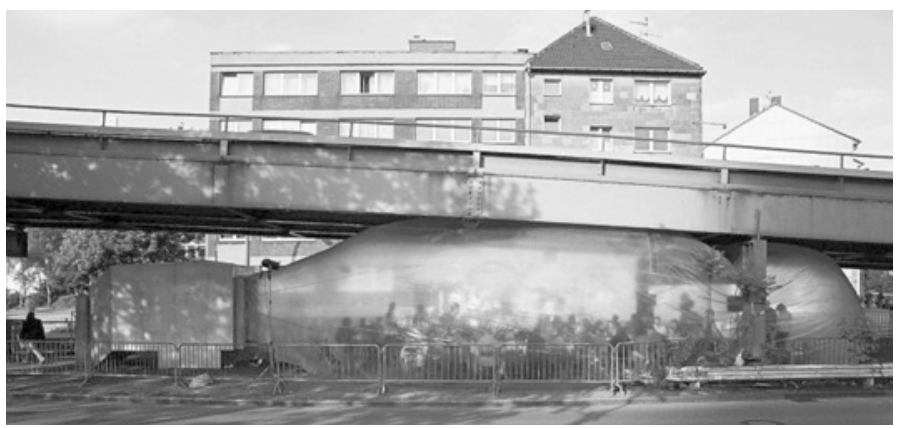

11 Küchenmonument (portabel), RaumlaborBerlin, seit 2006

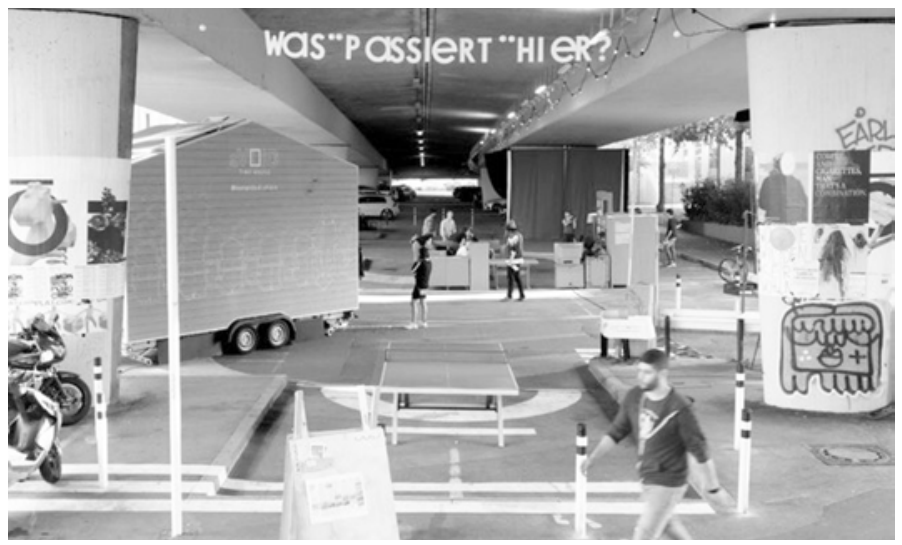

12 Paulinenbrücke, Österreichischer Platz, Stuttgart, Stadtlücken e. V., 2019

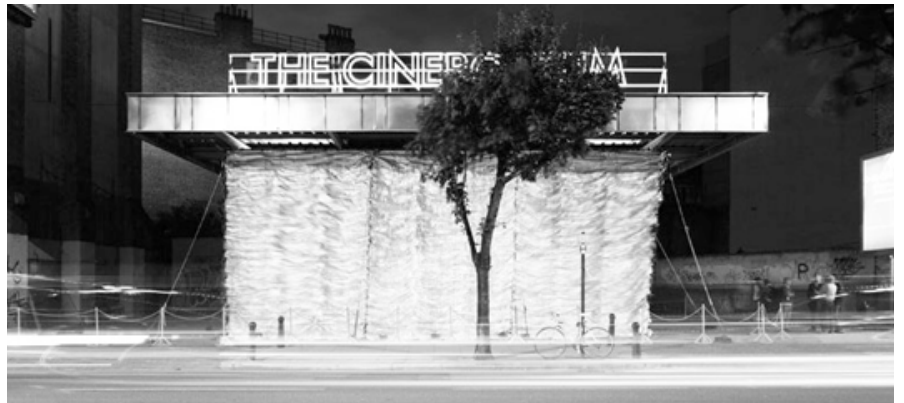

13 The Cineroleum, Assemble, London/UK, 2010 
Die jeweilige ästhetische Qualität eines Mikro-Utopos hängt folglich — neben dem Kontext (Ort/Zeit) — mit der Auswahl und dem Umgang der Materialität und Konstruktionsweise zusammen, die die architektonische Gestalt und die Einbettung in ihre Umgebung entscheidend prägen.

Die Formgebung eines solchen Ortes ist auch in besonderer Weise als eine Art der sozialen Kommunikation zu verstehen, die ihre Gesellschaft noch nicht gefunden hat. Die ästhetische Organisation von außerästhetischen Bedeutungen macht hier Erwartungen kenntlich, die außerhalb ihrer sprachlos blieben. ${ }^{\text {Io }}$ In der Raumproduktion von Mikro-Utopoi drücken sich womöglich transformativemanzipatorische Hoffnungen aus, die auf sich verändernde politisch-ökonomische Rahmenbedingungen gerichtet sind.

Methodik: Kollektivität und Partizipation Ein Teil der jüngeren Architekt*innen-Generation hat sich in diesem Kontext neu formiert. Praktizierende Akademiker*innen aus den Bereichen Architektur, Design und Kunst gehen mit stadterforschenden Wissenschaftler*innen, z. B. aus den Bereichen Anthropologie/ Ethnologie, Geographie, Soziologie und politischen Akteur*innen Kollaborationen ein, woraus unterschiedliche Gestaltungskollektive und forschende Ateliergemeinschaften erwachsen. Sie arbeiten transdisziplinär, sind nicht-hierarchisch organisiert, agieren oft international und begreifen ihre Tätigkeit als Ausdruck einer ,,initiierenden, integrativen Praxis“, die traditionellen Bürostrukturen, d.h. dem klassischen Architekturprozess kritisch gegenübersteht. ${ }^{\text {I I }}$ Diese neu entstandene Organisationsstruktur entspringt dem Zeitgeist der kollektiven Autor*innenschaft digitalgestützter Kollaborationen; sie sind damit als Anzeichen eines veränderten Verständnisses der Architekt*in zu werten, die dem „Geniekult“I2 des auf sich selbst gestellten Generalisten widersteht (Abb. I6 und I7). Dabei werden vielfältige soziale Techniken der Partizipation bzw. der basisdemokratischen Kommunikation eingesetzt und ausprobiert. ${ }^{\mathrm{I} 3}$

Obwohl die jeweiligen Rahmenbedingungen der Projektentstehung von höchster Diversität sind-abhängig von Kontext, Formgebung und Methodik - , spielen Strategien der Partizipation gewöhnlich eine zentrale Rolle im Gestaltungsprozess, ebenso nach dessen Abschluss. Die soziale Interaktion rückt ins Zentrum; der*die aufgeklärte, engagierte Bürger*in wird auf szenische Weise 


\section{Ästhetik der experimentellen Konstruktion}

kleinteilig, fragmentarisch, porös, widerständig, prekär (verletzlich), menschlicher Maßstab, Bricolage, Favela chic

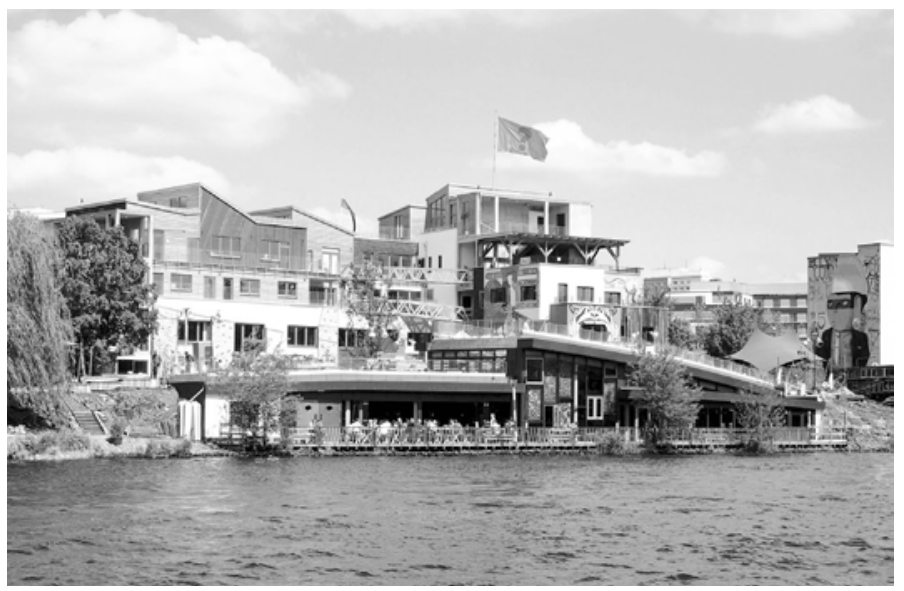

14 Holzmarkt 25, Spree für alle, Berlin, seit 2017 (Bar25 2003-10)

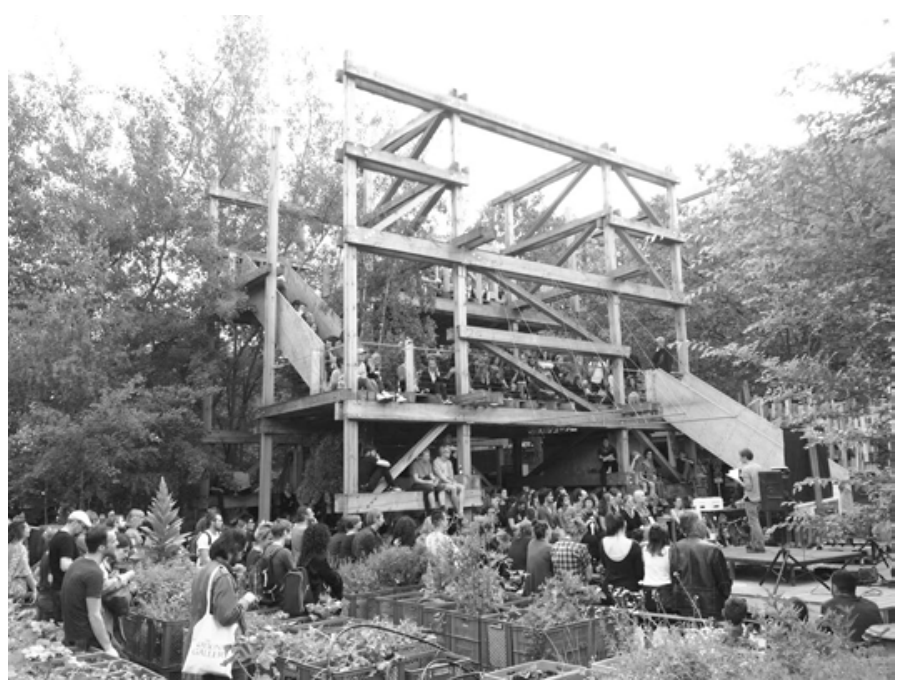

15 Postwachstums-Slam in der Laube (2017), Prinzessinnengarten Berlin, seit 2010 
zentraler Teil der Gesamtstruktur. Damit ist das soziale Programm nicht nur Teil der visuellen Identität der Projekte, sondern meist auch ihre Raison d'être. Daraus ergibt sich eine neue Bildsprache in den korrespondierenden Projektdokumentationen. In entsprechenden Darstellungen setzt sich die gesamte Architekt*innenschaft (scheinbar) aus teilnehmenden Laien und Bürger*innen zusammen.

Diese Organisationsmethode wirft brisante politische Fragestellungen auf, z. B. birgt die transdisziplinäre Praxis ${ }^{\mathrm{I}}$ Konflikt- $^{-}$ potential, das auch Machtverhältnisse auf lokaler Ebene berührt. Unter Umständen werden Konflikte mit anderen Akteursgruppen verursacht, z. B. weil staatliche Ressourcen umgelenkt werden. Aber nicht nur das Zusammenwirken mit den äußeren Bedingungen erzeugt Reibung und Widerstände, auch die inneren, originären Motive sind von Divergenzen und Widersprüchen geprägt. Es ist nicht auszuschließen, dass so manches Projekt von Eigeninteressen geleitet ist. Allzu leicht wird lokalen Initiativen Gemeinwohlinteresse zugeschrieben. ${ }^{15}$

Die jeweilige Wirksamkeit bzw. Qualität eines Mikro-Utopos hängt folglich — neben Kontext (Ort/Zeit) und Formgebung (Material/Konstruktion) - von der Initiative und Zusammenarbeit der Akteur*innen (Fachkundige, Laien und Politik) ab; sowohl während als auch nach Abschluss des Bauprozesses. In Entscheidungsprozessen dechiffrieren sich Machtstrukturen und das angestrebte Emanzipationspotential der Projekte wird erprobt. Im Fokus steht hier die Abkehr von institutionalisierten Organisationsstrukturen und -abläufen in der Architekturproduktion. Emanzipation entspricht in diesem Zusammenhang der gleichberechtigten Mündigkeit aller Projektbeteiligten. Die Befreiung von traditionell hierarchisch organisierten Normen und Standards in der Architekturproduktion ist deshalb ein wesentlicher Bestandteil architekturutopischen Denkens. 
Ästhetik der performativen Kollaboration

nicht-hierarchisch, gemeinschaftlich, kooperativ (Agency,

(o-op), spielerisch

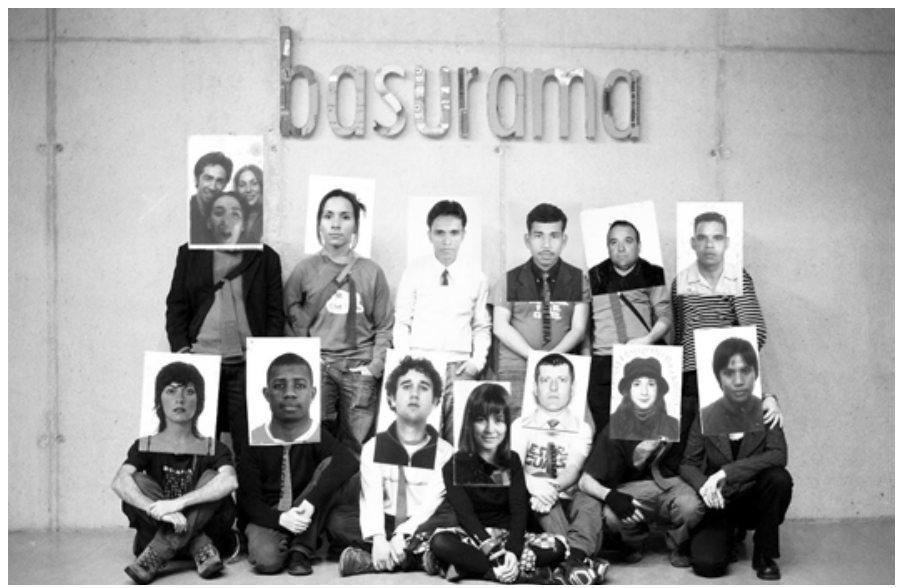

16 Gruppenfoto Basurama, seit 2001

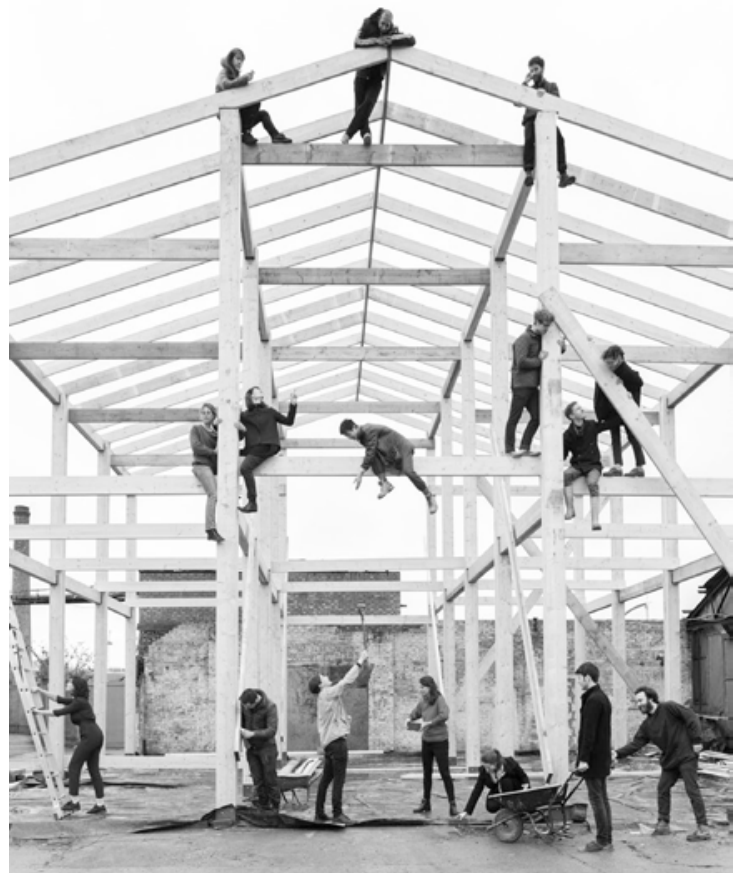

17 Gruppenfoto Assemble, 2014 


\section{Soziale Wende in der Architektur}

Kritische Architekturformate werden heute als Teil einer sozialen Wende in der Architektur rezipiert. Im Zuge des kulturwissenschaftlichen Spatial turns steigt die Sensibilisierung für sozialräumliches Denken bereits seit den I980er Jahren an. Die 7. internationale Architekturbiennale in Venedig mit dem Motto Less Aesthetics, More Ethics (2000), kuratiert von dem Architektenduo Massimiliano und Doriana Fuksas, steht im Diskurs dafür indikativ. Auch das Institute for the Future (Palo Alto/CA) erklärte-nach der Finanzkrise 2007/08-,social production“ zum Schlüsselthema des folgenden Jahrzehnts.

Im Kern des heutigen, kritisch ausgerichteten Architekturdiskurses liegen dementsprechend die sozioökologischen Herausforderungen der Architekturdisziplin. In entsprechenden Projekten zeigt sich, implizit oder explizit, eine wachstumskritische Haltung. Viele Architekturschaffende sind zunehmend auf der Suche nach neuen raumökonomischen Modellen, in denen das ökologische Bewusstsein und der soziale Zusammenhalt eine zentrale Rolle spielen. In diesem Sinne steckt im architektonischen Prozess ein wesentliches utopisches Potential. Die Soziologin und Utopieforscherin Ruth Levitas versteht das kritisch-ästhetische Vorgehen in der Architektur als ,utopische Methode“ und Utopie nicht als Zielvorgabe. ${ }^{16}$

Die soziale Wende in der Architektur erreicht durch populäre Events mittlerweile auch die breitere Öffentlichkeit. Die DiskursHöhepunkte der vergangenen Jahre bilden größere Ausstellungen ${ }^{17}, \mathrm{z}$. B. die I5. internationale Architekturbiennale mit dem Motto Reporting from the Front (20I6) und die Vergabe einschlägiger Auszeichnungen, z. B. wurde der Pritzker Prize 20 I6 dem 
chilenischen Architekten und Kurator dieser Biennale Alejandro Aravena verliehen; und der britische Turner Prize 20I 5 ging an das Londoner Kollektiv Assemble. ${ }^{18}$ In den betreffenden Architekturprojekten wird nach lokalen Lösungen gesucht, die pragmatisches Handeln, inkl. Formen der zivilgesellschaftlichen Selbstorganisation, mit ästhetischem Anspruch verbinden. ${ }^{\text {I9 }}$

Unterdessen protestieren die Menschen weltweit verstärkt, um ihrem Unmut über die sozialen und ökologischen Verhältnisse Ausdruck zu verleihen, z. B. bei Occupy (20I I) und Fridays for Future (2019). In diesem Zusammenhang wird auch der Status quo von Immobilienmärkten problematisiert, der zusätzlich durch exklusive Miet- und Mobilitätsformen der Share Economy verschärft wird. Dieser renditeorientierten Raumökonomie werden Alternativen gegenübergestellt, z. B. Initiativen der Recht-auf-Stadt bzw. Recht-auf-Wohnraum-Bewegung. In der Protestkultur sieht das Sozialwissenschaftlerduo Alexander Neupert und Lisa Doppler sozialkritisches und mithin utopisches Bewusstsein anwachsen. ${ }^{20}$

Latour bezeichnet jene Räume, die von politischen Aktivist*innen besetzt und verteidigt werden als zones à défendre (Frz. zu verteidigende Zonen); in ihnen stünde die ,,Repolitisierung der Zugehörigkeit zu einem Boden“ auf dem Spiel. ${ }^{2 I}$

Das alles geschieht auch im Zuge der voranschreitenden Privatisierung des öffentlichen — inkl. des medialöffentlichen — Raums. Die Forderung nach städtischem Gemeingut steht dabei gleichberechtigt neben demokratischen Grundrechten, wie der Rede-, Bewegungs- und Versammlungsfreiheit, der politischen Teilhabe und informationellen Selbstbestimmung, dem Recht auf Inklusion und Diversität. Diese Rechte sind nicht nur an die ,Sphäre der Öffentlichkeit “"22 gebunden, sondern werden auch von ihr geschützt.

Insgesamt kann das sozial motivierte und temporäre Bauen in unterschiedliche Traditionslinien gestellt werden; dies ließe sich, anhand divergierender Erzählstränge, auf vielfältige Weise darstellen. Die Referenzen stehen allerdings in so komplexen Wechselbeziehungen zueinander, dass sie sich je nach Erzählperspektive vollständig überlagern oder vollständig unterscheiden würden, z. B. portable bzw. mobile Architekturen nomadischer Kulturen und Völker, Propaganda- und Scheinbauten der russischen Konstruktivisten, Blasen- und Körperarchitekturen der I96oer Jahre und nicht zuletzt das informelle bzw. anonyme Bauen oder 
die Camp-Architektur von zunächst meist temporär angelegten Zeltstädten und Flüchtlingslagern. ${ }^{23}$

Da es im Rahmen dieser Arbeit weder möglich noch zielführend ist die vielfältigen Entstehungs- und Wirkungspunkte sozial engagierter Architekturen nachzuzeichnen, sei hier lediglich auf zwei historische - sich durchaus widersprechende-Maßstabsund Denkebenen hingewiesen. Beide Pole sind für den argumentativen Fortgang der Arbeit gleichermaßen von Bedeutung; sie spannen einen Rahmen für den utopischen Wesenskern des temporären Bauens in Krisenzeiten auf:

— städtischer Ausnahmezustand mit gesellschaftspolitischem Schwerpunkt (Mangel)

- architektonischer Ausnahmezustand mit künstlerisch-kulturellem Schwerpunkt (Überfluss).

Städtischer Ausnahmezustand Praktiken des subsidiär-motivierten Bauens kommen besonders häufig in historischen Übergangszeiten bzw. Umbruchsituationen zum Einsatz, z. B. fand die unbehauste Bevölkerung - etwa nach der Weltwirtschaftskrise in den späten I920er Jahren oder in den zerbombten Stadtzentren Europas nach dem Zweiten Weltkrieg_-jahrelang Unterschlupf in provisorischen Notbehausungen, wie Barackensiedlungen bzw. Nissenhütten mit angegliederter Subsistenzwirtschaft an den Stadträndern der Moderne. Subsistenzwirtschaft und Solidargemeinschaft spielten auch in der kubanischen „Periodo especial“" (Sonderzeit) in Form von Organóponicos (urbane Landwirtschaft) in den I990er Jahre nach der Unabhängigkeit von der UdSS. eine besonderen Rolle; sowie gegenwärtig, z. B. in informellen Siedlungen größerer Städte im globalen Süden.

In „Krisenzeiten der geordneten Planung“ wird das informelle Bauen und Wohnen - teils mit verklärtem Blick auf diese kaum dokumentierten Lebensrealitäten - in die Architektur- und Stadtdiskurse zurückgeholt, z. B. in den I96oer Jahren, als das paternalistische Selbstverständnis der Planer*innen als autoritäre Allüre zunehmend in Frage gestellt wurde und partizipative Planungsansätze breiteren Zuspruch fanden. Oder in den I 990er Jahren, als das städtebauliche Leitbild der ,europäischen Stadt“ in eine ,formalästhetische Normierung“ überführt bzw. im wiedervereinigten Berlin ,kritisch rekonstruiert“ wurde und parallel dazu sich die 
prägende Transformation für die jüngere Architekt*innen-Generation in informellen Projekten auf städtischen Randgebieten vollzog.

In dieser Zeit dezimierte sich auch die Bündelung der Planungshoheit der öffentlichen Hand und private Akteure wurden als Partner in Planungsaufgaben eingebunden, d.h. Aufgaben und Entscheidungen der Städte und Kommunen wurden durch privatwirtschaftliche Investitionen beeinflusst. So wurde in Stadträume, deren Entwicklungspotential zweifelhaft erschien, nicht mehr investiert. In diese ausgemusterten Orte sprangen zivilgesellschaftlich organisierte Akteure ein. Dabei entstanden neue urbane Testräume, die mit einfachen Mitteln aneignet wurden und der Bevölkerung bunt gemischte Programme anboten. ${ }^{24}$

Dieser Entwicklung entspringt ein Wandel im Verhältnis von Architektur, Kunst und städtischer Politik. Beispielsweise greift die derzeitige Berliner Senatsbaudirektorin Regula Lüscher dies mit der Frage auf, ob sich Kunst, Architektur und öffentliche Planung im Diskurs über die Zukunft des urbanen Raumes weiterhin produktiv aufeinander beziehen können, oder ob sie sich in Opposition oder Konkurrenz begegnen werden. ${ }^{25}$

Diese Schnittstelle von Raumpolitik und Architekturkultur wird bereits in vielen Städten experimentell ausgelotet, z. B. in (temporären) Gemeinschaftsgärten in Berlin oder London (Abb. I 8 und I9), deren Ergebnisse international diskutiert werden.

Architektonischer Ausnahmezustand ${ }^{26}$ Das Potential temporärer Architekturen-im Folgenden als der utopische „Augenblickskern-Keim“27 bezeichnet—sei anhand des Ausnahmezustandes architektonischer Experimente veranschaulicht: In den letzten Jahren sind für den Moment konzipierte Experimentalbauten, d.h. die Zeitnischen gesellschaftlicher Transformationszustände nutzende temporäre Architekturen im urbanen Raum, vermehrt entstanden. Ihre Entstehungsbedingungen kennzeichnen sich durch kontrollierte Momente räumlicher und zeitlicher Freiheit. In der Verwandlung des Gewohnten wird der Augenblick zelebriert, d.h. gerade in den eng umrissenen Zeiträumen ihrer Existenz liegt ein wesentliches Merkmal kritischer Architekturpraxis begründet, z. B. bei der Reichstagsverhüllung von Christo und Jeanne-Claude ( I995) oder der Zwischennutzung des Palastes der Republik (2003-05) in Berlin, die beide als monumentale architek- 


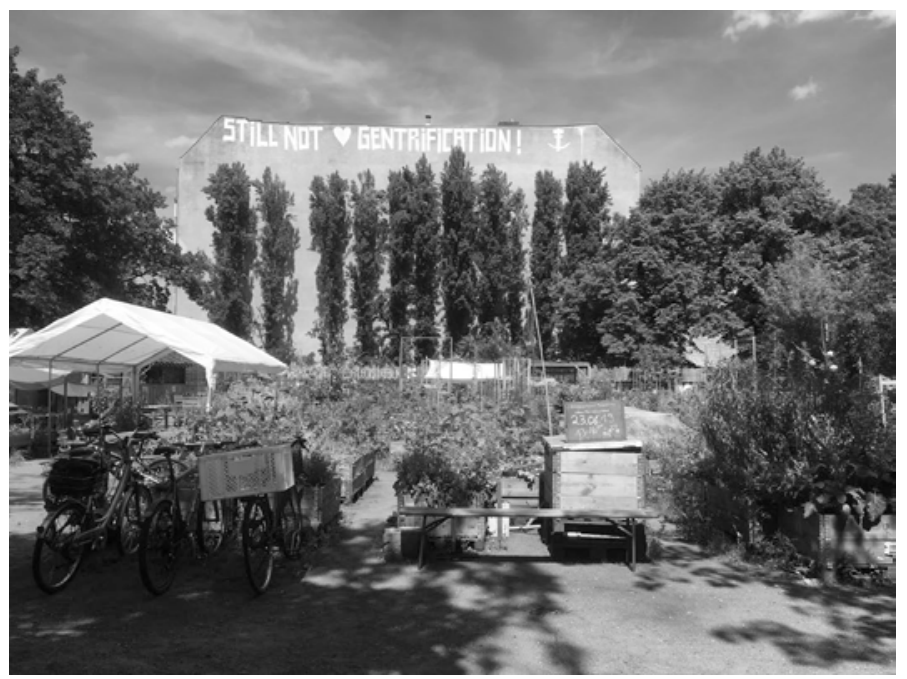

18 Himmelbeet, ein interkultureller Gemeinschaftsgarten, Berlin-Wedding, 2013-21 - Brandwand-Graffito: „still not $\bigcirc$ gentrification!"

tonische Metamorphosen und Zeichen gesellschaftlicher Neuordnung verstanden werden können.

Diesen temporären Architekturen liegen, wie allen anderen, die Dimensionen Raum und Zeit zugrunde. Für die anschließende Argumentation lohnt sich ein genauerer Blick darauf. Raum und Zeit haben in der philosophischen Ästhetik von Immanuel Kant und Ernst Bloch den Rang von absoluten Dimensionen. Bei Kant sind Raum und Zeit ,apriorische Anschauungsformen“, d.h. sie liegen der subjektiven Erfahrung zugrunde (Kritik der reinen Vernunft, I78I/87). Bei Bloch sind Raum und Zeit „Rahmenkategorien“, d. h. sie umfassen die „Bewegung auf dem Weg, den es ohne diesen Rahmen gar nicht gäbe“ (Experimentum Mundi, 1975).

Erst auf diesem Weg, wenn er denn mit einem kritischen Bewusstsein beschritten wird, können sich Wünsche formieren, d.h. das utopische Bewusstsein kann sich als Gesellschaftskritik etablieren und daraus resultierende Idealvorstellungen können sich entfalten. Das kann auf unterschiedliche Weise geschehen. Bei Kant bildet sich die Utopie als geschichtsphilosophisches Modell heraus (Zum ewigen Frieden, I795). Bei Bloch zeigt sich die Utopie im „Dunkel des gelebten Augenblicks“ als Weg der Selbst- 


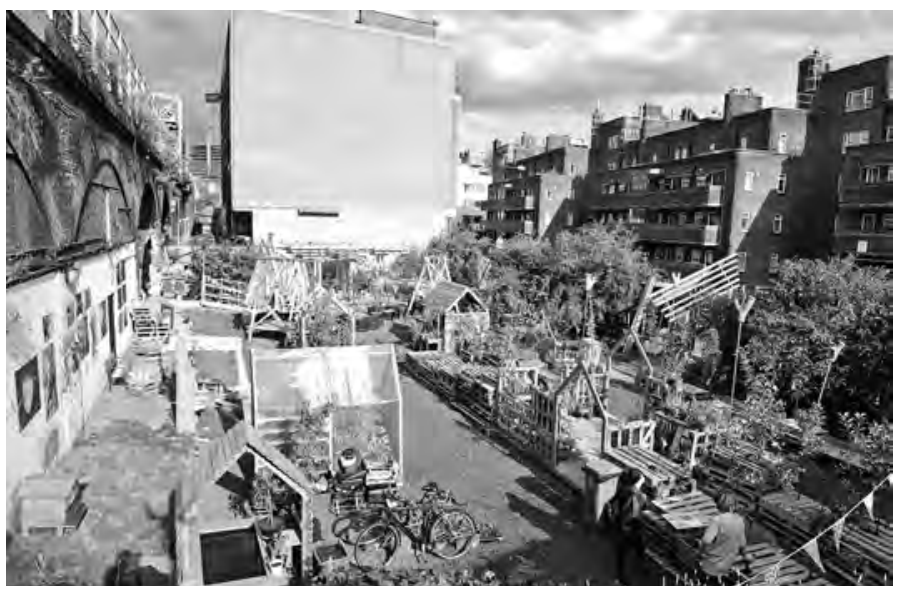

19 The Union Street Urban Orchard London, Wayward, 2010

begegnung, „ohne die aller Blick nach außen nichtig bleibt“ (Geist der Utopie, 1918/23).

Aber in welchem Verhältnis steht der als außergewöhnlich erlebte Augenblick eines empfindenden Subjekts zum historischen Prozess des allgemeinen Weltgeschehens? Beschränkt man das utopische Bewusstsein auf einen „Augenblick“, könnte man daraus eine Reduktion des Utopischen auf eine individuelle Glückserfahrung, jenseits von Ethik und geschichtlichen Zielvorstellungen, schließen. Diese Annahme würde eine radikale Subjektivierung und politische Entschärfung der Utopie bedeuten. ${ }^{28}$ Umgekehrt lässt sich argumentieren, dass gerade erst die subjektive Wahrnehmung und Reflexion eines „Momentums“ im Bewusstsein der Außenwelt in der historischen Kontinuität es zu einem utopischen „Augenblick“ macht. ${ }^{29}$ Walter Benjamin konstatiert in seinen Thesen Über den Begriff der Geschichte ( I940), dass ,das Bewußtsein, das Kontinuum der Geschichte aufzusprengen, [...] den revolutionären Klassen im Augenblick ihrer Aktion eigentümlich [ist]. “30 Der plötzlich eintretende ,Augenblick“" erscheint dabei als „Moment einer politisierten Wahrnehmungs-Ästhetik“3I , d.h. als günstiger Zeitpunkt für eine subjektive Bewusstwerdung über den historischen Kontext, der eine Veränderbarkeit der Verhältnisse ermöglichen kann, die unter Umständen zuvor nicht möglich war und danach nicht mehr möglich sein wird. 
Temporäre Architekturen sind kein neues Phänomen. Bereits die herrschaftlichen Festarchitekturen der Renaissance schufen einen Rahmen für die ,erhöhte[n] Moment[e] im Dasein des Volkes“.32 Ebenso wurden durch die temporären Demonstrationsarchitekturen der Weltausstellungen seit der Mitte des I9. Jahrhunderts regelmäßig Versuchsaufbauten möglicher neuer Wirklichkeiten geschaffen, die außerordentliche Erlebnisse evozierten. Die Künstlergruppe Situationistische Internationale (SI) versuchte in den I96oer Jahren Situationen zu konstruieren, die sie jeweils als „Aufbau einer vorübergehenden Mikroumgebung und eines Satzes von Ereignissen für einen einzigen Augenblick im Leben einiger Personen“ verstanden wissen wollten; als „Ausdruck von Spiel und Ernst einer freieren Gesellschaft." 33

Visionäre Vorstellungen werden gerade durch unkonventionelle Architekturen, die zur Kommunikation und Partizipation anregen, provoziert. Jene Orte, die Sehgewohnheiten irritieren und damit Ausnahmezustände schaffen, bieten das Potential, Menschen vorübergehend ihrem Alltag zu entheben und sich dem Experiment zu stellen. Im Moment des Erschreckens bzw. der Irritation vollzieht sich ein Akt des infrage stellenden Öffnens: ist das gut oder muss man das fürchten? Im Idealfall werden Dialoge initiiert, ,die geeignet erscheinen, die allgemeine Tendenz passiver Sprachlosigkeit zu überwinden." 34

Obwohl die utopietheoretische Reduktion auf den Augenblick Symptom historischen Zweifelns ist, bleibt der utopische Horizont unbestimmt offen, denn wird der Zweifel als Zweifel konsequent gedacht, hat er keinen Absolutheitsanspruch und verstellt den Blick in die Zukunft nicht. ${ }^{35}$ Der ,Theoretiker des Augenblicks“ Robert Musil macht die Utopie im Augenblick explizit und schreibt, dass Utopien

„, ungefähr so viel wie Möglichkeiten [bedeuten]. [D]aß eine Möglichkeit [noch] nicht Wirklichkeit ist, drückt [...] nichts anderes aus, als daß die Umstände, mit denen sie gegenwärtig verflochten ist, sie daran hindern, denn andernfalls wäre sie ja nur eine Unmöglichkeit; löst man sie nun aus ihrer Bindung und gewährt ihr Entwicklung, so entsteht die Utopie.“"36

Es stellt sich also die Frage, inwiefern der utopische „Augenblickskern-Keim“ des Ästhetischen als bewusste Reflexion der Rezipient*innen verstanden werden kann: Wird eine konstruktive 
Infragestellung des ,umgebenden ,Sein[s]““37 angestoßen oder vollzieht sich ein Verlust des reflexiven Moments, weil der paradigmatische Raum als zeitenthobene Mythologie wahrgenommen wird, der zur realen Gesellschaft keinen Bezug mehr hat $3^{38}$ Ein freiheitliches Gemeinschaftsgefühl kann Enthusiasmus auslösen. Durch den Zugewinn an Mut kann sich dann unter Umständen eine Affektverwandlung vollziehen: von Freiheit in Zukunftsglauben, z. B. in der Hoffnung auf die Rückeroberung des eigenen Handlungsspielraums durch die Wiederaneignung städtischer Lebensräume. Das Erzählen neuer Geschichten, die Entwicklung von Zukunftsszenarien spielt dabei eine wesentliche Rolle und dient dazu, die individuell mutmaßlich vorhandene, aber gesamtgesellschaftlich derzeit scheinbar brachliegende Vorstellungskraft zu reaktivieren. ${ }^{39}$ 


\section{Autonomie und Heteronomie in der Ästhetik}

Überlegungen zur Autonomie der Kunst sind immer im Zusammenhang mit bzw. in Abgrenzung von der jeweiligen gesellschaftlichen Wirklichkeit zu verstehen. Die Anfänge der Forderung nach einer Autonomie der Kunst und damit der Freiheit der Künstler*innen, d.h. die Selbstbehauptung des Individuums gegenüber gesellschaftlichen Interessen, fällt in die Zeit der Aufklärung. Am Beginn stand eine Befreiungsbewegung der Kunst von Naturnachahmungen, moralischen Zwängen und gesellschaftlichen Einflüssen; im Weiteren entwickelten sich Emanzipationsbewegungen aus der Einflusssphäre von Kirche und Adel und später der bürgerlichen Gesellschaft. ${ }^{40}$

Als neuerlicher Ausgangspunkt dieser-bisweilen hochpolitischen - Debatte kann die Entstehung der Ästhetik als Teildisziplin der Philosophie mit der Schrift Aesthetica ( 1750) des Philosophen Alexander Gottlieb Baumgarten verstanden werden. Seither lässt sich das Programm der philosophischen Ästhetik als Analyse der Eigengesetzlichkeit der sinnlichen Anschauung und ihrer Relevanz für die menschliche Weltorientierung beschreiben; erst einmal unabhängig von der diskursiven Rationalität. ${ }^{\mathrm{I}}$ Die Autonomie der Kunst ist bis heute ein zentraler Bestandteil des ästhetischen Diskurses.

Kant subjektiviert die Empfindung des Schönen in seiner Schrift Kritik der Urteilskraft ( I790) radikal. Die Überschrift des zentralen Paragraphen (\$2) lautet: „Das Wohlgefallen, welches das Geschmacksurteil bestimmt, ist ohne alles Interesse“"42; damit entkoppelt bzw. enthebt Kant die Wahrnehmung und Empfindung von Schönheit, d.h. die wahre (autonome) ästhetische Erfahrung jeglicher Vorkenntnisse und Wissen über die Entstehungsbedin- 
gungen, sowie den Nutzen und Gebrauch (Inhalt) eines Gegenstandes (Form).

Kaum später prägt der Dichter Friedrich Schiller im I5. Brief seiner gesellschaftsanalytischen Schriftenreihe Über die ästhetische Erziehung des Menschen (I795) die berühmte These, dass ,[...] der Mensch [nur] spielt [...], wo er in voller Bedeutung des Worts Mensch ist, und er [...] nur da ganz Mensch [ist], wo er spielt."43 Für die ästhetische Theorie bedeutet die Schiller'sche These im Wesentlichen, dass die ,spezifische Deformation der bürgerlichen Gesellschaft“, d. h. das System der Arbeitsteilung, nur durch die Kunst (als Selbstzweck) kompensiert werden kann. ${ }^{44}$ In der darauffolgenden Zeit liegt die treibende Kraft der Kunst in ihrem Abgrenzungsbedarf__, l'art pour l'art“_— von der vereinnahmenden bürgerlichen Gesellschaft.

Verallgemeinernd lässt sich sagen, dass Autonomiebestrebungen immer als Befreiungsbewegungen bzw. Auflehnung gegenüber vereinnahmenden (äußeren) Kräften entstehen. Der Impuls des In-Sich-Zurückziehens, d.h. ,keine Beziehung auf irgend etwas außer sich zu haben“45 kann einerseits als Schutzmechanismus verstanden werden, z. B. in gesellschaftlichen Krisenzeiten oder auch in Krisenzeiten einer ästhetischen Disziplin; andererseits zeugt ein solcher Widerstand aber auch von einem Rückzug aus gesellschaftlicher Verantwortlichkeit. Dies kann wiederum eine Bewegung motivieren, die sich gegen den Autonomiestatus selbst richtet. So geschah es, dass das Befreiungspostulat der Autonomie der Kunst im 20. Jahrhundert von den Avantgardebewegungen der Ioer und 6oer Jahre umgekehrt wurde. Sie forderten programmatisch die „Humanisierung der Welt durch Liquidation der Differenz von ,Kunst" und ,Leben "“.46

Adorno wies der Kunst eine zentrale Stellung in der bürgerlichen Gesellschaft zu, indem er sie als Feld theoretisierte, das Menschen in die Lage versetze eine Versöhnung mit dem ,,beschädigten Leben“ anzustreben. Er beschreibt die Kunst als Wesen mit Doppelcharakter, d.h. als dialektisches Phänomen. Der „Doppelcharakter der Kunst: fait social und Autonomie" 47 bedeutet für ihn, dass die Kunst zugleich eine soziale Tatsache (fait social) und ein autonomes Gebilde (Autonomie) ist. Der Gedanke der Kunstautonomie solle Adorno zufolge also weder verabsolutiert, noch einfach weggestrichen werden; Kunstwerke seien sozial produziert und zugleich autonom. Gerade dort, wo die Werke der Moderne nichts 


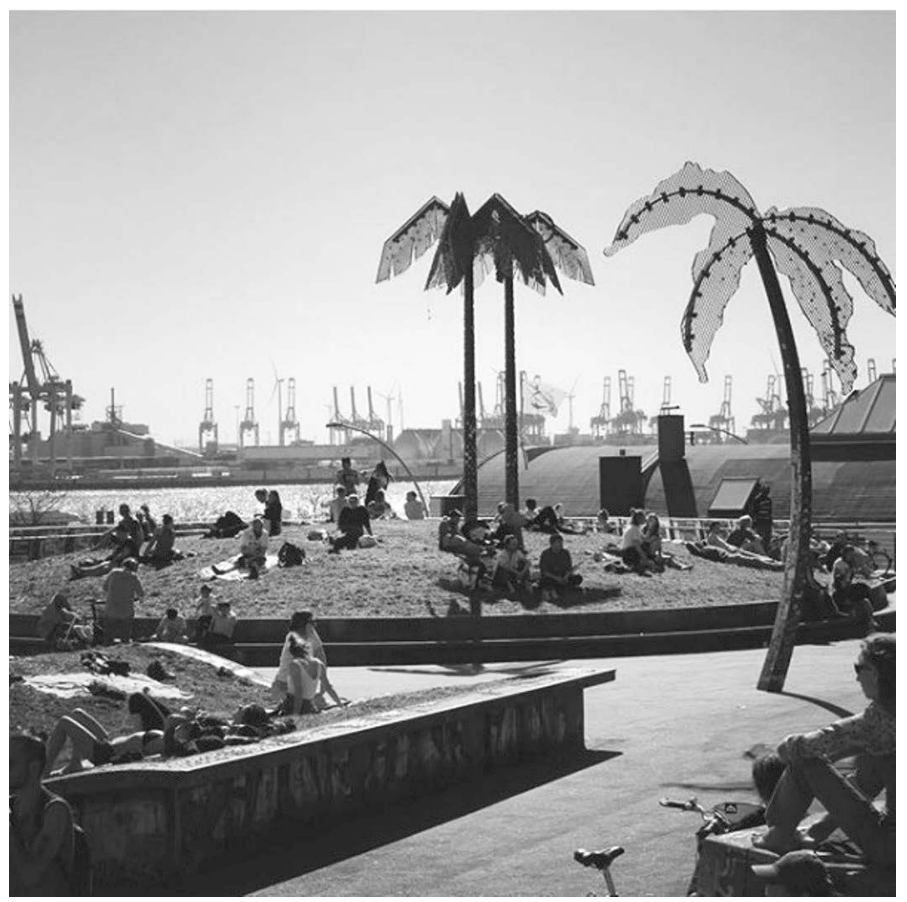

20 Park Fiction, Hamburg, seit 1995

anderem verpflichtet sind als den Erfordernissen ihrer eigenen Formgesetze, können sie am differenziertesten historische und gesellschaftliche Erfahrungen ausdrücken und soziologische Reflexionen ermöglichen. ${ }^{48}$

Im Gegensatz dazu stehen heutige künstlerische Strategien, die eine kritische Haltung gegenüber dem Kunstwerk als autonomes, selbstreferentielles Objekt einnehmen und die Rezipient*innen aktiv miteinbeziehen. Diese werden z. B. als Socially engaged practice, Activist art, Community art oder auch New genre public art bezeichnet. ${ }^{49}$ Sie beschäftigen sich mit relationalen Taktiken, d.h. der Verbindung von menschlichem Handeln und raumbildender Materie, wobei die Urheberschaft der Künstler*innen nur eine katalytische Funktion einnimmt..$^{\circ}$

Das Interesse an sozialen Prozessen keimte bereits in den I990er Jahren verstärkt wieder auf; im deutschsprachigen Raum z. B. durch die Initiative Park Fiction des Künstlers Christoph Schäfer (seit I995) (Abb. 20) oder in der Kleinstpartei Chance 2000 


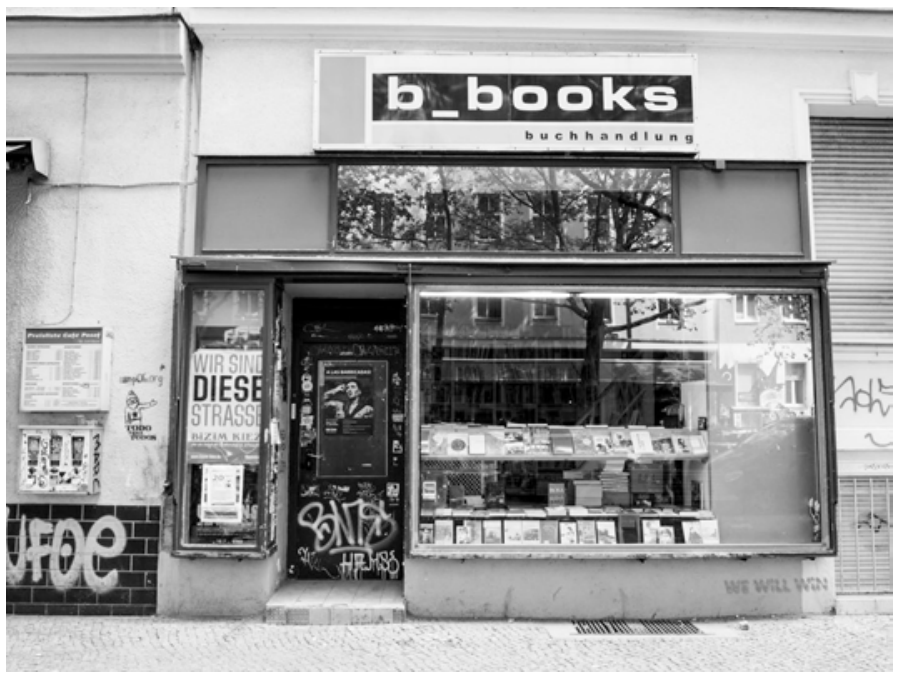

21: b_books, Buchladen, Veranstaltungsort, Verlag und politisches Zentrum in Berlin-Kreuzberg seit 1996; entsprang Projekten der Berliner Nachwendezeit, die sich für eine Repolitisierung der Kultur im Rahmen von Gegenöffentlichkeitskonzepten einsetzen.

des Künstlers Christoph Maria Schlingensief (I998). Die Kasseler documenta X ( I997) nahm dabei, unter der künstlerischen Leitung von Catherine David und unter Rückbezug auf Themen der I960er Jahre, eine Schlüsselrolle ein. ${ }^{51}$ In Debatten des aktuellen Kunstdiskurses geht es auch um die Revision der ,jüngsten Geschichte“52, d. h. der I990er Jahre. Beispielsweise gehörte in der Berliner Nachwendezeit gesellschaftliches Engagement_-insbesondere auch die kritische Beschäftigung mit der Stadtentwicklung — als selbstverständlicher Teil zur projektbasierten künstlerischen Alltagspraxis. ${ }^{53}$ Die soziale Relevanz der Kunst wurde zum Credo des kulturellen Handelns, wobei die interdisziplinäre Organisation eine Grundbedingung darstellt, zu der Architekt*innen genauso wie andere ,außerakademische[n] ,Kulturproduzent*innen“" beitrugen ${ }^{54}$ (Abb. 2I).

Die Übertragung bzw. der kritische Einbezug von kunsttheoretischen Aspekten auf die aktuelle Architekturdebatte ist sinnfällig für die Theoriebildung der Mikro-Utopie. 
Dazu werden Positionen der I990er, I960/70er und I930er Jahre herangezogen, d.h. es werden Verbindungen hergestellt, die soziale Ein- und Ausgrenzungsmechanismen thematisieren (Bourriaud/ Bishop); es werden historische Fenster in die I96oer Jahre (Beuys/ Eco) und in die I93oer Jahre (Benjamin/Brecht) geöffnet, worin Fragestellungen der gesellschaftlichen Teilnahme und Teilhabe aufgeworfen werden, die bis heute nicht an Aktualität verloren haben. Und zum Abschluss dieses Kapitels wird eine Gegenüberstellung von autonomer Architektur (zugunsten einer Selbstvergewisserung der Disziplin) und heteronomer Architektur (zugunsten einer gesellschaftlichen Einmischung) vorgenommen (Rossi/ Kroll).

Bourriaud/Bishop: Kritik der „relationalen Ästhetik“ Ein heteronomer Theorieansatz mit Signalwirkung ging in den I99oer Jahren von dem französischen Kunstkritiker und Kurator Nicolas Bourriaud aus. Er entwickelte seine Theorie der „,relationalen Ästhetik“ vor dem Hintergrund der Kunstkritik jener Zeit, die die partizipative Kunstproduktion mit überholten Kategorien der I96oer Jahre dekodierte, in denen das Publikum lediglich durch Handlungsbefehle der Künstler*innen einbezogen wurde z. B. Fluxus und Happening. In der Praxis der relationalen Ästhetik hingegen werde die Möglichkeit geboten sich politisch-aktiv zu betätigen, denn dem Publikum würde ein eigener Handlungsspielraum gewährt, so Bourriaud. Er führt in seiner Schrift künstlerische Positionen an, die Modelle der Interaktion verfolgen und schlägt folgende Typologien vor: „connections/meetings“, „,conviviality/encounters“, „,collaborations/contracts“, ,professional relation: clienteles“ und „how to occupy a gallery“. 55

In solchen Modellprojekten werden alternative Formen der Kommunikation angeboten; der Zusammenhang von der Materialität eines Artefakts und seinem monetären Wert befragt; das Verhältnis von Kund*innen und Unternehmen thematisiert, wobei das kapitalistische System en passant zur Sprache kommt, d.h. als gegeben akzeptiert wird. Die künstlerischen Aktivitäten würden als soziale Zwischenräume platziert und erprobten so alternative Formen des Zusammenlebens inmitten der Konsensgesellschaft, der sie sich gleichzeitig entgegensetzten.

Die ästhetisch-relational arbeitenden Künstler*innen wendeten sich - im Unterschied zu den Avantgarden des 20. Jahrhunderts, 
die noch eine umfassende Emanzipation des Individuums aus der repressiven Gesellschaft verfolgten - von radikalen Gesellschaftsutopien ab. Sie schlagen minimalinvasive Modifikationen vor, d.h. Kleinsteingriffe in die gesellschaftliche Realität der Postmoderne, in der das aufklärerische Ideal und Ziel einer radikalen Emanzipation aufgegeben wurde. Gerade in dieser Nüchternheit liege die Chance einer Renaissance des Politischen in der Kunst; ${ }^{6}$ aber, so muss man ergänzen, auch das Risiko ihrer Entpolitisierung.

Für Bourriaud bildet der französische Philosoph Louis Althusser und seine Theorie des „Materialismus der Begegnung“ den Ausgangspunkt für weitere Überlegungen. Althusser beschreibt die zwischenmenschliche Begegnung bzw. Kommunikation als an sich risikobehaftet, d.h. sie werde von Intersubjektivität geformt, sprich, sie ist nicht planbar bzw. ihr Resultat ist immer ergebnisoffen. ${ }^{57}$ Nach Bourriaud führe der von den Künstler*innen gegebene Anstoß zu Diskussionen in intersubjektiven Begegnungen, die dann durch ergebnisoffene Debatten - erstmal innerhalb des künstlerischen Feldes - eine neue gemeinschaftliche Weltsicht formen könnten. ${ }^{5}{ }^{8}$ Über diese Grenzen hinausgetragen könne dies dann in einen breiteren Konsens verwandelt werden, d.h. schlussendlich reale Veränderungen im gesellschaftlichen Gefüge hervorbringen, so seine Hoffnung. 59

Die in den I990er Jahren entsprechend poststrukturalistisch informierte Kritik daran lautet, dass der Ausgangspunkt solcher Debatten nicht in befriedeten Orten wie Kunsträumen und Galerien stattfinden könne, weil in solchen konsensorientierten Feldern ${ }^{60}$ keine radikale Meinungsverschiedenheit herrsche. Aber gerade konfliktreiche Diskussionen sind eine wichtige Voraussetzung für die demokratische Meinungsbildung. Demokratie erfordert, dass Exklusion, d.h. Ausschluss sozialer Gruppen aus dem Kreis derer, die sich als Mehrheitsgesellschaft verstehen, sichtbar gemacht und so zur Disposition gestellt wird, wenn man eine pluralistische Demokratie, d.h. die Herrschaft aller anstrebe, so nimmt die amerikanische Kunsthistorikerin Rosalyn Deutsche Stellung mit der poststrukturalistischen Hegemonietheorie von Ernesto Laclau und Chantal Mouffe. ${ }^{6 I}$

Die britische Kunsthistorikerin Claire Bishop gibt ebenfalls zu bedenken, dass die relationale Ästhetik als künstlerisch-partizipative Praxis der Form nach zwar eine neue Plattform für zwischenmenschliche Begegnungen schaffe, die aber eher affirmativ, d.h. 
harmonie- und konsensorientiert ist. Nicht in der ,äußeren Form des Relationalen“"stecke das politische Potential, sondern in einem „inhaltlichen Typus zwischenmenschlicher Relation“. Wenn die künstlerische Praxis als politisch deklariert werden soll, dann genügt ein solcher Austausch nicht. Der Schritt vom „Labor künstlerischer Produktion“ zum Freizeit- und Unterhaltungsort ist sehr klein. Worin besteht also die „Mikroutopie“, fragt Bishop und fährt fort: Was ist das Surplus der künstlerischen Kochaktion gegenüber nachbarschaftlichen Kochabenden außerhalb des Kunstkontextes? ${ }^{62}$

Hier werden Fragen angestoßen, die seit den I990er Jahren im Kunstdiskurs als Künstlerkritik verhandelt werden. Der Soziologe Luc Boltanski und die Wirtschaftswissenschaftlerin Ève Chiapello unterscheiden in ihrem Buch Le nouvel Ésprit du Capitalisme (Frz. Der neue Geist des Kapitalismus, I999) zwischen zwei historisch gewachsenen kapitalismuskritischen Tendenzen: der Künstler- und Sozialkritik. Ihr kritisches Potential entwickeln sie dabei dialektisch: Die Künstlerkritik sei antimodernistisch, wenn sie den „Entzauberungsaspekt" hervorhebt und modernistisch, wenn sie sich mit „Emanzipationsbelangen“ auseinandersetzt. Demgegenüber sei die Sozialkritik eher modernistisch, wenn sie Ungleichheiten in den Mittelpunkt stellt und eher antimodernistisch, wenn sie die mangelnde Solidarität in den Blick nimmt und als Individualismuskritik auftritt. ${ }^{63}$

Daran anschließend lässt sich fragen, ob sich im Architekturdiskurs derzeit eine Architektenkritik etabliert, in der sich Künstlerund Sozialkritik in einer übergreifenden Kapitalismuskulturkritik vereinen. Die Vermutung knüpft daran an, dass sich in den MikroUtopoi unterschiedliche Empörungsthematiken der Künstlerkritik (Entzauberung und Emanzipation) und der Sozialkritik (soziale Ungleichheit und mangelnde Solidarität) zeigen und in ihrem kritischen Potential nicht unvereinbar scheinen.

Beuys/Eco: „Soziale Plastik” als „offenes Kunstwerk” In der Moderne wird das künstlerische Tätigsein zur Kritik mit utopischer Bedeutung. Die Kunst lässt die Mannigfaltigkeit möglicher Lebensformen anschaulich werden und kann zur Suche nach humaneren Lösungen motivieren. Dabei werden die Unterschiede zwischen dem Ästhetischen und dem Wirklichen akzentuiert und die utopischen, realitätsverändernden Dimensionen des Ästheti- 
schen artikuliert: Wie sind die Möglichkeiten ästhetischer Erfahrung gesellschaftlich bedingt? ${ }^{64}$

Diese Frage spielt auch in der Kultur der 1960-70er Jahre - zwischen Engagement und Selbstbezogenheit - eine zentrale Rolle. In dieser Zeit werden ästhetische und performative Qualitäten des Offenheitsprinzips erprobt, die für die vorliegende Arbeit von Interesse sind.

In der Gesellschaft des Spektakels der späten I960er Jahre waren Individuen in reglementierten Räumen noch zur Passivität gezwungen, anstatt die eigene Lebensform aktiv und kreativ zu gestalten, so das Verständnis des situationistischen Künstlers und Philosophen Guy Debord. Zur selben Zeit kritisiert der Künstler Joseph Beuys, dass der herkömmliche Kunstbegriff ein inhaltsleerer Akademismus geworden sei, der nicht mehr wisse, was „Kunst ihrem Wesen nach" sei. Über den mithin als tradiert empfundenen Begriff der Plastik entwickelt er einen neuen, erweiterten Kunstbegriff — einen anthropologischen „Jedermannbegriff“—, der sich auf jeden einzelnen auf der Erde lebenden Menschen beziehen kann.

„Wie kann jedermann, ein Gestalter, ein Plastiker, ein Former [der lebendigen Substanz des] [...] sozialen Organismus werden?" “65

In Beuys' Werk, das eine Einheit aus künstlerischem und lebensweltlichem Denken als "Geflecht von Ganzheitsvorstellungen“ mit „unsystematische[r] Offenheit" ${ }^{* 66}$ bildet, fließen spiritualistisches Sendungsbewusstsein und politische Realität unweigerlich zusammen. Im Kontext der Realwirtschaft müsse nun vor allem Arbeit zugunsten des Wachstums der ,sozialen Skulptur“ geleistet werden. An der Stelle, wo

„ die Entfremdung zwischen den Menschen sitzt — man könnte fast sagen als eine Kälteplastik —, da muß eben die Wärmeplastik hinein. Die zwischenmenschliche Wärme [Liebe] muß da erzeugt werden." 67

Er versteht die soziale Skulptur als neue Grundlagenwissenschaft. Erst im Anschluss an diese Erweiterung des Kunstbegriffes werde es für die Menschen überhaupt erst wieder einen Grund geben, Etwas aus Eisen, Holz oder Ton auszudrücken oder Bilder zu malen, zuvor habe „die Kunst [...] keinen Anlass. “68 
Das kognitive Potential von Kunst, d.h. ihre kritische Funktion wird durch Beuys' künstlerische Praxis in anschaulichen Orientierungsvorschlägen vergegenwärtigt. Er begegnet der Entfremdungssituation der Moderne mit sozialem Engagement, d.h. unter Einbezug der Menschen als aktiv Teilhabende und eingedenk aller gesellschaftlichen Sphären (Wirtschafts-, Rechts-, Staats- und Geistesleben). ${ }^{69}$

Ähnlich dazu formuliert der Philosoph und Semiotiker Umberto Eco in einem mit „Form als Engagement“ übertitelten Abschnitt, dass sich der Mensch nicht im ,Tempel seiner Innerlichkeit“" verschließen darf. Denn tut er dies und kultiviert „,seine Reinheit und absolute spirituelle Unabhängigkeit [...], so rettet er sich nicht, sondern löscht sich selbst aus." Eco empfiehlt, dass sich der Mensch in seinem Werk veräußerlichen soll, denn obwohl er sich damit auch an das Werk entfremdet, könne die entfremdende Situation nicht überwunden werden, wenn man sich dem Werk verwehrt. Darin sei die ,einzige Bedingung unseres Menschseins“ zu erkennen. Hingegen ist ,die , schöne Seele ‘ [...] eine Bewußtseinsform, die sich dieser Erkenntnis verweigert."70

Eco expliziert diese Theorie in seiner Schrift Das offene Kunstwerk (1962) als Grundmotiv. Ist ein Werk offen, dann ist die Kommunikation zwischen Produzent*in und Rezipient*in nicht determiniert. Das Werk vervollständigt sich erst im Prozess der Rezeption. Im hypothetischen Modell der Offenheitsästhetik herrscht Freiheit für die Interpret*innen zum Interpretierten beizutragen was sie eben möchten, d.h. die Formen der subjektiven Aneignung sind unbegrenzt; das Werk konstituiert sich mit dezidiert handlungsbezogenem Aspekt durch den Faktor der Mit-Realisierung. ${ }^{\text {I }}$

Dieses modernistische Modell kann zwar prinzipiell auf alle denkbaren Zeiten, Formen und Genres der Kunst angewendet werden, ${ }^{72}$ aber häufig entstehen Konzepte ästhetischer Selbstbestimmung im Kontext von soziokultureller Selbstbestimmung. ${ }^{73}$

Das Schaffen von denjenigen, die der Avantgarde zugerechnet werden, widmete sich vorzugsweise neuen Lebensformen, z. B. die russischen Konstruktivisten; sie wollten keine Kunst im Dienste der Politik bzw. überhaupt Kunstwerke schaffen. An erster Stelle stand bei ihnen der Versuch neue Formen der Kunst als neue Formen der Existenz zu denken. Sie wollten die Grenzen zwischen Kunst, 
Leben und Politik, sowie zwischen Arbeit, Erholung und Freizeit einreißen und folgten dabei einer bestimmten ästhetischen Logik, die im Gegensatz zu einer im Dienste politischer Ziele stehenden repräsentativen Logik steht, ${ }^{74}$ denn im utopischen Denken gibt es noch nichts zu repräsentieren.

So gesehen lässt sich—mit Benjamin-zwischen einer Vereinnahmung des Künstlerischen durch die Politik (Ästhetisierung der Politik) und einer Emanzipation menschlicher Lebensformen durch die Kunst (Politisierung der Kunst) unterscheiden. ${ }^{75}$

\section{Benjamin: Trias „Tendenz-Qualität-Technik” Der Kulturkri-} tiker Walter Benjamin reflektiert in seinem Aufsatz Der Autor als Produzent (1934) die Autonomie des Künstlers. Er widmet sich zunächst dem Schaffen des Dichters/Schriftstellers, überträgt seine These im Textverlauf aber auch auf andere Kunstformen, z. B. das Theater. Diese Übertragung lässt sich auch auf die Mikro-Utopoi anwenden.

Benjamin schreibt, dass auf der einen Seite des Dichters „Freiheit zu dichten, was er eben wolle" steht, auf der anderen Seite aber die Entscheidung, abhängig von der jeweiligen politischen Lage, seine Aktivität in den gesellschaftlichen Dienst-eine Tendenz verfolgend - zu stellen. ${ }^{76}$

Benjamin stellt dem Begriff der Tendenz (Leistung des Künstlers) den Begriff der Qualität (Leistung des Werkes) gegenüber. Der „richtige“ Zusammenhang liege aber in der Kombination beider, denn gute Kunst könne nur mit kritischem Anspruch gelingen. Ein Werk, das die richtige Tendenz aufweist, muss also notwendig jede sonstige Qualität aufweisen, ${ }^{77}$ so Benjamins Eingangsthese, die in seinen Worten ausführlicher lautet:

„[D]ie Tendenz einer Dichtung [kann] politisch nur stimmen [...], wenn sie auch literarisch stimmt. Das heißt, daß die politisch richtige Tendenz eine literarische Tendenz einschließt. [...] [D]iese literarische Tendenz, die implicit oder explicit in jeder richtigen politischen Tendenz enthalten ist-die und nichts anderes macht die Qualität des Werks. Darum also schließt die richtige politische Tendenz eines Werkes seine literarische Qualität ein, weil sie seine literarische Tendenz einschließt." ${ }^{\text {"78 }}$ 
In dieser mäandernden Formulierung wird Benjamins Verständnis eines dialektischen Zusammenhangs von Tendenz und Qualität deutlich. Demnach muss sich ein Werk in die ,lebendigen, gesellschaftlichen Zusammenhänge einstellen"79 und steht damit der Betrachtung von einem ,starren isolierten Dinge: Werk, Roman, Buch" entgegen.

Je nachdem wie ein Werk $z u$ den gesellschaftlichen Produktionsverhältnissen der Epoche steht, ist es von reaktionärem oder revolutionärem Charakter, so die historisch-materialistische Kritik. Das sei aber nicht immer unmissverständlich zu beantworten, deswegen schlägt Benjamin eine abgewandelte Fragestellung zur Funktion des Werkes vor: Wie steht ein Werk in den Produktionsverhältnissen der jeweiligen Zeit? ${ }^{80}$

Anfänglich formulierte er, dass die ,richtige politische Tendenz eines Werks seine literarische Qualität einschließt, weil sie seine literarische Tendenz einschließt", und definiert nun genauer, dass „diese literarische Tendenz [...] in einem Fortschritt oder in einem Rückschritt der literarischen Technik bestehen [kann]. “81

Alleine die Tendenz, also die politische Gesinnung, reiche nicht aus, um revolutionär wirken zu können, die Wandlung vom Autor zum Produzenten müsse vollzogen werden. Dabei ist der Modellcharakter der Produktion maßgebend. Erstens, um andere Produzenten zur Produktion anzuleiten und zweitens, um ihnen einen ,verbesserten Apparat“ zur Verfügung zu stellen. Dieser Apparat ist umso besser, je mehr er aus Lesern oder Zuschauern Mitwirkende macht, also die Konsumenten der Produktion zuführt. Das epische Theater von Bertolt Brecht dient Benjamin dabei als Hauptreferenz: Im Zentrum dieses Modells steht die Veränderung des Funktionszusammenhangs zwischen Bühne und Publikum, Text und Aufführung, Regisseur und Schauspieler. ${ }^{82}$

Entsprechend der ihr zur Verfügung stehenden technischen Möglichkeiten, bringt jede Zeit ihre eigenen künstlerischen Formate hervor, z. B. den Roman, die Tragödie, die Rhetorik oder andere Spielformen am Rande der Literatur. Beispielsweise leiste das Medium Zeitung der „Literarisierung der Lebensverhältnisse“ Vorschub. Die Unterscheidung zwischen Autor und Publikum verschwinde, der Lesende wird zum Schreibenden, er wird Sachverständiger und gewinne damit Zugang zur Autorschaft. ${ }^{83}$ Darin begründet Benjamin den „Umschmelzungsprozeß“ vom Autor zum Produzenten. ${ }^{84}$ 
Die jeweils im Werk verwendete Technik stellt einen neuen Ansatzpunkt dar, um die dabei entstehenden künstlerischen Produkte einer gesellschaftlichen Analyse zugänglich zu machen, d.h. der Technik-Begriff nimmt eine vermittelnde Position ein, zur richtigen Bestimmung des Verhältnisses von Tendenz und Qualität eines Werkes. Benjamin sieht die herkömmliche, aber unfruchtbare Unterscheidung von Form und Inhalt damit dialektisch überwunden. ${ }^{85}$

Außerdem überträgt er seine These auf verschiedene Genres: Literatur $>$ Fotografie $>$ Musik $>$ Theater. Eine erweiternde Übertragung ist auch auf die Produktion von Architektur und Stadt möglich, denn schlussendlich geht es um die Stellung der Produzent*in im Produktionsprozess und die Teilhabe an der Gesellschaft.

Übertragen auf die Mikro-Utopoi heißt das: die politische Tendenz (humanistische Utopie) ist zwar eine notwendige, aber nicht hinreichende Bedingung für die Qualität des Werks (ästhetische und politische Funktion/Wirksamkeit). Erst wenn die eingesetzte Technik (architektonische Minimaltechniken, d.h. Auswahl und Einsatz der Mittel und Methoden, z. B. transdisziplinäre Praxis als Brechen von Kompetenzschranken) stimmt, kann die sozialpolitische Funktion dieses kritischen Architekturansatzes Wirksamkeit erlangen.

Die gegenwärtige kritische Architekturpraxis entsteht als Reaktion auf gesellschaftliche Missverhältnisse und lässt sich als souveräne Kritik der Disziplin an diesen Missverhältnissen verstehen. Aktualisiert man das Konzept „Autor*in als Produzent*in“, kann eine zweifache Solidarität für die Gegenwart zurückgewonnen werden: I) Der*die Autor*in wird vom Selbst- zum Mitgestaltenden; 2) der*die Betrachter*in ändert seine Rolle vom rezeptiv Teilnehmenden zum produktiv Teilhabenden.

Die „Alphabetisierung/Literarisierung der Lebenswelt“" wurde einst als „Transformationsriemen“ der Revolution bezeichnet. ${ }^{86}$ Heute lässt sich vielleicht von der „Alphabetisierung/Qualifizierung der Gesellschaft“ im Sinne des sozialräumlichen Denkens als „Souveränisierung“ sprechen. Souveränität ist hier im Sinne der Selbstbestimmung gemeint. Im vorliegenden Zusammenhang heißt das, dass Souveräne jene sind, die eine sozialräumliche Fragestellung oder Aufgabe selbstbestimmt, d.h. sicher und überlegen erkennen, benennen, beherrschen und lösen können. 
Autonome Architektur und partizipatorisches Bauen Im Vergleich zur Kunst steht die Architektur in einem konkreteren Verhältnis zur gesellschaftlichen Wirklichkeit. Der ästhetische Diskurs um Autonomie und Engagement künstlerischer Praktiken findet sich insbesondere in der Architektur der I970er Jahre wieder. Dort wird der Autonomiebegriff dem partizipatorischen Bauen gegenübergestellt. Der Architekt und Theoretiker Ingo Bohning differenziert in seinem Buch „Autonome Architektur“ und „partizipatorisches Bauen“ (I98I) die wesentlichen Unterschiede der beiden Ansätze; diese Differenzierung ist von besonderer Relevanz für die Diskussion der vorliegenden Arbeit.

Wenn die Architekturdisziplin sich auf ihre ,inneren Werte“ beruft, dann geschieht dies meist auf Grundlage der Geometrie ${ }^{87}$, wie z. B. in der Revolutionsarchitektur im I 8 . Jahrhundert, oder bei neueren Entwicklungen der 200oer Jahre, so etwa im sogenannten Parametrismus, dessen Protagonisten dezidiert mit der neoliberalen Wirtschaftsideologie koalieren, oder, obwohl auf gänzlich andere Weise, in DOGMAs „Project of Autonomy“, das sich dezidiert gegen das kapitalistische Ganze wendet. ${ }^{88}$

Ähnliches vollzog sich Anfang I970er Jahre. Die architektonischen Autonomiebestrebungen dieser Zeit sind als Fliehbewegung vor den vereinnahmenden Tendenzen des Bauwirtschaftsfunktionalismus, d.h. einer kapitalistischen Verwertungslogik, zu verstehen, z. B. zelebrierte die XV. Mailänder Triennale (1973) die Unabhängigkeit der Architektur von jedweder außerarchitektonischen Bindung.

Die Architektur sollte, nachdem die Erfolglosigkeit der funktionalistischen Methode zutage getreten war, nun wieder in den künstlerischen Bereich zurückkehren und ihre Aufgaben als eine Disziplin, die ihren ganz eigenen Regeln bzw. Logiken folgt und den Architekturentwurf ins Zentrum des Schaffens rückt, lösen. ${ }^{89}$ Radikal ließe sich formulieren, dass eine autonome Formensprache sich dem sozialen Anspruch der Architektur und ihrer integrierenden Ästhetik entledigt; aber das bleibt zu hinterfragen.

Aldo Rossi konstatiert in seinem Buch L'Architettura della Città (Ital. Die Architektur der Stadt, I966), dass nicht die sozialen Aktivitäten und Funktionen einer Stadt ihre konstituierenden Merkmale seien, sondern die architektonischen Formen eine Stadt entstehen lassen, womit jedes Bauwerk einen wesentlichen Bestandteil der städtebaulichen Realität ausmacht. Rossi trat 


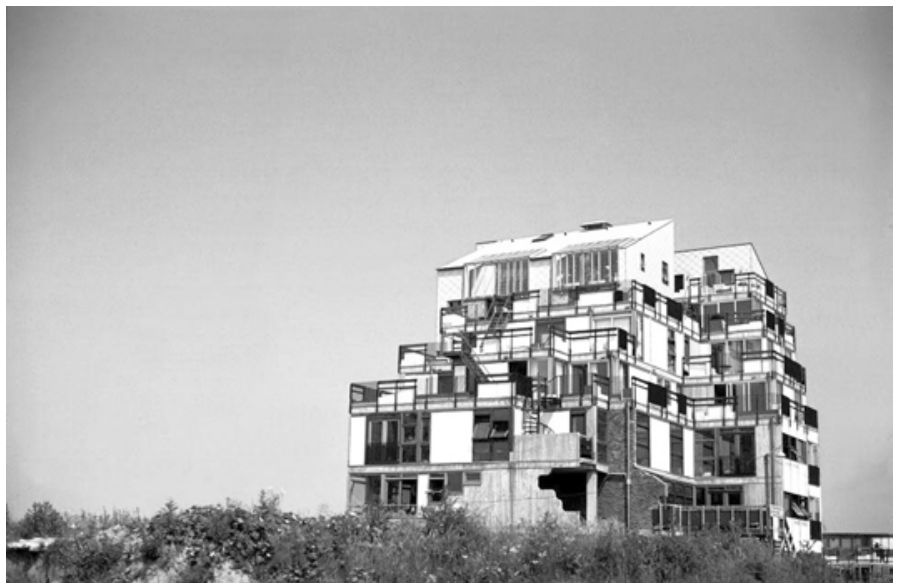

22 Gebäudekomplex der Universität Leuven/Belgien, medizinische Fakultät (Studentenwohnheim, Restaurants, Geschäfte, Schule, Kindergarten und weitere Sozialeinrichtungen), Lucien Kroll, 1970-76

I972-74 seine Architekturlehre als Gastdozent an der ETH Zürich zwar an, um ,die wissenschaftlichen und methodischen Grundlagen einer autonomen Architektur neu zu formulieren“" ${ }^{\circ}$, er nahm aber ,vielmehr eine poetische, ganzheitliche Stellung zwischen Architektur und Gesellschaft ein, und zwar durch das Medium der Stadt" ${ }^{\prime \prime}$, damit oszillierte er zwischen einer Autonomie der Form und einem Funktionalismus der Architektur. Rossi legte ,eine Architekturtheorie der Stadt [vor], die er als Reaktion und Opposition gegenüber einer funktionalistischen Haltung in der Architektur und im Städtebau, die irgendwo ohne Standpunkt war, entwickelt hatte." 92

Während bei der autonomen Architekturästhetik die Reinheit der Form, die Geschlossenheit des architektonischen Werks und die Künstlerpersönlichkeit des Architekten eine zentrale Rolle spielt - wozu Rossi oftmals beispielhaft und etwas undifferenziert herangezogen wird-, kommt es beim partizipatorischen Bauen gerade auf die ,Zerstörung des geschlossenen Werkcharakters und die Dezentralisierung der ästhetischen Erfahrung an." 93

Zur Beschreibung dessen eignet sich Lucien Krolls Gebäudekomplex der Universität Leuven besonders gut, denn hier findet das partizipatorische Moment zu seinem formensprachlichen Ausdruck 
in der realen Umsetzung. Die Ästhetik der Bricolage bzw. Patchworkarchitektur erscheint als Ausdruck einer kollektiven Anstrengung, d. h. zivilgesellschaftlicher Teilhabe, inbegriffen eines Bewusstseins für Ökologie und soziale Diversität. Das Fehlen einer durchgängigen Ordnung, der Mangel an Komposition, Verstöße gegen die Gesetze der Logik und das Nebeneinander heterogener Elemente tragen maßgeblich dazu bei (Abb. 22); diesem Gestaltungsprinzip folgen z. B. auch die Berliner Ökohäuser von Frei Otto (IBA I987).

Aber die Absichten Krolls liegen auf einer anderen Ebene, die ebenfalls in der äußeren Erscheinung zum Ausdruck kommt. In der Gesamtschau sind die Fassadenoberflächen der Bauwerke in Zonen unterteilt, die sich in ihrer plastischen Beschaffenheit unterscheiden. Kroll vergleicht diese Zonen mit organischen Strukturen, z. B. Pilz- oder Schwammkulturen, die einem Wachstums- und Veränderungsprozess unterliegen und damit ein geeignetes Milieu für mikrokosmisches Leben bieten, d. h. günstige Bedingungen für die Entfaltung weiteren Lebens schafften. Das vegetative Prinzip korrespondiere mit Freiheit und individueller Selbstbestimmung und einer emanzipierten und selbstbewussten Haltung des Menschen. Form wird hier im unmittelbaren Zusammenhang mit der Reaktion menschlichen Verhaltens verstanden. ${ }^{94}$ Dementsprechend ist auch die angewandte Planungsmethodik und Arbeitsorganisation strukturiert; wobei verschiedene Arten der Partizipation (subjekt-, aktions- und objektorientiert) zum Einsatz kommen. ${ }^{95}$ Während autonome Bestrebungen die revolutionäre Aktion bevorzugen, sind heteronome Bestrebungen durchdrungen von utopischer Vorstellungskraft. ${ }^{6}$ 

Exkurs:

Macht und Geschlecht 
Im utopischen Denken steckt immer ein Moment der (temporären) (Selbst-)Täuschung. Dieser Moment kann als methodischer Anstoß eine zentrale Funktion erfüllen, denn Idealvorstellungen setzen stillgelegte Triebkräfte der Handlungsfähigkeit frei.

Ein Interpretationsfenster öffnet sich in der Komödie Weibervolksversammlung bzw. Frauen in der Volksversammlung (Ekklēsiázousai, 39I v. Chr.) des griechischen Dichters Aristophanes. Er kritisiert darin unter anderem genau das, für was die griechische Polis in aktuellen Diskursen über die Stadt meist idealisiert wird: der öffentliche Raum als die Sphäre politischen Handelns.

Die Unterscheidung der privaten und öffentlichen Sphäre hat ihren Ursprung im Altertum. Sie geht zurück auf den griechischen oikos, den privaten Haushalt und auf die ekklesia, die Stätte der Politik, wo die alle Mitglieder der polis, d.h. die Bürgerschaft, betreffenden Angelegenheiten aufgegriffen und geklärt wurden. Doch zwischen oikos und ekklesia richteten die Griechen eine weitere Sphäre (agora) ein und zwar die der Коттиnikation zwischen beiden. Die wesentliche Rolle dieser Sphäre bestand darin, einen fließenden Übergang und stetigen Verkehr zwischen dem territorial scharf getrennten Privaten und Öffentlichen sicherzustellen, sie verknüpfte diese beiden Extreme bzw. hielt sie zusammen. Die agora war entscheidend für die Aufrechterhaltung einer wahrhaft autonomen Polis, ${ }^{\mathrm{I}}$ denn die Antike kennt das schützende "Gehäuse eines Staates" noch nicht. ${ }^{2}$ Ohne diese vermittelnde Sphäre hatten weder die polis noch ihre Mitglieder die Freiheit über Sinn und Zweck ihres Allgemeinwohls sowie über das dafür Notwendige zu entscheiden. Dieser Schauplatz, wie jedes andere Gebiet mit zu vielen Eigentümer*innen und strittigen Eigentumsverhältnissen, war ebenso ein Gebiet ständiger Spannung und des „unaufhörlichen Tauziehens wie eine 
Stätte des Dialogs, der Kooperation oder des Kompromisses.“ Die agora kann auf unterschiedliche Weise angegriffen, ihre Integrität in Gefahr gebracht und ihre Rolle verzerrt oder untergraben werden. Eine Form des Angriffs besteht in der totalitären Tendenz, wie die Menschen im 20. Jahrhundert auf unterschiedliche Weise gleich mehrfach erfahren mussten. Das ist eine Erklärung, weshalb diese vermittelnde Sphäre eine so zentrale Referenz der politischen Vorstellungskraft der Gegenwart ist. Die meisten gegenwärtigen Modelle der Zivilgesellschaft, dem angeblich heutigen Äquivalent der agora, erhielten ihre Form im Schatten dieser Erinnerung, so der Soziologe und Philosoph Zygmunt Bauman. ${ }^{3}$

Aber nun zurück zu Aristophanes: Nachweislich war die Parlamentsmitgliedschaft zu jener Zeit ausschließlich Männern vorbehalten, die laut Aristophanes ihre politischen Beschlüsse wie „Narren im Rausch“ fassten, während die Frauen nur für den privaten Bereich, d.h. die soziale Sphäre zuständig waren.

Unzufrieden mit ihren politischen Repräsentanten und ohne eigene Stimme im politischen Leben, vereinte sich eine Gruppe von Athenerinnen in der Überzeugung, diese missliche Lage hin zu einer auf Gleichberechtigung beruhenden Gesellschaft umzugestalten. Wahrlich kühn, als Männer verkleidet, hielten sie Einzug in das Parlament (ein Versammlungsort auf dem Hügel Pnyx), präsentierten ihre politische Agenda-eine frühe Form des Sozialismus - und kamen dann, unerkannt, mit einer Stimmenmehrheit an die Macht. All das geschah in Übereinstimmung mit den Standards der damaligen demokratischen Ordnung. ${ }^{4}$ Ihre subversive Strategie, der Verkleidungstrick, entfaltete im Moment der Täuschung volle Wirkung und veränderte eine dysfunktionale Gesellschaftsordnung hin zum Besseren.

Es lässt sich eine Analogie herstellen zu den gegenwärtigen Mikro-Utopoi, die sich erst einmal als harmlose Nachbarschaftsinitiativen zeigen, sich letztlich aber gegen die durchdringende Kommodifizierung des urbanen Raums richten und darüber hinaus die Umgestaltung gesamtgesellschaftlicher Prozesse im Blick haben. Der erst kürzlich verstorbene Anthropologe, Occupy-CoInitiator und Autor des Buches The Democracy Project (2013) David Graeber schreibt in diesem Zusammenhang von ,ssmall-a anarchists [who] are the real locus of historical dynamism right now."5 
Zum Thema Geschlechtergerechtigkeit gibt es sowohl in der Utopieforschung als auch in der kritischen Architektur- und Stadtforschung vielzählige Forschungsdesiderate. ${ }^{6}$ In den ausgewählten Erzählungen - aus der griechischen Antike, dem französischen Spätmittelalter und der europäischen Neuzeit — steckt bereits eine Fülle von gedanklichen Anstößen und Ansatzpunkten, die für die Gegenwart fruchtbar gemacht werden können. Bereits zu Beginn des I9. Jahrhunderts weist der utopische Sozialist Fourier darauf hin, dass

„, [d]ie Stellung der Frau [...] der Probierstein einer jeden Gesellschaftsordnung [sei]. Am Verhältnis der Geschlechter lasse sich das Verhältnis des Menschen zu sich selbst, zu seiner eigenen Natur ablesen. Darum sei das Maß der Befreiung der Frau das Maß menschlicher Emanzipation."7

Im Übergang vom Mittelalter zur Renaissance verfasste die Schriftstellerin und Philosophin Christine de Pizan Das Buch von der Stadt der Frauen (I405). Die Venezianerin Pizan entwirft im Umfeld des französischen Hofes ein Gemeinwesen, das die Autorin Marit Rullmann als „das erste weibliche Utopia“8 bezeichnet.

Pizan formt den Entwurf zwar nicht explizit aus, d.h. sie nimmt keine genaue Bestimmung von Regeln des Zusammenlebens vor, aber sie gibt Hinweise auf den prinzipiellen Aufbau des Gemeinwesens. Es ist ein Zufluchtsort für Frauen, die dann Zutritt erhalten, wenn sie eine „gewisse Vorbildlichkeit“, d.h. religiöser, intellektueller oder moralischer Art, mitbringen. Die Jungfrau Maria wird als Königin der Stadt berufen und soziale Unterschiede, die Pizan nicht aufhebt, werden durch unterschiedliche städtische Ebenen symbolisiert.

Der Reiz des Buches liegt in erster Linie im stilistischen Vorgehen der Verfasserin, wie die Gesellschaftswissenschaftlerin Bettina Roß schildert:

„Historische Frauen sind der Boden, die Steine und der Bauplan mit denen [Pizan] schreibend die Stadt erbaut. Sie als Autorin ist gleichsam die Architektin der Stadt. Geleitet wird sie dabei durch die Personifizierung von ,Vernunft", ,Gerechtigkeit" und ,Rechtschaffenheit"."9

Die Romanistin Margarete Zimmermann kommentiert in der Einleitung zu Pizans Buch, dass sie so 
„, den gesamten geistigen Vorgang des Schreibens eines Buches zur Verteidigung der Frauen auf die bildlich-konkrete Ebene der Errichtung einer gut befestigten mittelalterlichen Stadt [überträgt].“'Io

Pizan setzt die Kardinaltugenden Vernunft, Rechtschaffenheit und Gerechtigkeit, in dieser Reihenfolge als allegorische Frauenfiguren „überirdischer Herkunft"II ein. Sie steht mit ihnen im Dialog und strukturiert mit ihnen den dreiteiligen Aufbau des Buches.

Außerdem errichtet Christine, so die Selbstbezeichnung der Autorin, die utopische Stadt mit Hilfe dieser Tugenden, indem sie sich z. B. über die Fertigkeiten erkundigt, die nötig sind um das Ausheben der Erde, die Errichtung einer Umfriedung oder die Konstruktion der hohen Dächer der Türme und Paläste zu bewerkstelligen.

Aber nicht nur Pragmatisches ist Inhalt ihrer Gespräche und Diskussionen, es werden zuvorderst sozialethische Fragestellungen ergründet. Beispielsweise fragt Christine Frau Vernunft, wieso Frauen weder bei der Staatskunst noch bei Regierungsgeschäften vertreten sind. Frau Vernunft entgegnet dieser Annahme mit Exempla verschiedenen großen Herrscherinnen vergangener Zeiten. ${ }^{\mathrm{I} 2}$ Das dialogische Grundgerüst des Buches wird insgesamt mit Erzählungen von großen Frauengestalten aus der Frühgeschichte und Antike, aus der Bibel, der antiken Mythologie und der eigenen Zeit veranschaulichend bereichert.

Die Autorin verfolgte mit diesem spätmittelalterlichen Lesebuch verschiedene Ziele. Sie will den Frauen ihrer Zeit und denen späterer Epochen Mut machen und den Blick für die Bedeutung des eigenen Geschlechts schärfen, damit sie sich misogynen Denkweisen selbstbewusst entgegenstellen können.

Pizan kann aus heutiger Perspektive nicht als feministische Autorin insbesondere gelten; das Emanzipationsverständnis nachaufklärerischer Frauenrechtsbewegungen unterscheidet sich von ihrer Position. Dennoch eignen sich Erzählungen, die auf eine Gleichberechtigung der Geschlechter zielen im Allgemeinen gut dazu, die Veränderlichkeit der Utopie vor einem breiteren historischen Hintergrund zu betrachten.

Die Politikwissenschaftlerin und Europapolitikerin Ulrike Guérot greift in ihrem Buch Warum Europa eine Republik werden muss. Eine politische Utopie (2017) auch einen Mythos aus der grie- 
chischen Antike auf: Zeus verliebt sich in Europa, die Tochter des phönizischen Herrschers Agenor. Um die Prinzessin zu verführen, verwandelt er sich in einen weißen Stier, lockt sie auf seinen Rücken, geht mit ihr in das Ägäische Meer und schwimmt nach Kreta, wo er sich in Zeus zurückverwandelt; dieser Verbindung entsprangen drei Kinder. Ob das nun als Verführung (patriarchalische Deutung) oder Entführung (matriarchalische Deutung) gewertet wird, liegt wohl im Auge der Betrachter*in. Auf den Mythos von Zeus und Europa-zugleich Liebesbeziehung und Geschlechterkampf — wird in der Kunstgeschichte immer wieder Bezug genommen. Guérot schreibt, dass die Europa in den bildenden Künsten den jeweiligen politischen Zustand Europas widerspiegelt, d.h. je ,kriegerischer das Treiben der Zeit, desto schlechter ergeht es der Europa in den bildlichen Darstellungen. Die stolze Königstochter verliert ihre Grazie, wird fett oder im Sande kauernd gemalt, sie ist sichtbar unglücklich." ${ }^{33}$ Die Kunst reagiert auf den Umbruch und andauernden Zerfall der europäischen Körperlichkeit seit nunmehr vier Jahrhunderten. Immer wenn nationalstaatliches Aufbegehren spürbar wird und Europa zu zerreißen droht, wird das in der Kunstgeschichte mit starken Bildern reflektiert, die auch heute noch sprechen, weil sie einen Hinweis darauf geben, was in der Debatte um Europa schiefläuft: das Klammern am Nationalstaat. ${ }^{\mathrm{I}}$

Zur Rettung Europas ersinnt Guérot die Vision von einem Umbau des politischen Systems hin zu einer (gemeinwohlorientierten) Europäischen Republik (res publica, Lat. öffentliche Angelegenheit, Gemeinwesen, Gemeinwohl). Als europäische Bürger*innen sind wir der mittelbare Souverän und die Nationalstaaten nur Treuhänder dieser Souveränität. Die Autorin schreibt, dass die Staaten die Souveränität nur von uns geliehen haben und wir sie uns jetzt zurückholen, um die erste transnationale europäische Demokratie aufzubauen: dezentral, regional, postnational, sozial und demokratisch - vorgestellt als ein Netzwerk aus europäischen Regionen und Städten, über das das schützende Dach einer Europäischen Republik gespannt wird und unter dem alle europäischen Bürger in ihren bürgerlichen und politischen Rechten gleichgestellt sind. Die res publica europaea ist ein am Gemeinwohl orientiertes transnationales Gemeinwesen und zugleich Schutzraum für alle europäischen Völker und Ethnien. Sie ist ein Projekt der Grenzenlosigkeit, dessen weltbürgerliche Grundlagen stets den 
Anspruch hatten, normative Avantgarde zu sein und sich über den Globus zu erstrecken. Sie ist ein Projekt der bürgerlichen Emanzipation, gebunden an den allgemeinen Gleichheitsgrundsatz und die Universalität der Menschenrechte der Französischen Revolution. Sie ist ein Projekt der Freiheit, des (sozialen) Friedens, der Demokratie, des guten Regierens und des Rechts! Dies ist der europäische Anspruch im 2 I. Jahrhundert: ein neues Staatsbürgerkonzept. ${ }^{15}$ Die legitime Einschränkung der Freiheit durch den Gleichheitsanspruch wird zur zentralen Stellschraube der Philosophie des modernen Republikanismus in Abgrenzung von einem inzwischen pervertierten Verständnis des Liberalismus. ${ }^{16}$ Guérot schreibt, dass Europa nur als Republik frei sein kann (und nicht als ,,Vereinigte Staaten von Europa"), d.h. frei nach ihrer Emanzipation vom leviathanischen (National-)Staat, von Grenzen und (männlicher) Macht. Greift man den kunsthistorischen Erzählstrang des Mythos von Europa zwischen Verführung und Entführung kritisch auf, wird die historische Aufgabe für Europa im 2 I. Jahrhundert klar: „Das Projekt Europa ist und bleibt die Überwindung der Nationalstaaten."17 Und wenn das soweit ist, dann kann man vielleicht davon träumen, wie es die ungarische Philosophin Ágnes Heller einst ausdrückte und zwar, dass

„, die Frauenbewegung [als] [...] bisher größte Revolution der Menschheit, und im Gegensatz zu allen anderen Revolutionen [...] eines Tages vollendet sein [wird]. “I8 

Mikro-Utopien der Architektur:

Politische Implikationen 
Go ahead, take the road with the pilgrims. Head for the temples of democracy, freedom, growth, reason, liberty, [and] hope. [...] She said, "decode the language, unfold the symbols. [...] Following intellect, they let go of wisdom. And now they'll tell you the soul's a closed system. They sacrificed instinct to phony ambition. [...] But total existence needs meaning and myth. [...] Your loneliness is the symptom, not the sickness." [...] And a voice said, "this is the garden. Now you better start sowing or there won't be a harvest."

Kate Tempest (2019)

Holy Elixir, Strophe $2 \& 4$ (Exzerpt). In: The Book of Traps and Lessons.

Denn mit dem Handwerkszeug des Herren läßt sich niemals sein Haus abreißen.

Audre Lorde (198I)

Du kannst nicht das Haus des Herren mit dem Handwerkszeug des Herren abreißen. In: Dies., Adrienne Rich ( I993) Macht und Sinnlichkeit, S. I99. 
Politik architektonischer Minimaltechniken: Das politische Wesen der Mikro-Utopoi, die durch architektonische Minimaltechniken entstehen, wird hier erfasst. Die politischen Implikationen werden anhand von drei Funktionspaaren charakterisiert:

— kultureller Freiraum/öffentliche Aushandlungszeit

- ökologisches Sorgetragen/demokratische Mitgestaltung

- Arbeitsweise Agency/zivilgesellschaftliche Teilnahme und -habe.

Der Gesellschaftsprozess und daraus resultierende politische Fragestellungen prägen die Basis ihrer Entstehung, d.h. die soziale Dimension des Ästhetischen.

Lokalismus und Postwachstum: Die Praxis lokaler Kleinsteingriffe steht in der Kritik; ihre globale Wirkmacht wird infrage gestellt. In Gegenüberstellung dazu steht der Ansatz einer Postwachstumsökonomie als Kritik des Gegenwärtigen und Vision für Zukünftiges, worin das Potential lokalen Handelns begründet liegt.

Kulturelle Partikularität und partikulare Erzählungen: Während die Moderne von kulturellen Dichotomien geprägt ist, bildet sich in der Kultur der Postmoderne eine politische und kulturelle Differenz heraus, womit das Phänomen des Singulär-Pluralen entsteht. Im Übergang von der Postmoderne zur Globalisierungsmoderne bilden sich Mikro-Utopoi, d.h. partikulare Architekturutopien heraus. Die Neukonzeption des Denkmodells Utopie kann dadurch nachgewiesen werden. 


\section{Politik architektonischer Minimaltechniken}

Ein architektonischer Mikro-Utopos entsteht bzw. architektonische Minimaltechniken kommen unter bestimmten Bedingungen zum Einsatz, deren Wirkebenen sich differenziert betrachten lassen: Kontext, Formgebung und Methodik. Diese haben Einfluss auf die jeweilige mikro-utopische Qualität. Im Folgenden werden die ästhetischen Implikationen als Trägerschicht von außerästhetischen Bedeutungen identifiziert, d. h. die politischen Implikationen werden präzisiert (Tab. 4).

Kontext: Freiraum und Aushandlungszeit Der typische örtliche Kontext eines Mikro-Utopos wurde zunächst als „Leerraum“ bezeichnet und sein ästhetisches Wesen, z. B. eine unbestimmte, programmatisch frei bespielbare, urbane Brachfläche, entsprechend beschrieben. Im Folgenden wird das politische Wesen dieses örtlichen Kontexts als ,,kultureller Freiraum“ präzisiert.

Ein unbespieltes Terrain ist erst einmal nichts weiter als Raum und kann sich so ,jeglichem Dasein ohne irgend ein Präjudiz“ öffnen. Es erlaubt menschliche Begegnungen, die auf einem genutzten Gebiet nicht möglich wären; damit ist der neutrale Raum ein bedeutsamer soziologischer Typus, der sich überall wiederfindet, schreibt der Soziologe Georg Simmel in seinem Aufsatz Über räumliche Projektionen sozialer Formen (I903). Und weiter: Ein ,leere[r], unokkupierte[r] Grenzbezirk“, befähigt zu ,positiven Diensten“, weil er als neutrale Zone eine verbindende Funktion, z. B. zwischen gegnerischen oder zerstrittenen Parteien, einnehmen kann. ${ }^{\mathrm{I}}$

Als Grenze wird hier aber nicht ein trennendes Raumelement verstanden, z. B. in Form einer Mauer, sondern ein Grenzbereich 
Tabelle 4: Implikationen für Ästhetik und Politik

\begin{tabular}{|l|l} 
Ästhetische Implikationen & $\begin{array}{l}\text { Politische Implikationen } \\
\text { > Ästhetik }\end{array}$
\end{tabular}

Kontext

\begin{tabular}{|c|c|c|}
\hline Ort & Leerraum & Kultureller Freiraum \\
\hline Zeit & Transformationszeit & $\begin{array}{l}\text { Öffentliche } \\
\text { Aushandlungszeit }\end{array}$ \\
\hline & $\begin{array}{l}\text {, Ästhetik der } \\
\text { begrenzten } \\
\text { Zeitlichkeit }\end{array}$ & $\begin{array}{l}\text { Politik der } \\
\text { freiräumlichen } \\
\text { Aushandlung }\end{array}$ \\
\hline
\end{tabular}

Formgebung

\begin{tabular}{l|l|l}
\hline Materialität & Material as found & $\begin{array}{l}\text { Ökologisches } \\
\text { Sorgetragen }\end{array}$ \\
\hline Konstruktion & Formoffenheit & $\begin{array}{l}\text { Demokratische } \\
\text { Mitgestaltung }\end{array}$ \\
\hline & $\begin{array}{l}\text {, Ästhetik der } \\
\text { experimentellen } \\
\text { Kethodik }\end{array}$ & $\begin{array}{l}\text {, Politik der } \\
\text { sorgetragenden } \\
\text { Mitgestaltung }\end{array}$ \\
\hline Organisation & Kollektivität & $\begin{array}{l}\text { Agency als } \\
\text { Arbeitsweise }\end{array}$ \\
\hline Performanz & Partizipation & $\begin{array}{l}\text { Gesellschaftliche } \\
\text { Teilnahme/-habe }\end{array}$ \\
\hline & , Ästhetik der & $\begin{array}{l}\text { > Politik der } \\
\text { integralen Arbeits- } \\
\text { gemeinschaft }\end{array}$ \\
& Pellaborativen & Performanz
\end{tabular}

wird als verbindendes Raumphänomen konzeptualisiert, das sich insbesondere in gesellschaftspolitischen Transformationszeiten herausbildet bzw. besondere Bedeutung erlangt.

Dazu kann ein Vergleich mit dem Begriff Gegenwart fruchtbar gemacht werden, denn damit wird meist nicht die jetzt-genaue Gegenwart bezeichnet, sondern es ist eine Zeitspanne gemeint, die sich ,diesseits und jenseits dieses bloßen Punktes aus einem Stückchen Vergangenheit und einem Stückchen Zukunft zusammensetzt." ${ }^{2}$ Eine Zustandsbeschreibung der Gegenwart kann damit als Verfassung der Grenze zur Zukunft verstanden werden, z. B. 
zwischen nationalstaatlichen Terrains, lokalen Grundstücken oder auch sozial konstruierten Grenzen (Zugangsberechtigung). ${ }^{3}$

Wo auch immer sich ,zwei Parteien im Konflikt" befinden, z. B. in der Aushandlung über die mögliche Verstetigung eines MikroUtopos, ist es für den Fortgang des Konfliktes von Bedeutung, dass die Beteiligten sich auf neutralem Terrain begegnen können, schreibt Simmel. So wird ein einvernehmliches Entgegenkommen erleichtert, ohne dass die Beteiligten ihr eigenes Hoheitsgebiet verlassen oder das gegnerische Hoheitsgebiet betreten müssen; anders gewendet: es kann eine sozialräumliche Erweiterung des Eigenen in Überschneidung mit dem Anderen stattfinden, sowohl offensiv als auch defensiv. Dabei enthüllt sich der Negationscharakter des Leerraums, auf den alle einen gleichberechtigten Zugriff haben, ,als Träger und Ausdruck soziologischer Wechselwirkung."4

Der typische zeitliche Kontext eines Mikro-Utopos wurde zunächst als „Transformationszeit“ bezeichnet und sein ästhetisches Wesen entsprechend als Übergang von Werden-SeinVergehen beschrieben. Im Folgenden wird diese besondere Zeitlichkeit von Mikro-Utopoi als „öffentliche Aushandlungszeit“" bestimmt und ihr politisches Wesen präzisiert, d.h. als Moment einer möglichen Veränderung begriffen. Die öffentliche Aushandlung intensiviert sich, wenn z. B. die politische Macht wechselt oder marktwirtschaftliche Entscheidungsfindungen sich hinziehen. Bezeichnend dafür ist z. B. der Übergangszustand Berlins in der deutschen Nachwendezeit, das Gefüge von Belgrad und Zagreb nach dem Ende Jugoslawiens, oder die Neuerfindung Detroits als postindustrielle Stadt. 5

Auf unterschiedliche Weise wurden dort jeweils öffentliche Flächen frei, beträchtliche Leer- oder Grenzräume, die dann neu definiert und denen neue Funktionen zugewiesen werden konnten, z. B. die Entwicklung von Pioniernutzungen, wie urbane Gartenund Land(wirt)schaftsprojekte. Der Garten wird dabei meist als letzter Ort der Menschlichkeit inszeniert, der Distanzen abbaut zwischen den Menschen und zur Natur. Man kann sich fragen, ob das eine Form von zeitgenössischem Eskapismus ist oder ein (symbolpolitischer) Ansatz zur Auflösung der einseitigen Naturbeherrschung durch den Menschen? Letztere wird von Horkheimer und Adorno als Ursache der Schwächung und Unmündigkeit des Menschen ausgemacht. 
In Zeiten des unbestimmten Neubeginns geht es letztlich um das freiheitliche Potential des Ausprobierens. Verschiedene Ansätze finden sich in den letzten Jahren vermehrt, jedenfalls in den Metropolen des globalen Nordens, wieder. Beispielsweise werden vormals industriell genutzte Flüsse und Flussufer wieder benutzbar und für die Öffentlichkeit zugänglich gemacht. Genauso beliebt sind temporär autobefreite Straßenzüge (Abb. 23) oder auch langfristig angelegte Projekte, z. B. solche der urbanen Landwirtschaft (Abb. 24); das alles geht meist einher mit einer neuen räumlichen Organisation und architektonischen Ausgestaltung. ${ }^{6}$

Das was zunächst als kultur-experimentelles Testfeld städtischer Entwicklungsstrategien von unten erscheint, kann-im Gegenteil - auch als Instrument der unternehmerischen Stadtentwicklung angelegt sein, z. B. als grüne und kreative Standortaufwertung. Wirtschaftlich weniger attraktive Gebiete werden durch temporäre Nutzungen reaktiviert. Der Erfolg ephemerer Prozesse ist deshalb interessant für die Wirtschaftsförderung. ${ }^{7}$ In einem solchen Fall wird kurzzeitige Raumaneignung ermöglicht bzw. toleriert bis zur Wertsteigerung und konventionellen Bebauung des betreffenden Grundstücks; ein sicheres Anzeichen dafür, dass ein Gentrifizierungsprozess im Gange ist. ${ }^{8}$

Wenn sich ein lokaler Freiraum öffnet, in dem ein MikroUtopos Einzug halten kann, dann lässt sich das meist mit übergeordneten, d.h. städtischen, regionalen, nationalen oder globalen Transformationsprozessen in Verbindung bringen. ${ }^{9}$

Im besten Falle findet ein kritischer Rückkopplungsprozess statt. Aus der Kritik am bestehenden Ganzen (Makrogeschehen) wird im Kleinen reagiert und es wird Neues ausprobiert. Daraus entstehen neue Narrative (Mikro-Utopien), die als Kritik und/oder Vision dazu geeignet scheinen in den Diskurs über das große Ganze zurückgeführt zu werden.

\section{Formgebung: Ökologisches Sorgetragen und demokratische}

Mitgestaltung Die typische Vorgehensweise architektonischer Minimaltechniken im Umgang mit Baustoffen wurde zunächst als „Material as found" bezeichnet und die experimentelle Improvisation als ihr ästhetisches Wesen beschrieben. Im Folgenden wird der Einsatz der Materialität in den Mikro-Utopoi als ,ökologisches Sorgetragen“ bezeichnet, denn die oft ressourcenschonende Materialauswahl zeugt von einem ökologischen Bewusstsein der Akteure, 


\section{Politik der freiräumlichen Aushandlung}

transformativ, im Übergang von Werden-Sein-Vergehen, Kombination von Form und Leere

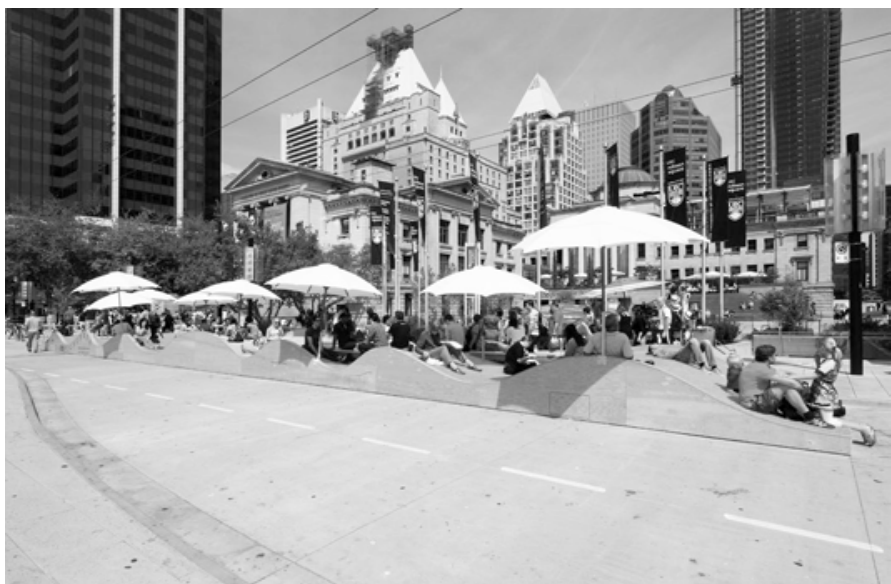

23 Picnurbia, Loose Affiliates, Vancouver/BC, 2011

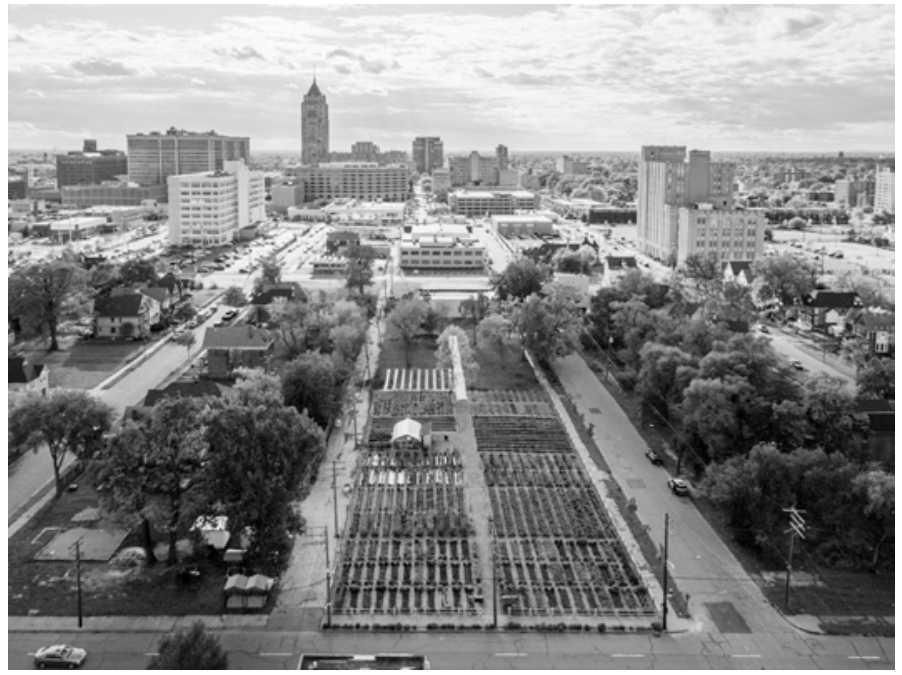

24 The Michigan Urban Farming Initiative (MUFI), Detroit North End, seit 2011 
d. h. die Ästhetik des Recycelns lässt sich—über Budgetfragen hinausgehend - auf eine umweltpolitische Haltung zurückführen. $\mathrm{Zu}$ einer ressourcenschonenden Materialverwendung gehört auch die Umnutzung vorhandener Baustrukturen, wie z. B. im Berliner Modellprojekt ExRotaprint, das sich durch eine gemeinnützige Bodenpolitik auszeichnet. Die ExRotaprint $\mathrm{gGmbH}$ hat durch einen 99-jährigen Erbbaurechtsvertrag eine eigentumsgleiche Position inne, d.h. die Finanzierung und Entwicklung des Geländes wird vollständig durch sie verantwortet, lediglich der Verkauf des Geländes bleibt ausgeschlossen (Abb. 25). ${ }^{\text {Io }}$

Bis auf Ausnahmen ist auch die Kulturproduktion heute weitgehend von einer profitorientierten, neoliberalen Wirtschaftsideologie durchdrungen, das gilt insbesondere auch für die Baubranche. Die Beziehung zwischen Ressourcenverbrauch und Industriekapitalismus ist ursächlich. Die Kritik an der Destabilisierung des planetaren Ökosystems ist von einer kapitalismuskritischen Perspektive kaum zu trennen. ${ }^{\text {II }}$

Der Soziologe Ulrich Beck schreibt in seinem Buch Die Metamorphose der Welt (2017), dass gerade Städte dazu geeignet sind zu neuen „Schauplätzen der Klimahoffnung“ zu werden. Keine Organisationsform sei besser gerüstet, um mit den ,facettenreichen Architekturen der politischen Entscheidungsfindung im 2 I. Jahrhundert zu experimentieren, sie zu erfinden und tatsächlich einzuführen“; wozu Mikro-Utopoi im kleinen Maßstab beitragen. Er stellt seine Vision der Ökologisierung der Städte dem Bestreben gegenüber, städtische Klimainitiativen lediglich auf technokratische Eingriffe in die Infrastruktur zu begrenzen und so der neoliberalen Forderung nach der „unternehmerisch handelnden“, auf Kapitalakkumulation fixierten Stadt zu entsprechen, so warnen kritische Stadtforscher*innen vor den postpolitischen Tendenzen der Nachhaltigkeit. ${ }^{\mathrm{I} 2}$ Die technikoptimistische Fortschrittsidee der Moderne, die sich auch in vielen Smart-City-Programmen wiederfindet - mit Ausnahmen, z. B. der Stadt Barcelona — ist im Angesicht der ökologischen Katastrophe nicht mehr haltbar. Obwohl die umweltschädlichen Exzesse des Spätkapitalismus nur im globalen Verbund zu lösen sind, sind es lokale Initiativen, die als Testfelder dienen können. Beck plädiert für „Weltstadtallianzen“ der „,vereinten Städte“, die über nationalstaatliche Interessen hinausgehende Zusammenschlüsse bilden. ${ }^{13}$ 


\section{Politik der sorgetragenden Mitgestaltung}

eingebettet, adaptiv, umweltbewusst, modular, mobil, kleinteilig

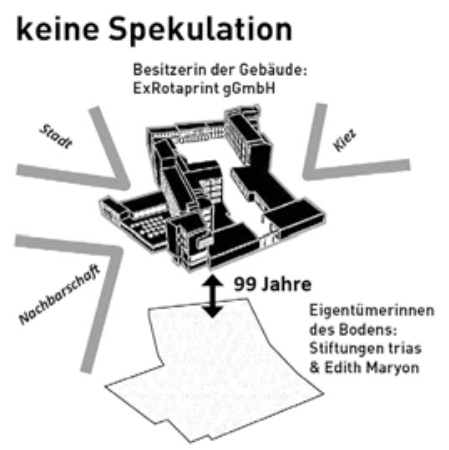

25 Ex-Rotaprint, Berlin-Wedding, seit 2007

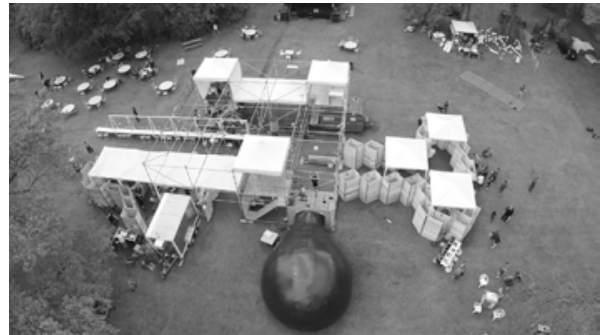

26 Festivalarchitektur Babel im Park, On/Off, Hildesheim, 2017

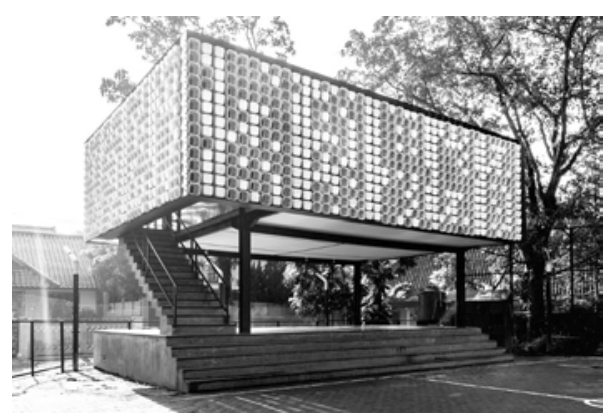

27 Microlibrary Taman Bima (Pilotprojekt), SHAU Architects, Bandung/Indonesien, 2016 
Die typische Bauweise eines Mikro-Utopos wurde zunächst als „formoffen“ beschrieben, denn sein ästhetisches Wesen kann als einladende Geste verstanden werden, die eine versöhnende Wirkung auf den*die Betrachter*in bzw. Besucher*in ausübt. Im Folgenden wird das politische Wesen der formoffenen Konstruktion über den Begriff der ,,demokratischen Mitgestaltung“ erfasst. Die Ästhetik der Formoffenheit lässt sich also auf der politischen Ebene mit der Grundidee des öffentlichen Raums verknüpfen.

Der stets neu zu konzeptionierende öffentliche Raum bzw. die Öffentlichkeit, ist eine der Grundlagen demokratischer Gesellschafen, die sich in einem Prozess des ständigen Werdens befinden. Mitgestaltung bedeutet sich im Austausch zu verändern, Andere willkommen zu heißen und neue Gemeinschaften zu bilden. ${ }^{14} \mathrm{Im}$ imaginären Vorgriff auf Noch-nicht-Existierendes steckt die Triebkraft demokratischer Entwicklung, so der amerikanische Philosoph und Pädagoge John Dewey. ${ }^{15}$

Das Wesen der Demokratie liegt wesentlich in ihren dynamisch-provisorischen Aushandlungsprozessen begründet. Die Offenheitsästhetik des Unfertigen kann als ästhetische Über-/ Umsetzung demokratischen Werdens verstanden werden. Eine einsehbare, offen gestaltete Konstruktion, die ohne Zutrittskontrolle auskommt, spiegelt eine nicht-hierarchische Idee von Kultur bzw. kulturellem Leben wider, z. B. bei der Festivalarchitektur von Babel im Park, die ,um eine Leere herum“ angeordnet ist. Die Gruppe ON/OFF versteht ihr Projekt als ,,moderne Interpretation einer Agora“, die mit einer „Doppelfunktion als politischer und kommerzieller Raum“I6 es sowohl den Besucher*innen als auch den Künstler*innen erlaubt, aktiv und passiv an allen Interventionen, die während des Festivals stattfinden, teilzunehmen (Abb. 26).

Auch die langfristig angelegte Projektinitiative Microlibraries, die der Verbreitung gemeinschaftlicher Leseeinrichtungen dient, wird von SHAU Architects in Zusammenarbeit mit der lokalen Gemeinde geplant und umgesetzt. Das architektonische Konzept sieht vor, den Boden funktionsoffen freizugeben, während sich die Bibliothek jeweils auf einer erhöhten Etage befindet (Abb. 27). ${ }^{17}$

Als Ausgangspunkt einer solchen sozialräumlichen Kommunikation kann eine Verweigerung der Vereinsamung dienen. Während Isolierung nur den politischen Bereich des Lebens betrifft, berührt die Vereinsamung das menschliche Leben in seiner Gesamtheit, 
d. h. den Untergang der privaten Individualität und die Zugehörigkeit zur Welt, schreibt die politische Theoretikerin Hannah Arendt. Totalitäre Systeme können nicht existieren, ohne den öffentlichen Bereich des Lebens zu zerstören, das gilt auch für die totale Ökonomisierung der menschlichen Lebenswelt. Obwohl Arendt die totalitären Regime des 20. Jahrhunderts, die deutsche NS-Diktatur und die kommunistische Sowjetdiktatur, im Blick hat, kann man sie mit Adorno lesen und seinen Blick auf die Ökonomisierung der Lebenswelt auf das impersonale Diktat des Neoliberalismus übertragen. ${ }^{18}$

Durch die Isolierung der Menschen werden ihnen ihre politischen Fähigkeiten genommen; doch die totalitäre Herrschaft ist mit dieser Isolierung nicht zufrieden und zerstört das private Leben ebenso.

„, [Totalitäre Herrschaft] basiert auf Vereinsamung, auf der Erfahrung absoluter Nichtzugehörigkeit zur Welt, was eine der radikalsten und verzweifeltsten Erfahrungen des Menschen ist." 19

Durch die Auflösung traditioneller Gemeinschaften, z. B. familiärer Verbünde, dörflicher Strukturen oder ethnischer Zugehörigkeiten, findet die Verwirklichung des Gemeinwohls in sich neu formierenden Gemeinschafen statt. Ihre Vorgehensweise kann immer nur ein provisorischer, stets unfertiger Zustand sein. ${ }^{20}$ Aber gerade das Bewusstsein über den Prozess des Werdens bzw. die Einwilligung in das Unfertige unterscheidet die Demokratie von anderen politischen, insbesondere totalitären Systemen. Die Demokratie und das demokratisch gesinnte Individuum bleiben im Zustand einer immerwährenden offenen Konstruktion. Der Richtwert ihrer Selbstdefinition bleibt in die Zukunft projiziert; ihre Grenze ist der Horizont. $^{2 \mathrm{I}}$

Der Philosoph Jürgen Habermas beschreibt in seinem Buch Strukturwandel der Öffentlichkeit (1962) die neue bürgerliche Öffentlichkeit des I8. Jahrhunderts in Westeuropa; er rekonstruiert damit ein Stück der Vorgeschichte von Demokratie. ${ }^{22}$ Aber während in dieser Zeit noch das Bürgertum die Schalthebel der Macht bediente, werden heute machtpolitische Entscheidungen oftmals zugunsten von global agierenden Konzernen getroffen, die damit nicht unwesentliche Bereiche des öffentlichen Geschehens mitbestimmen, z. B. das Recht auf informationelle Selbstbestimmung. 
Die Öffentlichkeit ist weder sozial neutral noch steht sie automatisch im Dienste eines allgemein Besseren oder Besten; man sollte sich zurückhalten sie als unfehlbar gutes Gewissen der Demokratie zu idealisieren oder gar zu romantisieren und sie damit ihrer eigentlichen Stärke zu berauben, warnt der Historiker Paul Nolte. ${ }^{23}$

Der Zustand des öffentlichen Raums kann als Gradmesser von Freiheit (negativ oder positiv) und als Anzeiger von Herrschaftsverhältnissen dienen. Das lässt sich leicht mit der Frage überprüfen, wer bzw. welche (Teil-)Öffentlichkeit sich uneingeschränkt zeigen, bewegen und äußern darf, sowohl kritisch gegenüber Gegenwärtigem als auch progressiv im Hinblick auf Zukünftiges?

Politik organisiert sich an der Schnittstelle zwischen privatem und öffentlichem Leben. Dabei kolonisiert sie unsere Vorstellungen, formt unsere Bedürfnisse und prägt unsere alläglichen Handlungen mit ihren Regeln. Derselbe Prozess kann einen entscheidenden Raum des Widerstands beschreiben; jede demokratische Politik der Opposition bzw. Emanzipation ,muß auf diesem Terrain kreativ arbeiten." ${ }^{24}$

Die menschliche Freiheit - programmatisch offen, spielerisch, selbst- und geschichtsvergessen - ist ein klassisches Thema der I968er. Die Libido ist nicht disziplinierbar, sie ist frei, getrieben von Lustgewinn und aufgeladen mit utopischem Überschuss. Im Zuge der studentischen Revolte um I967/68 wurde das freiheitlich-spielerische Lustprinzip der Gegenkultur bzw. -öffentlichkeit dem zwanghaften Realitätsprinzip der bürgerlichen Öffentlichkeit gegenübergestellt. ${ }^{25}$

Während der soziale Klassenkampf in den marxistisch dominierten Kulturdiskursen dieser Zeit eine zentrale Rolle einnahm, stellte Arendt das Gemeinwohl und die Organisation des Zusammenlebens in den Fokus ihrer Schrift Vita Activa. Oder vom tätigen Leben (1958). Durch praktische Politik, die von der Übereinkunft vieler Menschen abhinge, könnten Probleme moderner Gesellschaften gelöst werden, z.B. das Verschwinden des öffentlichen Raums zugunsten des privaten Raums in der Neuzeit.

Dazu gehört im Kern politisches Handeln und die aktive Staatsbürgerschaft jeder/s Einzelnen, die zunehmend durch die Bürokratie, d. h. die Herrschaft des Niemand ersetzt werde. Arendt reaktiviert das Sprechen und Handeln philosophisch als die „,höchsten und menschlichsten Tätigkeiten“; diese betreffen den Zwischenraum in dem sich die Menschen bewegen und bilden sich zugleich 
in ihm. Ein wortloses Handeln bzw. Handeln ohne Kommunikation gibt es nach Arendt nicht, denn es wäre ein Handeln ohne Handelnde.

Die eigentlichen Produkte des Handelns und Sprechens sind Geschichten, die keine Autor*in haben; Handeln ist daher niemals in Isolierung möglich. Das Handeln ist bereits seit der Antike die politische Tätigkeit par excellence, denn es ermöglicht selbst einen Anfang zu machen. Es gibt einen erkennbaren Anfang des Handelns, aber dann wird es endlos fortgeführt und hat keinen Zweck, den man in Gewissheit verfolgen könnte; Handeln und Sprechen sind vielmehr Selbstzwecke, ihr Vollzug ist das Bewirkte oder das Werk. ${ }^{26}$

Arendts Handlungsbegriff ist untrennbar mit ihrem performativen Machtbegriff verbunden; Macht ist immer Machtpotential, niemand besitzt Macht, sie ,entsteht zwischen Menschen, wenn sie zusammen handeln, und sie verschwindet, sobald sie sich wieder zerstreuen.“

„, Macht ist, was den öffentlichen Bereich, den potentiellen Erscheinungsraum zwischen Handelnden und Sprechenden, überhaupt ins Dasein ruft und am Dasein erhält.“"27

Methodik: Agency und Teilnahme/-habe Die typische arbeitsmethodische Organisation eines Mikro-Utopos wurde zunächst als digitalgestützte „Kollektivität/Kollaboration“ und „Partizipation" bezeichnet und die daraus resultierende performative Ästhetik beschrieben. Im Folgenden wird die politische Bedeutungsebene präzisiert, wobei arbeitsstrukturelle Fragestellungen aufgeworfen werden und die Teilnahme/-habe der Zivilgesellschaft problematisiert wird.

Zur Einordnung des veränderten gesellschaftlichen Rollenbildes von Architekt*innen folgt eine kurze historische Rückschau: Während in den I920er Jahren die Rolle des Architekten noch als Wohlfahrtshelfer für die Bevölkerungsmassen verstanden wurde, beginnt sich in den I96oer Jahren - aus der Kritik an den sozialen Verfehlungen des modernistischen Städtebaus ${ }^{28}$ — der architektonische Blick vom gebauten Objekt auf die sozioökonomischen Bedingungen zu verschieben. Der (städtische) Raum wird von dem Soziologen Henri Lefebvre als ,,soziales Produkt“"29 theoretisiert. In dieser Zeit bildet sich allmählich auch eine alternative Planungs- 
kultur heraus; z. B. stellte der amerikanische Planer Paul Davidoff die Annahme eines allgemeinen Wohls, aus dem ein bester Plan abgeleitet wurde, infrage und plädiert in seinem Aufsatz Pluralism and Advocacy In Planning (1965) für eine Planungsmethodik, bei der das Gestalten für und mit machtlosen Bevölkerungsgruppen im Vordergrund steht; wobei der Architekt noch in der Anwaltsrolle auftritt.

Die Wissenschaftlerin Sherry P. Arnstein legt in ihrem Aufsatz A Ladder of Citizen Participation (1969) ein Stufenmodell zur Klassifikation von Bürgerbeteiligungsverfahren vor. Und der Planer John F. C. Turner spricht sich in seinem Buch Verelendung durch Architektur. Plädoyer für eine politische Gegenarchitektur in der Dritten Welt (I976) für eine Selbstermächtigung der Nutzer*innen aus. ${ }^{30}$ Im Planungsdenken bildet sich das Gewahrwerden über die Heterogenität der Gesellschaft zunehmend ab; komplexe Zusammenhänge, inklusive der zivilgesellschaftlichen Gestaltungskraft werden zur Grundbedingung planerischen Handelns. ${ }^{3 \mathrm{I}}$

In der Planungskultur der I990er Jahre beginnt sich die Kulturtechnik Agency herauszubilden. Parallel dazu wird im Architekturdiskurs der Begriff (critical) spatial agency popularisiert, ${ }^{32}$ in der Fachkundige und Laien als gleichberechtigte Agent*innen derselben Sache verstanden werden. Dabei liegt der Fokus auf

- den Handlungsmöglichkeiten von Individuen innerhalb von Gesellschaften;

- den Bedingungen der Handlungsfähigkeit gesellschaftlicher Akteure, individuell und sozial;

- der Einflussmächtigkeit in Anbetracht ihres sozialen Daseins. ${ }^{33}$ Die Kulturtechnik Agency ist ein Kernstück der relationalen Soziologie und bildet damit eine transdisziplinäre Schnittstelle. Hier werden zentrale Dichotomien, durch die die Soziologie seit ihren Anfängen geprägt war, zusammengeführt: Handlung/Struktur, Bewusstsein/Sein, Natur/Kultur, Gesellschaft/Individuum, lokal/ global. ${ }^{34}$

In der Organisationsstruktur und im Rollenverständnis der Architekturkollektive bildet sich auch der Strukturwandel der heutigen Arbeitswelt ab. Diese ist im Wandel von einer Erwerbsund Lohnarbeitswelt, d.h. der bürgerlichen Leistungsgesellschaft hin zu einer projektabhängigen, integralen Arbeits- und Organisationsstruktur begriffen. 
In Einzelprojekten formieren sich lokale Arbeitsverbünde, z. B. im Modellprojekt Haus der Statistik (HdS) in Berlin-Mitte (Abb. 28), das nach Io Jahren Leerstand seit 2015 kooperativ und gemeinwohlorientiert entwickelt wird. Auf Hinwirken der HdS-Initiative, einer Gruppe engagierter Künstler*innen, Architekt*innen, Kulturschaffender und Politiker*innen, konnten die Pläne für den Verkauf an Investoren und der geplante Abriss verhindert werden. Mit dem Erwerb des Gebäudes durch das Land Berlin von der Bundesanstalt für Immobilienaufgaben (BImA) Ende 2017 wurde der Weg für eine gemeinwohlorientierte Entwicklung auf dem Areal frei. Im Bestand und durch ca. 65.000 $\mathrm{m}^{2}$ Neubau entstehen Raum für Kunst, Kultur, Soziales und Bildung, bezahlbares Wohnen sowie ein neues Rathaus für Mitte und Verwaltungsnutzungen. Um dieses Ziel zu erreichen, wurde eine neuartige Akteurskonstellation geschlossen; die fünf Kooperationspartner (Koop5) - die Senatsverwaltung für Stadtentwicklung und Wohnen, das Bezirksamt Berlin-Mitte, die landeseigenen Gesellschaften Wohnungsbaugesellschaft Berlin-Mitte (WBM) und Berliner Immobilienmanagement (BIM), sowie die ZUsammenKUNFT Berlin e.G. - arbeiten seit Januar 20I 8 kooperativ und in gemeinsamer Verantwortung an der gemeinwohlorientierten Entwicklung des HdS. ${ }^{35}$

Einen anderen Ansatz verfolgt das internationale Netzwerk Cooperative City, das sich zur Aufgabe gemacht hat widerstandsfähige und integrative lokale Gemeinschaften, Einrichtungen und Dienste aufzubauen und zu stärken. In ihrem Buch Funding the Cooperative City (Abb. 29) untersuchen sie, wie Bürgerinitiativen, Genossenschaften, gemeinnützige Unternehmen, Community Land Trusts, Crowdfunding-Plattformen, Ethikbanken und Antispekulationsstiftungen aus den regulären Dynamiken der Immobilienentwicklung ausbrechen und neue Mechanismen für den Zugang, den Kauf, die Renovierung oder den Neubau von Gebäuden für Gemeinden einrichten. Anhand von konkreten Modellen der Gemeindefinanzierung und Zivilökonomie werden hilfreiche Ressourcen vorgestellt und eingeführt. Als Zielgruppen werden dabei Gemeindeorganisationen, Initiator*innen von Bürgerräumen, aber auch kooperationsbereite private Bauträger, Gemeinden und EU-Institutionen angesprochen. ${ }^{36}$

Die Organisationsfrage ist ein wiederkehrendes Thema linkspolitischer Debatten, die heute erneut gestellt wird. Bezogen auf die neuen Raumunternehmer*innen der Mikro-Utopoi und ihre ,integ- 
rale [Form der Projekt-]Organisation“37 bleibt die Frage offen, ob sie als Avantgarde, d.h. als lokale Elite oder „High Bohème““38, gar als ,organische“39 oder ,kollektive Intellektuelle“40 verstanden werden können. Oder sind sie Teil des neuen Prekariats ${ }^{4 I}$

Obwohl die Intervention des/der ,kollektiven Intellektuellen“ bzw. eines „Intellektuellenkollektivs“ auf der professionellen Arbeit Einzelner beruht, versucht dieser Typus den Gefahren des Personenkultes zu entgehen. Entgegen dem Prinzip des/r ,organischen Intellektuellen“ ist hierbei ein zentrales Anliegen die Stimme der Unterdrückten hörbar zu machen und nicht in ihrem Namen zu sprechen. Das steht im Widerspruch zum klassischen Typus engagierter Linksintellektueller, die sich als Weggefährt*innen einer Partei oder Organisation verstehen und damit die soziale, kulturelle und politische Kluft verschweigen, die sie objektiv von denen trennt, deren Interesse sie zu vertreten behaupten; die Menschen können dabei in den Dienst politischer Ziele gestellt oder gar zu Objekten der Intervention gemacht werden.

In der Geschichte der politischen Theorie verändert sich das Subjekt der gesellschaftlichen Transformation: Heute liegt die Hoffnung auf Transformation nicht mehr bei der Arbeiterklasse (Marx) oder bei den Intellektuellen (Mannheim), sondern die Motivation geht hauptsächlich von der (sich selbst ermächtigenden) Zivilgesellschaft aus. ${ }^{42}$

Die Partizipation engagierter Bürger*innen, d.h. der Einsatz der Zivilgesellschaft wird oftmals als gelungene Projektarbeit verstanden bzw. dargestellt; dabei ist sie projektabhängig und auf unterschiedlichen Ebenen kritisch zu bewerten. Kommt es durch die Prozessorientierung in der Planung und durch das Mainstreaming des Ephemeren zu einer Machtverschiebung hin zur lokalen Ebene? Zur Beantwortung dieser Frage sind zwei Aspekte zentral:

I) Machtpolitisch: Im Regieren über Gemeinschaften, d.h. in der Bestimmung über Teilnahme, Einsatz und Engagement der Zivilgesellschaft kommen auch Formen der Exklusion (un/bewusste inklusive bzw. exklusive Solidarität gegenüber bestimmten Bevölkerungsgruppen) zum Tragen;

2) Austeritätspolitisch: In der Übertragung staatlicher Verantwortlichkeiten, z. B. auf das Ehrenamt von Kulturschaffenden, kommen Formen der zivilgesellschaftlichen Selbstausbeutung zum Tragen. ${ }^{43}$ 


\section{Politik der integralen Arbeitsgemeinschaft}

basisdemokratisch, aushandelnd, prozesshaft, veränderlich

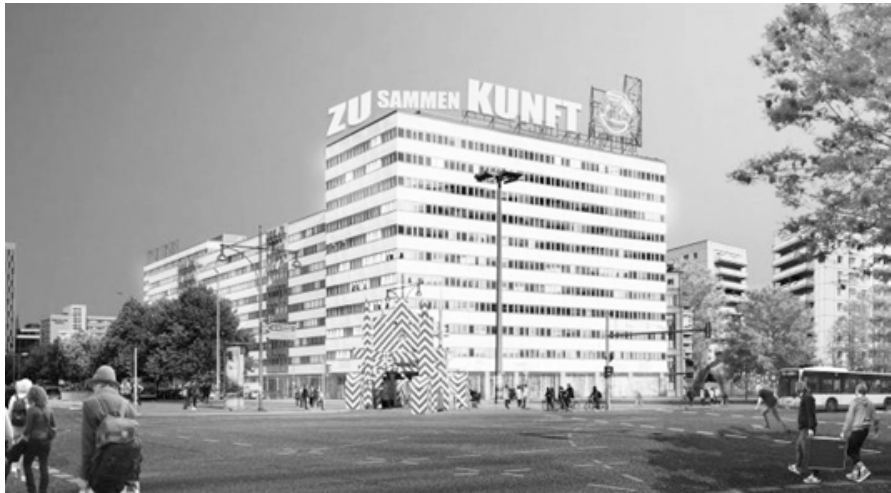

28 Haus der Statistik, RaumlaborBerlin/ZUsammenKUNFT

Berlin e.G., Genossenschaft für Stadtentwicklung, seit 2015

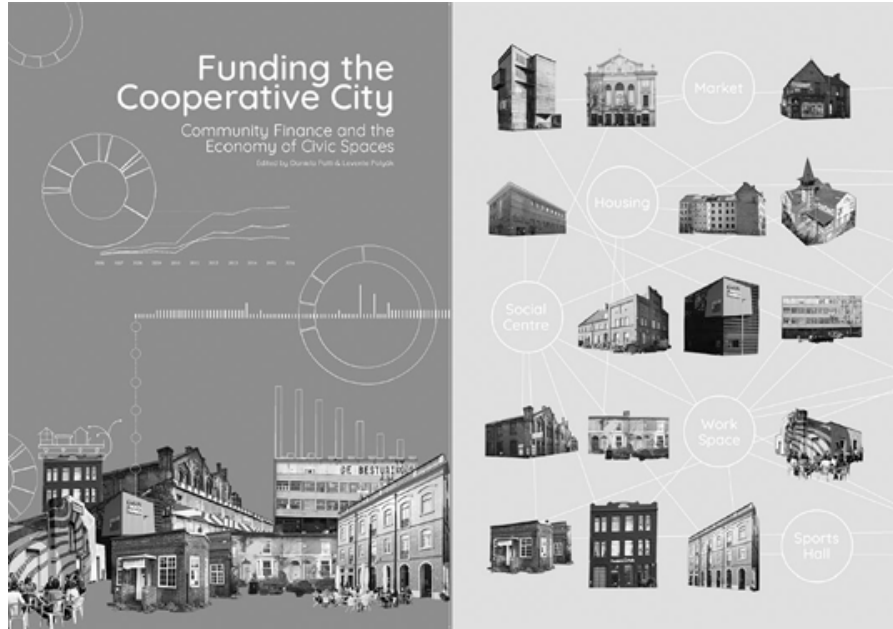

29 Finanzierungshandbuch für gemeinschaftliche Stadtentwicklung, Funding the Cooperative City, Magazine for Urban Partnerships, 2017 


\section{Lokalismus und Postwachstum}

Weltweit werden alternative Formen des sozialökologisch nachhaltigen Lebens und solidarischen Wirtschaftens in unzähligen lokalen und regionalen Projekträumen erprobt, wie z. B. in inkludierenden Kulturprojekten, selbstorganisierten Wohn- und Nachbarschaftsinitiativen, (urbanen) Landwirtschaftskooperativen, (ruralen) Permakulturkollektiven, in der Transition-Town-Bewegung, die teils lokale Währungen einführt oder auch in Energiegenossenschaften; dabei werden in vielen Ansätzen neue ökonomische Modelle, wie die Kreislaufwirtschaft, ausprobiert. ${ }^{44}$

Einerseits lassen sich darin experimentelle Schritte, hin auf der Suche nach humanistisch und ökologisch verträglich gestalteten Zukunftsvisionen entdecken, in denen Mensch und Natur versöhnt miteinander leben. Sie zeichnen sich durch Überschaubarkeit, Authentizität und Gemeinschaft aus und hegen die Hoffnung über sich selbst hinaus als Stimulantia zu wirken, d. h. als Mittel mit anregender Wirkung zur Nachahmung. Andererseits lässt sich der „Fetischisierung lokaler Räume, der Unmittelbarkeit und des Ephemeren [und anderen] Partikularismen“ eine sozialromantische Weltflucht attestieren; die lediglich als Zufluchtsorte vor den „Zumutungen des globalen Neoliberalismus"45 dienen und damit als Sedativa, d. h. als systemisch irrelevante Beruhigungsinseln wirken.

In der Ethik des Lokalismus zeichnet sich ein Dilemma der politischen Linken der vergangenen Jahrzehnte ab, die nunmehr als inkohärente Bewegung zwar für soziale Gerechtigkeit kämpft, die ein schlüssiges Programm aber ablehnt. Mit der neoliberalen Ideologie ist der Gegner ausgemacht, aber gemeinsame Ziele, um den Weg eines Wandels zu beschreiten, fehlen. Dementsprechend 
hinterlassen sie eher den Eindruck einer kleinteiligen und räumlich zersprengten Opposition.

Die mangelnde Geschlossenheit lässt sich nachvollziehen, wenn man annimmt, dass die einzige Alternative das ist, was die Linke im 20. Jahrhundert als ,Sozialismus“ bezeichnete; ein Begriff der heute vor allem mit staatlicher Lenkung und Wirtschaftsnationalismus in Verbindung gebracht wird und damit scheinbar im Gegensatz zu liberalen Werten steht. ${ }^{46}$

Der antikapitalistische Lokalismus linker Graswurzelinitiativen wird von den Politikwissenschaftlern Greg Sharzer (in seinem Buch No Local, 2012) und Nick Srnicek, Alex Williams (in ihrem Buch Die Zukunft erfinden, 20 I 5) ,präzise und vorsichtig“47 demontiert. Sharzer zufolge geht der Lokalismus von falschen Grundannahmen aus und zwar, dass gemeinschaftliche und kollektive Werte unter einer maßstäblichen Hochskalierung (up-scaling) Schaden nehmen würden und die Konzentration von politischer und wirtschaftlicher Macht außerdem per se gesellschaftliche Ungleichheit befördere. Und eine weitere falsche Grundannahme sei der Glaube, dass es möglich wäre sozialistische Alternativen auf der Mikroebene im kapitalistischen Ganzen zu implementieren, d.h. langfristige Gegenstrategien und Netzwerke über die Methode der subversiven Durchdringung zu entwickeln und sich damit der Marktlogik zu entziehen bzw. sich in ihr als Alternativen zu behaupten..$^{8}$ Diesen Annahmen stellt Sharzer eine kritische Lesart Kapitalismus-intrinsischer Logiken gegenüber, z. B. die notwendige Einverleibung von außerhalb des Marktes Liegendem. Er zeigt damit die limitierte Wirkung kleinmaßstäblicher Systemalternativen auf; davon ausgehend, dass erst eine bessere Systemkenntnis dazu beitragen kann den notwendigen Wandel anzustoßen. ${ }^{49}$

Srnicek und Williams stellen der ,horizontalen“ Folklorepolitik von Graswurzelbewegungen (Utopien von unten) ,vertikale“ hegemoniepolitische Alternativen (Utopien von oben) gegenüber. Für sie stehen systemische Strukturüberlegungen im Vordergrund; ihr Plädoyer für Utopie zielt ab auf das Herrschaftssystem als Ganzes,${ }^{50}$ denn ein Problem der Ideologie des Lokalen bestehe darin, dass der

„Versuch die großen systemischen Unübersichtlichkeiten auf die leichter handhabbare Sphäre lokaler gesellschaftlicher 
Zusammenhänge herunterzubrechen, letztlich die strukturelle Vernetztheit der heutigen Welt leugnet."5I

Srnicek und Williams plädieren für die Rückeroberung der ,,Modernisierungsinitiative" durch eine global aufgestellte Linke, die für Fortschritt und universelle Befreiung einsteht..$^{52}$ Sie skizzieren die wichtigsten Tendenzen im gegenwärtigen Kapitalismus als „Krise der Arbeit“ und der ,gesellschaftlichen Reproduktion“. Genau dort müsse eine solche Bewegung ansetzen, um systemrelevant wirksam werden zu können. ${ }^{53}$ Sie refokussieren die Kritik an der Schuldenpolitik und an der gesellschaftlichen Ungleichheit auf das ,Ende der Arbeitsgesellschaft" und zeigen Wege zum Erreichen dieses Ziels auf, z. B. die Einführung eines Grundeinkommens für die Bevölkerung und die Einführung einer Finanztransaktionssteuer, d. h. die Besteuerung von (meist kurzfristig angelegten) Transaktionen des Finanzsektors; eine Forderung, die schon die globalisierungskritische Vereinigung ATTAC (Association pour la Taxation des Transactions financières et pour l'Action Citoyenne) ihrer Gründung (1998) zugrunde legte. ${ }^{54}$

Auch der Kapitalismuskritiker Paul Mason plädiert für radikale Reformen, die weitgehend ,von oben“ durch den Staat durchgesetzt werden müssten. Die Idee einer gerechten Globalisierung könne nur gerettet werden, wenn der Neoliberalismus beseitigt, $d$. h. die Hochfinanz unterdrückt, die Sparpolitik rückgängig gemacht, in grüne Energien und gut bezahlte Arbeit investiert und von der Vergesellschaftung von Schulden abgesehen werde. Darüber hinaus könne das planetarische Ökosystem nur gerettet werden, wenn der Kapitalismus überwunden würde — das sei die eindeutig schwierigere Aufgabe - , wobei Mikroebenen und -mechanismen eine bedeutende Rolle spielen. ${ }^{55}$

Der kritische Stadtforscher Neil Brenner beschreibt eine Vision des Kollektivs Atelier d'Architecture Autogérée (AAA): Sie imaginieren Räume, die unter neoliberalen Stadtentwicklungstendenzen gelitten haben und machen sie zu Ankerzentren alternativer Stadtgestaltung, kollektiver Selbstverwaltung und des gemeinsamen Lebens (Abb. 30 bis 32). Der visionäre Ansatz des Architekturkollektivs kann als Prozess des Gemeinschaffens [commoning] verstanden werden. Gestalter*innen tragen dann dazu nicht nur durch die räumliche Reorganisation von Wohn- und Arbeitsstrukturen bei, sondern sie geben auch organisatorische Impulse mit dem Ziel sozialen Bedürfnissen zu dienen, die Stadtbewohner*innen zu 


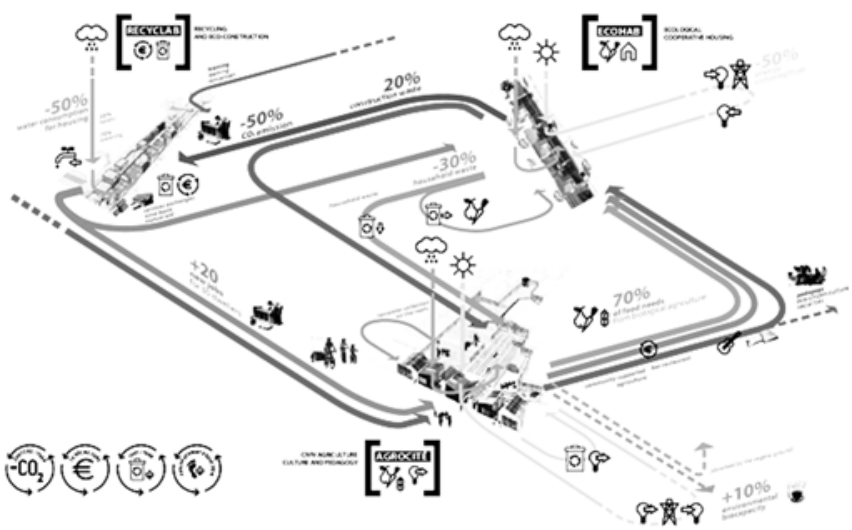

30 R-Urban, Pilot-Basiseinheiten und Kreisläufe von Atelier d'Architecture Autogérée (AAA), Colombes, île de France, 2009-17

ermächtigen und zu einer echten städtischen Öffentlichkeit beizutragen. Denkbar ist z. B. die Transformation rückständiger bürokratischer Strukturen und des Prinzips Privateigentums, sowie Alternativen zu städtischen Grundstücksmärkten und profitorientierten Immobilieninvestitionen. ${ }^{56}$

Die Postwachstumsdebatte zeichnet sich generell, neben dem Plädoyer für radikale staatspolitische Reformen - das betrifft v. a. die Demokratisierung von Wirtschaft und Technikentwicklung, die Einkommensumverteilung und die Neubewertung von Arbeit und sozialer Absicherung - auch gerade durch einen Fokus auf kleinteilige Alternativen und selbstorganisierte Nischenprojekte aus, die von neuen Gemeinschaften und Kollektiven getragen werden. ${ }^{57}$

Kritik und Vision der Postwachstumsökonomie Der Grundkonsens postwachstumstheoretischer Ansätze lautet: Wirtschaftswachstum-gemessen am Bruttoinlandsprodukt (BIP) - ohne Naturzerstörung ist eine Illusion. Damit wird die Schrumpfung dieses Wachstums in Industrieländern zu einer Notwendigkeit. Der Verzicht auf gewohnte Annehmlichkeiten - die nicht unbedingt welche sind, zieht man die Grenzen der persönlichen Freiheit beim globalen Ressourcenverbrauch oder dem Statuszwang — kann 


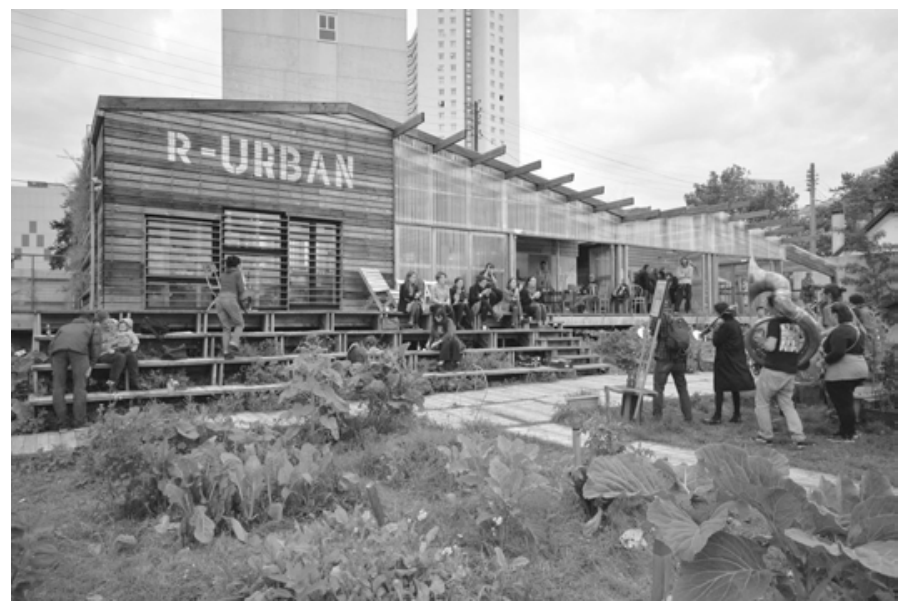

31 Eco-Box in Colombes und die teilhabende Bewohnerschaft

durchaus eine befreiende Wirkung haben. ${ }^{5}$ Die Transformation zu einer Postwachstumsgesellschaft muss friedlich sein und kann von unten kommen, sie läuft auf die Überwindung des Kapitalismus hinaus, wobei die Geschlechtergerechtigkeit ein zentrales Thema ist. ${ }^{59}$

Der Volkswirt Niko Paech setzt bei den Konsument*innen an, die mit dem Verzicht auf Überflüssiges die Nachfrage im Stande wären $\mathrm{zu}$ verändern-entsprechend würde sich das Angebot anpassen — und bezeichnet als Postwachstumsökonomie eine Wirtschaft, die

„, ohne Wachstum des Bruttoinlandsprodukts über stabile, wenngleich mit einem vergleichsweise reduzierten Konsumniveau einhergehende Versorgungsstrukturen verfügt. Die Postwachstumsökonomie grenzt sich von landläufigen, auf Konformität zielende Nachhaltigkeitsvisionen wie ,qualitatives‘, , nachhaltiges', ,grünes', ,dematerialisiertes ‘ oder ,decarbonisiertes ‘ Wachstum ab. Den vielen Versuchen, weiteres Wachstum der in Geld gemessenen Wertschöpfung dadurch zu rechtfertigen, dass deren ökologische ,Entkopplung ' kraft technischer Innovationen möglich sei, wird somit eine Absage erteilt."60

Kulturelle Freiräume können als Teil von gegenhegemonialen Transformationsbewegungen verstanden werden. ${ }^{61}$ 


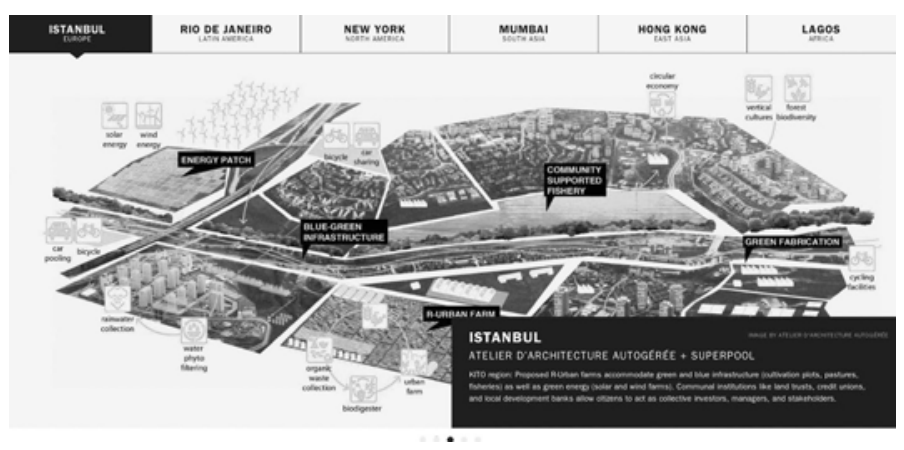

32 Istanbul. AAA + Superpool. KITO-Gebiet: Vorgeschlagene r-urbane Farmen beherbergen grüne und blaue Infrastrukturen (Anbauflächen, Weiden, Fischerei), sowie grüne Energieerzeugung (Solar- und Windfarmen). Kommunale Institutionen wie Land trusts, Kreditgenossenschaften und lokale Entwicklungsbanken ermöglichen den Bürger*innen, als kollektiv Investierende, Manager und Interessenvertreter*innen zu agieren.

Eine bestehende Unzufriedenheit kann konstruktiv genutzt werden, d.h. aus „spezifischen Krisenherden“ können Handlungsfelder entwickelt werden, die wiederum als Vorlage für ,handhabbare Strategien der Krisenbewältigung“ dienen (Tab. 5). In konkreten Handlungsfeldern ist immer Verantwortung mit im Spiel; in kleinen Wirkungsformaten noch mehr als in einem abstrakten Willen, der sich auf das große Ganze bezieht. Wirkliche Verantwortung kann nur für jene Räume übernommen werden, deren Gestaltung den Menschen konkrete Eingriffsmöglichkeiten verschafft und deren wahrnehmbare Resultate bewertet werden können. ${ }^{62}$ Die Spezifika jeweiliger Orte werden durch lokales Wissen und möglicherweise bereits vorhandenes lokales Engagement unterstützt, was der Anpassungsfähigkeit des jeweiligen Projekts an die partikularen Gegebenheiten zuträglich ist und damit zielgerichteter wirksam zu werden vermag, auch wenn es sich nur über einen bestimmten Zeitraum abspielt. ${ }^{63}$

Das wirkt selbst dann sinnstiftend, wenn jene Orte nur den „selbstbewussten Denkhorizont des Subjekts erweitern“64 und neue Erzählungen und Raumbilder, in denen unter Umständen Szenarien einer Postwachstumsgesellschaft imaginiert werden, in 
Tabelle 5: Postwachstumsökonomische Ansätze

\begin{tabular}{|c|c|c|}
\hline & $\begin{array}{l}\text { Postwachstum } \\
\text { als Kritik }\end{array}$ & $\begin{array}{l}\text { Postwachstum } \\
\text { als Vision(en) }{ }^{68}\end{array}$ \\
\hline $\begin{array}{l}\text { Kontext der Frei- } \\
\text { heit } \\
\text { (Ästhetik der } \\
\text { begrenzten Zeitlich- } \\
\text { keit, Politik der } \\
\text { freiräumlichen } \\
\text { Aushandlung) }\end{array}$ & $\begin{array}{l}\text { Konsumkulturkritik, } \\
\text { Neoliberalismuskritik }\end{array}$ & $\begin{array}{l}\text { Suffizienzorientiert, } \\
\text { Postkapitalistisch }\end{array}$ \\
\hline $\begin{array}{l}\text { Form der Gleich- } \\
\text { berechtigung } \\
\text { (Ästhetik der expe- } \\
\text { rimentellen Konst- } \\
\text { ruktion, Politik der } \\
\text { sorgetragenden } \\
\text { Mitgestaltung) }\end{array}$ & $\begin{array}{l}\text { Ökologische Kritik, } \\
\text { Feministische Kritik, } \\
\text { Nord-Süd-Kritik }\end{array}$ & $\begin{array}{l}\text { Institutions- } \\
\text { orientiert, } \\
\text { Gleichberechtigt } \\
\text { (Geschlechter, } \\
\text { Ethnien, Klassen) }\end{array}$ \\
\hline $\begin{array}{l}\text { Methodik der } \\
\text { Solidarität } \\
\text { (Ästhetik der kolla- } \\
\text { borativen Perfor- } \\
\text { manz, Politik der } \\
\text { integralen Arbeits- } \\
\text { gemeinschaft) }\end{array}$ & $\begin{array}{l}\text { Arbeitsökonomische } \\
\text { Kritik, Sozialpoliti- } \\
\text { sche Kritik }\end{array}$ & $\begin{array}{l}\text { Solidarökonomisch, } \\
\text { Gemeinwohl- } \\
\text { orientiert }\end{array}$ \\
\hline
\end{tabular}


Kritik und Vision von Postwachstumsstrategien korrespondieren mit den Ideen der aufklärerischen, humanistischen Utopie auf allen Ebenen architektonischer Minimaltechniken:

- Kontext der Freiheit: Freiräume in Transformationszeiten nutzen.

- Form der Gleichberechtigung: Ökologisch-demokratisches Bewusstsein stärken.

- Methodik der Solidarität: Handlungs- und Arbeitsgemeinschaften aufbauen.

Der Zusammenhang der ästhetischen und politischen Ebenen architektonischer Minimaltechniken sei noch einmal zusammenfassend erläutert und in Korrespondenz mit Tabelle 4 und 5 idealisch dargestellt:

- Ästhetik der begrenzten Zeitlichkeit und Politik der freiräumlichen Aushandlung (Kontext der Freiheit): Auf der Ebene lokaler Freiräume wird in politischen Aushandlungszeiten Neoliberalismuskritik geübt, z. B. an der Ökonomisierung der Lebenswelt. Eine progressiv-utopische Handlungsweise bzw. Reaktion darauf ist z. B. die Schaffung eines suffizienzorientierten Mikro-Utopos.

- Ästhetik der experimentellen Konstruktion und Politik der sorgetragenden Mitgestaltung (Form der Gleichberechtigung): Auf der materialtechnischen und konstruktiven Ebene wird produktionspolitische Kritik geübt, z. B. im Sorgetragen über die Ökologie und demokratische Mitgestaltungsprozesse. Eine progressiv-utopische Handlungsweise bzw. Reaktion darauf ist z. B. die Schaffung eines institutionsorientierten, d.h. nicht wachstumsfixierten Mikro-Utopos.

- Ästhetik der performativen Kollaboration und Politik der arbeitsteiligen Gemeinschaft (Methodik der Solidarität): Auf der Ebene des gemeinschaftlichen Engagements wird arbeitsökonomische Kritik geübt, z. B. an der traditionellen Arbeitsteilung. Eine progressiv-utopische Handlungsweise bzw. Reaktion darauf ist z. B. die Bildung dynamischer, überregionaler Netzwerke, die die Gestaltung von solidarökonomischen und gemeinwohlorientierten Mikro-Utopoi anstreben. 
Mikro-Utopoi physisch erlebbar werden. Solche raumweltlichen Szenarien können durchaus Mut machen und Wirkmacht haben. Denn durch verantwortliches Handeln im Kleinen stellt sich unter Umständen ein gesellschaftliches Bewusstsein her, das, demokratisch gedacht, Auswirkungen auf die Vorstellungen eines globalen Besseren haben kann, wie stockend oder ineffizient das auch zunächst scheinen mag. ${ }^{65}$

Auch wenn der ursprüngliche Grund der Zusammenkunft verschwinden mag, wie das bei temporären Architekturprojekten oft der Fall ist, kann die Begegnung der beteiligten Akteure über das Projekt hinausgehend Bestand haben, z. B. wenn temporäre Arbeitsgemeinschaften in Projektnetzwerken weitergeführt werden. ${ }^{66}$

Der Systemumbau (Top-down-Planung) und die Basisarbeit (Bottom-up-Organisation), als zwei Seiten derselben Suchbewegung, müssen nicht gegeneinandergestellt werden. Im Zusammenwirken bedarf es letztlich einer Einbindung von sozialem und kulturellem Engagement auf der realpolitischen Ebene, um nachhaltig wirken zu können. Die erste Instanz einer gemeinsamen Aushandlung kann z. B. die städtische Basisinfrastruktur bilden, die sowohl Nutzungsfragen (Grundstück, Wasser, Strom) als auch die Klärung von Eigentums- und Finanzierungsmodellen betrifft; und damit einhergehende Rechte, Pflichten und Ziele der Projektbeteiligten, z. B. die interne und externe Organisation und Verwaltung langfristiger Transformationsprozesse und -strategien, wie eine Institutionalisierungs- oder Netzwerkstrategie. ${ }^{67}$ 


\section{Kulturelle Partikularität und partikulare Erzählungen}

Das Scheitern bzw. die Abwesenheit von Zukunftsentwürfen gilt als konstitutiv für die postmoderne Kultur; die nicht mehr sei als eine „Moderne ohne Illusionen“, so Bauman. ${ }^{69}$ Auch der Medienphilosoph Paul Virilio interpretiert die Postmoderne als eine Zeit der „Krise des ,Erzählens“ an sich“, aber weniger als Erosion der „Fundamente historischen Sinns“, zugunsten von Erzählungen über die „Entwicklung von voneinander unabhängigen Individuen“, sondern mehr als Krise der Erfassung einer-auf die Zukunft gerichteten - Gegenwart. ${ }^{70}$ Die Krise der Erzählung erscheint so als die andere Seite der Krise der Dimension, d. h. als Erosion ,der Messbarkeit eines allen gemeinsam gegebenen sichtbaren Wirklichen“ und damit als „Ausdruck einer Krise der Vorstellung vom Ganzheitlichen".71

Auch Jameson thematisiert die politische Schwäche der Utopie, die in den vergangenen Generationen

„, nicht einmal ansatzweise eine Handlungsanweisung lieferte und kein schlüssiges, historisches und praktisch-politisches Bild vom Übergang zu zeichnen vermochte. ${ }^{\text {} 72}$

Aber es war ihm wichtig - vor dem Hintergrund seines Bewusstseins von einem postmodernen Stillstand, d. h. einer ewigen Gegenwart im Angesicht zwar weit entfernter, aber unvermeidlicher Katastrophen-ein Bekenntnis zum Utopismus abzulegen. In seinem Buch Archeologies of the Future. The Desire Called Utopia and Other Science Fictions (2005) huldigt er der Potentialität der utopischen Dialektik und schließt den ersten Teil seiner Schrift ab mit einer Untersuchung der Utopie und einer Einschätzung ihres politischen Wertes für die Gegenwart. 
Auf der Schwelle von der Moderne zur Postmoderne lässt sich eine politisch-ökonomische Ereignisverdichtung erläutern, ohne die der Eintritt in das ,postideologische Zeitalter“ nach I989 (und damit der Auflösung der dualistisch geprägten Weltordnung kapitalistischer Westen / kommunistischer Osten) nicht denkbar gewesen wäre:73

Im Jahre I97I wurde der Grundstein für das heutige Wirtschaftssystem gelegt, indem der US-Präsident Richard Nixon die Goldbindung des Dollars aufhob. Im darauffolgenden Jahr veröffentlichte der Club of Rome den Bericht Die Grenzen des Wachstums (1972), aus dem hervorging, dass ein unkontrolliertes Wirtschaftswachstum die Menschheit in eine ökologische Krise führen wird. Im Jahre I973 trug sich die erste Ölpreiskrise zu, die den Industriestaaten ihre Abhängigkeit von fossiler Energie demonstrierte. Gleichzeitig brach das Bretton-Woods-Abkommen-die ,stabilitätssichernde Architektur des internationalen Finanzmarktes" seit I944-zusammen, wodurch sich das Finanzmarktgeschehen globalisierte und verselbstständigte; infolgedessen und weiteren Liberalisierungen des Finanzsektors ist auch die Weltwirtschaftskrise $2007 / 08$ einzustufen. ${ }^{74}$

Im Jahre I979 vollzog sich schließlich der Wandel von der fordistischen zur postfordistischen Ökonomie, d.h. verkürzt dargestellt die Verschiebung von einer nachfrage- zu einer angebotsorientierten Wirtschaftspolitik, die die heutige wirtschaftliche Realität konstituiert. ${ }^{75}$

Im selben Jahr veröffentlicht Lyotard Das postmoderne Wissen (I979), in dem er die universellen Metaerzählungen von Freiheit und Aufklärung angreift, die der Geschichte der Moderne ein kollektives Subjekt unterstellten und damit die kleinen Geschichten bzw. Identitäten zugunsten einer übergreifenden Identität auslöschten. ${ }^{76}$ Kaum später veröffentlicht Sloterdijk seine Kritik der zynischen Vernunft ( 1983) - 200 Jahre nach Kants Kritik der reinen Vernunft ( $\mathrm{I} 78 \mathrm{I}$ ) - , eine Text und Bild verschränkende, ideologiekritische Diagnose zum Geisteszustand des ,nachaufgeklärten Zynismus“. Darin schreibt er, dass in der

„,polyperspektivisch zerborstenen Welt [...] die ,großen Blicke" aufs Ganze tatsächlich mehr den schlichten Gemütern, nicht den Aufgeklärten, vom Gegebenen Erzogenen [gehören]. Keine Aufklärung geschieht ohne den Effekt, das 
Standpunktdenken zu zerstören und perspektivisch-konventionelle Moralen aufzulösen; psychologisch geht das mit IchZerstreuung einher, literarisch und philosophisch mit dem Verfall der Kritik."77

Er fährt fort, dass die Kritische Theorie allerdings ein

„, provisorisches Ich der Kritik gefunden hat und einen

,Standort', der ihr Perspektiven auf eine wahrhaft einschneidende Kritik gewährte [...]. Es ist nicht die Basis erhobener distanzierter Kritik, die zu großen Überblicken gelangt, sondern eine Haltung äußerster Nähe - Mikrologie. “78

Obwohl in dieser Zeit noch politische Systeme und Ideen existierten, die zumindest dem Namen nach Alternativen zum Kapitalismus darstellen, erklärte die großbritannische Premierministerin Margaret Thatcher im Jahr I984 die im Aufbau begriffene neoliberale Wirtschaftsideologie für alternativlos und dass es so etwas wie Gesellschaft ohnehin nicht gäbe.

Die US-amerikanische Schriftstellerin und Aktivistin Audre Lorde kritisiert zur gleichen Zeit, dass eine Gesellschaft, die das Gute weniger im Hinblick auf menschliche Bedürfnisse, sondern eher im Hinblick auf Profit definiert

„,immer eine Gruppe von Menschen [braucht], die man durch systematisierte Unterdrückung glauben machen kann, daß sie überflüssig seien, daß sie zu den dehumanisierten Minderwertigen [d.h. Schwarze und Dritte-Welt-Menschen, Arbeiter*innen, ältere Menschen und Frauen] gehören.“

„,Ein Großteil der westeuropäischen Geschichtsschreibung konditioniert uns, menschliche [und kulturelle] Unterschiede in simplifizierter Form als Polaritäten zu sehen: dominierend/ untergeordnet, gut/schlecht, oben/unten, überlegen/unterlegen." 79

Während die Dichotomien der Moderne dazu geeignet waren das Fremde bzw. Andere zu identifizieren und damit Feindbilder und Hierarchien zu konstruieren, etabliert sich in der Postmoderne - in allen gesellschaftlichen Sphären, wie Kultur, Politik, Ökonomie, Ökologie und Geschichte gleichermaßen - eine Kultur des Pluralismus; das ist im Hinblick auf die soziale Emanzipation als Fortschritt zu werten. 
In der Moderne herrschte das Prinzip der Standardisierung vor. Im postmodernen Kulturkapitalismus ist das Singuläre, d.h. das Einzigartige und Besondere, prägend, schreibt Reckwitz. Das gilt sowohl für materielle (Kultur-)Güter wie für Dienstleistungen, sowohl im Mainstream, als auch in der Subkultur. An die Stelle der Massenproduktion uniformer Waren treten „Ereignisse und Dinge [...], die nicht für alle gleich oder identisch sind, sondern einzigartig, das heißt singulär sein wollen. "80 Im Zuge der Digitalisierung schreitet die Individualisierung aller Lebenswelten (mass customization) voran. In der Architektur zählen dazu z. B. ikonische Bauten von Stararchitekt*innen, aber auch kleinmaßstäbliche Architekturprojekte einer kritisch-situativ ausgerichteten Praxis.

Auch der Mensch untersteht dieser postmodernen Logik, denn während in der alten Industriegesellschaft noch formale Qualifikationen und Leistungsanforderungen im Vordergrund standen, geht es ,,in der neuen Wissens- und Kulturökonomie darum, dass die Arbeitssubjekte ein außergewöhnliches ,Profil" entwickeln. "8I $\mathrm{Zu}$ diesem Prozess schreibt der kamerunische Politikwissenschaftler Achille Mbembe, dass der heutige Mensch sich in vielfältiger Weise von dem ,entfremdeten Subjekt der ersten Industrialisierung“ unterscheidet. Das heutige Individuum ist in seinem Begehren gefangen und ist

„,[f]ür sein Vergnügen [...] nahezu vollständig auf seine Fähigkeit angewiesen, sein inneres Leben öffentlich zu rekonstruieren und es wie eine handelbare Ware auf einem Markt anzubieten. [...] [D]ieser Code-Mensch [versucht] sein Verhalten an den Normen des Marktes auszurichten, und zögert dabei kaum, sich selbst und andere für die Optimierung seines Anteils am Vergnügen zu instrumentalisieren. Verdammt zu lebenslangem Lernen, zur Flexibilität, zur Herrschaft des Augenblicks, muss er seine Lage als auflösbares und fungibles Subjekt hinnehmen, um der Forderung zu entsprechen, die ständig an ihn gestellt wird: ein anderer zu werden. “82

Im Prozess der spätmodernen Singularisierung erhält jedes einzelne Phänomen einen unvergleichlichen Stellenwert, nicht zuletzt auch aufgrund von Marktverwertungsinteressen; das widerspricht auch einem Serialitätsprinzip nicht, d.h. Besonderheit und Repetition schließen sich nicht aus. 
Der Prozess der Singularisierung (Vereinzelung/Verselbstständigung) ist Teil des Prozesses der Pluralisierung (Vermehrung/ Vervielfachung) oder anders gewendet: es vollzieht sich eine Pluralisierung des Singulären. ${ }^{83}$ Der einzigartige Mensch, das herausragende Ereignis sind zur Norm geworden. Die totale Diversifizierung zeichnet ein Bild der Welt, in dem sich die Pluralität von Ethien, Religionen, Kulturen, sexuellen Orientierungen und Identitäten als globale Einheit entfalten kann. Das postmoderne Denken beschreitet einen Weg der Befreiung von Identifikationszwängen. Dabei geht es um die Verschiebung bzw. Auflösung der Dichotomie Zentrum und Peripherie, sowohl kulturanthropologisch als auch technologisch.

Im — für die Arbeit zentralen — Begriff der Partikularität liegt die Betonung nicht nur auf der Vielheit (Pluralität) des Besonderen, sondern insbesondere auf der Unterschiedlichkeit (Differenz) der Vielheit des Besonderen. Obwohl auch das Prinzip der Ähnlichkeit - Anerkennung von Gleichheit in der Unterschiedlichkeit —zentral ist für kulturelle Identifikationsprozesse, soll hier die Grundhaltung in der Anerkennung von Vielheit und Unterschiedlichkeit hervorgehoben werden und zwar, dass es nicht nur eine richtige Version gibt, um das einzig Wahre zu erkennen (Tab. 6).

Der Partikularismus ist eine schwache Theorie, die sich durch die Ermächtigung von Kleinsteinheiten, von unten geleitetem Beziehungsdenken auszeichnet, z. B. die Einmischung der Vielen als demokratisches Prinzip oder die Vervielfältigung utopischen Denkens. $^{84}$

Im Universalismus wird hingegen nach universellen Werten und Gesetzen gesucht. ${ }^{85}$ Der Universalismus ist eine starke Theorie, die sich durch ein vereinheitlichendes, von oben geleitetes Regeldenken auszeichnet, z. B. der Kapitalismus oder auch die Menschenrechte. Eine Koexistenz mit Partikularismen ist für den Kapitalismus (als Universalismus) kein Problem. ${ }^{86}$

Die kritische Macht kommt heute von den Rändern der Gesellschaft. Das gilt auch für architektonische Minimaltechniken, die nicht im Zentrum der Macht, sondern auf den Grenzbereichen des Realraums, z. B. auf Brachflächen ihren Ort der Umsetzung finden.

Kulturelle und politische Differenz In dem Moment, als man die Vision einer ,homogenisierenden, ,modernisierenden“ Mission“ aufgegeben hatte, wurde die multi- bzw. transkulturelle Gesell- 
Tabelle 6: Eine begriffsdifferenzierende Übersicht, aufgeschlüsselt nach ihren kulturellen, raumzeitlichen und sozialräumlichen Bedeutungsebenen

\begin{tabular}{l|l|l}
$\begin{array}{l}\text { Struktur } \\
\text { (kulturell) }\end{array}$ & \multicolumn{1}{l}{$\begin{array}{l}\text { Dimension } \\
\text { (raumzeitlich) }\end{array}$} & \multicolumn{1}{l}{$\begin{array}{l}\text { Verortung } \\
\text { (sozialräumlich) }\end{array}$} \\
\hline $\begin{array}{l}\text { singular-plural (ein- } \\
\text { zigartig } \\
\text { vielfältig) }\end{array}$ & $\begin{array}{l}\text { minimal } \\
\text { (sehr klein, gering) }\end{array}$ & $\begin{array}{l}\text { marginal oder } \\
\text { peripher (auf der } \\
\text { Grenze, am Rande, } \\
\text { nebensächlich) }\end{array}$ \\
$\begin{array}{l}\text { divers (unterschied- } \\
\text { lich, ungleich) }\end{array}$ & $\begin{array}{l}\text { liminal (an der } \\
\text { Grenze, Schwelle, } \\
\text { abseits) }\end{array}$ \\
$\begin{array}{l}\text { different (anders, } \\
\text { abweichend) }\end{array}$ & $\begin{array}{l}\text { heterogen (unein- } \\
\text { heitlich, verschie- } \\
\text { den) }\end{array}$ & \\
\hline $\begin{array}{l}\text { partikular (das Ein- } \\
\text { zelne oder die Min- } \\
\text { derheit betreffend) }\end{array}$ & mikro (klein, kurz) & $\begin{array}{l}\text { minor (untergeord- } \\
\text { net, unterlegen) }\end{array}$ \\
\hline
\end{tabular}

schaft realisierbar. Multikulturalismus ist, so Bauman, ,die Trennung der Staatsbürgerschaft von der kulturellen Berufung und Selbstzuschreibung der Bürger; bedeutet, letztere im wesentlichen zur Privatsache zu erklären, die in keiner Weise öffentliche Rechte beeinflußt.“ Die multikulturelle Gesellschaft verhält sich ,,tolerant gegenüber kultureller Differenz, dem freien Fluß kultureller Inhalte und der Freiheit kultureller Wahlen“; sie ist bereit, ,die bewegliche Grenzlinie zwischen akzeptablen Unterschieden des Lebensstils [...] ständig auszuhandeln. “87

Der indische Theoretiker des Postkolonialismus Homi Bhabha weist darauf hin, dass eine ,kulturelle Differenz“ aber nicht als „das freie Spiel von Polaritäten und Pluralitäten“ verstanden werden darf und fährt fort: 


\begin{abstract}
„,Der Widerstreit von Bedeutungen und Werten, der im Prozeß kultureller Interpretation erzeugt wird, ist ein Ergebnis der perplexen Lebensverhältnisse in den liminalen Räumen der nationalen Gesellschaft [...]. Als eine Form der Einmischung hat kulturelle Differenz an den Gesetzmäßigkeiten der supplementären Subversion teil, die den Strategien des Minoritätendiskurses ähnelt. “88
\end{abstract}

Für Bhabha hat die kulturelle Differenz eine einmischende Funktion. Sie funktioniert, ähnlich der Wirkungsweise von Minoritätendiskursen, als ergänzende Durchdringung des gesellschaftskulturellen Mainstreams.

„,Die Frage kultureller Differenz konfrontiert uns mit einer Verteilung von Kenntnissen und Praktiken, die nebeneinander existieren; abseits bedeutet hier eine Form von sozialem Widerspruch oder Antagonismus, die verhandelt werden muß und die nicht einfach aufgehoben werden darf." 89

Bhabha plädiert dafür, dass

„Unterschiede zwischen unverbundenen Orten und Darstellungen des gesellschaftlichen Lebens [...] artikuliert werden [müssen], ohne daß dabei die inkommensurablen Bedeutungen und Urteile überwunden würden, die im Prozeß transkulturellen Verhandelns entstehen." 90

In dieser Zeit der Transformation bilden sich auch zahlreiche, in Abgrenzung zur Moderne stehende Wortkomposita heraus; zur Verdeutlichung soll die nachstehende post-Begriffsauswahl dienen:

Postdemokratie, posteurozentrisch, postfordistisch, postfossil, postfundamentalistisch, postheroisch, Posthistoire, postideologisch, postindustriell, postkapitalistisch, postkolonial, postkritisch, postmigrantisch, postoperaistisch, postpolitisch, postreduktionistisch, postsozialistisch, poststrukturalistisch, posttheoretisch, postutopisch, Postwachstum. ${ }^{9 \mathrm{I}}$

Das Präfix post- zeigt an, dass der den jeweiligen Wortstamm bildenden Begriff, sich überlebt hat und das Begriffskonzept in seiner bisherigen Verwendung bzw. Anwendung neu gedacht oder bewertet wird. Es findet eine kritische Ausdifferenzierung von Begrifflichkeiten statt, die noch der Moderne zugeeignet schienen. Die eurozentrische Perspektive verschiebt sich zugunsten einer 
globalen Perspektive. Die Epoche der Postmoderne geht in die Epoche der „Globalisierungsmoderne“92 über.

Um die Aktualisierung und Anpassung an die Globalisierungsmoderne zu verdeutlichen, wird hier exemplarisch auf das Begriffskonzept „Postdemokratie“ des Soziologen Colin Crouch (gleichnamige Schrift von 2003) Bezug genommen. Darin vertritt er die These, dass die Demokratie im Digitalzeitalter zunehmend degeneriere; bestimmt von — durch Politiker*innen vertretene - Konzerninteressen. Demokratische Institutionen hätten nur noch formal Bestand. Der Neoliberalismus höhle die Mitbestimmungsrechte der Bürger*innen aus und räume den Konzernen, vermittelt durch die Politik, übermäßige Macht ein. ${ }^{93}$ Dieses Konzept müsse allerdings unter Berücksichtigung der veränderten globalpolitischen Lage aktualisiert werden, vor allem bezüglich des Zusammenhangs von Neoliberalismus und Rechtspopulismus. ${ }^{94}$

Alle postmodernen Begriffskonzepte sollten im Spannungsfeld mikro/lokal und makro/global neu gedacht und definiert werden, denn der heutige „kapitalistische Realismus“"95 inszeniert eine Konfrontation mit dem Modernismus nicht länger. Auch die herkömmlichen Politikbegriffe sind in ,einer Art Bereichsdenken, einem Denken in gesellschaftlichen Handlungssphären oder Funktionssystemen verhaftet. " 96

Der britische Historiker Geoff Eley bezeichnet in den I99oer Jahren die Erkenntnis, dass gesellschaftsprägende Sphären bzw. Kategorien wie Politik, Recht, Kultur und Glaube sich gegenseitig durchdringen als antireduktionistische Erkenntnis. All diese Sphären verhalten sich weder zueinander noch zur Wirtschaft und ihren sozialen Beziehungen äußerlich, sondern überlagern und verbinden sich, immer eingebettet in komplexe Einheiten von Struktur und Aktion, unauflöslich und konstitutiv mit konkreten Praktiken und individuellen Leben.

Dies hat das Interesse an den verborgenen Geschichten des Alltags, d.h. an der Mikrohistorie befördert, denn hier kann die Dynamik von diesen komplexen Beziehungen empirisch nachvollzogen werden. Und das kann auch für die Architektur geltend gemacht werden, denn

„, [w]enn Macht sowohl in gesellschaftlichen als auch in formal politischen Strukturen angesiedelt ist, und Kultur sowohl eine Auswirkung als auch ein Medium von Macht und Herrschaft 
ist, dann unterliegen all die banalen Beziehungen des Alltagslebens dem Einfluß der Macht.“97

Die Herausforderung für die politische Theorie dieser antireduktionistischen, postfundamentalen Konstellation-also in Lebenszusammenhängen angesichts der Abwesenheit eines letzten Grundes - liegt in der Neudefinierung der Essenz des Politischen.

„,[I]m postfundamentalistischen Denken [hat sich] eine Differenzierung herausgebildet zwischen dem Bereich der Politik und der [...] Dimension des Politischen: Nennen wir sie die politische Differenz" ${ }^{* 88}$

Zur Erläuterung: Das Politische ist gekennzeichnet von einer kommunikativen Prozesshaftigkeit und von relativer Offenheit, d.h. von Prozessen, in denen etwas politisch ir/relevant wird. Dabei geht es um den kommunikativen Raum - wozu auch der Bereich des Antagonistischen ${ }^{99}$ gehört - , der sich durch solche Prozesse konstituiert, z. B. die kollektive Ordnung.

Die Politik ist gekennzeichnet von regulierten, institutionalisierten staatlichen Prozessen, die auf verbindliche Entscheidungen und Machtausübung zielen, z. B. im Parlamentarismus. ${ }^{100}$

Offene Prozesse lassen sich nicht denken, ohne sie von den regulierten und institutionalisierten Prozessen abzugrenzen; ebenso umgekehrt. Die Offenheit und Dynamik des Politischen muss irgendwann die Aufmerksamkeit der Politik beanspruchen (mit entsprechenden Konsequenzen). Und Politik sollte gegenüber den offeneren Kommunikationsprozessen des Politischen sensibel sein, sonst entfremdet sie sich denjenigen, für die sie Politik zu machen beansprucht; insofern ist sie Teilmenge des sich kommunikativ vollziehenden Politischen. ${ }^{\mathrm{I} I}$

Die Differenzierung zwischen dem Bereich der Politik und der Dimension des Politischen lässt sich bereits, neben Arendt, auf den umstrittenen politischen Denker Carl Schmitt und seine Abhandlung Der Begriff des Politischen (1932) zurückführen. Schmitts berühmtes Kriterium des Politischen "die Unterscheidung von Freund und Feind ${ }^{\text {"102 }}$ enthält allerdings eine totalisierende Politik der Gemeinschaft, die auf eine „Homogenisierung des Gemeinwesens"103 abzielt. Um eben dies zu überwinden muss die Essenz des Politischen neu gedacht werden, z. B. mit dem Philosophen JeanLuc Nancy, der die Schmitt'sche „,Gleichartigkeit des Volkes“ im Sinne einer ,substanzielle[n] Homogenität"“ mit einem Denken 
des Gemeinsam-Seins ersetzt, ,das ,der außerordentlichen Singularität eines jeden ' gerecht wird und jeder Vereinheitlichung widersteht."I04

Aus der Theorie der politischen Differenz ergibt sich ein Verständnis minimaler Politik, d. h. selbst die bescheidensten politischen Handlungsformen-die kleinsten Demonstrationen, die geringsten Proteste, die schwächsten sozialen Bewegungen und architektonische Minimaltechniken, d.h. mikro-utopische Eingriffe in die Gesellschaft — haben potenziell an der instituierenden Dimension des Politischen teil. Darüber hinaus wird mit dem Denken der politischen Differenz der Versuch unternommen

„ die Minimalkriterien solchen Handelns zu ermitteln, also ein Politikverständnis und ein Handlungs- und Subjektmodell zu entwickeln, das dem Machiavell'schen Moment [d.h. ein Moment, in dem das Volk und die Eliten miteinander um Macht und Einfluss ringen] angemessen ist."I05

\section{Mikro-Utopie als neue Theorie utopischen Denkens und Han-} delns Die Politik vermittelt auf der Grenze von Privatheit und Öffentlichkeit. Im Internetzeitalter hat sich diese Grenze allerdings verschoben; es findet eine historische Veränderung des Prinzips Öffentlichkeit statt, in der z. B. das Recht auf Stadt auch eine „,virtuelle“ Dimension annimmt. Durch das Internet und die Sozialen Medien wird die Verteilung von Information bzw. Wissen zur zentralen Fragestellung der Demokratie. ${ }^{\text {Io6 }}$ Der Prozess der Digitalisierung bildet also die Grundlage für die Neuausrichtung des Politischen. In Zeiten der digitalen Kommunikation lässt sich kaum mehr zwischen einer (bürgerlichen) Öffentlichkeit und einer (marginalisierten) Gegenöffentlichkeit unterscheiden.

In der vorliegenden Arbeit wird deutlich, dass die heteronome Geschichte architektonischer Mikro-Utopien den gleichen Anspruch wie andere selbstreflexive Genres in der Welt der Kunst und der Philosophie erhebt, die als utopische Realität verstanden werden und somit Wahrheiten über die Welt offenbaren, in der sie entstanden sind. ${ }^{107}$

Im Gegensatz zu den ,,politisierten Gegen- bzw. Alternativwelten“ der I970er Jahre, z. B. Hausbesetzungen als praktische Testräume für systemkritische Utopien, wird im Architekturdiskurs in und über die I990er Jahre dem pragmatischen Vorrang gegen- 
über dem utopischen Denken eingeräumt. Die Mikro-Utopoi des Berliner Intimraums ${ }^{108}$ der Nachwendezeit entsprangen, entsprechend dem Selbstverständnis der Akteur*innen, einer freiheitlichen Geisteshaltung und einem dem Lustprinzip folgenden Machen und lassen sich demnach als ,regressive Utopien“ verstehen. Es ist eine Zeit in der sich die Neuordnung der Welt gerade erst vollzieht und das gesellschaftliche Wohlstandsversprechen, eine selbstverständlich gewordene Errungenschaft, die Demokratie zu sichern schien.

Heute sind diese „regressiven“, aus dem Spiel entstandenen Utopieansätze in der Realität angekommen und haben sich zu „reaktiv-progressiven“ Utopieansätzen entwickelt, die eine ernsthafte Auseinandersetzung im Umgang mit der neoliberalen Realität (ver-)suchen.

Geht man davon aus, dass die kritische Praxis architektonischer Minimaltechniken eine utopisch motivierte Praxis ist und sich infolgedessen als besonderes geschichtsphilosophisches Modell deuten lässt, d.h. als partikulare Utopie, unterliegt auch sie, die Mikro-Utopie der Ideologiebildung des Singulär-Pluralen. Denn eine partikulare Utopie, verstanden als dissidente oder widerständige Strategie gegen das vorherrschende System, unterliegt derselben kulturalistischen Systemlogik bzw. ist dadurch erst emporkommen, d. h. sie ist ein ihr inhärenter Teil. Was also

„, können wir über unsere eigene Zeit herausfinden, wenn wir Produkte unserer eigenen historischen Einbildungskraft untersuchen? Was erzählen sie uns über uns selbst?"“I09

Das Verständnis eines Mikro-Utopos als offene architektonische Analyse- und Erzählform bzw. utopisches Narrativ zeigt im Kleinen auf, nicht nur ,was wir gegenwärtig sind, [...] sondern, was wir wie und zuweilen auch warum geworden sind und vor allem, wie wir dazu stehen. "I Io Die soziale Funktion des Erzählens liegt in der Ausbildung der gesellschaftlichen Vorstellungskraft begründet.

Die positive Funktion der Utopie besteht darin die bestehende Welt zu erschüttern, indem sie der Gesellschaft neue Erwartungshorizonte eröffnet; wesentlich dabei ist die Bewahrung einer Distanz zur gesellschaftlichen Wirklichkeit.

Sofern die Ideologie die gesellschaftliche Ordnung bewahrt oder sogar verschleiert, wird klar, warum die Utopie von vornherein als Ideologiekritik in Erscheinung tritt. 
„Während die Ideologie im positiven Sinne die phantastische Tendenz der Utopie abwendet, vermag diese, in ihrer positiven Funktion, wiederum den konservativen und verschleiernden Tendenzen der Ideologie entgegenzuwirken, indem sie andere Existenzmöglichkeiten aufzeigt." "I I

Das Erforschen von Utopien, d. h. gesellschaftliche Verhältnisse durch einen auf die Zukunft gerichteten Blick zu untersuchen, kann als Gegenwartskritik verstanden werden. Nur durch eine immer wieder erneuerte Analyse der Gegenwart und ihren Herrschaftsmechanismen - ,mit ihren unzähligen Funktionen, Registern und Dimensionen in Verbindung mit dem unverwüstlichen Willen, die Welt im Sinne einer größeren sozialen Gerechtigkeit zu verändern“- — ist es möglich den vielgestaltigen Kräften der Unterdrückung zu widerstehen und eine Politik zu schaffen oder aufrechtzuerhalten, die das Prädikat demokratisch tatsächlich verdient. ${ }^{\text {II } 2}$

Die Arbeit des Imaginären erkundet die komplexen Beziehungen der Gegenwart (als Überschneidung von Vergangenheit und Zukunft), die mit Hilfe des herkömmlichen Vokabulars bzw. von Sprechgewohnheiten noch-nicht konzeptualisierbar, d.h. begrifflich zu fassen sind. Augenblicke der Angst bzw. des Zweifels schöpferisch zu nutzen bedeutet das Gegenteil von kulturpessimistischem Denken.

Dabei formiert sich eine Vielzahl schwacher MikroUtopoi - auch zur Vermeidung totalitärer Tendenzen ${ }^{113}$ — als neue starke Theorie utopischen Denkens und Handelns. Es geht darum Ziele und Forderungen zu formulieren und mithin eine neue kritische Sprache zu entwickeln, z. B. die der Mikro-Utopie. 



\section{Zusammenfassung}


[I]m Moment beobachten wir die schwierige Geburt einer neuen Art Gemeinschaft aus der realisierten Totalität aller Gemeinschaften der Welt. Sie wird realisiert in Konflikt, Ausschluß, Massaker, Intoleranz, aber immerhin realisiert, denn heute träumen wir nicht mehr vom Welt-Ganzen, wir stehen mit ihm in Verbindung, wir sind mittendrin.

Was traditionell ein universalisierender und vereinheitlichender Traum des Dichters war, wird für uns zu einem schwierigen Eintauchen in eine Chaos-Welt. [...] [Aber] [d]as Chaos ist schön, wenn man all seine Bestandteile als gleich notwendig betrachtet.

Édouard Glissant (2005 [Frz. I996])

Kultur und Identität. Ansätze zu einer Poetik der Vielheit, S. 27. 
Nachdem die Utopie mit dem Eintritt in die "Postmoderne" ab I968 allmählich in Verruf geriet, zeigt sich in den gegenwärtigen kulturellen Diskursen ihre Rückkehr. Der Tief- und Wendepunkt dieser Entwicklung wird vom Zusammenbruch der kommunistischen Regime I989/9I markiert.

Die dazu in der vorliegenden Arbeit Mikro-Utopien der Architektur eingangs gestellte Forschungsfrage lautet:

> Zeigt sich in der gegenwärtigen kritischen Architekturpraxis eine veränderte Erscheinungsform utopischen Denkens und Handelns?

Die dazu eingangs aufgestellte Hypothese lässt sich nun als Antwort, d. h. als Ergebnis der Arbeit formulieren:

> Mikro-Utopoi der Architektur reflektieren die kulturelle Partikularität der Globalisierungsmoderne. Das Utopiemodell der Gegenwart zeigt sich in Form pluraler Mikro-Utopien.

Im Wesentlichen wird nachgewiesen, dass die Utopie bzw. die utopische Praxis

I. historischen Veränderungsprozessen unterliegt: geschichtsphilosophisch, gesellschafts- und architekturtheoretisch.

Daraus folgt, dass

2. die Mikro-Utopien der Architektur an diesen historischen Prozess angeschlossen und als gegenwärtige utopische Praxis eingeordnet werden können.

Mit Hilfe der Begriffsneubildung Mikro-Utopie(n) können gegenwärtige architektonische Handlungsweisen als utopische Praxis neu bestimmt werden. Dabei bezieht sich das Präfix mikro- auf ihre Dimension und der Wortstamm -u-topie auf ihr dialektisches Wesen (Kritik und Ideal). Ihr Anknüpfen an die geschichtsphilosophische Entwicklung der Mikrohistorie im späten 20. Jahrhundert wird dargelegt.

In der Utopiegeschichte orientiert sich der kritische und zugleich idealistische Blick traditionell an der jeweiligen Gegenwart. In der griechischen Antike und in der italienischen Renaissance war das utopische Denken vom Herrschaftssystem der Stadtstaaten geprägt; dies findet seine Entsprechung sowohl in den philosophischen Schriften als auch in den hermetisch-statisch angelegten Idealstadtkonzepten. 
Mit dem technischen Fortschritt im I8. Jahrhundert entstehen utopische Schriften insbesondere als frühsozialistisch-wissenschaftliche Abhandlungen. Parallel dazu, im Zuge der industriellen Entwicklung, entstehen offen-veränderliche Stadtutopien.

In der individualistisch geprägten Gesellschaftsstruktur des 20. Jahrhunderts entstehen sozialphilosophische Schriften zur Utopie, in denen das utopische Bewusstsein des Individuums zur Basis der politischen Vorstellungskraft wird, mit vier unterschiedlichen Zielrichtungen: das Seiende infrage zu stellen (Negation); die mentalen Wünsche mit der materiellen Realität abzugleichen (Intention); das politisch Mögliche zu erörtern (Konkretion); sich kulturell zu aktivieren und zu artikulieren (Motivation).

Parallel dazu entwickeln sich in der Architektur zwei Hauptlinien utopischen Denkens: technische und soziale Utopien. Während die technizistische Linie charakteristischerweise von oben gesteuerte Ansätze vorschlägt, setzt die humanistische Linie von unten, d.h. von den Menschen ausgehend an; das Konzept der MikroUtopie ist im Anschluss an die humanistische Linie zu verstehen.

Im Umbruch von der Moderne zur Postmoderne vollzieht sich eine Veränderung des geschichtsphilosophischen Blicks von den großen heroischen Erzählungen hin zu den kleinen Alltagserzählungen. Das wirkt sich auch auf die Erzählstruktur, Dimension und Verortung der Utopie aus. Im Anschluss an das postmodern-fragmentierte Welt- und Geschichtsverständnis verbindet sich in der heutigen Globalisierungsmoderne das lokale mit dem globalen Denken. In den kulturellen Diskursen ist die Dichotomie von Zentrum und Peripherie schon länger in einem Auflösungsprozess begriffen; dort stehen kulturelle Differenzen gleichberechtigt nebeneinander. Dies bildet die Basis der neuen räumlichen Vorstellungskraft. Die Sozialutopie wird dabei in Form der Mikro-Utopie rehabilitiert.

Die heutige Gegenwart wird weltweit von vielen Menschen als krisenhafte Zeitenwende empfunden. Gerade in den kapitalistischen Peripherien zeigt sich die Problematik des globalen Spätkapitalismus schon seit längerer Zeit besonders deutlich; nun geraten auch die hegemoniepolitisch (immer noch) dominierenden kapitalistischen Zentren unter enormen Transformationsdruck.

In Zeiten der Transformation haben Utopien traditionell Hochkonjunktur. Gegenwärtig treten sie-realisiert mit architektoni- 
schen Minimaltechniken - als Mikro-Utopoi vor dem Hintergrund stadträumlicher Neoliberalisierungsprozesse in Erscheinung. Sie können damit als temporäre Gegenstrategien, im Sinne einer alternativen, kritischen Architekturpraxis verstanden werden. Dafür charakteristisch sind kleinmaßstäbliche, eher unvollkommene Konstruktionsweisen, die oftmals unter prekären Produktionsbedingungen — zurückzuführen auf minimale Budgets - hergestellt werden. Die Projektinitiative geht meist von transdisziplinär arbeitenden Architekturkollektiven aus, die in Verbindung mit zivilgesellschaftlichen und politischen Akteuren jeweils ortsspezifisch drängende Themen bearbeiten und zur Diskussion stellen. Dabei werden Missstände aufgedeckt, die mithilfe von architektonischen Minimaltechniken sichtbar gemacht werden und mithin neue Aufenthaltsorte schaffen. Auf der Suche nach Zukunftsszenarien gemeinschaftlichen Lebens, vorwiegend im städtischen Kontext, vollzieht sich eine Entwicklung mikro-utopischer Denk- und Handlungsstrategien.

Das architektonische Projekt erlangt damit einen konstitutiven Stellenwert für das utopische Denken der Gegenwart. In mikroutopischen Projekten wird dabei keine gesellschaftliche Totalperspektive entworfen, sondern es wird eine analytisch-offene, experimentelle und wachstumskritische Perspektive durch eine sozial engagierte Architekturpraxis zurückgewonnen. Dabei ist eine Entwicklung hin zu offenen Raum-Utopien zu erkennen.

Die damit verbundenen sinnlich-ästhetischen Erfahrungen sensibilisieren uns von Neuem für soziopolitische Fragestellungen. Nicht nur die architektonische Realisation, sondern auch die soziopolitische Intention ist utopisch durchdrungen. Mikropolitische Vorgänge auf der lokalen und kommunalen Ebene, z. B. zivilgesellschaftliche und kulturelle Organisationsformen, stehen in direktem Zusammenhang mit makropolitischen Vorgängen auf der globalen Ebene, z. B. der politischen Ökonomie und Ökologie. Diese werden durch mesopolitische Entscheidungen vermittelt, d.h. auf der Ebene des Regionalen, des Nationalen und von Staatenverbünden. Abstrakte globale Zusammenhänge werden durch konkrete Mikro-Utopien verständlich. Utopische Grundanliegen wie Freiheit, Gleichberechtigung und Solidarität werfen Fragen nach der Würde des Menschen und seiner Stellung in der Welt auf. Dabei werden Machtfragen zum Verhältnis von Individuum (individuelle Selbstermächtigung) und Gemeinschaft (gesellschaftliche 
Handlungsfähigkeit) immer wieder von Neuem gestellt. Nur dann, wenn das Lokale in einer Zusammenschau mit dem Globalen neu gedacht wird, lässt sich zukünftig ein sozialökologisch verträgliches Leben auf und mit dem Planet Erde gestalten. 


\section{Utopie und soziale Realität Nachwort von Jörg H. Gleiter}

Mit Mikro-Utopien der Architektur legt Sandra Meireis eine kritische Theorie mikroarchitektonischer Praktiken vor. In sozialutopischer Perspektive und geschichts- und kulturphilosophischer Vertiefung greift sie jene zeitgenössischen Entwicklungen in der Architektur auf, die als lokal begrenzte, temporäre und kleinmaßstäbliche Aktionen im städtischen Raum unmittelbar in die Gesellschaft hineinwirken, die sich bisher aber der theoretisch-begrifflichen Klärung ihrer Verfahren und Inhalte entzogen haben. Gezeigt wird, wie in den mikroarchitektonischen Praktiken die Utopien als Mikro-Utopien in Architektur und Gesellschaft zurückkehren.

Meireis gelingt es, die mikroarchitektonischen Praktiken in den Gesamtkontext der gesellschaftlichen Entwicklungen der Gegenwart einzuordnen und einer kritischen Bewertung zu unterziehen. Es zeichnet die Arbeit aus, dass sie in einer Reihe jener Formen der kritischen Reflexion steht, die nicht einfach bei der Theorie im Sinne eines Legitimations- oder Metadiskurses stehen bleibt, sondern die gesellschaftliche Wirkung, die die Theorie im Alltag auslöst, in dialektischer Brechung in die Reflexion darüber zurückbindet.

Mit der Frage nach den neuen, utopischen Inhalten und Verfahren greift Meireis ein Thema auf, das mit seinen theoretischen, philosophischen, politischen und historischen Konnotationen für jeden Autor eine Herausforderung darstellen würde. Die vorliegende Arbeit überzeugt dagegen durch ihre Systematik und das methodisch klar strukturierte Vorgehen. Durch die historische Kontextualisierung der aktuellen Phänomene entgeht sie der Gefahr, sich in der Überfülle aktueller wie auch historischer Positionen zu verlieren. Dass die einmal erarbeitete Methode strin- 
gent durchgehalten wird, stellt eine der Stärken der Arbeit dar und ist Voraussetzung für die hier vorliegende umfassende kritische Theorie mikroarchitektonischer Praktiken.

Im Zentrum der Arbeit stehen jene partizipativen Verfahren, die seit Beginn des 2 I. Jahrhunderts Teil der öffentlichen Debatten um Architektur und Gesellschaft sind. Dazu zählen so unterschiedliche Formen wie die Zwischennutzung des Palasts der Republik in Berlin 2003-05, das Ex-Rotaprint Gelände in Berlin 2007 oder The Michigan Urban Farming Initiative (MUFI) in Detroit 20I I. Als Kritik an der neoliberalen Alternativlosigkeit entstanden diese in kleinen, überschaubaren Maßstäben, mit bescheidenem Budget und aus lokaler Initiative heraus. Wie Meireis überzeugend darstellt, entziehen sich die mikroarchitektonischen Praktiken weitgehend den klassischen Zuschreibungen in der Architektur wie auch den herrschenden politischen Kräften und verweigern sich gleichzeitig auch der avantgardistischen, künstlerischen Attitüde, denn einerseits setzen sie sich von den offiziellen öffentlichen Projekten wie zum Beispiel den verschiedenen Bauausstellungen ab, genauso wie sie andererseits unter den aktuellen gesellschaftlichen Bedingungen in kritischer Brechung wiederum daran anknüpfen.

Zurecht wird die Thematik in den Kontext des Gegensatzpaares von revolutionärer Aktion und utopischer Vorstellungswelt gestellt, denn während ,autonome Bestrebungen die revolutionäre Aktion bevorzugen, [die auf unmittelbare Implementierung drängt,] sind heteronome Bestrebungen durchdrungen von utopischer Vorstellungskraft" (S. I68). Damit ist das Grundthema der Arbeit expliziert, nämlich die Weitung des Begriffs der Utopie, der auf pluralistischer Basis und mittels mikroarchitektonischer Interventionen in die Gesellschaft zurückkehrt. Nach Unterdrückung des utopischen Denkens durch die postmodernen Diskurse seit den I970er-Jahren wandeln sich Inhalte und Verfahren des utopischen Denkens.

So muss festgestellt werden, dass für Meireis Theorie alles andere ist als eine in spitzfindiger Kleinteiligkeit sich verlierende Historiographie, weder ist sie lediglich eine Geschichte der verschiedenen theoretischen Positionen, noch ist sie freie Spekulation über Architektur. Die Arbeit versteht dagegen die theoretische Reflexion als genuin theoriebildend, was sich in der Begriffsbildung Mikro-Utopie zeigt, aber auch darin, dass die Arbeit das Gebiet der Theorie der Architektur in ihrer Unmittelbarkeit durchbricht und, nicht zuletzt mit den drei Exkursen zu Macht und Herr- 
schaft, Macht und Boden und Macht und Geschlecht, die gesellschaftlichen und politischen Grundlagen in den Fokus bringt. Es steht im Zentrum der Arbeit nichts weniger als die kritische Repolitisierung der Architektur als immanent utopische Praxis.

Die Arbeit setzt konzeptuell an jener historischen Phase an, in der mit der Postmoderne Begriff und Praxis der Utopie diskreditiert worden waren. Die Ablehnung der Utopie stand, wie plausibel dargelegt wird, ganz im Zeichen der Entideologisierung der kulturellen Diskurse, was einerseits zur Öffnung und Pluralisierung der Gesellschaft führte, andererseits aber auch zur Beliebigkeit der gesellschaftlichen Orientierungen, was letztendlich dem Neoliberalismus Tür und Tor in den Geistes- und Sozialwissenschaften öffnete. Dies wird theoretisch eingefangen durch den von Gustav Landauer in Die Revolution (I905/07) geprägten heterogenen und pluralistischen Begriff der Utopie. Mit Landauer gelingt, die verschiedenen und zum Teil konträren, philosophischen Positionen zur Utopie von Ernst Bloch (Prinzip Hoffnung), Theodor W. Adorno (Negative Ästhetik) und Karl Mannheim (Ideologie und Utopie) in ein Kontinuum zu setzen.

Daran anschließend wird mit Fredric Jamesons Bestimmung der Postmoderne als Logik der Kultur im Spätkapitalismus aufgezeigt, wie sich um die Jahrhundertwende aus der Opposition gegen die großen multinationalen Industriekonzerne, gegen Globalisierung, Kommerzialisierung und Massenkonsum eine Neuorientierung gesellschaftlicher Inhalte und damit eine „Rückkehr des Utopischen in den kulturellen Diskursen“ (S. 220) beobachten lässt. Das führt zur zentralen These der kritischen und pluralistischen Ausdifferenzierung von Begriff und Praxis der Utopie in den mikroarchitektonischen Praktiken.

Hier wird die geschichtsphilosophisch große Linie sichtbar, an der entlang die Autorin die Wandlung im Konzept des Begriffs der Utopie nachzeichnet. Damit ist aber kein großes Narrativ oder die Entwicklungsgeschichte des Begriffs der Utopie gemeint. Davon ist die Arbeit weit entfernt. Es wird dagegen erkenntlich, wie der Begriff der Utopie auch historisch keineswegs geschlossen und unwandelbar ist, sondern in reziproker Abhängigkeit von den politischen, weltanschaulichen und ökonomischen Verhältnissen selbst der Wandlung unterlag. Es zeigt sich das utopische Denken selbst als eine Grundform des Denkens, die dem Handeln des Menschen, getrieben von der Sorge um die Erhaltung des Lebens, als utopisch- 
humanistischer Erwartungshorizont eingeschrieben ist. Oder wie der Renaissancehumanist Pico della Mirandola feststellte, dass der Mensch als „Schöpfung eines Gebildes ohne besondere Eigenart“ in die Welt gestellt ist, um sich, weder als ,einen Himmlischen noch als einen Irdischen"I nach eigenem freiem Willen sein Leben zu gestalten.

Es kann daher der These nur zugestimmt werden, dass die kritische Theorie mikroarchitektonischer Praktiken das Augenmerk auf die der Utopie immanente Dialektik von Projektion und Regression ausgerichtet sein muss. Die Unterdrückung des utopischen Denkens ist selbst eine Form negativer Utopie, dessen sich, entgegen ihrem eigenen Programm, die Postmoderne schuldig machte. Sichtbar wird die Utopie als ein Modell gesellschaftlichen Handelns, das auf anthropologischer Grundlage über die Zeit hinweg der Wandlung ihrer Konzeption unterliegt, was heute, jenseits des postulierten Endes der Utopie, in den mikroarchitektonischen Praktiken und den ihnen zugrundeliegenden gesellschaftlichen Partizipationsprozessen sichtbar wird.

In klarer Strukturierung führt die Arbeit im Kapitel „MikroUtopos. Mikro-Utopoi. Mikro-Utopie(n)“ auf etymologischer Grundlage in den Begriff der Utopie ein. Mit Bezug auf Thomas Morus Utopia schließt sich daran im Kapitel „Utopie in der Philosophie“ ein makrohistorischer Überblick an über die Geschichte des Begriffs der Utopie und über die Wandlung der Utopie von einem philosophischen Modell zum Modell praktischen Handelns. Beginnend mit dem I 8. Jahrhundert und orientiert an Louis-Sébastian Merciers Buch Das Jahr 2440 ( I77I) macht Meireis sichtbar, wie parallel zum Übergang von den Raum- zu den Zeitutopien sich auch der Übergang zum praktischen Handeln vollzieht. Utopien werden hier als epochenspezifische „Resonanzphänomen[e]“ (S. 44) gesamtgesellschaftlicher Befindlichkeit dargestellt, was den Boden für das Argument bereitet, dass die Utopien zum notwendigen Bestand gesellschaftlicher Selbstbestimmung gehören, sie sich daher kontextspezifisch in ihrer gesellschaftlichen Ausrichtung, im Erkenntnisinteresse und ihrem kritischen Potenzial unterscheiden.

Mit Mannheim plädiert die Arbeit dann für die Notwendigkeit der „Rückbindung des Denkens und damit der Erkenntnis an die soziale Realität“, was die „Begrüßung von pluralen Denkstilen“ (S. 70) beinhaltet. Spätestens mit den daran anschließenden 
Ausführungen zum architekturspezifischen Begriff der Utopie und zu der mit ihm einhergehenden ,räumliche[n] Vorstellungskraft“ (S. 84) kommt die Arbeit zu sich und beginnt, ihr ganzes Potenzial $\mathrm{zu}$ entfalten. Von zentraler Bedeutung ist die Aussage, dass keine Utopie ohne eine Vorstellung der architektonisch-räumlichen Organisation von Gesellschaft möglich ist, wie auch umgekehrt. Utopie und architektonische Praxis sind von jeher aufeinander bezogen und ineinander verschränkt. Das macht den Begriff der Utopie $\mathrm{zu}$ einem Grundbegriff gesellschaftlichen und gestalterischen Handelns, woraus sich das Spannungsverhältnis der ,ästhetischen“ und ,politischen Implikationen“ ergibt, die die Konzeptualisierung der Mikro-Utopien überhaupt erst möglich machen.

Hier wird dann das Erkenntnisinteresse sichtbar, das die Arbeit motiviert: Dass die Architektur in ihrer ästhetisch-räumlichen Konfiguration immer sozio-politischer Natur und im eigentlichen Sinne gesellschaftskritisch und deswegen immer utopisch ist. Gesellschaftskritik und Utopie sind die zwei Seiten einer Medaille. Daran anknüpfend spricht sich Meireis für eine Aufweitung der funktionalen Lesart des Begriffs der Utopie aus und differenziert nach utopischer Form, utopischem Inhalt und utopischer Funktion. Sie stellt die Utopie dann in eine genealogische Abfolge von Utopie als Kritik der Realität (Renaissance), Utopie als revolutionäres Element der Realität (Aufklärung) und Utopie als Ideologie (Moderne). In der Differenzierung zwischen Ideologie und Utopie zeigt sich, dass die Mikro-Utopien an die utopischen Konzepte der frühen modernen Architektur anknüpfen und diese in kritischer Reflexion ins 2 I. Jahrhundert weiterführen.

Im „Mikro“ zeigen sich aber nicht nur die Veränderungen auf der produktionsästhetischen, sondern auch die auf der wirkungsästhetischen Seite. Mikroarchitektonische Verfahren knüpfen an ein, wie Bloch formulierte, ,Denken [...] im Kleinen an, auch in kleinen Geschichten“ (S. 70), sie sind Interpolationen im Kleinen, sie intervenieren von innen heraus in die gesellschaftlichen Systeme hinein, sie sind Nadelstiche oder Injektionen von innen. Mikro-Utopien bereiten im Inneren und im Kleinen die Veränderungen vor, bevor sie außen sichtbar und wirkmächtig werden. Daran schließt sich die wichtige Erkenntnis an, dass in der mikroutopischen, räumlich-lokalen Verortung des Utopischen die älteren Techniken der kritischen Konfrontation und unterminierenden Subversion der modernen Avantgarden in Techniken intervenie- 
render Kooperation überführt werden. Die Mikro-Utopien treten nicht als das Andere der gesellschaftlichen Wirklichkeit und damit als verändernde Kraft von außen auf, sondern aus dem Gefüge der Architektur heraus.

Meireis formuliert dann im Kapitel ,Utopie in der Architektur“ die streitbare These, dass das utopische Potenzial für das Neue Bauen der I920er-Jahre mehr in der technologischen Steuerung als im sozial-analytischen Blick für die politischen Veränderungen begründet war. Mit Adorno, Rowe und Koetter kritisiert sie die Praxisferne der utopischen Visionen der Moderne. So ist die Kritik an der Moderne immer auch die Kritik an der Verengung des mit ihr einhergehenden Begriffs der Utopie. So mussten auch, in der Tradition der Moderne stehend, die technischen und technizistischen Utopien der Spätmoderne, Archigram oder die situationistische Bewegung, ihre Ziele verfehlen. Spät erst, um die Jahrtausendwende, sind es dann die mikroarchitektonischen Interventionen, die die humanistische Idee einer emanzipierten Gesellschaft ins postindustrielle Zeitalter weitergeben.

Mit Bezug auf Umberto Eco und Joseph Beuys formuliert Meireis die Feststellung, dass die mikroarchitektonischen Praktiken sich aus dem ,Zeitgeist der kollektiven Autor*innenschaft digitalgestützter Kollaborationen“ (S. I42) heraus entwickeln. Die utopischen Potenziale sind immer nur mittels der ,mit-arbeitende[n] Prozesshaltung" (S. I I4) der Nutzer, also in partizipativen Praktiken einlösbar. Die Autorin verweist auf die Smartphonetechnologie, die ihre gesellschaftlichen Potenziale nur in der gemeinschaftlichen Realisierung entfalten kann. Bedeutend ist dies, weil hier die digitalen Technologien nicht in ihrem vereinzelnden und neoliberalen, sondern in ihrem gesellschaftskritischen und innovativen Potenzial gezeigt werden. Es sind gerade die mikroarchitektonischen Praktiken, die die Verknüpfung der virtuellen Welten mit den sozialen Welten der konkreten Lebenspraxis ermöglichen.

Mit Foucault wird dann im Folgenden der Unterschied von mikroskopischen und makroskopischen Abstufungen eingeführt, was zur Theorie der Heterotopien führt, die das klassische dualistische Denken in Gegensatzpaaren zu überwinden sucht. Darin sieht die Autorin einen Schlüssel zu einem erweiterten Begriff utopischer Praxis, was zu der einsichtigen und die Arbeit tragenden These führt, dass in ihrem utopischen Gehalt die mikroarchitektonischen Praktiken per se heterotope Praktiken sind, die utopisch 
in ihrem Gehalt sind, insofern sie die etablierte Syntax der Dinge auflösen. Sie entlarven den ,realen Raum als noch größere Illusion“ (S. I I8), so die kritische Position, die die Autorin mit und gleichzeitig gegen Tafuris Utopie- und Kapitalismuskritik dann in den folgenden Kapiteln produktiv in Hinblick auf ihre kritischästhetische Implementierung wendet.

Zentral ist in diesem Sinne die an Walter Benjamin geschärfte Erkenntnis einer souveränen Kritik der Architektur, in der Benjamins Autor als Produzent in zweifacher Solidarität für die Gegenwartspraxis zurückgewonnen wird: Im Übergang vom Selbst- zum Mitgestaltenden und vom rezeptiv zum produktiv Teilhabenden. Seine konkreten architektonischen Artikulationsformen erhält dies im Begriff des „sozialräumlichen Denkens“ als Souveränisierung und Emanzipierung der an der Architektur Beteiligten. In sozialutopischer Perspektive lösen sich in den mikroarchitektonischen Praktiken tendenziell die Kategorien von Architekt, Bauherr und Nutzer auf.

Meireis verweist dann im Kapitel „Mikro-Utopien der Architektur: Ästhetische Implikationen“ auf das emanzipatorische Potenzial der mikroarchitektonischen Praktiken, ,der*die aufgeklärte, engagierte Bürger*in wird auf szenische Weise zentraler Teil der Gesamtstruktur" (S. I42 ff.), wobei es allerdings nicht bleibt, denn die erarbeiteten „Organisationsmethoden“ werfen ,brisante politische Fragestellungen auf", es bergen die transdisziplinären Praktiken Konfliktpotenziale, die die „Machtverhältnisse auf lokaler Ebene“ (S. I44) berühren. Die Mikro-Utopien müssen demnach als Fortsetzung der kritisch konzipierten Architekturpraxis der zweiten Hälfte des 20. Jahrhunderts, und die Theorie der Mikro-Utopien als Fortsetzung der kritischen Theorie der Architektur im digitalen Zeitalter verstanden werden.

Die Arbeit kulminiert in den Ausführungen zu den ästhetischen und politischen Implikationen der Mikro-Utopien und in der These, dass die Qualität heutiger architektonischer Techniken in der „Alphabetisierung/Qualifizierung der Gesellschaft“" im Sinne des sozialräumlichen Denkens besteht, analog zur „Alphabetisierung/Literarisierung der Lebenswelt“" (S. I65) im I9. Jahrhundert. Die Grundlage für die heutige zivilgesellschaftliche Teilhabe ist die plural organisierte Verknüpfung von Ökologie, sozialer Diversität und Geschlechtergerechtigkeit. 
Bezogen auf die drei Unterscheidungskriterien Kontext, Form und Methodik verdichtet das Kapitel ,Mikro-Utopien der Architektur: Politische Implikationen“ dann die Argumentation und zeigt, wie in den architektonischen Interventionen und den Mikro-Utopien die Kritik und Vision der Postwachstumsstrategien in einer Traditionslinie mit den humanistischen Utopien stehen, was Meireis unter den Begriffen „Freiräume in Transformationszeiten“, ,ökologisch-demokratisches Bewusstsein“ und „Handlungs- und Arbeitsgemeinschaften“ (S. 203) thematisiert. Sie stellt dies ins Zentrum ihrer These einer „Kultur des Pluralismus“ (S. 207), wobei die, wie sie in großer Klarheit darstellt, nur in der Transformation hin zu einer geschlechtergerechten Postwachstumsgesellschaft geschehen kann. Ohne sie könne eine friedliche gesellschaftliche Transformation im 2 I. Jahrhundert nicht gelingen. Die Autorin plädiert für „,reaktiv-progressive Utopieansätze“ (S. 2 I5) als zentrale Bestandteile einer kritischen Theorie mikroarchitektonischer Praktiken und für eine „,neue starke Theorie utopischen Denkens und Handelns“, die zur Vermeidung von totalitären Tendenzen nur als ,Vielzahl schwacher Mikro-Utopoi“ (S. 2 I6) denkbar ist.

Entstanden ist eine Arbeit, die sich das Ziel der Formulierung einer umfassenden kritischen Theorie aktuellen utopischen Denkens und Handelns stellt und dies souverän ausführt. Mit dem gewählten theoretischen Ansatz und der konsequenten Fokussierung auf die soziopolitische Dimension der mikroarchitektonischen Praktiken stellt die Arbeit einen innovativen Beitrag zur kritischen Theorie der Architektur dar.

Berlin, 20. Juli 2020

Jörg H. Gleiter 


\section{Dank}

Zuerst möchte ich mich herzlich bei Prof. Dr. Jörg H. Gleiter (TU Berlin) bedanken, denn durch seine stets pointiert konstruktive Kritik konnte meine Arbeit erst zu dem werden, was sie nun ist. Mein Dank gilt ebenso Prof. Dr. Gerhard Schweppenhäuser (FHWS Würzburg-Schweinfurt), insbesondere für die prozessbegleitende Kritik bis zur Veröffentlichung. Ebenso gilt mein Dank Assoz. Prof. Dr. Katharina Borsi (University of Nottingham/UK), die das Potential der vorgelegten Theorie für die architektonische Praxis betont.

Mein Dank gilt außerdem jenen Weggefährt*innen, die unterschiedliche Manuskriptabschnitte sowohl inhaltlich als auch sprachlich sorgsam durchgesehen und kritisch kommentiert haben. Das sind: Philipp Dittus, Dr. Eva Eylers, Prof. Dr. Nina Gribat, Julia Maria Hartmann, Sven Oliver Kärtkemeyer, Achim Kaufer, Dr. Tom Steinert und Tine Tillmann.

Darüber hinaus danke ich jenen Student*innen, die in meinen Architekturtheorie-Seminaren an der TU Berlin (2014-I7) relevante Themen für die vorliegende Arbeit mit anregenden Diskussionen bereichert haben. 

Anmerkungen 


\section{Vorwort}

1 Luc Boltanski, Ève Chiapello (2006 [Frz. 1999]) Der neue Geist des Kapitalismus. UVK Verlagsgesellschaft, Konstanz, S. 79 [Hervorh. i. O.].

2 Karl Marx, Friedrich Engels (1846-48) Lemma: Utopie. Erklärung der Fremdwörter, der fremdsprachigen und seltenen Ausdrücke, S. 703-713. In: Marx-Engels-Werke (MEW), Bd. 4 (1977) hrsg. v. Institut für Marxismus-Leninismus beim ZK der SED. Dietz, Berlin, S. 713.

\section{Einführung}

1 Vgl. Marcus Vitruvius Pollio (1964 [Lat. ab 33 v. Chr.]) Zehn Bücher über Architektur. Übers. u. mit Anmerkungen versehen v. Curt Fensterbusch. Wiss. Buchgesellschaft, Darmstadt; hier insbesondere Buch 1, Kapitel 2: Die ästhetischen Grundbegriffe der Baukunst, S. 36-43.

2 Das ist eine eigene Bezeichnung; in einschlägigen Medien ist oft die Rede von alternativer Stadtentwicklung, kritischer Raumproduktion bzw. -praxis, Bottom-up-Ansätzen, Graswurzelorganisation oder im Engl. etwa Critical Spatial Agency/Practice.

3 Der Prozess des „zur-Ware-Werdens", übertragen aus dem Engl. commodity, Ware; Prozess der Kommerzialisierung, Vermarktlichung.

4 Vgl. Lewis Mumford (1970 [Engl. 1965]) Utopie, Stadt und Maschine, S. 27-51. In: Frank E. Manuel (Hrsg.) Wunschtraum und Experiment. Vom Nutzen und Nachteil utopischen Denkens. Rombach, Freiburg, S. 28 [Hervorh. i. O.].

5 Siehe dazu, z. B. Werner Müller (1961) Die heilige Stadt. Roma quadrata, himmlisches Jerusalem und die Mythe vom Weltnabel. Kohlhammer, Stuttgart.

6 Vgl. Joachim Szidat (1980) Hippodamos von Milet. Seine Rolle in Theorie und Praxis der griechischen Stadtplanung, S. 31-44. In: Verein von Altertumsfreunden im Rheinlande (Hrsg.) Bonner Jahrbücher. Jahrbücher des Vereins von Altertumsfreunden im Rheinlande, Bd. 180, S. 39-41.

7 Aristoteles (2010 [4. Jh. v. Chr.]) Politik. Schriften zur Staatstheorie. Buch II/8: Kritik an der Staatsverfassung des Hippodamos. Übers. u. hrsg. v. Franz F. Schwarz. Reclam, Stuttgart, S. 130.

8 Vgl. Rudolf Blüher (1920) Moderne Utopien. Ein Beitrag zur Geschichte des Sozialismus. Kurt Schroeder, Bonn u. Leipzig, S. 1; 
Burghart Schmidt (1988) Kritik der reinen Utopie. Eine sozialphilosophische Untersuchung. Metzler, Stuttgart, S. 4.

"Konkrete Utopien“, eine Veranstaltungsreihe der Heinrich-BöllStiftung, Berlin, seit 2013; "100 Jahre Gegenwart", ein gegenwartsanalytisches Projekt mit Rückkopplung an historische Utopien, Haus der Kulturen der Welt, Berlin, 2015-19; „utopisch-dystopisch. Visionen einer ,idealen' Gesellschaft", Tagung an der Universität Hildesheim, Okt. 2016; „What's left? Was bleibt von der linken Utopie?", Veranstaltungsreihe der Friedrich-Ebert-Stiftung, Berlin, seit Mai 2018; „Unkonkrete Utopien“, eine Workshop-Reihe zum Kulturstandort Alte Münze der Koalition der freien Szene Berlin, seit 2017; „Planetarische Utopien. Hoffnung, Sehnsucht, Imagination in einer post-kolonialen Welt", Symposium der Akademie der Künste Berlin und Bundeszentrale für politische Bildung, Juni 2018. Der Ruf nach neuen Utopien wird gegenwärtig wieder lauter; v. a. von politischen Denker*innen, wie Bini Adamczak, Rutger Bregman, Angela Davis, Ulrike Guérot, Ágnes Heller, Alexander Kluge, Maria do Mar Castro Varela, Gayatri Chakravorty Spivak, Harald Welzer oder Jean Ziegler.

10 Vgl. Axel Honneth (2015) Die Idee des Sozialismus. Suhrkamp, Berlin, S. 16-20.

11 Wolfgang Biesterfeld (1982) Die literarische Utopie. Metzler, Stuttgart, S. 15.

12 „Differenzierungen im Begriff ,Utopie“" und „Probleme der Typologie" mit einem Fokus auf "die im Text manifestierte SozialUtopie", a. a. O., S. v-vii.

13 Vgl. Norbert Elias (1982) Thomas Morus' Staatskritik. Mit Überlegungen zur Bestimmung des Begriffs Utopie, S. 101-150. In: Wilhelm Voßkamp (Hrsg.) Utopieforschung. Interdisziplinäre Studien zur neuzeitlichen Utopie, Bd. 2. Metzler, Stuttgart, S. 107.

14 Neuere Publikationen zu Utopien der späten Architekturmoderne, z. B. Martin van Schaik, Otakar Mácel (Hrsg.) (2005) Exit Utopia. Architectural Provocations 1956-76; Felicity Scott (2010) Architecture or Techno-Utopia. Politics after Modernism; Sofia Borges et al. (Hrsg.) (2016) The Tale of Tomorrow. Utopian Architecture in the Modernist Realm; Andrew Blauvelt (Hrsg.) (2016) Hippie Modernism. The Struggle for Utopia; Johanna Diehl, Niklas Maak (Hrsg.) (2017) Eurotopians. Fragments of a Different Future; Pino Brugellis et al. (Hrsg.) (2017) Radical Utopias, Beyond Architecture: Florence 1966-1976.

15 Richard Saage (2004) Wie zukunftsfähig ist der klassische Utopiebegriff? S. 617-636. In: UTOPIE kreativ. Diskussion sozialistischer Alternativen, Nr. 165/166. Hrsg. v. Rosa-Luxemburg-Stiftung, S. 631. 
Online: http://www.rosa-luxemburg-club.de/fileadmin/rls_uploads/ pdfs/165_166-saage.pdf (17.4.17).

16 Vgl. Lemma: Theorie. In: Wörterbuch der philosophischen Begriffe (2005) hrsg v. Arnim Regenbogen, Uwe Meyer. Meiner, Hamburg, S. 663.

17 Gunilla Budde, Dagmar Freist, Hilke Günther-Arndt (Hrsg.) (2008) Geschichte. Studium-Wissenschaft-Beruf. Akademie Verlag, Berlin, S. 116 .

\section{Mikro-Utopos. Mikro-Utopoi. Mikro-Utopie(n)}

1 S. Goldmann (1998) Lemma: Topik; Topos, S. 1263-1288. In: Historisches Wörterbuch der Philosophie, Bd. 10: St-T. Hrsg. v. Joachim Ritter, Karlfried Gründer. Wiss. Buchgesellschaft, Darmstadt u. Schwabe, Basel, S. 1263.

2 Vgl. a. a. O., S. 1264.

3 Ebd.

4 A. a. O., S. 1279.

5 Vgl. Alberto Manguel, Gianni Guadalupi (1981) Von Atlantis bis Utopia. Ein Führer zu den imaginären Schauplätzen der Weltliteratur. Christian Verlag, München, S. 240-241.

6 Andreas Reckwitz (2017) Die Gesellschaft der Singularitäten. Zum Strukturwandel der Moderne. Suhrkamp, Frankfurt/M., S. 102-103.

7 Alf Lüdtke (1998) Alltagsgeschichte, Mikro-Historie, historische Anthropologie, S. 557-578. In: Hans-Jürgen Goertz (Hrsg.) Geschichte. Ein Grundkurs. Rowohlt, Reinbek bei Hamburg, S. 558.

8 Überblicksdarstellungen zur Mikrogeschichte, z. B. Giovanni Levi (2001 [zuerst 1991]) On Microhistory, S. 97-119. In: Peter Burke (Hrsg.) New Perspectives on Historical Writing; Carlo Ginzburg (1993) Mikro-Historie. Zwei oder drei Dinge, die ich von ihr weiß, S. 169-192. In: Historische Anthropologie, Bd. 1, Heft 2; Sigurdur Gylfi Magnússon, István M. Szijártó (2013) What is Microhistory? Theory and Practice.

9 Lüdtke (1998) Alltagsgeschichte, Mikro-Historie, historische Anthropologie, S. 569.

10 Klassische Studien der Mikrogeschichte, z. B. Emmanuel Le Roy Ladurie (1975) Montaillou. Ein Dorf vor der Inquisition, 1294-1324; Carlo Ginzburg (1976) Der Käse und die Würmer; Natalie Zemon Davis (1989 [Engl. 1983]) Die wahrhaftige Geschichte von der Wiederkehr des Martin Guerre; Hans Medick (1996) Weben und 
Überleben in Laichingen, 1650-1900. Lokalgeschichte als Allgemeine Geschichte.

11 Vgl. Hans Medick (1994) Mikro-Historie, S. 40-53. In: Winfried Schulze (Hrsg.) Sozialgeschichte, Alltagsgeschichte, Mikro-Historie. Eine Diskussion. Vandenhoeck und Ruprecht, Göttingen, S. 44-45.

12 Ein Oxymoron, das auf den Historiker Edoardo Grendi zurückgeht; vgl. Carlo Ginzburg, Carlo Poni (1985) Was ist Mikrogeschichte? S. 48-52. In: Geschichtswerkstatt Nr. 6. Schwierigkeiten beim Entdecken der Heimat. Hrsg. v. Alf Lüdtke, Hans Medick, Wolfgang Schäfer für die Geschichtswerkstatt e.V. Verlag die Werkstatt, Göttingen, S. 51.

13 Ginzburg, Poni (1985) Was ist Mikrogeschichte? S. 51.

14 A. a. O., S. 51-52.

15 Vgl. Medick (1994) Mikro-Historie, S. 44.

16 Ginzburg (1993) Mikro-Historie, S. 191.

17 Peter Burke (2005) Was ist Kulturgeschichte? Suhrkamp, Frankfurt/M., S. 70;

Vorläufer der Mikrogeschichte, z. B. Fernand Braudel (1990 [Frz. 1949] Das Mittelmeer und die mediterrane Welt in der Epoche Philipps II.; Theodor W. Adorno (2003 [zuerst 1951]) Minima Moralia. Reflexionen aus dem beschädigten Leben; Siegfried Kracauer (1971 [Engl. 1969]) Geschichte. Vor den letzten Dingen.

18 Vgl. Ginzburg (1993) Mikro-Historie, S. 180-181.

19 Vgl. a. a. O., S. 190-191.

20 Medick (1994) Mikro-Historie, S. 43.

21 Vgl. Lüdtke (1998) Alltagsgeschichte, Mikro-Historie, historische Anthropologie, S. 560.

22 Vgl. Gerd Ueding (1982) Ernst Blochs Philosophie der Utopie, S. 293-303. In: Voßkamp (Hrsg.) Utopieforschung, Bd. 1, S. 293.

23 Zur Paradoxie der Utopie: sie ist ein Phänomen der christlich-westlichen Zivilisation, d.h. eines auf Fortschritt gerichteten Denk- und Geschichtsmodells; um sie zu realisieren müssen die Grundpfeiler ihrer Entstehung abgerissen werden, vgl. Myriam Yardeni (1980) Utopie et Révolte sous Louis XIV zit. nach Richard Saage (1991) Politische Utopien der Neuzeit. Wissenschaftliche Buchgesellschaft, Darmstadt, S. 115.

Ideal im Außerhalb anderer Kulturkreise, z. B. Utopieansätze aus dem asiatischen, indischen und afrikanischen Raum, vgl. Plath David (1971) Aware of Utopia; vgl. Ralph Pordzik, Hans Ulrich Seeber (2002) Utopie und Dystopie in den neuen englischen Literaturen (dazu vgl. Saage (2008) Utopieforschung, Bd. 2: An der Schwelle des 
21. Jahrhunderts, S. 105-106); vgl. Felwine Sarr (2019 [Frz. 2016]) Afrotopia; zum Unterschied von Afrofuturismus und -pessimismus, vgl. Jaye Austin Williams im Interview (2019) Die Welt als Desaster ist Realität. Online: https://kritisch-lesen.de/interview/die-welt-alsdesaster-ist-realitat (15.7.19).

24 Rosa Luxemburg (1913) Karl Marx. Beitrag zur Leipziger Volkszeitung, Nr. 60. In: Gesammelte Werke, Bd. 3, S. 178-184. Online: https://www.marxists.org/deutsch/ archiv/luxemburg/1913/03/marx2. htm (4.9.19).

25 Karl Marx (1960 [zuerst 1852]) Der achtzehnte Brumaire des Louis Bonaparte, S. 111-207. In: MEW, Bd. 8, S. 115.

26 Luxemburg (1913) Karl Marx, a. a. O.

27 Vgl. Alex Demirović (2018) Bevölkerung und Klassenpolitik. Gramscis hegemonietheoretische Annäherung an die Frage der Migration. Online: https://www.zeit schrift-luxemburg.de/bevoelkerung-und-klassenpolitik-gramscis-hegemonietheoretische-annaeherung-an-die-frage-der-migration/ (16.8.19).

28 Vgl. Antonio Gramsci (1994 [Ital. 1975/1929-35]) Gefängnishefte. Kritische Gesamtausgabe, Bd. 6 (Heft 10 u. 11): Philosophie der Praxis. Hrsg. v. Wolfgang Fritz Haug. Argument, Hamburg, S. 13251326 [Hervorh. d. Verf.].

Siehe dazu Gayatri Chakravorty Spivak (2008 [Engl. 1988]) Can the Subaltern Speak? Postkolonialität und subalterne Artikulation. Turia + Kant, Wien.

29 Maria do Mar Castro Varela (2004) Utopien. Kitsch, Widerstand und politische Praxis, S. 111-122. In: Susanne Kollmann, Kathrin Schödel (Hrsg.) PostModerne De/Konstruktionen. Ethik, Politik und Kultur am Ende einer Epoche. LIT Verlag, Münster, S. 117 [Hervorh. i. O.].

30 Vgl. Homi K. Bhabha (2007 [Engl. 1994]) Wie das Neue in die Welt kommt: Postmoderner Raum, postkoloniale Zeiten und die Prozesse kultureller Übersetzung, S. 317-352. In: Ders. Die Verortung der Kultur; Edward Soja (1996) Thirdspace. Journeys to Los Angeles and Other Real-and-imagined Places.

Siehe zu den Denkanfängen eines dritten Geschlechts Ernst von Wolzogen (1899) Das dritte Geschlecht; und zur Ebnung eines dritten Weges zwischen Kapitalismus und Kommunismus bzw. Sozialismus Anthony Giddens (1999 [Engl. 1998]) Der dritte Weg. Die Erneuerung der sozialen Demokratie.

Siehe zu neuen Narrativen der postkolonialen Geschichtsschreibung, z. B. Dipesh Chakrabarty (2010 [Engl. 2000]) Europa als Provinz. Perspektiven postkolonialer Geschichtsschreibung; María do Mar Castro Varela, Nikita Dhawan (2015) Postkoloniale Theorie. Eine kritische Einführung; zu neuen Narrativen der Kunstkritik; 
Sabeth Buchmann, Isabelle Graw (2019) Kritik der Kunstkritik. In: Texte zur Kunst (TzK), Nr. 113: Diskriminierung. Online: https:// www.textezurkunst.de/113/kritik-der-kunstkritik (13.3.19).

31 Michel Foucault (2018 [Frz. 1969]) Archäologie des Wissens. Suhrkamp, Frankfurt/M., S. 22-23.

Im Anschluss an die (neomarxistische) K/kritische Theorie der Frankfurter Schule und an das machttheoretische Werk von Michel Foucault bilden sich die (postmarxistischen) Critical Studies heraus, insbesondere im anglophonen Sprachraum. Die neueren kritischen Studien fokussieren die Handlungsfähigkeit und Wirkkraft des sich selbstermächtigenden Subjekts innerhalb des gesellschaftlichen Ganzen noch stärker.

Siehe dazu auch Max Horkheimer (2005 [zuerst 1937]) Traditionelle und kritische Theorie. In: Ders. Traditionelle und kritische Theorie. Fünf Aufsätze. Fischer, Frankfurt/M.; vgl. Peggy H. Breitenstein (2013) Die Befreiung der Geschichte. Geschichtsphilosophie als Gesellschaftskritik nach Adorno und Foucault. Campus, Frankfurt/M., S. 277-278.

32 Vgl. Angela Davis, Vortrag auf dem Symposium Planetarische Utopien. Hoffnung, Sehnsucht, Imagination in einer post-kolonialen Welt. Akademie der Künste Berlin, Bundeszentrale für politische Bildung, 24.6.2018. Online: https://www.youtube .com/watch?v=ccnGN07gnk (25.6.18) [ab Min. 43:00, Übers. d. Verf.].

Davis fährt fort, dass die Bekämpfung der Sklaverei nur im kollektiven Aufstand („wir") möglich war und ist; die Befreiungsvision der Vorfahren [no-place als Gruppenutopie] materialisiert sich in der Produktion einer postkolonialen Gegenwart.

\section{Utopie in der Philosophie}

1 Klassische Schriften der Utopieforschung, z. B. Robert von Mohl (1855) Die Staatsromane; Andreas Voigt (1906) Die sozialen Utopien; Hans Freyer (1936) Die politische Insel; Judith N. Shklar (1957) After Utopia; Martin Schwonke (1957) Vom Staatsroman zur Science Fiction; Werner Krauss (1964) Reise nach Utopia; Helmut Swoboda (1972) Utopia. Geschichte der Sehnsucht nach einer besseren Welt; Barbara Goodwin (1978) Social Science and Utopia; Frank E. u. Fritzie P. Manuel (1979) Utopian Thought in the Western World; Wilhelm Voßkamp (1982) Utopieforschung, 3 Bde.; Arnhelm Neusüss (1986) Utopie. Begriff und Phänomen des Utopischen; Burghart Schmidt (1988) Kritik der reinen Utopie; Richard Saage (1991) Politische Utopien der Neuzeit; (2008) Utopieforschung, 2 Bde.; Bettina Roß (1998) Politische Utopien von Frauen; Gregory 
Claeys, Lyman Tower Sargent, Roland Schaer (2000) Utopia. The Search for the Ideal Society in the Western World; Arno Waschkuhn (2003) Politische Utopien. Ein politiktheoretischer Überblick von der Antike bis heute; Ina-Maria Maahs (2019) Utopie und Politik. Potenziale kreativer Politikgestaltung.

2 Vgl. Saage (2004) Wie zukunftsfähig ist der klassische Utopiebegriff?, S. 623.

3 Vgl. Saage (1991) Politische Utopien der Neuzeit, S. 9-10.

4 Siehe z. B. Barbara Zehnpfennig (2007) Lemma: Platon, Politeia, S. 418-424. In: Hauptwerke der politischen Theorie. Hrsg. v. Wilhelm Hofmann, Giesela Riescher, Theo Stammen. Kröner, Stuttgart.

5 Vgl. Karl Vretska (2010 [zuerst 1958]) Einleitung. Platon. Der Staat (Politeia), S. 61. Übers. u. hrsg. v. ders. Reclam, Stuttgart.

6 Der lateinische Originaltitel nach der Referenzausgabe von 1518, Basel: Froben Edition, lautet: De optimo reip[ublicae] statu, deque nova insula Utopia libellus vere aureus nec minus salutaris quàm festivus, vgl. doi: http://www.e-rara.ch/doi/10.3931/e-rara-30626; auf Englisch zuerst 1551 in London erschienen; und in aktueller dt. Übersetzung mit umgestelltem Satzgefüge von Gerhard Ritter (2003, Reclam): Ein wahrhaft goldenes Büchlein, genauso wohltuend wie heiter von der besten Staatsverfassung und von der neuen Insel Utopia.

7 Thomas Morus (1516) Utopia, S. 8-110. In: Klaus J. Heinisch (Hrsg.) (2011 [zuerst 1960]) Der utopische Staat. Morus: Utopia, Campanella: Sonnenstaat, Bacon: Neu-Atlantis. 30. Auflage. Rowohlt, Reinbek bei Hamburg, S. 17.

8 Otfried Höffe (Hrsg.) (2016) Einleitung. Politische Utopien der Neuzeit. Thomas Morus, Tommaso Campanella, Francis Bacon. De Gruyter, Berlin, S. 4.

9 Vgl. Morus (1516) Utopia. In: Heinisch (Hrsg.) (2011 [zuerst 1960]) Der utopische Staat, S. 18, 36, 43, 44 (hier wird Platon genannt).

10 Elias kommentiert dazu: „Die Begeisterung [...] war ein Generationenerlebnis, das heute möglicherweise nicht mehr leicht nachvollziehbar ist. Ein - sicherlich hinkender-Vergleich ist das Generationenerlebnis des Marxismus in den sechziger Jahren des 20. Jahrhunderts." Elias (1982) Thomas Morus' Staatskritik, S. 114.

11 Vgl. a. a. O., S. 116.

12 Vgl. Morus (1516) Utopia. In: Heinisch (Hrsg.) (2011 [zuerst 1960]) Der utopische Staat, S. 17-47; Richard Saage (1991) Politische Utopien der Neuzeit, S. 18-20. 
13 Vgl. Theo Stammen (2007) Lemma: Thomas Morus, S. 389-392. In: Hauptwerke der politischen Theorie, S. 391.

14 Saage (1991) Politische Utopien der Neuzeit, S. 5.

15 Vgl. ebd.

16 Vgl. Ernst Bloch (1959) Das Prinzip Hoffnung, Bd. 2, Teil 4. Suhrkamp, Frankfurt/M., S. 604; Biesterfeld (1982) Die literarische Utopie, S. 41; Arnhelm Neusüss (1986) Nachwort. Hythlodeus oder die Entbehrlichkeit utopischen Denkens in der Moderne, S. 447-466. In: Ders. (Hrsg.) Utopie. Begriff und Phänomen des Utopischen. Campus, Frankfurt/M., S. 457.

17 Elias (1982) Thomas Morus' Staatskritik, S. 131.

18 Siehe dazu, z. B. rhetorische Stilmittel, Übersicht: B) Figuren, IV) Satzfiguren, 2) Subiectio/Percontatio. Online: http://www.prolatein. de/stilmittel.htm (1.7.17); und zur Funktion des Dialogs bei Morus, z. B. John D. Schaeffer (1981) Socratic Method in More's ,Utopia', S. 5-18. In: Moreana XVIII, Nr. 69. Online: https://www.euppublishing.com /doi/pdfplus/10.3366/more.1981.18.1.3 (1.7.17).

19 Elias (1982) Thomas Morus' Staatskritik, S. 131.

20 Siehe dazu, z. B. Ludwig Schick (2010) Der Gottesstaat Augustins. Maßgabe für heutige Staaten? Festrede zur Jahresvollversammlung der Gesellschaft zur Förderung der Augustinus-Forschung e.V. Online: https://de.zenit.org/articles/der-gottesstaat-augustins-massgabe-fur-heutige-staaten/ (18.12.18); und vgl. Matthias Schloßberger (2013) Geschichtsphilosophie. Akademie Verlag, Berlin, S. 50.

21 Vgl. Saage (1991) Politische Utopien der Neuzeit, S. 198-202.

22 Vgl. Immanuel Kant (2013 [zuerst 1798]) Der Streit der Fakultäten. Zweiter Abschnitt. Der Streit der philosophischen Fakultät mit der juristischen, S. 183-200. In: Ders. Schriften zur Geschichtsphilosophie. Reclam, Stuttgart, S. 189.

Das lineare Geschichtsverständnis westlich-christlicher Prägung und Utopien anderer Kulturkreise kommentieren die Politikwissenschaftler Gregory Claeys, Lyman Tower Sargent (2017) Introduction. The Utopia Reader, S. 6.

23 Die kürzer werdenden Abstände der zeitgeschichtlichen Einteilung erklären sich durch die geringe Distanz zur Gegenwart; über eine geschichtsphilosophische Objektivation bleibt zu spekulieren; Erläuterung: 1967 Studentenrevolte und Foucaults Heterotopie; 1971 Aufhebung der Goldpreisbindung; 1989/91 Fall des Eisernen Vorhangs; 2001 9/11; 2008 Wirtschaftskrise global; 2011 Arabischer Frühling und Occupy; 2019 Fridays for Future; 2020 CoronaPandemie und Black Lives Matter. 
24 Richard Saage (1991) Politische Utopien der Neuzeit, S. 225; frühneuzeitliche Utopien, z. B. Tommaso Campanella (1602) Der Sonnenstaat; Johann Valentin Andreae (1619) Christianopolis; Francis Bacon (1627) Neu-Atlantis; Gerrard Winstanley (1652) Das Gesetz der Freiheit.

25 Vgl. Saage (1991) Politische Utopien der Neuzeit, S. 24, 32-33.

26 Vgl. a. a. O., S. 15-76.

Eine feinere zeitgeschichtliche Einteilung nehmen die Manuels vor: "The Birth of Utopia" und "Flowering und Death of the Christian Utopia", S. 117-410. In: Frank E. und Fritzie P. Manuel (1979) Utopian Thought in the Western World. Basil Blackwell, Oxford/UK; eine gröbere zeitgeschichtliche Einteilung nehmen Gregory Claeys, Lyman Tower Sargent, Roland Schaer vor: „Of Other Worlds: The Spread of the Utopian Imagination, from Thomas More to the Enlightenment", S. 95-183. In: Gregory Claeys et al. (2000) Utopia. The Search for the Ideal Society in the Western World. Oxford University Press, New York/NY.

27 Max Horkheimer (1971 [zuerst 1930]) Anfänge der bürgerlichen Geschichtsphilosophie. In: Ders. Geschichtsphilosophie / Hegel / Montaigne. Eingel. v. Alfred Schmidt. Fischer, Frankfurt/M., S. 60.

28 Umfangreiche Bibliographien zur utopischen Literatur, z. B. Rita Falke (1953), Glenn Negley (1977), Wolfgang Biesterfeld (1982); lebendig berichten Alberto Manguel, Gianni Guadalupi (1981) Von Atlantis bis Utopia. Ein Führer zu den imaginären Schauplätzen der Weltliteratur; Richard Saage (2001-204) Utopische Profile, 4 Bde.; Umberto Eco (2013) Die Geschichte der legendären Länder und Städte.

29 Vgl. Saage (1991) Politische Utopien der Neuzeit, S. 77-150, hier S. 80-86, 91-92, 102.

30 Vgl. a. a. O., S. 78, 97-102, 132; vgl. Horkheimer (1971 [zuerst 1930]) Anfänge der bürgerlichen Geschichtsphilosophie, S. 59, 60, 65; siehe dazu weiterführend, z. B. Benedict Anderson (2005 [Engl. 1983]) Die Erfindung der Nation. Zur Karriere eines erfolgreichen Konzepts. Campus, Frankfurt/M.

Anarchistische Ansätze im 17./18. Jahrhundert, z. B. Gabriel de Foigny (1676) Südland; Louis-Armand de Lahontan (1703) Gespräche mit einem Wilden; Étienne-Gabriel Morelly (1753) Basiliade; Denis Diderot (1773-74) Nachtrag zu ,Bougainvilles Reise'; vgl. Saage (2001) Utopische Profile, Bd. 1: Renaissance und Reformation. LIT Verlag, Münster, S. 45.

31 Hans Freyer (1936) Die politische Insel. Eine Geschichte der Utopien von Platon bis zur Gegenwart. Bibliographisches Institut, Leipzig, S. $120-121$. 
32 Thomas Nipperdey (1962) Die Funktion der Utopie im politischen Denken der Neuzeit, S. 357-378. In: Archiv für Kulturgeschichte, Bd. 44, S. 377. Online: https://doi.org/10.7788/akg-1962-jg20 (29.3.17).

33 Vgl. Saage (1991) Politische Utopien der Neuzeit, S. 77, 92, 224.

34 A. a. O., S. 151-233.

35 Vgl. a. a. O., S. 152-154; siehe dazu auch, z. B. Thomas Piketty (2020 [Frz. 2019]) Kapital und Ideologie. C.H.Beck, München.

36 Dystopien im 20. Jahrhundert, z. B. Jewgeni Samjatin (1920) Wir; Aldous Huxley (1932) Schöne neue Welt; George Orwell (1949) 1984; Ray Bradbury (1953) Fahrenheit 451.

Bei späteren Schriften liegt der Schwerpunkt auf ökologischen und feministischen Ansätzen, z. B. Ernst Callenbach (1975) Ökotopia; Ursula Le Guin (1974) Planet der Habenichtse; Marge Piercy (1991) Er, Sie und Es.

37 Raymond Trousson (1982) Utopie, Geschichte, Fortschritt. Das Jahr 2440, S. 15-23. In: Voßkamp (Hrsg.) Utopieforschung, Bd. 3, S. 21.

38 Reinhart Koselleck (1982) Verzeitlichung der Utopie, S. 1-14. In: Voßkamp (Hrsg.) Utopieforschung, Bd. 3, S. 1, 5-6.

39 Vgl. Lucian Hölscher (2016) Die Entdeckung der Zukunft. Wallstein Verlag, Göttingen, S. 42-55, speziell S. 43.

40 Vgl. Barbara Goodwin, Keith Taylor (1982) The Politics of Utopia. Hutchinson, London/UK, S. 15.

41 Vgl. Rüdiger Safranski (2007) Romantik. Eine deutsche Affäre. Hanser, München, S. 31 [Hervorh. d. Verf.].

42 Nipperdey (1962) Die Funktion der Utopie im politischen Denken der Neuzeit, S. 367-368.

43 A. a. O., S. 368 [Hervorh. d. Verf.].

44 Frühsozialistische Utopien im 19. Jahrhundert, z. B. Charles Fourier (1808-36) Schriften zu einer neuen sozialen Ordnung; Claude Henri de Saint-Simon (1814-25) Schriften zur Industriegesellschaft; Robert Owen (1836-44) Die neue moralische Welt; Étienne Cabet (1839) Reise nach Ikarien; vgl. Saage (1991) Politische Utopien der Neuzeit, S. 225.

45 Vgl. Marc Berdet, Thomas Ebke (2014) Einleitung, S. 35-71. In: Dies. (Hrsg.) Anthropologischer Materialismus und Materialismus der Begegnung. Vermessungen der Gegenwart im Ausgang von Walter Benjamin und Louis Althusser. xenomoi, Berlin, S. 47.

46 Vgl. Richard Saage (2002) Utopische Profile, Bd. 3: Industrielle Revolution und Technischer Staat im 19. Jahrhundert. LIT Verlag, Münster, S. 9-33. 
47 Vgl. Edward Bellamy (1888) Ein Rückblick aus dem Jahr 2000 auf 1887; Theodor Hertzka (1889) Freiland; William Morris (1890) Kunde von Nirgendwo.

Siehe dazu auch Saage (1991) Politische Utopien der Neuzeit, S. 226-228; Richard Kilminster (1982) Zur Utopiediskussion aus soziologischer Sicht, S. 64-96. In: Voßkamp (Hrsg.) Utopieforschung, Bd. 1, S. 77-80.

48 Vgl. Gerd de Bruyn (1996) Die Diktatur der Philanthropen. Entwicklung der Stadtplanung aus dem utopischen Denken. Bauwelt Fundamente, Bd. 110. Vieweg, Braunschweig u. Wiesbaden, S. 12 [Hervorh. d. Verf.].

49 Vgl. MEW, Bd. 1 (1981) Vorwort des Instituts für Marxismus-Leninismus beim ZK der SED. Dietz, Berlin, S. xiv-xv; und Karl Marx (1844) Zur Kritik der Hegelschen Rechtsphilosophie. Einleitung, S. 378-391. In: a. a. O., S. 391 [Hervorh. i. O.].

Nach Recherchen d. Verf., dank digitaler Volltextsuche, taucht der Begriff Utopie in den 43 Hauptbänden der MEW ca. 300 Mal auf; exklusive: Utopia, utopique, utopisch, Utopismus, utopistisch. Davon entfallen ca. 160 Nennungen auf die Anhänge, größtenteils Literaturverweise auf die zentralen Werke von Friedrich Engels, Jean Guillaume Colins und Karl Kautsky. Von den ca. 140 Nennungen im Haupttext entfallen wiederum ca. 60 Stellen auf die Nennung des Titels von Engels Schrift Die Entwicklung des Sozialismus von der Utopie zur Wissenschaft. In den verbleibenden 80 Stellen, wiederum v. a. in Textpassagen von Engels, steht der Begriff inhaltlich meist in kritischem Zusammenhang mit den utopischen Sozialisten Robert Owen, Charles Fourier und Etiènne Cabet, sowie den sozialistischen Ökonomen Pierre-Joseph Proudhon, John Gray, David Ricardo und Karl Rodbertus.

50 Vgl. Friedrich Engels (1880) Die Entwicklung des Sozialismus von der Utopie zur Wissenschaft, S. 177-228. In: MEW, Bd. 19 (1987); basierend auf seiner drei Jahre zuvor verfassten Schrift Herrn Eugen Dührings Umwälzung der Wissenschaft, die als Anti-Dühring bekannt wurde.

51 Bloch (1959) Das Prinzip Hoffnung, Bd. 2, Teil 4, S. 675.

52 A. a. O., S. 724.

53 Vgl. ebd. [Hervorh. i. O.].

54 A. a. O., S. 725-727 [Hervorh. i. O.].

55 Koselleck (1982) Verzeitlichung der Utopie, S. 1, 5-6.

56 Elias (1982) Thomas Morus' Staatskritik, S. 103.

57 A. a. O., S. 105 [Hervorh. d. Verf.]. 
58 Kilminster (1982) Zur Utopiediskussion aus soziologischer Sicht, S. 69-70; Kilminster bezieht sich hier auf eine "soziologische Skizze" von Elias, eine kurze Notiz zum Begriff der Utopie und den Aufgaben der Utopieforschung, Manuskript, Zentrum für interdisziplinäre Forschung, Universität Bielefeld, 1981. Die angeführten Zitate stammen aus einer erweiterten Fassung, die Elias ihm zur Verfügung stellte.

In Zitaten werden alte Rechtschreibweisen unkommentiert übernommen, hier z. B. „überschwenglich".

59 Vgl. Alexander Neupert-Dopplers Vortrag „Utopiebewusstsein. Zu den Grundlagen eines funktionalen Utopiebegriffs" auf der Tagung Utopisch-Dystopisch. Visionen einer ,idealen' Gesellschaft, Universität Hildesheim, Okt. 2016.

60 Siehe dazu Neupert-Doppler (2015) Utopie, S. 52-92; Neusüss (1986) Utopie, S. 21-33; Saage (2004) Wie zukunftsfähig ist der klassische Utopiebegriff?, S. 618-620.

61 Saage (2004) Wie zukunftsfähig ist der klassische Utopiebegriff?, S. 620 .

62 Ebd.

63 Robert Leucht (2016) Dynamiken politischer Imagination. Die deutschsprachige Utopie von Stifter bis Döblin in ihren internationalen Kontexten, 1848-1930. De Gruyter, Berlin u. Boston, S. 399.

64 Neusüss (1986) Utopie, S. 32.

65 Siehe dazu Lisa Doppler, Alexander Neupert (2014) Das Recht auf Stadt als konkrete Utopie? Utopisches Bewusstsein als Gegenstand der Bewegungsforschung, S. 163-178. In: Norbert Gestring et al. (Hrsg.) Stadt und soziale Bewegungen. Springer VS, Wiesbaden; Neupert-Doppler (2015) Utopie, S. 172-180; Ruth Levitas (2013) Utopia as Method. The Imaginary Reconstitution of Society. Palgrave Macmillan, Hampshire/UK.

66 Gustav Landauer (1923 [zuerst 1905/07]) Die Revolution. Rütten u. Loening, Frankfurt/M., S. 12-13 [Hervorh. i. O.]; widersprüchliche Jahresangaben zur Erstveröffentlichung: 1905 (Impressum) und 1907 (Fließtext, S. 106).

67 Landauer über den Begriff der Geschichte („Offenheit der Geschichte") und ihre Vergegenwärtigung, a. a. O., S. 8-10, 27-28; und zur Gleichsetzung von Revolution und Sozialpsychologie, ebd.

68 Vgl. Andreas Heyer (2006) Sozialismus statt Marxismus. Peter Kropotkin, Gustav Landauer und Martin Buber, S. 74-88. In: Ders. Die Utopie steht links! Ein Essay. Dietz, Berlin, S. 86. Die Landkommune Neue Gemeinschaft, um Landauer und die Gebrüder Hart, war eine von vielen, aber die berühmteste, die sich 
im Rahmen des Wandervogels und der Siedlungsbewegung bildete; sie übte besondere Anziehungskraft auf Künstler, Schriftsteller und Philosophen aus, die ihrem Leben eine romantische und von Friedrich Nietzsche inspirierte Bedeutung zurückgeben wollten, nicht zuletzt der Persönlichkeit Landauers geschuldet, vgl. Safranski (2007) Romantik, S. 307-308.

69 Neupert-Doppler (2015) Utopie, S. 58.

70 Vgl. Ulrich Dierse (2001) Lemma: Utopie, S. 510-526. In: Historisches Wörterbuch der Philosophie, Bd. 11: U-V. Hrsg. v. Joachim Ritter, Karlfried Gründer, Gottfried Gabriel. Wiss. Buchgesellschaft, Darmstadt u. Schwabe, Basel, S. 519.

71 Ähnlich dem Anarchisten Peter Kropotkin, der die wirtschaftliche und politische Vernetzung kleiner Einheiten ländlicher Industriedörfer als vollkommen natürlich voraussetzt, vgl. Peter Kropotkin (1892) Die Eroberung des Brotes zit. nach Neupert-Doppler (2015) Utopie, S. 52.

72 Dierse (2001) Lemma: Utopie, S. 519.

73 Sein Wirken in der Münchner Räterepublik 1918/19 verdeutlicht das, vgl. Volker Weidermann (2018) Träumer. Als die Dichter die Macht übernahmen. Kiepenheuer \& Witsch, Köln, S. 156-157.

74 Gustav Landauer (1967 [zuerst 1911]) Aufruf zum Sozialismus. Europäische Verlagsanstalt, Frankfurt/M., S. 98.

75 Landauer (1923 [zuerst 1905/07]) Die Revolution, S. 91; Landauer kommentiert zu seiner Aneignung und Umdeutung von Richard Treitzschkes Revolution als Mikrokosmos, dass dies „in unglaublich kurzer Zeit, in großartiger Zusammendrängung [geschieht], weil die Geister der Menschen komprimiert waren und aufspringen, wird die Welt des Möglichen wie ein Fanal das über die Zeiten flammt, zur Erfüllung gebracht. In der Revolution geht alles unglaublich schnell, so wie im Traum der Schlafenden, die von irdischer Schwere befreit scheinen. Man hat wohl auch noch wachend, in Abendstunden geistiger Arbeit, des Schauens und Phantasierens, der Vorsätze und des Schaffens, oft eine Stimmung, wo einem alles federleicht, ohne Hemmnis, möglich und durchführbar erscheint. Dann kommt der graue Tag und man begreift nicht mehr, daß man so tapfer, so gläubig, so hoffungsvoll und so zweifellos gewesen ist. Dieser Tag ist lang [...]. So ist es mit dem Verhältnis der traumhaft schnellen, aber auch kurzen Revolutionen zu den langen und langsamen Zwischenzeiten." Landauer (1923 [zuerst 1905/07]) Die Revolution, S. 80-81, vgl. S. 90 [Hervorh. d. Verf.].

76 Neupert-Doppler (2015) Utopie, S. 60. 
77 Vgl. a. a. O., S. 70-71; in Bezugnahme auf Bloch (1962) Über Politik als Kunst des Möglichen.

78 Vgl. Ueding (1982) Ernst Blochs Philosophie der Utopie, S. 295.

79 Hans Heinz Holz (1975) Logos spermatikos. Ernst Blochs Philosophie der unfertigen Welt. Luchterhand, Darmstadt u. Neuwied, S. 102.

80 Siehe dazu Peter Zudeick (1985) Der Hintern des Teufels. Ernst Bloch - Leben und Werk. Elster, Moos u. Baden-Baden, S. 50-70.

81 Nipperdey (1962) Die Funktion der Utopie im politischen Denken der Neuzeit, S. 358.

82 Bloch (1959) Das Prinzip Hoffnung, Bd. 1, Teil 2, S. 166 [Hervorh. i. O.].

83 Vgl. Bloch (1959) Entdeckung des Noch-Nicht-Bewußten oder der Dämmerung nach Vorwärts. Noch-Nicht-Bewußtes als neue Bewußtseinsklasse und als Bewußtseinsklasse des Neuen, S. 129-203. In: Das Prinzip Hoffnung, Bd. 1, Teil 2, hier S. 197-198; vgl. Bloch (1977) Zur Ontologie des Noch-Nicht-Seins, S. 210-242. In: Tübinger Einleitung in die Philosophie, hier S. 219.

Siehe dazu weiterührend auch Eberhard Braun (1983) Antizipation des Seins wie Utopie. Zur Grundlegung der Ontologie des Noch-Nicht-Seins im ,Prinzip Hoffnung', S. 123-150. In: Burghart Schmidt (Hrsg.) Seminar. Zur Philosophie Ernst Blochs. Suhrkamp, Frankfurt/M.

84 Karl Marx (1843) Brief an den Schriftsteller Arnold Ruge. Nach: Briefe aus den ,Deutsch-Französischen Jahrbüchern' (1844). In: MEW, Bd. 1 (1981) S. 346 [Hervorh. d. Verf.].

85 1938-47 in den USA verfasst, 1953 und 1959 durchgesehen.

86 Vgl. Gerd Ueding (2009) Utopie in dürftiger Zeit. Studien über Ernst Bloch. Königshausen u. Neumann, Würzburg.

87 Holz (1975) Logos spermatikos, S. 102 [Hervorh. i. O.].

88 Vgl. Ernst-Bloch-Zentrum. Online: http://www.bloch.de/wissenschaft/wer-ist-ernst-bloch/philosophie/ (27.6.17).

89 Bloch (1959) Das Prinzip Hoffnung, Bd. 1, Teil 2, S. 164.

90 A. a. O., S. 197.

91 Vgl. Levitas (2013) Utopia as Method, S. 6 [Übers. d. Verf.].

92 Bloch (1959) Das Prinzip Hoffnung, Bd. 1, Teil 2, S. 166.

93 Bloch (1971) Utopien des kleinen Mannes und andere Tagträume. Ein Gespräch mit Gerd Ueding, S. 41-57. In: Gespräche mit Ernst Bloch. Hrsg. v. Rainer Traub, Harald Wieser, S. 56.

94 Vgl. Bloch (1959) Das Prinzip Hoffnung, Bd. 2, Teil 4, S. 727. 
95 Vgl. Bloch (1959) Das Prinzip Hoffnung, Bd. 1, Teil 2, S. 198 [Hervorh. i. O.].

96 Bloch (1959) Das Prinzip Hoffnung, Bd. 2, Teil 4, S. 727.

97 Ueding (1982) Ernst Blochs Philosophie der Utopie, S. 293.

98 „Blochs Denken [...] verschlingt alles, was ihm aus der Geschichte entgegenkommt, und assimiliert es in einem Stoffwechselprozeß ohne gleichen. Ein ungeheures enzyklopädisches Wissen und eine mit allen Wassern gewaschene Kunst der Interpretation vermögen jeden Stoff dem eigenen System anzuverwandeln." Holz (1975) Logos spermatikos, S. 102.

$99 \mathrm{Vgl}$. Bloch in einem Rundfunkgespräch mit Adorno: Etwas fehlt... über die Widersprüche der utopischen Sehnsucht. In: Bloch (1978) Tendenz-Latenz-Utopie. Suhrkamp, Frankfurt/M., S. 355.

100 Bloch schematisiert zwei Grundtypen: „Utopien der Freiheit (Alchymie) und Utopien der Ordnung (Astrologie)"; exemplarisch steht Morus' Utopia für Erstere, in der „zum erstenmale Demokratie im humanen Sinn, im Sinn öffentlicher Freiheit und Toleranz, mit Kollektivwirtschaft verbunden"; Campanellas Sonnenstaat für Letztere, der "personenlosen Ordnung, gedacht im Weltstaat", hier: Holz (1975) Logos spermatikos, S. 104; vgl. Bloch (1959) Das Prinzip Hoffnung, Bd. 2, Teil 4, S. 612-614.

101 Ueding (1982) Ernst Blochs Philosophie der Utopie, S. 301.

102 Vgl. Bloch (1959) Das Prinzip Hoffnung, Bd. 1, Teil 2, S. 166.

103 Siehe dazu, z. B. Jörg H. Gleiter (2014) Stoff, Form, Hylemorphismus, S. 127-131. In: Mario Rinke, Joseph Schwartz (Hrsg.) Holz: Stoff oder Form. Transformation einer Konstruktionslogik. Niggli, Salenstein/ $\mathrm{CH}$.

104 Anja Müller (n. a.) Ernst Bloch: Spuren, 1930. In: Bibliothek verbrannter Bücher. Online: www.verbrannte-buecher.de/?page_ id=882 (29.3.17).

105 Navid Kermani (2011) Bloch, gegen die Gegenwart gedacht. Eine Rede anlässlich der Verleihung des Ernst-Bloch-Förderpreises im Jahr 2000, S. 220-223. In: Julian Nida-Rümelin, Klaus Kufeld (Hrsg.) Die Zeitkritik der Utopie. Zeitkritik und Denkwende. Karl Alber, Freiburg u. München, S. 221.

106 Louis Wirth (1937) Vorwort zur englischen Ausgabe, später ins Deutsche übertragen, S. ix-xxvii. In: Karl Mannheim (1969 [zuerst 1929]) Ideologie und Utopie, Verlag Schulte-Bulmke, Frankfurt/M., S. xix.

107 Vgl. Gerhard Schulte-Bulmke (1952) Vorwort zur dritten Auflage, S. v-vi. In: Mannheim (1969 [zuerst 1929]) Ideologie und Utopie, S. v. 
108 Entsprechend Mannheims lebensgeschichtlicher Erfahrung; dies übersehe die Kritik an diesem soziologischen Ideal oftmals, so Wilhelm Hofmann (1996) Karl Mannheim. Zur Einführung. Junius, Hamburg, S. 35.

109 Neupert-Doppler (2015) Utopie, S. 82.

110 Hofmann (1996) Karl Mannheim, S. 98-100.

111 Mannheim (1969 [zuerst 1929]) Ideologie und Utopie, S. 70 [Hervorh. i. O.].

Zur allgemeinen Problematik der totalen Ideologiekritik als selbstkritische Kunde: Die Erkenntnistheorie des historischen Materialismus (nach Marx) lautet, dass der jeweils gegenwärtige Mensch (bzw. seine Gedanken, Fühlen und Wollen, d. h. sein Bewusstsein) Produkt seiner sozioökonomischen Situation ist; darin besteht seine Entfremdung. Er lebt in bzw. sein Bewusstsein ist falsches Bewusstsein.

Marx hat dieses Problem gesehen und erklärt, dass die Abhängigkeit des Bewusstseins von der sozioökonomischen Situation in dem Augenblick, in dem die Klassengegensätze aufgehoben sind, ebenso aufgehoben wird; erst im Moment ihrer Aufhebung (Revolution/Ende der Klassengegensätze) kann die entfremdete Situation verstanden werden. Solange die Klassengegensätze nicht aufgehoben sind, bleibt dem Anhänger der Lehre nichts Anderes übrig, als sich an der Möglichkeit eines immerhin ,aufgeklärten falschen Bewusstseins' [Sloterdijk] festzuhalten, vgl. Schloßberger (2013) Geschichtsphilosophie, S. 159-160.

112 Wirth (1937) Vorwort zur englischen Ausgabe, S. xix; siehe zur komplexen Begriffsgeschichte der Ideologie, z. B. Terry Eagleton (1993 [Engl. 1991]) Ideologie. Eine Einführung. Metzler, Stuttgart, speziell S. 1-41.

113 Mannheim (1969 [zuerst 1929]) Ideologie und Utopie, S. 36.

$114 \mathrm{Vgl}$. Andreas Heyer (2007) Ursprung und Gehalt des Utopiebegriffs von Karl Mannheim, S. 241-251. In: UTOPIE kreativ. Diskussion sozialistischer Alternativen, Nr. 197. Hrsg. v. Rosa-Luxemburg-Stiftung, S. 245. Online: https://www.rosalux.de/fileadmin/rls_uploads/pdfs/ Utopie_kreativ/197/197Heyer.pdf (20.6.17).

115 Mannheim (1969 [zuerst 1929]) Ideologie und Utopie, S. 36-37.

116 Vgl. Heyer (2007) Ursprung und Gehalt des Utopiebegriffs von Karl Mannheim, S. 245; siehe zur kritischen Auseinandersetzung mit Mannheim vertiefend Horkheimer (1930) Ein neuer Ideologiebegriff?, S. 271-294. In: Ders. (1987) Gesammelte Schriften, Bd. 2: Philosophische Frühschriften 1922-32. Hrsg. v. Gunzelin Schmid Noerr. Fischer, Frankfurt/M.; und vgl. Adorno (1979) Beitrag zur 
Ideologienlehre, S. 457-477. In: Ders. (1972) Soziologische Schriften I. Gesammelte Schriften, Bd. 8. Hrsg. v. Rolf Tiedemann. Suhrkamp, Frankfurt/M., speziell S. 471-476.

117 Heyer (2007) Ursprung und Gehalt des Utopiebegriffs von Karl Mannheim, S. 245.

118 Wilhelm Hofmann (2007) Lemma: Karl Mannheim, Ideologie und Utopie, S. 338-342. In: Hauptwerke der politischen Theorie, S. 342.

$119 \mathrm{Vgl}$. Hofmann (1996) Karl Mannheim, S. 111, 115.

120 Hofmann (2007) Lemma: Karl Mannheim, S. 342.

121 Vgl. Hofmann (1996) Karl Mannheim, S. 110.

Die Stadt- und Raumsoziologin Silke Steets aktualisiert in ihrem Buch Der sinnhafte Aufbau der gebauten Welt. Eine Architektursoziologie (2015) die Architekturtheorie als wissenssoziologische Praxis.

122 Horkheimer (1971 [zuerst 1930]) Anfänge der bürgerlichen Geschichtsphilosophie, S. 62.

123 Schmidt (1988) Kritik der reinen Utopie, S. 63.

124 Vgl. Horkheimer (1971 [zuerst 1930]) Anfänge der bürgerlichen Geschichtsphilosophie, S. 62-63.

Hegels Doppelsatz aus der Vorrede seiner Rechtsphilosophie lautet: „Was vernünftig ist, das ist wirklich; und was wirklich ist, das ist vernünftig." G. W. F. Hegel (2013 [zuerst 1820]) Grundlinien der Philosophie des Rechts. Hrsg. v. Horst D. Brandt. Meiner, Hamburg, S. 16; dazu vgl. Thomas Sören Hoffmann (2004) Georg Wilhelm Friedrich Hegel. Eine Propädeutik. Marix, Wiesbaden, S. 21, 44.

125 Adorno (2003 [zuerst 1977]) Aldous Huxley und die Utopie, S. 97-122. In: Ders. Kulturkritik und Gesellschaft I. Prismen. Ohne Leitbild. Gesammelte Schriften, Bd. 10.1. Hrsg. v. Rolf Tiedemann. Suhrkamp, Frankfurt/M., S. 102.

126 Siehe dazu Horkheimer, Adorno (2013 [zuerst 1944]) Dialektik der Aufklärung. Philosophische Fragmente. Fischer, Frankfurt/M.; Adorno (2003 [zuerst 1951]) Minima Moralia. Reflexionen aus dem beschädigten Leben. Suhrkamp, Frankfurt/M.

127 Christian Kreis (2006) Das Verhältnis der "Kritischen Theorie" von Max Horkheimer und Theodor W. Adorno zum utopischen Denken. Ibidem, Stuttgart, S. 11.

128 Vgl. Gerhard Schweppenhäuser (1996) Theodor W. Adorno zur Einführung. Junius, Hamburg, S. 21. 


\section{Macht und Herrschaft}

1 Niccolò Machiavelli (2011 [Ital. 1513]) Der Fürst. Übers. v. August W. Rehberg. Nikol Verlag, Hamburg, S. 88.

2 Vgl. Thomas Schölderle (2012) Geschichte der Utopie. Eine Einführung. Böhlau, Köln, S. 21.

3 Vgl. Horkheimer (1971 [zuerst 1930]) Anfänge der bürgerlichen Geschichtsphilosophie, S. 17, 20.

4 Machiavelli (1513-19) Discorsi zit. nach Horkheimer (1971 [zuerst 1930]) Anfänge der bürgerlichen Geschichtsphilosophie, S. 20.

5 Siehe dazu, z. B. Ulrike Guérot (2019 [zuerst 2017]) Warum Europa eine Republik werden muss. Eine politische Utopie. 3. Auflage. Piper, München; hier speziell S. 105-146.

6 Vgl. Elias (1982) Thomas Morus' Staatskritik, S. 110-111.

7 Vgl. Andreas Tönnesmann (2004) Filarete im Dialog: Der Architekt, der Fürst und die Macht, S. 153-163. In: Bodo Guthmüller, Wolfgang G. Müller (Hrsg.) Dialog und Gesprächskultur in der Renaissance. Sonderdruck. Harrassowitz Verlag in Kommission der Herzog August Bibliothek Wolfenbüttel, S. 159-162.

Siehe dazu auch, z. B. Hubertus Günther (2012) Der Architekt in der Renaissance, S. 81-103. In: Winfried Nerdinger (Hrsg.) Der Architekt. Geschichte und Gegenwart eines Berufsstandes, Bd. 1. Publikation zur gleichnamigen Ausstellung des Architekturmuseums der TU München. Prestel, München.

$8 \quad$ Kruft (2004 [zuerst 1985]) Geschichte der Architekturtheorie, S. 59.

9 Max Weber (1922) Wirtschaft und Gesellschaft: Grundriss der verstehenden Soziologie. Erster Teil: Die Wirtschaft und die gesellschaftlichen Ordnungen und Mächte. III. Die Typen der Herrschaft, 1. Die Legitimitätsgeltung: § 1. Definition der Herrschaft. Legitimität, Gehorsam. Online: https://www.textlog.de/7354.html (5.8.20). [Hervorh. i. O.].

Siehe auch a. a. O. Erster Teil. I. Soziologische Grundbegriffe: § 16. Macht und Herrschaft). Online: https://www.textlog.de/7312.html (3.9.19).

10 Peter Imbusch (1998) Macht und Herrschaft in der Diskussion, S. 9-26. In: Ders. (Hrsg.) Macht und Herrschaft. Sozialwissenschaftliche Konzeptionen und Theorien. Leske + Budrich, Opladen, S. 20-21.

11 Vgl. Dirk Hülst (1998) ,Nicht bei sich selber zu Hause sein' Horkheimer und Adorno über Macht und Herrschaft, S. 110-129. In: Imbusch (Hrsg.) Macht und Herrschaft, S. 124-125. 
12 A. a. O., S. 125. Siehe dazu auch Theodor W. Adorno (1972 [zuerst 1968]) Spätkapitalismus oder Industriegesellschaft? Einleitungsvortrag zum 16. Deutschen Soziologentag, S. 354-370. In: Soziologische Schriften I. Gesammelte Schriften, Bd. 8. Hrsg. v. Rolf Tiedemann. Suhrkamp, Frankfurt/M.

Max Horkheimer (1981 [zuerst 1942]) Autoritärer Staat, S. 13-35. In: Gesellschaft im Übergang. Aufsätze, Reden und Vorträge 19421970. Hrsg. v. Werner Brede. 2. Auflage. Fischer, Frankfurt/M.

13 Vgl. G. W. F. Hegel (1986 [zuerst 1807[) Phänomenologie des Geistes. Werke 3. Neu editierte Ausgabe auf Grundlage der Werke von 1832-45. Suhrkamp, Frankfurt/M., S. 145-155.

14 Peter Sloterdijk (1983) Kritik der zynischen Vernunft. Suhrkamp, Frankfurt/M., S. 21-22 [Hervorh. i. O.].

15 Vgl. Erik Olin Wright (2017 [Engl. 2010]) Reale Utopien. Wege aus dem Kapitalismus. Suhrkamp, Berlin, S. 174 [Hervorh. i. O.].

16 Imbusch (1998) Macht und Herrschaft in der Diskussion, S. 10-11.

17 Foucault analysiert den Wandel der Machttypen der nahen Vergangenheit und Gegenwart und erklärt den Übergang von der Souveränitäts- zur Disziplinarmacht und die Ausdifferenzierung der Disziplinar- zur Biomacht, vgl. Breitenstein (2013) Die Befreiung der Geschichte, S. 274.

18 Geoff Eley (1994) Wie denken wir über Politik? Alltagsgeschichte und die Kategorie des Politischen, S. 17-36. In: Berliner Geschichtswerkstatt (Hrsg.) Alltagskultur, Subjektivität und Geschichte. Zur Theorie und Praxis von Alltagsgeschichte. Westfälisches Dampfboot, Münster, S. 21-23.

\section{Utopie in der Architektur}

1 Vgl. Suzanne Lang (1952) The Ideal City. From Plato to Howard, S. 91-101. In: The Architectural Review, Nr. 868, S. 91-92.

2 Standardwerke der Idealstadtgeschichte, z. B. Lewis Mumford (1922) The Story of Utopias; Helen Rosenau (1959) The Ideal City; Ian Tod, Michael Wheeler (1978) Utopia; Hanno-Walter Kruft (1989) Städte in Utopia; Virgilio Vercelloni (1994) Europäische Stadtutopien; Gerd de Bruyn (1996) Die Diktatur der Philanthropen; Ruth Eaton (2001) Die ideale Stadt.

3 Vgl. Lemmata: Hippodamisches System, Hippodamos von Milet. In: Nikolaus Pevsner et al. (1992 [Engl. 1966]) Lexikon der Weltarchitektur. Prestel, München, S. 276; Berthold F. Weber (2004) Der Stadtplan des kaiserzeitlichen Milet, S. 231-240. In: Ernst-Ludwig 
Schwandner, Klaus Rheidt (Hrsg.) Macht der Architektur. Architektur der Macht. Diskussionen zur archäologischen Bauforschung, Bd. 8, S. 240.

4 Vgl. Szidat (1980) Hippodamos von Milet. Seine Rolle in Theorie und Praxis der griechischen Stadtplanung, S. 40-41.

5 Charlotte Triebel-Schubert, Ulrike Muss (1983) Hippodamos von Milet. Staatstheoretiker oder Stadtplaner? S. 37-60. In: Hephaistos. Kritische Zeitschrift zu Theorie und Praxis der Archäologie und angrenzender Gebiete. Heft 5/6, S. 55-56.

6 Politeia, Timaios (Welt entsteht), Kritias (Welt vergeht; Atlantisbericht), Nomoi.

7 Vgl. Lewis Mumford (1961) The City in History. Its Origins, Its Transformations, and Its Prospects. Harcourt, Orlando/FL, S. 180; Aristoteles begrenzt die ideale Anzahl der jeweiligen Bewohnerschaft auf ca. 10.000 Menschen.

8 Vgl. Mumford (1970 [Engl. 1965]) Utopie, Stadt und Maschine, S. 28, 34.

9 Die bildnerische Ausdeutung utopischer Schriften stellt ein eigenständiges Forschungsfeld dar, z. B. sind der Diskrepanz von Morus Beschreibung der Insel Utopia zu den bekannten Holzschnitten ganze Abhandlungen gewidmet oder Utopias Hauptstadt Amorautum wird auf unterschiedliche Weise zeichnerisch rekonstruiert.

Siehe dazu, z. B. Eva Eylers (2015) Thomas More's Utopia. Amorautum and the vision of a public life. Konferenzbeitrag Research Committee 21, Urbino/Italien. Online: https://www.rc21. org/en/wp-content/uploads/2014/12/B2_Eylers.pdf (23.11.18); oder: Harald Kegler (2018) Der Plan von Amorautum, S. 13-28. In: Irene Leser, Jessica Schwarz (Hrsg.) utopisch-dystopisch. Visionen einer ,idealen' Gesellschaft. Springer VS, Wiesbaden.

10 Platon (2014 [ca. 350 v. Chr.]) Timaios, S. 11-103. In: Sämtliche Werke, Bd. 4. Übers. v. Friedrich Schleiermacher u. hrsg. v. Ursula Wolf. Rowohlt, Reinbek bei Hamburg, S. 31-32, § 33.b [Hervorh. d. Verf.].

11 Vgl. Colin Rowe (1998 [Engl. 1959]) Die Architektur Utopias, S. 209-226. In: Die Mathematik der idealen Villa und andere Essays. Birkhäuser, Basel, S. 210.

12 Vgl. Rowe (1998 [Engl. 1959]) Die Architektur Utopias, S. 209-210; Hermann Bauer (1993) Über einige utopische Topoi und die Anfänge der Kunsttheorie in der Renaissance, S. 1-9. In: Georg Jenal (Hrsg.) Gegenwart in Vergangenheit. Beiträge zur Kultur und 
Geschichte der Neueren und Neuesten Zeit. Oldenbourg Verlag, München, S. 5-7; Saage (2001) Utopische Profile, Bd. 1, S. 205-210.

13 Vgl. Hanno-Walter Kruft (1989) Städte in Utopia. Die Idealstadt vom 15. bis zum 18. Jahrhundert zwischen Staatsutopie und Wirklichkeit. C.H.Beck, München, S. 13, 20-21.

14 Vgl. Hermann Bauer (1993) Über einige utopische Topoi und die Anfänge der Kunsttheorie in der Renaissance, S. 5-7, 8-9.

15 Vgl. Tönnesmann (2004) Filarete im Dialog, S. 157.

16 Vgl. Hanno-Walter Kruft (2004 [zuerst 1985]) Geschichte der Architekturtheorie. Von der Antike bis zur Gegenwart. C.H.Beck, München, S. 59.

17 Saage (1991) Politische Utopien der Neuzeit, S. 27-28.

$18 \mathrm{Vgl}$. Rowe (1998 [Engl. 1959]) Die Architektur Utopias, S. 209-210.

19 Kruft (1989) Städte in Utopia, S. 11.

20 Vgl. ebd.

21 Realisierte Idealstädte, z. B. in Italien u. a. Pienza (Umgestaltung zur Idealstadt ab 1459), Palmanova (realisiert durch Vincenzo Scamozzi ab 1593), Sabbioneta (Errichtung 1554-1571); in Deutschland u. a. Freudenstadt (Gründungsdatum 1599), Karlsruhe (1715); und solche in Malta, Frankreich und Nordamerika. Siehe dazu, z. B. Kruft (1989) Städte in Utopia; Lewis Mumford (1961) Stadt. Geschichte und Ausblick; Joseph Rykwert (1963) The Idea of a Town; Leonardo Benevolo (1975) Geschichte der Stadt.

22 Vgl. Schloßberger (2013) Geschichtsphilosophie, S. 43-46.

23 Vgl. Saage (2001) Utopische Profile, Bd. 1, S. 210.

24 Vgl. a. a. O., S. 41-42.

25 Vgl. Kruft (1989) Städte in Utopia, S. 17; Saage (2004) Wie zukunftsfähig ist der klassische Utopiebegriff? S. 618, 625.

26 Vgl. Frank E. Manuel (1970 [Engl. 1965]) Zur psychologischen Geschichte der Utopien, S. 80-114. In: Ders. (Hrsg.) Wunschtraum und Experiment, S. 94-95.

27 Siehe dazu Emil Kaufmann (1933) Von Ledoux bis Le Corbusier. Ursprung und Entwicklung der autonomen Architektur. Verlag Dr. Rolf Passer, Wien u. Leipzig.

28 Vgl. Kruft (1989) Städte in Utopia, S. 112-126; Teilrealisierung der Salines Royales in Arc-et-Senans bei Besançon/Frankreich.

29 Vgl. Johannes Langner (1986) Bauten in Bildern der Zukunft. Utopische Architektur, S. 163-173. In: Der Traum vom Raum. Gemalte Architektur aus 7 Jahrhunderten. Katalog zur gleichnamigen 
Ausstellung der Albrecht Dürer Gesellschaft in Zusammenarbeit mit der Kunsthalle Nürnberg. Hitzeroth, Marburg, S. 167-168.

30 A. a. O., S. 168.

31 Manfredo Tafuri (1977 [Ital. 1973]) Kapitalismus und Architektur. Von Corbusiers „Utopia” zur Trabantenstadt VSA, Hamburg u. Westberlin, S. 19.

32 Vgl. Charles Fourier (1966 [Frz. 1808]) Theorie der vier Bewegungen und der allgemeinen Bestimmungen. Hrsg. v. Theodor W. Adorno u. eingel. v. Elisabeth Lenk. Europäische Verlagsanstalt, Frankfurt/M. zit. nach Richard Saage (1999) Utopie und Eros. Zu Charles Fouriers „neuer sozietärer Ordnung", S. 68-80. In: UTOPIE kreativ. Diskussion sozialistischer Alternativen, Nr. 105. Hrsg. v. Rosa-Luxemburg-Stiftung, S. 68. Online: https://www.rosalux.de/fileadmin/rls_ uploads/pdfs/105_Saage.pdf (16.4.17).

33 Vgl. Mumford (1970 [Engl. 1965]) Utopie, Stadt und Maschine, S. 46.

34 Vgl. Mechthild Schumpp (1972) Stadtbau-Utopien und Gesellschaft. Der Bedeutungswandel utopischer Stadtmodelle unter sozialem Aspekt. Bauwelt Fundamente, Bd. 32. Bertelsmann, Gütersloh, S. 57-58.

35 Vgl. Manuel (1970 [Engl. 1965]) Zur psychologischen Geschichte der Utopien, S. 95.

36 Vgl. a. a. O., S. 98.

37 Vgl. Elisabeth Lenk (1966) Einleitung. Charles Fourier. Theorie der vier Bewegungen und der allgemeinen Bestimmungen, S. 16, 22.

38 Franziska Bollerey (1991 [zuerst 1977]) Architekturkonzeptionen der utopischen Sozialisten. Alternative Planung und Architektur für den gesellschaftlichen Prozeß. Ernst \& Sohn, Berlin, S. 110-111 [Hervorh. d Verf.].

39 Vgl. Roland Barthes (1971) Sade, Fourier, Loyola zit. nach Manfred Russo (2016) Projekt Stadt. Eine Geschichte der Urbanität. Birkhäuser, Basel, S. 195-196.

40 Vgl. die Zeichnungen in seiner späteren Schrift Le nouveau monde industriel et sociétaire (Frz. Die neue Welt der Industrie und Vergesellschaftung, 1829), S. 116-117; vgl. Bollerey (1991 [zuerst 1977]) Architekturkonzeptionen der utopischen Sozialisten, S. 119, 121, 124-125, 128, 145.

41 Colin Rowe, Fred Koetter (1997 [Engl. 1978]) Collage City. Birkhäuser, Basel, S. 33.

42 Vgl. Lenk (1966) Einleitung. Charles Fourier, S. 35.

43 Theodor W. Adorno (1966) Vorwort. Charles Fourier. Theorie der vier Bewegungen und der allgemeinen Bestimmungen, S. 6. 
45 Vgl. Reinhard Bentmann, Michael Müller (1992 [zuerst 1970]) Die Villa als Herrschaftsarchitektur. Versuch einer kunst- und sozialgeschichtlichen Analyse. Europäische Verlagsanstalt, Hamburg, S. 10-21.

46 Vor dem Hintergrund von Englands fortgeschrittener sozioökonomischer Entwicklung: In der Kritik von Friedrich Engels Lage der arbeitenden Klasse in England (1845); unter Einfluss von Robert Owens idealem Gemeinschaftsmodell, das er als autarke, landwirtschaftlich organisierte Produktionseinheiten außerhalb der keimenden Erwerbsgesellschaft verwirklicht sieht: Umsetzungsbestrebungen zuerst in Schottland (New Lanark, 1797), später in Nordamerika (New Harmony, 1824/25). „[Eine] neue Art von Siedlung [...], die in wohldurchdachten Ausmaßen ein Zwischending zwischen Stadt und einem großen Bauernhof darstellt: klein genug, um einen engen Zusammenhang aller Einzelbereiche zu gewährleisten, aber doch groß genug, um ein ausgefülltes und von außen unabhängiges Wirtschafts- und Kulturleben zu ermöglichen." Leonardo Benevolo (2007 [Ital. 1975] Die Geschichte der Stadt. Campus, Frankfurt/M., S. 804-805.

47 Ebenezer Howard (1907 [Engl. 1898]) Gartenstädte in Sicht zit. nach Julius Posener (Hrsg.) (1968) Ebenezer Howard. Gartenstädte von morgen: Das Buch und seine Geschichte, Bauwelt Fundamente, Bd. 21, S. 58-61.

Diese Entwicklung entstand unter dem Eindruck des Werkes von Patrick Geddes, eines schottischen Biologen, dessen Stadtkonzept auf der Auffassung beruht, dass die Stadt durch die Kräfte der Natur hervorgebracht wird, vgl. Russo (2016) Projekt Stadt, S. 215-226.

48 Siehe dazu Tony Garnier (1969 [Frz. 1917]) The Cité Industrielle; vgl. Ruth Eaton (2001) Die ideale Stadt. Von der Antike bis zur Gegenwart. Nicolai, Berlin, S. 196-198.

49 Vgl. Dora Wiebenson (1960) Utopian Aspects of Tony Garnier's Cité Industrielle, S. 16-24. In: Journal of the Society of Architectural Historians (JSAH), xix, University of California Press, Berkeley/CA, S. 19.

50 Garniers Werk ist unter dem Eindruck von Émile Zolas Roman Travail (1901) entstanden und gilt als dessen architektonische Umsetzung. Zola ersetzt eine alte Stadt L'Abîme (Frz. Der Abgrund) durch eine neue Stadt La Crêcherie (La crèche, Frz. Die Krippe). Die Organisation der Arbeit, wiederum beeinflusst von Fouriers Lehren, bildet das Zentrum der Gesellschaft. Die Umfunktionierung der Schlüsselbauten symbolisiert die Wandlung der alten zur neuen 
Gesellschaft. Das Gerichtsgebäude [Beurteilung] wird zum Museum [Bildung], das Gefängnis [Züchtigung] wird ein Badehaus [Freizeit], vgl. Eaton (2001) Die ideale Stadt, S. 197-199.

51 Zurückzuführen auf die "Verhältnislehre” (1792) des deutschen Philanthropen Franz Heinrich Ziegenhagen.

52 Siehe dazu, z. B. Tanja Poppelreuter (2007) Das Neue Bauen für den Neuen Menschen. Zur Wandlung und Wirkung des Menschenbildes in der Architektur der 1920er Jahre in Deutschland. Olms Verlag, Hildesheim.

53 Vgl. Nathaniel Coleman (2005) Utopias and Architecture. Routledge, Oxon/UK, S. 55-56; Sigfried Giedion (2015 [Engl. 1941]) Raum Zeit Architektur. Die Entstehung einer neuen Tradition. Birkhäuser, Basel, S. 340.

54 Schumpp (1972) Stadtbau-Utopien und Gesellschaft, S. 14 [Hervorh. i. O.].

55 Technizistische Architekturutopien sind von der Technik ausgehend gedacht, wobei die Verabsolutierung des Wertes der Technik eine Schwierigkeit darstellt. Humanistische Architekturutopien sind vom Menschen ausgehend gedacht, wobei die Konstruktion eines Menschen- bzw. Gesellschaftsbildes eine Schwierigkeit darstellt, vgl. Tafuri (1973) Architektur und Utopie, S. 100-102.

Die Unterscheidung in "technische und soziale Utopien" wäre zu kurz gegriffen, denn technisch ausgerichtete Utopien können durchaus sozialpolitische Ideen beinhalten und sozial ausgerichtete Utopien können durchaus technische Komponenten beinhalten, z. B. Handwerk, Infrastruktur oder basieren gar auf technischen Grundlagen, heute etwa Soziale Medien.

Schon der Begriff der Technik selbst beinhaltet beide Komponenten, d.h. Gegenstände und Systeme (Maschinen, Geräte, Apparate) sind technischer Natur; aber auch gesellschaftspolitisches Vorgehen und Systeme (Formen des Wissens und Handelns) werden als soziale Techniken verstanden.

Architektonische Minimaltechniken umfassen sowohl materiellkonstruktive als auch sozialpolitische Techniken, werden aber als Instrumente zugunsten von humanistischen Architekturutopien verstanden.

In der Dichotomie Humanismus/Technizismus soll sich auch der von Dichotomien geprägte Diskurs der Moderne widerspiegeln, z. B. Zivilisation/Natur, Stadt/Land, öffentlicher/privater Raum, Gemeinschaft/Gesellschaft, Arbeit/Freizeit, Mann/Frau, Orient/Okzident.

56 Vgl. Friedrich Achleitner (1967) Aufforderung zum Vertrauen. Architektur seit 1945, S. 48-76. In: Ders. (1987) Aufforderung zum 
Vertrauen. Aufsätze zur Architektur. Residenz Verlag, Salzburg und Wien, S. 57.

57 Sieh dazu, z. B. Sebastian Haffner (2018 [zuerst 1969]) Die deutsche Revolution 1918/19. Rowohlt, Reinbek bei Hamburg.

58 Marcel Bois (2019) „Die Kunst—das ist eine Sache!, wenn sie da ist". Zur Geschichte des Arbeitsrates für Kunst in der frühen Weimarer Republik. Online: http://www.bauhaus-imaginista.org/ articles/3207/the-art-that-s-one-thing-when-it-s-there/de (2.2.19).

59 Vgl. Eaton (2001) Die ideale Stadt, S. 164-167.

60 Siehe dazu Jörg H. Gleiter (2010) Urgeschichte der Moderne: Japan, S. 112-140. In: Ders. Urgeschichte der Moderne. transcript, Bielefeld.

61 Bloch (1959) Das Prinzip Hoffnung, Bd. 2, Teil 4, S. 872; vgl. Doris Zeilinger (2017) Zur technischen Utopie (4. Teil Nr. 37, 38), S. 203-225. In: Ernst Bloch. Das Prinzip Hoffnung (Klassiker auslegen). Hrsg. v. Rainer E. Zimmermann. De Gruyter, Berlin, S. 223

62 Vgl. Landauer (1911) Aufruf zum Sozialismus zit. nach Eaton (2001) Die ideale Stadt, S. 164-167; siehe dazu auch Bruno Taut (1920) Die Auflösung der Städte oder die Erde eine gute Wohnung oder auch: Der Weg zur Alpinen Architektur. Folkwang Verlag, Hagen in Westfalen.

63 Siehe dazu, z. B. Weidermann (2018) Träumer; Birte Förster (2018) 1919: Ein Kontinent erfindet sich neu. Reclam, Stuttgart.

64 Tafuri (1977 [Ital. 1973]) Kapitalismus und Architektur, S. 90-92 [Hervorh. i. O.].

65 Vgl. Rowe, Koetter (1997 [Engl. 1978]) Collage City, S. 41.

66 Antonio Sant'Elia, Filippo Tommaso Marinetti (1914) Futuristische Architektur, S. 30-35. In: Ulrich Conrads (Hrsg.) (2001 [zuerst 1964]) Programme und Manifeste zur Architektur des 20. Jahrhunderts. Bauwelt Fundamente, Bd. 1. Vieweg, Braunschweig u. Wiesbaden, S. 31-32.

67 Weidermann (2018) Träumer, S. 33

68 Vgl. Rowe, Koetter (1997 [Engl. 1978]) Collage City, S. 38-39, 42-43.

69 Vgl. Le Corbusier (1985 [Frz. 1922]) Ausblick auf eine Architektur. Bauwelt Fundamente, Bd. 2. Vieweg, Braunschweig u. Wiesbaden, S. 201-215.

70 Vgl. Le Corbusier (2015 [Frz. 1925]) Städtebau. DVA, München, S. 252-253.

71 Julius Posener (2013 [zuerst 1981]) Vorlesungen zur Geschichte der Neuen Architektur. Vorlesungsreihe V/8: Die moderne Architektur (1924-33), Le Corbusier I, S. 308-315. In: Archplus, Nr. 210: Julius 
Posener. Vorlesungen zur Geschichte der Neuen Architektur, Bd. 2, S. 309-310.

72 Le Corbusier (2001 [Frz. 1929]) Feststellungen zu Architektur und Städtebau. Bauwelt Fundamente, Bd. 12. Birkhäuser, Basel, S. 47.

73 Posener (2013 [zuerst 1981]) Vorlesungen zur Geschichte der Neuen Architektur, Vorlesungsreihe V/8: Die moderne Architektur (192433), Le Corbusier I, S. 309.

74 A. a. O., S. 314-315 [Hervorh. i. O.].

75 Vgl. Jörg H. Gleiter (2018) Architekturtheorie Grundlagen I. Traditionelle Theorie 1863-1938. DOM, Berlin, S. 138-139.

76 Vgl. Ian Tod, Michael Wheeler (1978) Utopia. Orbis, London/UK, S. 140-141.

77 In der deutschen Übersetzung „Internationale Kongresse für Neues Bauen", mit Betonung auf das politisch-aktivistische neue Bauen, das die Vision einer kollektiven sozialen Transformation in sich trägt.

78 Tafuri (1977 [Ital. 1973]) Kapitalismus und Architektur, S. 94 [Hervorh. i. O.].

79 Siehe dazu, z. B. Max Risselada, Dirk van den Heuvel (Hrsg.) (2005) Team 10. A Utopia of the Present. Katalog zur gleichnamigen Ausstellung im Netherlands Architecture Institute Rotterdam. NAi publishers, Rotterdam.

80 Siehe dazu, z. B. Martin van Schaik, Otakar Mácel (Hrsg.) (2005) Exit Utopia. Architectural Provocations 1956-76. Prestel, München.

81 Manfredo Tafuri (2006 [Ital. 1992]) Interpreting the Renaissance. Princes, Cities, Architects. Yale University Press, New Haven/CT, S. xxix.

82 Siehe dazu, z. B. Dieter Hoffmann-Axthelm (2018) Hochhaus und Gemeinschaft. Zur Erbschaft der Moderne. DOM, Berlin.

83 Rowe, Koetter (1997 [Engl. 1978]) Utopia. Niedergang oder Untergang? S. 17-44. In: Collage City; vgl. Coleman (2005) Utopias and Architecture, S. 54.

84 Theodor W. Adorno in einem Rundfunkgespräch mit Ernst Bloch. Etwas fehlt... über die Widersprüche der utopischen Sehnsucht. In: Ernst Bloch (1978) Tendenz-Latenz-Utopie, S. 352-353.

85 Saage (2001) Utopische Profile, Bd. 1, S. 13.

86 Schumpp (1972) Stadtbau-Utopien und Gesellschaft, S. 9-11; siehe weiterführend, z. B. Martina Löw (2001) Raumsoziologie. Suhrkamp, Frankfurt/M. 
87 Georg Lukács (1977 [1968/zuerst 1923]) Die Verdinglichung und das Bewußtsein des Proletariats, S. 257-397. In: Geschichte und Klassenbewusstsein. Werke 2, Frühschriften II. 2. Auflage. Luchterhand, Darmstadt u. Neuwied, S. 257.

88 Vgl. Joachim Krause (1998) Planetarer Sinn. Metapher vom Raumschiff Erde, S. 249-255. In: Richard Buckminster Fuller (1998 [Engl. 1967/69]) Bedienungsanleitung für das Raumschiff Erde und andere Schriften. Verlag der Kunst, Dresden, S. 251.

89 Vgl. Richard Buckminster Fuller (1998 [Engl. 1967/69]) Raumschiff Erde, S. 45-51. In: a. a. O., S. 47-49.

90 Vgl. Breitenstein (2013) Die Befreiung der Geschichte, S. 36.

91 Christoph Menke im Gespräch mit Alexander Kluge (2017) Baustelle Revolution. Online: https://magazin.dctp.tv/2017/03/19/neu-imcatch-up-service-baustelle-revolution/ (19.5.19) [Hervorh. d. Verf.]. Siehe weiterführend, z. B. Aaron Bastani (2019) Fully Automated Luxury Communism. A Manifesto. Verso, London/UK.

92 Siehe dazu, z. B. Fredric Jameson (1991) Postmodernism, or, the Cultural Logic of Late Capitalism. Verso, London/UK; Wolfgang Welsch (1993) Unsere postmoderne Moderne. Akademie Verlag, Berlin.

93 Siehe Jameson (1991) Postmodernism, or, the Cultural Logic of Late Capitalism; und siehe ergänzend, z. B. Hal Foster (Hrsg.) (1983) Postmodernism: A Preface, S. ix-xvi. In: The Anti-Aesthetic. Essays on Postmodern Culture. Bay Press, Port Townsend/WA; Andreas Huyssen (1995) Memories of Utopia, S. 85-101. In: Twilight Memories. Marking Time in a Culture of Amnesia. Routledge, New York/ NY.

94 Vgl. Ole W. Fischer (2010) Zur Frage der Postmoderne in der Architektur. Rezension. In: Sehepunkte. Rezensionsjournal für die Geschichtswissenschaften, Ausgabe 10, Nr. 12. Online: http://www. sehepunkte.de/2010/12/18456.html (25.4.19).

95 Vgl. dazu die aristotelische Erkenntnis, dass „Ideale zur Naturgeschichte des Menschen als einem politischen Wesen gehören", Mumford (1970 [Engl. 1965]) Utopie, Stadt und Maschine, S. 34.

96 Michel Foucault (1992 [Frz. 1978]) Was ist Kritik? Merve, Berlin, S. 37-38 [Hervorh. d. Verf.].

97 Michel Foucault (2002 [Frz. 1971]) Nietzsche, die Geneaologie, die Historie, S. 166-191. In: Ders. Schriften, Bd. 2. Suhrkamp, Frankfurt/M., S. 180.

98 Foucault (2018 [Frz. 1969]) Archäologie des Wissens, S. 11.

99 A. a. O., S. 11-12 [Hervorh. i. O.]. 
100 Michel Foucault (1971 [Frz. 1966]) Die Ordnung der Dinge. Suhrkamp, Frankfurt/M., S. 17.

101 Die Rezeptionsgeschichte des Textes ist eng mit der Architektur verbunden: Zuerst von Foucault für einen Radiobeitrag 1966 konzipiert, dann 1967 als (kaum modifizierte) Rede vor einem Architektur-interessierten Publikum gehalten; schließlich verschriftlicht und dadurch popularisiert zum Anlass der Berliner IBA 1984/87 (Ausstellung und Katalog); organisiert und kuratiert von dem venezianischen Architekturhistoriker Marco de Michelis.

Radiofassung: Foucault (2017 [Frz. 2004/1966]) Die Heterotopien. Der utopische Körper. Zwei Radiovorträge. Suhrkamp, Berlin. Vortrags- und Artikelfassung (für Architekt*innen): Foucault (2006 [Frz. 1967/1984]) Von anderen Räumen, S. 317-329. In: Jörg Dünne, Stephan Günzel (Hrsg.) Raumtheorie. Grundlagentexte aus Philosophie und Kulturwissenschaften. Suhrkamp, Frankfurt/M.

102 Die Heterotopie im Verhältnis zum klassischen Utopiebegriff, vgl. Saage (2008) Utopieforschung, Bd. 2, S. 23-24.

103 Foucault (2006 [Frz. 1967/1984]) Von anderen Räumen, S. 321-326.

104 A. a. O., S. 327.

105 Siehe dazu vergleichend den glasüberdachten Innenhof einer Familistère des utopischen Sozialisten und Unternehmers Jean-Baptiste André Godin im französischen Guise (1859); vgl. Marvin Chlada (2005) Heterotopie und Erfahrung. Abriss der Heterotopologie nach Michel Foucault. Alibri Verlag, Aschaffenburg, S. 39.

106 Schriften zur Heterotopie, z. B. Michiel Dehaene, Lieven de Cauter (Hrsg.) (2008) Heterotopia and the City. Public Space in a Postcivil Society; Tobias Nikolaus Klass (2009) Von anderen Räumen. Zur Neubestimmung eines weit verbreiteten Konzepts, S. 141-155. In: Thomas Bedorf, Gerhard Unterthurner (Hrsg.) Zugänge, Ausgänge, Übergänge. Konstitutionsformen des sozialen Raums; Judith Leiß (2010) Inszenierungen des Widerstreits. Die Heterotopie als postmodernistisches Subgenre der Utopie; Ralf Mahlich (2011) Heterotopie im Kontext von Clubkultur; Anthony Faramelli, David Hancock, Robert G. White (Hrsg.) (2018) Spaces of Crisis and Critique. Heterotopias Beyond Foucault.

107 Foucault (1971 [Frz. 1966]) Die Ordnung der Dinge, S. 20 zit. nach Manfredo Tafuri (1987 [Ital. 1980]) The Sphere and the Labyrinth. Avant-Gardes and Architecture from Piranesi to the 1970s. MIT Press, Cambridge/MA, S. 40 [Hervorh. i. O.] [Übers. d. Verf.].

108 Tafuri (1987 [Ital. 1980]) The Sphere and the Labyrinth, S. 4-5 zit. nach Marco de Michelis (2017) Manfredo Tafuri und der Tod der 
Architektur, S. 36-45. In: Archplus, Nr. 229: Am Ende: Architektur / 50 Jahre Archplus - Projekt und Utopie, S. 45.

109 Tafuri sieht die Krise der Architektur und der Stadt in den bürgerlichen Revolutionen begründet, die zum Individualisierungsprozess der Menschen beitrugen und so der Stadt als "kollektivem Körper" entgegensteht. Tafuris Anerkennung des Auflösungsprozesses der einheitlichen Vorstellung von Architektur und Stadt am Ende des 18. Jahrhunderts - ihre Fragmentierung in Form und Konstruktion, Technik und Architektur, Wissenschaft und Kunst-, spielt eine entscheidende Rolle bei der Anerkennung des ideologischen Charakters der modernen Architektur in seinem Buch Kapitalismus und Architektur (Dt. Progetto e utopia), vgl. Michelis (2017) Manfredo Tafuri und der Tod der Architektur, S. 44-45.

110 Vgl. a. a. O., S. 45.

111 Mark Wigley (2000) Post-Operative History, S. 47-53. In: ANY, Nr. 25/26: Being Manfredo Tafuri, S. 47 zit. nach Michelis (2017) Manfredo Tafuri und der Tod der Architektur, S. 44.

112 Tafuri (1987 [Ital. 1980]) The Sphere and the Labyrinth, S. 2-3 zit. nach Michelis (2017) Manfredo Tafuri und der Tod der Architektur, S. 44.

113 Vgl. Clara Keyvanian (2000) Manfredo Tafuri: From the Critique of Ideology to Microhistories, S. 3-15. In: Designissues, Nr. 16/1, S. 6-7. Online: https://www.jstor. org/stable/1511926 (16.7.18).

114 Vgl. Manfredo Tafuri (1980 [Ital. 1968]) Theories and History of Architecture. Harper \& Row, New York/NY, S. 2.

115 Tafuri (1987 [Ital. 1980]) The Sphere and the Labyrinth, S. 3 zit. nach Michelis (2017) Manfredo Tafuri und der Tod der Architektur, S. 44. Siehe weiterführend, z. B. Marco Biraghi (2013) Project of Crisis. Manfredo Tafuri and Contemporary Architecture. MIT Press, Cambridge/MA.

116 Vgl. Tafuri (1977 [Ital. 1973]) Kapitalismus und Architektur, S. 131-133.

117 Vgl. a. a. O., S. 100; im Rekurs auf Hannes Meyer.

118 Vgl. Michelis (2017) Manfredo Tafuri und der Tod der Architektur, S. 43 .

119 Manfredo Tafuri (1977) II 'progetto' storico. In: Casabella 429; Engl. Übers. in: Oppositions 17 (1979), S. 55-75 zit. nach Michelis (2017) Manfredo Tafuri und der Tod der Architektur, S. 43.

120 Tafuri (1987 [Ital. 1980]) The Sphere and the Labyrinth, S. 1 zit. nach Michelis (2017) Manfredo Tafuri und der Tod der Architektur, S. 43. 


\section{Macht und Boden}

1 Vgl. § 903 Buch 3, Bürgerliches Gesetzbuch (BGB): Befugnisse des Eigentümers.

2 Der wiederholte Rekurs auf Marx und Engels - durch die gesamte Arbeit hinweg - ist darauf zurückzuführen, dass keine historischkritische Argumentation ohne den Einbezug ihrer umfangreichen Gesellschaftsanalyse möglich ist.

3 Vgl. Uwe Wesel (1997) Lemma: Eigentum, S. 79-85. In: Historischkritisches Wörterbuch des Marxismus, Bd. 3. Hrsg. v. Wolfgang Fritz Haug. Eine Veröffentlichung des Berliner Instituts für kritische Theorie (InkriT). Argument, Hamburg, S. 80; vgl. Marx und Engels (1845) Die deutsche Ideologie. In: MEW Bd. 3, S. 22.

4 Vgl. Michaela Rehm (2005) "Ihr seid verloren, wenn ihr vergeßt, daß die Früchte allen gehören und die Erde niemandem": Rousseaus bedingte Legitimation des Privateigentums, S. 103-104. In: Andreas Eckl, Bernd Ludwig (Hrsg.) Was ist Eigentum? Philosophische Eigentumstheorien von Platon bis Habermas. C.H.Beck, München.

5 Publikationen zur Boden- und Wohnungsfrage, z. B. Friedrich Engels (2015 [zuerst 1873]) Zur Wohnungsfrage. Mit Kommentaren von Reinhold Martin und Neil Smith; eine Neuauflage zur gleichnamigen Ausstellung und Publikationsreihe aus dem Berliner Haus der Kulturen der Welt (HKW); Stavros Stavrides, Mathias Heyden (Hrsg.) (2017) Gemeingut Stadt. Berliner Hefte zu Geschichte und Gegenwart der Stadt \#4; Andreas und Ilka Ruby (2017) Together! Die neue Architektur der Gemeinschaft. Katalog zu gleichnamiger Ausstellung im Vitra Design Museum, Weil am Rhein; Die Bodenfrage (2018) Stadtbauwelt, Nr. 217; Problems of Property, Tagung über Eigentum aus kritischer Perspektive, Center for Humanities and Social Change, HU Berlin, Dez. 2018.

6 Vgl. Rebecca Solnit (2007) Detroit Arcadia. Exploring the postAmerican Landscape. Letter from Michigan, S. 65-73. In: Harper's Magazine, Juli 2007, hier S. 72-73. Online: https://harpers.org/ archive/2007/07/detroit-arcadia/ (30.11.18); vgl. Manuel Shvartzberg Carrió (2018) Verteidigung der Demokratie. Gegen eine anarchokapitalistische Architektur. Erwiderung auf Schumacher, S. 102-107. In: Archplus, Nr. 231: The Property Issue, S. 105-106.

Die Politikwissenschaftlerin Elinor Ostrom legt in ihrem Buch Governing the Commons. The Evolution of Institutions for Collective Action (Engl. Die Verfassung der Allmende, 1990) Problematiken kollektiven Handelns bei knappen natürlichen Ressourcen eingehend dar. Sie ist für ihre Untersuchungen mit dem Nobelpreis für Wirtschaftswissenschaften (2009) ausgezeichnet worden; im 
Anschluss an die Weltwirtschaftskrise ist dies als sicherlich auch als "Zeichen der Zeit" zu werten.

7 Wolfgang Scheppe (2018) Die Grundrente der Kunst und der Ausschluss aus der Stadt. Das Exemplarische an Venedigs Singularität, S. 14-31. In: Archplus, Nr. 231: The Property issue, S. 24.

8 Vgl. Alain Thierstein (2018) Das Kind mit dem Bade ausschütten? Erwiderung auf Schumacher, S. 108-109. In: Archplus, Nr. 231: The Property Issue, S. 108.

9 Shvartzberg Carrió (2018) Verteidigung der Demokratie, S. 105-106.

10 Horkheimer (1971 [zuerst 1930]) Anfänge der bürgerlichen Geschichtsphilosophie, S. 60-61.

11 Vgl. Ágnes Heller (2016) Von der Utopie zur Dystopie. Was können wir uns wünschen? Edition Konturen, Wien u. Hamburg, S. 31, 36; Northrop Frye (1970 [Engl. 1965]) Spielarten der utopischen Literatur, S. 52-79. In: Manuel (Hrsg.) Wunschtraum und Experiment, S. $52,63,67$.

12 Die Erfindung des Geldes verändert dies entscheidend, d.h. Möglichkeit des Tauschs, Unterschiede in Fleiß und Geschick führen zu Vermögensunterschieden.

13 Walter Euchner (2007) Lemma: John Locke, S. 307-315. In: Hauptwerke der politischen Theorie, S. 311-313.

14 Adam Smith (2009 [1978/Engl. 1776]) Der Wohlstand der Nationen. Eine Untersuchung seiner Natur und seiner Ursachen. 12. Auflage Übers. u. hrsg. v. Horst Claus Recktenwald. DTV, München, S. 370-371 [Hervorh. d. Verf.].

15 Siehe dazu, z. B. Edward P. Thompson (1987 [Engl. 1963] Die Entstehung der englischen Arbeiterklasse. Suhrkamp, Frankfurt/M.

16 Marx (1867) Das Kapital, Bd. 1, Kap 24: Die sogenannte ursprüngliche Akkumulation. In: MEW Bd. 23, S. 789-790.

17 Marx (1894) Das Kapital, Bd. 3, Kap 46: Baustellenrente, Bergwerksrente, Bodenpreis. In: MEW Bd. 25, S. 782.

18 Vgl. Harald Trapp (2018) Kapital Heim, S. 34-39. In: Archplus, Nr. 231: The Property issue, S. 35.

19 Bruno Latour (2018) Das terrestrische Manifest. Suhrkamp, Berlin, S. 13 [Hervorh. i. O.].

20 Latour (2018) Das terrestrische Manifest, S. 65-66 [Hervorh. i. O.].

21 A. a. O., S. 106-107 [Hervorh. i. O.].

22 A. a. O., S. 18. 


\section{Ästhetische Implikationen}

1 Es galt die Architektur im Gegensatz zum Städtischen in den Fokus zu rücken und Konnotationen zu vermeiden, die bisher kursierende, uneinheitlich verwendete Begriffskombinate in unterschiedlichen Fachbereichen hervorgerufen hätten, z. B. temporäre Intervention oder Zwischennutzung, DIY-, Makeshift- oder taktischer Urbanismus; Abwandlungen sind vielfältig, z. B. kritische Stadtgestaltungspraxis / ephemere Stadtentwicklung durch experimentelle Raumproduktion. Auf planerischer Ebene ist oftmals die Rede von Graswurzelorganisation und Bottom-up-Entwicklung.

2 Projektkataloge kritischer Architekturpraxis, z. B. Jesko Fezer, Mathias Heyden (Hrsg.) (2004) Hier entsteht. Strategien partizipativer Architektur und räumlicher Aneignung; Florian Haydn, Robert Temel (2006) Temporäre Räume. Konzepte zur Stadtnutzung; Architecture for Humanity (Hrsg.) (2006) Design Like You Give a Damn; Klaus Overmeyer, Holger Lauinger (2007) Urban Pioneers. Berlin, Stadtentwicklung durch Zwischennutzung; Cynthia E. Smith (2007) Design for the Other 90\%; Bryan Bell, Katie Wakeford (Hrsg.) (2008) Expanding Architecture. Design as Activism; Nishat Awan et al. (2011) Spatial Agency. Other Ways of Doing Architecture; Peter Bishop, Lesley Williams (2012) The Temporary City; Philipp Oswalt et al. (2013) Urban Catalyst. Mit Zwischennutzungen die Stadt entwickeln; RaumlaborBerlin (Hrsg.) (2014) Art City Lab. Neue Räume für die Kunst; Francesca Ferguson, Urban Drift Projects (Hrsg.) (2014) Make_Shift City. Die Neuverhandlung des Urbanen; Pedro Gadanho (2014) Uneven Growth. Tactical Urbanisms for Expanding Megacities; Mike Lydon, Anthony Garcia (2015) Tactical Urbanism. Shortterm Action for Long-term Change; Giovanna Borasi (2015) The Other Architect; Cate St. Hill (2016) This Is Temporary. How Transient Projects Are Redefining Architecture; Daniela Patti, Levente Polyak (Hrsg.) (2017) Funding the Cooperative City. Community Finance and the Economy of Civic Spaces; Francesca Ferguson, Make_Shift (Hrsg.) (2019) MakeCity. Stadt anders machen.

3 U. a. London Festival of Architecture (seit 2004 regelmäßig, Thema 2016: Community); TodaysArt Festival, Den Haag/NL (seit 2005 jährlich); SynchroniCity Young Architecture Festival, Warschau/ Polen (seit 2007); CANactions International Architecture Festival, Kiew/Ukraine (seit 2008 jährlich, Thema 2019: Community); Urban Dreams, Plovdiv/Bulgarien (2012); MakeCity. Festival für Architektur und Andersmachen, Berlin (2015 u. 2018); urbanize! Internationales Festival für urbane Erkundungen, Berlin (2018).

4 Vgl. Silke Steets (2015) Der sinnhafte Aufbau der gebauten Welt. Eine Architektursoziologie. Suhrkamp, Berlin, S. 132-139; Peter L. 
Berger, Thomas Luckmann (2004 [zuerst 1969]) Die gesellschaftliche Konstruktion der Wirklichkeit. Eine Theorie der Wissenssoziologie. Fischer, Frankfurt/M., S. 65.

Vgl. Lüdtke (1998) Alltagsgeschichte, Mikro-Historie, historische Anthropologie, S. 563.

6 Vgl. Ruth Levitas (2013) Utopia as Method. The Imaginary Reconstitution of Society. Palgrave Macmillan, Hampshire/UK, S. 217-219.

7 Siehe dazu, z. B. Oswalt et al. (2013) Urban Catalyst. Mit Zwischennutzungen die Stadt entwickeln. DOM, Berlin.

8 Vgl. Stefan Krämer (2017) Ephemere Stadtentwicklung. Wie geht das? S. 6-7. In: Paola Alfaro d'Alençon, Bettina Bauerfeind, Daniela Konrad (2017) Ephemere Stadtentwicklung. Planungshilfe und Handbuch. DOM, Berlin, S. 6.

Im Vorlaufprozess („Phase Null“) realer Planungs- und Bauvorhaben kann ephemere Zwischennutzung maßgeblich dazu beitragen, das künftige Projekt vorzudenken, zu definieren und im Entwicklungsprozess mitzuverhandeln, vgl. Reiner Nagel (2017) Zum Verhältnis von ephemerer Stadtentwicklung und Planung, S. 18-19. In: Alfaro d'Alençon et al. (2017) Ephemere Stadtentwicklung, S. 19.

Auch planungsrechtliche Grundlagen wurden novelliert: BauGB (2004) § 9, Abs. 2: „Bauen auf Zeit”.

Es können "gesteuerte, geregelte und freie" Zwischennutzungen unterschieden werden; definiert anhand der beteiligten Akteure und ihres formellen bzw. informellen Charakters; Hauptunterscheidungskriterium ist dabei die Beteiligung der öffentlichen Hand, vgl. Felix Bentin, Ole Brandmeyer, Johannes Hipp (2017) Zwischen Hindernis und Ressource. Was können Planer und Gestalter von ephemeren Stadtentwicklungsinstrumenten lernen? S. 36-41. In: Alfaro d'Alençon et al. (2017) Ephemere Stadtentwicklung, S. 38.

9 Thomas Schriefers (2005) Für die Ideen dieser Welt. Temporäres Bauen, S. 10-15. In: Temporäre Architektur an besonderen Orten. Blaue Reihe StadtBauKultur NRW, S. 12. Online: https://stadtbaukultur-nrw.de/site/assets/files/1566/temparchitekur140205.pdf (4.7.17).

Auch das "Gebrauchte" lässt sich als kapitalistisch verwertbares Narrativ, d. h. als neue Form des ethischen Konsums verstehen; vgl. Reckwitz (2017) Die Gesellschaft der Singularitäten, S. 121-124. Siehe weiterführend, z. B. Luc Boltanski, Arnaud Esquerre (2019 [Frz. 2017]) Bereicherung. Eine Kritik der Ware.

10 Vgl. Ueding (1982) Ernst Blochs Philosophie der Utopie, S. 297.

11 U. a. Actopolis, Assemble Collective, Atelier d'Architecture Autogérée, Basurama Asociación, Bellastock Collectif, Centrala, Common Grounds e.V., CooperativeCity/Eutropian, ConstructLab, 
DIESE Studio, Exyzt, Guerilla Architects, muf architecture/art, Nomadisch Grün, ON/OFF, Office for Subversive Architecture (OSA), PlanBude, PublicWorksGroup, RaumlaborBerlin, RefuncNL, Social Design Collaborative, Stadtlücken e.V., überNormalNull, Umschichten, Urban Catalyst, Urbane Liga, ZUsammenKUNFT e.G., etc.

12 Siehe vergleichend, z. B. die Darstellung der Architektenpersönlichkeit bei Fritz Lang (1926) Metropolis oder Ayn Rand (1943 [verfilmt 1949]) The Fountainhead (Engl. Der ewige Quell bzw. Der Ursprung).

13 „Einer langen britischen Tradition von William Morris bis Walter Segal folgend, setzen [Assemble] den Prozess des Selbermachens und des gemeinschaftlichen Bauens ein, um alternative soziale und politische Ambitionen zu verwirklichen. Ihre Projekte sind Prototypen von möglichen Zukünften, ein optimistischer Anstoß, sich alternative Wege für das Bauen einer Gesellschaft vorzustellen." Oliver Wainwright (2017) Momentaufnahmen des Möglichen, S. 23-39. In: Angelika Fitz, Katharina Ritter (Hrsg.) Assemble. Wie wir bauen. Katalog zur gleichnamigen Ausstellung im Architekturzentrum Wien. Park Books, Zürich, S. 36.

Zur Reflexion von Partizipationstechniken im Zusammenhang mit ästhetischer Erziehung sei hier eine politische Urszene vorgeschlagen: Die Emanzipation der Arbeiter*in und Bürger*in vollzieht sich durch ästhetische Erfahrung im veränderten ästhetischen Blick. Der Klassenkampf beginnt mit der Blickveränderung: Sehen $>$ Wahrnehmen > Bewusstwerden (und schlussendlich Theoriebildung). Die zentrale Frage dabei ist: Muss das Sehen geschult sein bzw. werden, um den Blick verändern zu können? Vgl. Jacques Rancière im Gespräch mit Peter Engelmann (2016) Ästhetik und Politik. Passagen Verlag, Wien, S. 33-35.

Siehe dazu auch Peter Weiss (2018 [zuerst 1975-81]) Die Ästhetik des Widerstands; speziell in den ersten beiden Bänden wird die Auseinandersetzung mit Werken der Kunst geführt.

14 Transdisziplinarität wird hier als besonders integrative Form der Interdisziplinarität verstanden, für die die Überwindung disziplinärer Grenzen ebenso zentral ist, wie die Verbindung von Wissenschaft und Praxis, vgl. Rico Defila und Antonietta Di Giulio (1998) Interdisziplinarität und Disziplinarität, S. 111-137. In: Jan H. Olbertz (Hrsg.) Zwischen den Fächern, über den Dingen? Universalisierung versus Spezialisierung akademischer Bildung. Springer VS, Wiesbaden. Vgl. Misselwitz (2017) Und täglich grüßt das Murmeltier..., S. 22-24.

16 Vgl. Ruth Levitas (2013) Utopia as Method. The Imaginary Reconstitution of Society. Palgrave Macmillan, Hampshire/UK, S. 197-220. 
17 Der Architekturhistoriker und Kurator Andres Lepik setzt unterschiedliche Schwerpunkte mit den Ausstellungen: Small Scale Big Change. New Architectures of Social Engagement (MoMA, N.Y. 2010); Think Global, Build Social! Bauen für eine bessere Welt (DAM, Frankfurt/M. 2013); Afritecture. Bauen mit der Gemeinschaft (TUM, München 2013/14); Does Permanence Matter? Ephemeral Urbanism (TUM, München 2017).

Die Kulturtheoretikerinnen und Kuratorinnen Elke Krasny und Angelika Fitz setzen im Architekturzentrum Wien (AzW) folgende Schwerpunkte: Hands-on Urbanism 1850-2012. Vom Recht auf Grün (2012); Assemble: Wie wir bauen (2017); Critical Care. Architektur für einen Planeten in der Krise (2019).

182016 ging der Julius-Berger-Preis (für Stadtentwicklung) an die Initiative ExRotaprint in Berlin und der österreichische Friedrich-Kiesler Preis (für "Correlated arts") wurde an Andrés Jaque/Office for Political Innovation verliehen; 2017 ging der Curry Stone Design Prize (für humanitäre Gestaltung) an RaumlaborBerlin; 2018 wurde der Bundeswettbewerb „Europäische Stadt" (in der Kategorie Stadtraum) für das Projekt „Österreichischer Platz" der Stuttgarter Stadtlücken e. V. entschieden.

19 Siehe dazu Nina Gribat, Sandra Meireis (2017) A Critique of the New ,Social Architecture' Debate. Moving Beyond Localism, Developmentalism and Aesthetics, S. 779-788. In: CITY 21/6: Special Feature: Designed to Improve? The Makings, Politics and Aesthetics of the ,Social' Architecture and Design. Taylor \& Francis, Oxon/UK.

20 Alexander Neupert, Lisa Doppler (2014) Das Recht auf Stadt als konkrete Utopie? Utopisches Bewusstsein als Gegenstand der Bewegungsforschung, S. 163-178. In: Norbert Gestring et al. (Hrsg.) Stadt und soziale Bewegungen. Springer VS, Wiesbaden.

Eine Gegenposition zur Hoffnung auf den zivilen Ungehorsam: „Weil [die antikapitalistische Protestbewegung] unfähig war, ein kohärentes, alternatives polit-ökonomisches Modell auszuarbeiten, kam der Verdacht auf, dass ihr eigentliches Ziel nicht die Abschaffung des Kapitalismus sei, sondern nur die Bekämpfung seiner schlimmsten Exzesse [Konzern-Antikapitalismus]. Und weil ihre Aktivitäten eher die Form des Organisierens von Demonstrationen als die Form der politischen Organisation annahm, verfestigte sich der Eindruck, dass die wesentliche Aufgabe der globalisierungskritischen und antikapitalistischen Bewegung darin bestehen würde, eine Reihe von hysterischen Forderungen zu stellen, deren Einlösung sie selbst nicht erwartete. Proteste jeder Art haben eine Art karnevalistisches Hintergrundgeräusch zum kapitalistischen 
Realismus gebildet [...].” Mark Fisher (2013 [Engl. 2009]) Kapitalistischer Realismus ohne Alternative? Eine Flugschrift. VSA, Hamburg, S. 22.

Eine funktionsfähige Vision einer postkapitalistischen Gesellschaft zu entwickeln ist ein längerer Prozess. Die revolutionäre Erwartungshaltung an Occupy wurde demnach enttäuscht, sollte aber als Ziel nicht aufgegeben werden. Die wichtigste Funktion von Occupy (seit 2008) ist es den Prozess des Nachdenkens über eine Alternative zum Kapitalismus eingeleitet zu haben; vgl. a. a. O., S. 110.

21 Vgl. Bruno Latour (2018) Das terrestrische Manifest. Suhrkamp, Berlin, S. 66 [Hervorh. i. O.].

22 Siehe dazu Jürgen Habermas (1990 [Habil. 1962]) Strukturwandel der Öffentlichkeit. Untersuchungen zu einer Kategorie der bürgerlichen Gesellschaft. Suhrkamp, Frankfurt/M.

23 Sozial motiviertes und/oder temporäres Bauen, z. B. Bernard Rudofsky (1964) Architecture without Architects; Charles Jencks, Nathan Silver (1972) Adhocism; Werner Oechslin, Anja Buschow (1984) Festarchitektur; Mathias Schwartz-Clauss, Alexander van Vegesack (Hrsg.) (2003) Living in Motion; Christian Schittich (2010) Mikroarchitektur; Sascha Roesler (2013) Weltkonstruktion.

In den 1950-70er Jahren überschneidet sich das Verständnis "utopischer Architektur" mit der ökologisch motivierten „alternativen Architektur", vgl. Pevsner et al. (1992 [Engl. 1966]) Lemmata: Alternative Architektur, S. 25; Utopische Architektur, S. 663. In: Dies. (Hrsg.) Lexikon der Weltarchitektur.

24 Vgl. Misselwitz (2017) Und täglich grüßt das Murmeltier..., S. 20-21.

25 Vgl. Regula Lüscher (2014) Vorwort, S. 8-9. In: Francesca Ferguson, Urban Drift Projects (Hrsg.) Make_Shift City. Die Neuverhandlung des Urbanen. Jovis, Berlin.

26 Dieser Abschnitt ist eine leicht geänderte Fassung meines (im Hinblick auf den vorliegenden Abschnitt entwickelten) Beitrags: Visionäre Vorstellungen. Der utopische „Augenblickskern-Keim" des Ästhetischen, S. 56-59. In: der Architekt. Zeitschrift des BDA (4/2019): Orte des Denkens. Architektur als philosophische Praxis.

27 Schmidt (1988) Kritik der reinen Utopie, S. $x$.

28 Vgl. Ludwig Stockinger (1982) Aspekte und Probleme der neueren Utopiediskussion in der deutschen Literaturwissenschaft, S. 120-142. In: Voßkamp (Hrsg.) Utopieforschung, Bd. 1, S. 131-132.

29 Vgl. Karl Heinz Bohrer (1981) Plötzlichkeit. Zum Augenblick des ästhetischen Scheins. Suhrkamp, Frankfurt/M., S. 189. 
30 Walter Benjamin (2010 [zuerst 1940]) Über den Begriff der Geschichte. Werke und Nachlaß. Kritische Gesamtausgabe, Bd. 19. Suhrkamp, Berlin, S. 103 [Hervorh. d. Verf.].

31 Vgl. Bohrer (1981) Plötzlichkeit, S. 184.

32 Jacob Burckhardt (1989 [zuerst 1860]) Die Kultur der Renaissance in Italien. Deutscher Klassiker Verlag, Frankfurt/M., S. 397.

33 Constant Nieuwenhuys, Guy Debord (1953) Erklärung von Amsterdam. In: IS 2 (Dez. 1958). Online: http://www.si-revue.de/ nachrichten-von-der-internationalen-19582 [Hervorh. d. Verf.] (18.6.19).

34 Vgl. Schriefers (2005) Für die Ideen dieser Welt, S. 14.

35 Vgl. Bohrer (1981) Plötzlichkeit, S. 217-218 [Hervorh. d. Verf.].

36 Robert Musil (2002 [zuerst 1978]) Der Mann ohne Eigenschaften. Rowohlt, Reinbek bei Hamburg, S. 246.

37 Mannheim (1969 [zuerst 1929]) Ideologie und Utopie, S. 169.

38 Vgl. Bohrer (1981) Plötzlichkeit, S. 205.

39 Vgl. Christoph Menke im Gespräch mit Alexander Kluge (2017) Baustelle Revolution.

40 Siehe dazu, z. B. Michael Müller et al. (1974) Autonomie der Kunst. Zur Genese und Kritik einer bürgerlichen Kategorie. Suhrkamp, Frankfurt/M.

41 Vgl. Stefan Majetschak (2007) Ästhetik. Zur Einführung. Junius, Hamburg, S. 9-12.

42 Vgl. Immanuel Kant (2009 [zuerst 1790]) Kritik der Urteilskraft. Hrsg. v. Heiner F. Klemme. Meiner, Hamburg, §2, S. 49.

43 Friedrich Schiller (2009 [zuerst 1795]) Über die ästhetische Erziehung des Menschen. Suhrkamp, Frankfurt/M., S. 64 [Hervorh. i. O.].

44 Vgl. Safranski (2007) Romantik, S. 45.

45 Karl Philipp Moritz (1968 [zuerst 1788]) Über die bildende Nachahmung des Schönen, S. 12 [S. 16]. Kraus Reprint, Nendeln/Liechtenstein.

46 Jürgen Fredel (2004) Lemma: Autonomie der Kunst, S. 774-779. In: Historisch-kritisches Wörterbuch des Marxismus, Bd. 1, S. 777 [Hervorh. d. Verf.].

47 Theodor W. Adorno (2014 [zuerst 1970]) Ästhetische Theorie. Gesammelte Schriften, Bd. 7. Hrsg. v. Rolf Tiedemann. Suhrkamp, Frankfurt/M., S. 334-335.

Siehe dazu, z. B. Terry Eagleton (1994 [Engl. 1990]) Ästhetik. Die Geschichte ihrer Ideologie. Stuttgart, Metzler. 
48 Vgl. Gerhard Schweppenhäuser (2007) Ästhetik. Philosophische Grundlagen und Schlüsselbegriffe. Campus, Frankfurt/M., S. 198.

$49 \mathrm{Vgl.} \mathrm{http://www.tate.org.uk/art/art-terms/s/social-turn} \mathrm{(11.7.17).}$

50 Zur Kunst des Öffentlichen (im Unterschied zu Kunst im öffentlichen Raum), z. B. Thomas Ernst et al. (Hrsg.) (2008) Subversionen. Zum Verhältnis von Politik und Ästhetik in der Gegenwart; Hildegard Fraueneder, Gianni Stiletto (Hrsg.) (2010) Was tun. Figuren des Protests. Taktiken des Widerstands; Frauke Surmann (2014) Ästhetische In(ter)ventionen im öffentlichen Raum. Grundzüge einer politischen Ästhetik; Anette Baldauf et al. (Hrsg.) (2016) Spaces of Commoning. Artistic Research and the Utopia of the Everyday; Anina Falasca, Annette Maechtel, Heimo Lattner (2018) Wiedersehen in TUNIX! Ein Handbuch zur Berliner Projektekultur. Berliner Hefte zu Geschichte und Gegenwart der Stadt \#7; Michela Bstieler et al. (Hrsg.) (2018) Kunst als gesellschaftskritisches Medium; Karen van den Berg, Cara M. Jordan, Philipp Kleinmichel (Hrsg.) (2019) The Art of Direct Action. Social Sculpture and Beyond.

51 Eine Abkehr von der Objektzentrierung sollte aber nicht automatisch als gesellschaftskritische Abkehr vom Kunstmarkt gleichgesetzt werden, vgl. Stella Rollig, Eva Sturm (Hrsg.) (2002) Dürfen die das? Kunst als sozialer Raum. Turia + Kant, Wien; Holger Kube Ventura (2002) Politische Kunst Begriffe - in den 1990er Jahren im deutschsprachigen Raum. Edition Selene, Wien; im nordamerikanischen Kontext ist der Rückbezug auf die Bürgerrechtsbewegungen der 1960er Jahre bestimmend.

52 Andreas Koch (2018) Die Wahrheit 90er Spezial, S. 19-21. In: von hundert, Nr. 31. Online: http://vonhundert.de/2018-03/PDF_vonhundert31_03_2018.pdf, S. 20 (6.6.19).

53 Vgl. Scheinschlag und A.N.Y.P. im Interview (2018) Archäologie autonomer Zeitungen in den 90ern, S. 22-26. In: von hundert, Nr. 31, 5. 23.

54 Juliane Rebentisch im Gespräch mit PräPosition (2019) Texturen der Gegenwart \#6. Online: https://www.praeposition.com/text/vorzeichen/juliane-rebentisch (5.6.19); vgl. Sabeth Buchmanns Vortrag "(Politische) Kunst oder (soziale) Praxis? Eine Versuchsanordnung über die 1990er" im Rahmen des Forschungsprojekts Autonomie und Funktionalisierung am Institut für Geschichte und Theorie der Gestaltung, UdK Berlin, Nov. 2017.

Zum Unterschied von politischer und politisierter Kunst siehe auch, z. B. Birgit Eusterschulte (2018) Un/Mögliche Funktionalisierungen oder Die Fallen des Ausstellens; Akte des X. Kongresses der Deutschen Gesellschaft für Ästhetik; Hochschule für Gestaltung Offenbach/M. Online: http://www.dgae.de/wp-content/ 
uploads/2017/06/Eusterschulte-dgae_2018.pdf (7.6.19); Claire Colomb (2012) Pushing the Urban Frontier: Temporary Uses of Space, City Marketing, and the Creative City Discourse in 2000s Berlin, S. 131-152. In: Journal of Urban Affairs, Vol. 34, Nr. 2. Online: https://doi.org/10.1111/j.1467-9906.2012.00607.x (22.2.15).

55 Vgl. Nicolas Bourriaud (2002 [Frz. 1998]) Relational Aesthetics. Les presses du reel, Dijon, S. 29-40.

56 Vgl. Mona Wischhoff (2013) Geäußerte Künstlerkritik der Gegenwart. Das politische Potenzial einer "Relationalen Ästhetik", S. 60-82. In: DIENADEL. Kulturwissenschaftliche Zeitschrift für Kunst und Medien, Nr. 1/2013, S. 62-69 [Hervorh. i. O.].

57 Siehe dazu Louis Althusser (2010 [Frz. 1994]) Materialismus der Begegnung. Späte Schriften. Hrsg. u. übers. v. Franziska Schottmann. Diaphanes, Zürich.

Siehe weiterführend, z. B. Frieder Otto Wolf (2014) Was bedeutet der "Materialismus der Begegnung" bei Louis Althusser? Versuch, eine neue Perspektive zu eröffnen, S. 197-222. In: Berdet, Ebke (Hrsg.) Anthropologischer Materialismus und Materialismus der Begegnung.

58 Vgl. Bourriaud (2002 [Frz. 1998]) Relational Aesthetics, S. 18.

59 Vgl. Wischhoff (2013) Geäußerte Künstlerkritik der Gegenwart, S. 70-71.

60 In Kunsträumen gelten feldinterne, d. h. institutionalisierte Regeln, vgl. Pierre Bourdieu (1987 [Frz. 1979]) Die feinen Unterschiede. Kritik der gesellschaftlichen Urteilskraft. Suhrkamp, Frankfurt/M., S. 277-288, 355-362.

61 Siehe dazu Ernesto Laclau, Chantal Mouffe (1991 [Engl. 1985]) Hegemonie und radikale Demokratie. Zur Dekonstruktion des Marxismus. Passagen Verlag, Wien; eine Theorie im Anschluss an Antonio Gramscis Hegemonietheorie und Jacques Lacans Subjektivitätstheorie.

62 Siehe dazu Claire Bishop (2004) Antagonism and Relational Aesthetics, S. 51-79. In: October, Nr. 110. Online: http://www.teamgal.com/ production/1701/SS04 October.pdf (11.7.17); Dies. (2006) The Social Turn. Collaboration and Its Discontents, S. 178-183. In: Artforum, Nr. 44/6. Online: https://www.artforum.com/print/200602/ the-socialturn-collaboration-and-its-discontents-10274 (11.7.17). Nach Bishop lasse Bourriauds Verständnis abgeschlossener Subjektivitäten, die wie zwei Atome aufeinanderprallen und eine neue Welt, d. h. einen Konsens aus Meinungen) bilden, die Subjektivitätstheorie des Psychoanalytikers und postmodernen Großtheoretikers Jacques Lacan außer Acht. Nach Lacan vollzieht sich der 
Akt der Selbstidentifikation des*der Einzelnen überhaupt erst im Austausch mit anderen; ein fortdauernd unabgeschlossener Prozess. Der*die Einzelne begibt sich also stets in neue zwischenmenschliche Austauschbeziehungen zum Zwecke der Identifizierung der eigenen Subjektivität (Selbstwahrnehmung).

63 Vgl. Boltanski, Chiapello (2006 [Frz. 1999]) Der neue Geist des Kapitalismus, S. 84; siehe dazu vertiefend S. 377-511.

64 Vgl. Schweppenhäuser (2007) Ästhetik, S. 28, 30.

65 Joseph Beuys im Interview mit Rainer Rappmann (1975), S. 10-25. In: Rainer Rappmann, Volker Harlan, Peter Schata (1984 [zuerst 1976]) Soziale Plastik. Materialien zu Joseph Beuys. 3. erw. u. erg. Auflage. Achberger Verlag, Achberg, S. 20.

66 Werner Hofmann (1998) Die Moderne im Rückspiegel. Hauptwege der Kunstgeschichte. C.H.Beck, München, S. 368.

67 Joseph Beuys im Interview mit Rainer Rappmann (1975), S. 21.

68 Ebd.

69 Vgl. Beuys Bezug auf Rudolf Steiner: „Und die Menschheit wird nicht weiter mitreden können, ohne daß sie ihren sozialen Organismus im Sinne der Dreigliederung: des Sozialismus für das Wirtschaftsleben, der Demokratie für das Rechts- und Staatsleben, der Freiheit oder des Individualismus für das Geistesleben einrichtet. Das wird angesehen werden müssen als das einzige Heil, als die wirkliche Rettung der Menschheit." Rudolf Steiner (1919) Die Erziehungsfrage als soziale Frage (Dornach 1971, S. 16-17) zit. nach Rappmann. In: Ders. et al. (1984 [zuerst 1976]) Soziale Plastik, S. 28. Umberto Eco (1977 [Ital. 1962]) Das offene Kunstwerk. Suhrkamp, Frankfurt/M., S. 247-248.

71 Vgl. a. a. O., S. 12 [Hervorh. i. O.]; und vgl. Schweppenhäuser (2007) Ästhetik, S. 21-22.

72 Oftmals wird die informelle Malerei der 1940-50er Jahre oder die neue Musik, z. B. von Karlheinz Stockhausen oder John Cage angeführt, um das Konzept eines offenen, d.h. unabgeschlossenen Werkcharakters zu erläutern; vgl. Eco (1977 [Ital. 1962]) Das offene Kunstwerk, S. 27; Karl Baier (2003) Offenes Kunstwerk versus Kunst der Offenheit. Umberto Ecos abendländische Werk-Ästhetik und John Cages buddhistische Alternative, S. 38-56. In: Polylog. Zeitschrift für interkulturelles Philosophieren, Nr. 9, S. 39, 52.

Siehe dazu auch, z. B. Gesa Foken (2017) Offenheitszwang. Kritik der Offenheitsästhetik vor dem Hintergrund zeitgenössischer Zeichnung. Vgl. Schweppenhäuser (2007) Ästhetik, S. 8. 
74 Vgl. Jacques Rancière im Gespräch mit Peter Engelmann (2016) Ästhetik und Politik, S. 50.

75 Vgl. Walter Benjamin (2013 [zuerst 1936]) Das Kunstwerk im Zeitalter seiner technischen Reproduzierbarkeit. Suhrkamp, Berlin, S. 77 [Hervorh. i. O.].

76 Walter Benjamin (1991 [zuerst 1934]) Der Autor als Produzent, S. 683-701. In: Gesammelte Schriften, Bd. II.2. Hrsg. v. Rolf Tiedemann, Hermann Schweppenhäuser. Suhrkamp, Frankfurt/M., S. 683; der Aufsatz basiert auf einem Entwurf für eine geplante Ansprache Benjamins am Institut zum Studium des Faschismus (finanziert von der UdSSR) in Paris am 27. April 1934.

77 Benjamin (1991 [zuerst 1934]) Der Autor als Produzent, S. 684.

78 A. a. O., S. 684-685 [Hervorh. i. O.].

79 A. a. O., S. 685.

80 Vgl. Boris Buden (2004) Benjamins „Der Autor als Produzent": Eine Re-Lektüre im postkommunistischen Osten. In: transversal / EIPCP multilingual webjournal, Nr. 12/2004. Online: https://transversal.at/ transversal/1204/buden/de (5.9.20).

81 A. a. O., S. 686-687; Benjamin richtet seinen Blick auf den Schriftsteller Sergej Tretjakow, ein Vertreter des russischen Futurismus und aktiver Kämpfer für die landwirtschaftliche Kollektivwirtschaft in der Sowjetunion um 1928. Dabei setzt Benjamin die politische nicht mit der künstlerischen Tat gleich, weist aber darauf hin, dass man die Formen bzw. Gattungen des künstlerischen Schaffens anhand von den technischen Gegebenheiten der jeweiligen Zeit aus umdenken muss, um zu "jenen Ausdrucksformen zu kommen, die für die literarischen Energien der Gegenwart den Ansatzpunkt darstellen." Ebd.

82 Vgl. Sven Kramer (2012) Nachwort, S. 325-350. In: Walter Benjamin. Der Autor als Produzent. Aufsätze zur Literatur. Reclam, Stuttgart, S. 347 .

83 Tretjakow zit. nach Benjamin (1991 [zuerst 1934]) Der Autor als Produzent, S. 687-688.

84 „[D]ie Einsicht des Schriftstellers in seine gesellschaftliche Bedingtheit, in seine technischen Mittel und in seine politische Aufgabe [hat] mit den ungeheuersten Schwierigkeiten zu kämpfen." Auch im Medium Zeitung vereint sich Unvereinbares: die künstlerische Position liegt in den Händen des kapitalistischen Gegners.

Benjamin argumentiert, dass der Schriftsteller nur dann revolutionär agiere, wenn er sich als Produzent solidarisch mit dem Proletariat verbinde. Wenn er Solidarität nur seiner Gesinnung nach 
verkünde, bliebe er gegenrevolutionär, auch wenn die politische Tendenz noch so revolutionär erscheine.

Darüber hinaus sieht er den „bürgerlichen Produktions- und Publikationsapparat erstaunliche Mengen von revolutionären Themen assimilieren, ja propagieren [...], ohne damit seinen eigenen Bestand und den Bestand der inn besitzenden Klasse ernstlich in Frage zu stellen." A. a. O., S. 689-692.

Benjamin schlussfolgert, dass das Prinzip der Kollektivbildung an sich ein Reaktionäres ist, denn es agiert exklusiv, vgl. ebd.; vgl. dazu Bloch (1959) Das Prinzip Hoffnung, Bd. 2, Teil 4, S. 681: in spezialisierten Gruppenutopien fehlt der Wille zum Umbau der gesamten Gesellschaft.

85 Benjamin (1991 [zuerst 1934]) Der Autor als Produzent, S. 686.

86 Christoph Menke im Gespräch mit Alexander Kluge (2017) Baustelle Revolution, a. a. O.

87 Vgl. Andri Gerber (2014) Metageschichte der Architektur. Ein Lehrbuch für angehende Architekten und Architekturhistoriker. transcript, Bielefeld, S. 39-40.

88 Vgl. Patrick Schumacher (2018 [Engl. 2016]) Acht-Punkte-Manifest, S. 97. In: Archplus, Nr. 231: The Property Issue.

Siehe zur Autonomie der Architektur im Kapitalismus eingehend kritisch Pier Vittorio Aureli (2008) The Project of Autonomy. Politics and Architecture within and against Capitalism. Princeton Architectural Press, New York/NY.

89 Vgl. Ingo Bohning (1981) "Autonome Architektur" und "partizipatorisches Bauen" - Zwei Architekturkonzepte. Dissertation an der ETH Zürich. Birkhäuser, Basel, S. 8.

90 Ákos Moravánszky, Judith Hopfengärtner (2011) Wie man wird, was man ist. Eine Einführung, S. 9-22. In: Dies. (Hrsg.) (2011) Aldo Rossi und die Schweiz. Architektonische Wechselwirkungen. gta Verlag/ ETH, Zürich, S. 18.

91 Jan Verwijnen (1997) Politische Radikalität und poetische Präzision, S. 39-41. In: Viele Mythen, ein Maestro: Kommentare zur Zürcher Lehrtätigkeit von Ado Rossi, S. 37-44. In: Werk, Bauen + Wohnen, Nr. 84, Heft 12: Von den Neunzigern in die Siebziger und zurück, S. 39.

92 A. a. O., S. 40.

93 Bohning (1981) "Autonome Architektur" und "partizipatorisches Bauen", S. 11.

94 Vgl. a. a. O., S. 116-122, 130.

95 Vgl. a. a. O., S. 123-124, 192-253. 
Vgl. Cornelius Castoriadis, Paul Ricoeur (2019 [Frz. 2016/zuerst 1985]) Gespräch über die Geschichte und das gesellschaftlich Imaginäre. Passagen Verlag, Wien, S. 27.

\section{Macht und Geschlecht}

1 Vgl. Zygmunt Bauman (2000 [Engl. 1999]) Die Krise der Politik. Fluch und Chance einer neuen Öffentlichkeit, S. 128 [Hervorh. i. O.].

2 Vgl. Christian Meier (2012 [zuerst 1993]) Athen. Ein Neubeginn der Weltgeschichte. Pantheon, Berlin, S. 493.

3 Bauman (2000 [Engl. 1999]) Die Krise der Politik, S. 129.

4 Siehe dazu Aristophanes (1970 [391 v. Chr.]) Die Weibervolksversammlung. In: Sämtliche Komödien, Bd. 2. Artemis Verlag, Zürich, S. 581-635.

5 David Graeber (2002) The New Anarchists. In: New Left Review (NLR), Nr. 13, S. 61-73. Online: https://newleftreview.org/ll/13/davidgraeber-the-new-anarchists (30.6.15).

6 Feministische Perspektiven in Architektur und Stadt, z. B. Frau, Steine, Erde für den Verein Sozialwissenschaftliche Forschung und Praxis (Hrsg.) (1980) Frauen, Räume, Architektur, Umwelt. In: Beiträge zur feministischen Theorie und Praxis, Nr. 4; Leonie Sandercock (Hrsg.) (1998) Making the Invisible Visible. A Multicultural Planning History; Dörte Kuhlmann (2009) Raum, Macht, Differenz. Genderstudien in der Architektur; Felicita Reuschling (2015) Kapitalistischer Realismus, Postutopie und die heilige Familie, S. 129-143. In: Kitchen Politics (Hrsg.) Sie nennen es leben, wir nennen es Arbeit. Biotechnologie, Reproduktion und Familie im 21. Jahrhundert; Meike Schalk, Ulrika Gunnarsson-Östling, Karin Bradley (2017) Feminist Futures and ,Other Worlds'. Ecologies of Critical Spatial Practice, S. 447-463. In: Sherilyn MacGregor (Hrsg.) Routledge Handbook of Gender and Environment; Felicita Reuschling (2018) Soziale Wohnutopien 68: Everything must change, S. 159-172. In: sublurban. Zeitschrift für kritische Stadtforschung, Bd. 6, Nr. 2/3; Kim Trogal (2018) Caring. Die räumliche Dimension der Sorgearbeit, S. 122-127. In: Archplus, Nr. 232: An Atlas of Commoning. Orte des Gemeinschaffens; Caroline Criado-Perez (2020) Unsichtbare Frauen. Wie eine von Daten beherrschte Welt die Hälfte der Bevölkerung ignoriert; siehe dazu auch die Initiative Women in Architecture (WIA) und die Wanderausstellung Frau Architekt.

7 Vgl. Lenk (1966) Einleitung. Charles Fourier, S. 29. 
8 Marit Rullmann (1998) Christine de Pizan (1365-1429/30),

S. 101-108. In: Philosophinnen. Von der Antike bis zur Aufklärung. Suhrkamp, Frankfurt/M., S. 105.

9 Bettina Roß (1998) Politische Utopien von Frauen. Von Christine de Pizan bis Karin Boye. Edition Ebersbach, Dortmund, S. 126.

10 Vgl. Margarete Zimmermann (1990) Einleitung, S. 9-33. In: Christine de Pizan, Das Buch von der Stadt der Frauen (Frz. 1405) DTV, München, S. 23-24.

11 Vgl. a. a. O., S. 24

12 Vgl. Christine de Pizan (1990 [Frz. 1405]) Das Buch von der Stadt der Frauen. DTV, München, S. 63-64.

Die Reihung von Exempla ist ein typisch mittelalterliches Verfahren. Exempla sind erzählte „Beispiele" mit Beleg- und Beweischarakter, die ihren Aussagewert erst im Zusammenhang mit der These oder Lebensregel erhalten, die sie illustrieren sollen, vgl. Zimmermann (1990) Einleitung, S. 24.

13 Vgl. Ulrike Guérot (2019 [zuerst 2017]) Warum Europa eine Republik werden muss. Eine politische Utopie. 3. Auflage. Piper, München, S. 260-261.

14 Vgl. a. a. O., S. 264-265.

15 Vgl. a. a. O., S. 103-104 [Hervorh. i. O.].

16 Vgl. a. a. O., S. 119-122 [Hervorh. i. O.].

17 Vgl. a. a. O., S. 272 [Hervorh. i. O.].

18 Ágnes Heller (2014) Der Sinn des Lebens ist zu leben. Ein Interview mit dem SZ-Magazin, Nr. 4/2014. Online: https://sz-magazin. sueddeutsche.de/literatur/der-sinn-des-lebens-ist-zu-leben-80204 (10.8.20).

\section{Politische Implikationen}

1 Georg Simmel (1903) Über räumliche Projektionen sozialer Formen, S. 304-316. In: Jörg Dünne, Stephan Günzel (Hrsg.) (2006) Raumtheorie. Grundlagentexte aus Philosophie und Kulturwissenschaften. Suhrkamp, Frankfurt/M., S. 313-315.

2 Ebd.

3 Siehe dazu weiterführend, z. B. Gabriel Popescu (2012) Bordering and Ordering the Twenty-first Century. Understanding Borders. Roman \& Littlefield, Lanham/MD; Wendy Brown (2014) Walled States, Waning Sovereignty. Zone books, New York/NY. Grenzzone der griechischen Polis: Akademiegarten (Allopolis, die 
andere Polis = andere Stadt = anderer Standpunkt = extra muros), vgl. Peter Sloterdijk (2014 [zuerst 1994]) Die Stadt und ihr Gegenteil: Apolitologie im Umriss, S. 184-229. In: Ders. Der ästhetische Imperativ. Schriften zur Kunst. Suhrkamp, Berlin, S. 198, 200-202. Siehe dazu auch Jacques Derrida (2013 [Frz. 1987]) Chōra. Passagen Verlag, Wien; Gil M. Doron (2007) ... badlands, blank space, border vacuums, brown fields, conceptual Nevada, Dead Zones, derelict areas, ellipsis spaces, empty places, free space, liminal spaces, nameless spaces, No Man's Lands, polite spaces, post architectural zones, spaces of indeterminacy, spaces of uncertainty, smooth spaces, Tabula Rasa, Temporary Autonomous Zones, terrain vague, urban deserts, vacant lands, voids, white areas, Wasteland ...

SLOAPs, S. 10-23. In: Field. A Free Journal for Architecture, Vol. 1(1): Architecture and Indeterminacy. University of Sheffield, Sheffield/ UK. Online: http://field-journal.org/wp-content/uploads/2016/07/gdoron.pdf (31.7.19).

Grenzzonen in Film und Literatur, z. B. Andrej Tarkowski (1979) Stalker; Wim Wenders (1987) Himmel über Berlin; Marge Piercy (1991) Er, Sie und Es; Ahmed Khaled Towfik (2015) Utopia; Doris Dörrie (2016) Grüße aus Fukushima.

4 Simmel (1903) Über räumliche Projektionen sozialer Formen, S. 313-315 [Hervorh. d. Verf.].

5 Publikationen zu urbanen Transformationsprozessen, z. B. Kenny Cupers, Markus Miessen (2002/2018) Spaces of Uncertainty. Berlin Revisited; Srdjan Jovanovic Weiss (2005) Turbo Architecture. In: Atlas of Transformation. Online: http://monumenttotransformation.org/atlas-of-transformation/html/t/turbo-architecture/turboarchitecture-srdjan-jovanovic-weiss.html (23.7.19); Klaus Overmeyer, Holger Lauinger (2007) Urban Pioneers. Berlin, Stadtentwicklung durch Zwischennutzung; Eve Blau, Harvard GS. (Hrsg.) (2007) Project Zagreb. Transition as Condition, Strategy, Practice; ETH Studio Basel (Hrsg.) (2012) Belgrade. Formal/Informal. Eine Studie über Städtebau und urbane Transformation; Sergio Lopez-Pineiro (2020) A Glossary of Urban Voids.

6 U. a. die Ausstellung Dissident Gardens am Het Nieuwe Instituut, 2018; oder auch das Stadtraumprojekt Coop Campus, ein kooperatives Gartenprojekt mit Baumschule für Neuankömmlinge (aus Konfliktzonen), Schülerinnen und Interessierte an Garten-, Kunstund Bildungswerkstätten, angegliedert an den Jerusalem-Friedhof, Berlin-Neukölln. Initiative der Schlesischen 27 mit RaumlaborBerlin, in Zusammenarbeit mit dem Ev. Friedhofsverband Berlin-Mitte, seit 2015. Online: http://www.schlesische27.de/s27/portfolio/coopcampus/ (5.8.19).

Innerstädtische Rückzugsorte als Erfüllung eines traumwandlerisch- 
mythischen Wunsches nach einem Leben im Einklang mit der Natur; siehe dazu, z. B. Tom Avermaete im Gespräch mit Jørg Himmelreich (2019) Rückzug nach innen. In: Archithese, Nr. 2/2019: Rückzug, S. 18-27.

7 Vgl. Alfaro d'Alençon et al. (2017) Ephemere Stadtentwicklung, S. 16-17.

8 Siehe dazu, z. B. Lisa Vollmer (2018) Strategien gegen Gentrifizierung. Schmetterling Verlag, Stuttgart.

Grundlagentexte zum Recht auf Stadt, z. B. Henri Lefebvre (2016 [Frz. 1968]) Das Recht auf Stadt u. (2014 [Frz. 1970]) Die Revolution der Städte; David Harvey (2013 [Engl. 2012]) Rebellische Städte. Vom Recht auf Stadt zur urbanen Revolution.

9 Zur Bewertung eines Projekts sollte man in unterschiedlichen Projektstadien unterschiedliche Bewertungsmaßstäbe ansetzen, z. B. Gliederungsmodell in fünf Phasen: (1.) Latenzphase, (2.) Entstehungsphase, (3.) Fermentierungsphase, (4.) Stabilisierungsphase sowie (5.) Kritikphase, vgl. Thomas Honeck (2015) Zwischennutzung als soziale Innovation. Von alternativen Lebensentwürfen zu Verfahren der räumlichen Planung, S. 219-231. In: Informationen zur Raumentwicklung, Heft 3/2015, S. 222.

10 Vgl. ExRotaprint. Online: https://www.exrotaprint.de/erbbaurecht/ (15.8.20).

11 Siehe dazu, z. B. Angelika Fitz, Elke Krasny (2019) Critical Care. Architektur für einen Planeten in der Krise. Katalog zur gleichnamigen Ausstellung im Architekturzentrum Wien (AzW); Gilly Karjevsky, Rosario Talevi für die Floating University e.V. (August 2019) Climate Care. A Curriculum for Urban Practice. Online: https:// www.floatinguniversity.org/wp-content/uploads/2019/08/ClimateCare_Program_Doubble_Web_31-07.pdf (8.8.19).

Ein kritisches Umdenken zeichnet sich allmählich auch in der Bauwirtschaft ab, z. B. veröffentlichte der Bund Deutscher Architekten (BDA) kürzlich das Diskussionspapier „Das Haus der Erde“, worin „Positionen für eine klimagerechte Architektur in Stadt und Land" dargelegt werden. Daraus geht hervor, dass technische Lösungen, z. B. Smart-City-Konzepte nicht hinreichend dazu beitragen können rasante gesellschaftliche Wandlungen, die ökologische, sozialpolitische und nicht zuletzt ästhetische Aspekte betreffen, mitzugestalten. Online: https://www.db-bauzeitung. de/aktuell/diskurs/bda-fordert-radikale-abkehr-vom-wachstum/ (24.6.19); siehe auch die kürzlich gegründete Initiative Architects for Future. Online: https://www.architects4future.de (1.8.19). Auf deutscher Bundesebene wurde kürzlich die Maßnahme "Stadtnatur" verabschiedet. Einerseits zur Erhöhung der Arten- und 
Biotopvielfalt in Städten, andererseits als Beitrag zum Umgang mit der erwarteten Verschiebung der Klimazonen, d.h. Verbesserung der Stadtklimata durch die Reduktion sich aufheizender Betonflächen. Vorgesehen ist $u$. a. die Schaffung grüner Kühlungszonen, z. B. Stadtgärten (mit unversiegelten Bodenflächen), sowie die Begrünung von Fassaden und Dächern. Online: https://www.bmu. de/stadtnatur/ (8.8.19).

12 Swyngedouw zit. nach Ulrich Beck (2017 [Engl. 2016]) Die Metamorphose der Welt. Suhrkamp, Berlin, S. 234-235.

13 Der Kulturwissenschaftler Mark Fisher geht noch einen Schritt weiter und schreibt in seinem Buch Kapitalistischer Realismus ohne Alternative? (2009), dass der Wachstumsfetisch des Kapitals, d. h. sein Bedürfnis nach "konstanter Ausdehnung der Märkte" ist mit jeglichem Begriff von Nachhaltigkeit unvereinbar. Er geht so weit zu behaupten, dass die Umweltkatastrophe im Spätkapitalismus nur als Simulakrum vorkomme, weil ihre realen Implikationen zu traumatisch seien, um vom System assimiliert werden zu können, vgl. Fisher (2013 [Engl. 2009]) Kapitalistischer Realismus ohne Alternative? S. 26-27 [Hervorh. d. Verf.].

Fisher konstatiert, bezugnehmend auf Slavoj Žižek, dass der Kapitalismus auf seine eigene Verleugnung angewiesen ist. Die kapitalistische Ideologie bestünde genau darin, dass wir unseren Glauben (die subjektive Einstellung) auf Kosten der Glaubenssätze, die wir in unserem Verhalten externalisieren (nach außen tragen), überbewerten. Solange wir daran glauben (emotional, nicht rational), dass der Kapitalismus schlecht ist, erhalten wir uns die Freiheit, am kapitalistischen Tausch weiterhin teilzunehmen. Vgl. a. a. O., S. 21-22.

14 Vgl. Édouard Glissant (2005 [Frz. 1996]) Kultur und Identität. Ansätze zu einer Poetik der Vielheit. Wunderhorn, Heidelberg, S. 19-21, 32.

15 Vgl. John Dewey (1988 [Engl. 1934]) Kunst als Erfahrung. Suhrkamp, Frankfurt/M., speziell: Kap. vii, xi, xiv.

16 Vgl. ON/OFF. Online: http://www.onoff.cc/projects/babel/ (15.8.20) [Übers. d. Verf.].

17 Vgl. SHAU Architects. Online: http://www.shau.nl/de/project/53 (15.8.20) [Übers. d. Verf.].

18 Vgl. Breitenstein (2013) Die Befreiung der Geschichte, S. 272.

19 Hannah Arendt (2015 [Engl. 1951/Frz. 2002]) Elemente und Ursprünge totaler Herrschaft zit. nach Marc Augé (2015) Die illusorische Gemeinschaft. Matthes \& Seitz, Berlin, S. 30 (zit. aus der französischen Übersetzung (S. 834) des amerikanischen Originals, übertragen ins Deutsche von Till Bardoux). 
Arendt hat auch einen positiven Einsamkeitsbegriff formuliert. Sie unterscheidet zwischen Alleinesein (Solitude), Einsamkeit (Loneliness) und Isolation. Vereinfacht dargestellt: Das Alleinsein kann durchaus produktiv sein bzw. genutzt werden und ist teils selbst gewählt. Die Einsamkeit ist auf Dauer für die Gesundheit besorgniserregend und meist nicht selbst gewählt. Die Isolation ist unfreiwillig, z. B. durch Haft, Armut oder auch Krankheit und gilt als Symptom totalitärer Regime (wozu auch die neoliberale Herrschaft gezählt werden kann) und wird in diesen auch als Werkzeug eingesetzt, um unliebsame kritische Stimmen oder auch die politische Handlungsfähigkeit von Menschen (nicht nur an den gesellschaftlichen Rändern) kontrollieren bzw. unterdrücken zu können, vgl. Sandra Meireis (2020) Einsamkeit in der Großstadt. In: Ästhetik \& Politik. Online: https://sandrameireis.com/2020/06/02/einsamkeit-inder-grosstadt/ (15.8.20).

Großbritannien, das Mutterland der parlamentarischen Demokratie, berief erst kürzlich eine*n Einsamkeitsminister*in (Minister of Loneliness, seit 2018).

20 Vgl. Glissant (2005 [Frz. 1996]) Kultur und Identität, S. 11.

21 Vgl. Augé (2015) Die illusorische Gemeinschaft, S. 31 [Hervorh. d. Verf.].

22 Er stellt der bürgerlichen Öffentlichkeit der Eliten, die sich vor allem in Teestuben, Salons und Freimaurerlogen vollzog, eine "plebejische" Öffentlichkeit des einfachen Volkes gegenüber, das eigene Formen und Orte der politischen Artikulation entwickelte. Denn aus ihrer Sicht war die adlig-bürgerliche Öffentlichkeit ein Spiel innerhalb der Oberschicht, dessen Kritik an den Machtverhältnissen nicht weit genug ging, d. h. die Lebenswelt der einfachen Leute nicht berührte oder gar verbesserte, vgl. Habermas (1990 [Habil. 1962]) Strukturwandel der Öffentlichkeit, S. 16-21.

23 Vgl. Paul Nolte (2012) Was ist Demokratie? Geschichte und Gegenwart. C.H.Beck, München, S. 164-165.

24 Eley (1994) Wie denken wir über Politik? S. 33.

25 Siehe dazu in der marxistischen Literatur, z. B. Herbert Marcuse (1982 [Engl. 1955]) Triebstruktur und Gesellschaft. Ein philosophischer Beitrag zu Sigmund Freud. Suhrkamp, Frankfurt/M.; Christoph Spehr (2001) Lemma: Gegenöffentlichkeit, S. 1-13. In: Historischkritisches Wörterbuch des Marxismus, Bd. 5; siehe dazu im Architekturdiskurs, z. B. Nina Gribat, Philipp Misselwitz, Matthias Görlich (Hrsg.) (2017) Vergessene Schulen. Architekturlehre zwischen Reform und Revolte 1968. Spector, Leipzig; siehe dazu im Film, z. B. Pier Paolo Pasolini (1968) Teorema. Geometrie der Liebe. Aetos Produzioni Cinematografiche. 
26 Vgl. Heike Kahlert (2000) Lemma: Hannah Arendt, The Human Condition, S. 17-20. In: Hauptwerke der Soziologie. Hrsg. v. Dirk Kaesler, Ludgera Vogt. Kröner, Stuttgart.

27 Hannah Arendt (1981 [Engl. 1958]) Vita activa. Oder vom tätigen Leben. Piper, München, S. 252.

28 Siehe dazu Jane Jacobs (1992 [zuerst 1961]) The Death and Life of Great American Cities. Vintage Books, New York/NY; Alexander Mitscherlich (2008 [zuerst 1965]) Die Unwirtlichkeit unserer Städte. Anstiftung zum Unfrieden. Suhrkamp, Frankfurt/M.

29 Siehe dazu Henri Lefebvre (1991 [Frz. 1974]) The Production of Space. Blackwell Publishing, Malden/MA.

30 Das informelle Bauen erschien, gegenüber der in dieser Zeit weit verbreiteten Praxis des Massenwohnungsbaus, als positive Alternative im Hinblick auf Ressourcenschonung, soziale Einbindung und räumliche Anpassung sich verändernder Lebensumstände.

31 Planung nicht für sondern mit der Gemeinschaft. Der planungstheoretische Paradigmenwechsel Communicative turn oder Methoden wie z. B. Community planning, Community design practice, Scenario planning, Design thinking deuten auf eine Entwicklung hin, die seit den 1970er Jahren für die mehr Selbstverantwortung und -organisation der Nutzer*innen sensibilisiert.

32 In Rekurs auf den Soziologen Anthony Giddens (1987) Social Theory and Modern Sociology, vgl. Tatjana Schneider, Jeremy Till (2009) Beyond Discourse: Notes on Spatial Agency, S. 97-111. In: Footprint, Nr. 4: Agency in Architecture, S. 98. Online: https://doi.org/10.7480/ footprint.3.1.702 (30.4.14).

Siehe dazu auch Tom Holert (2011) Civic City Cahier 3: Distributed Agency, Design's Potentiality. Bedford Press, London/UK.

33 Carola Mick (2012) Das Agency-Paradigma, S. 527-541. In: Ullrich Bauer, Uwe Bittlingmayer, Albert Scherr (Hrsg.) Handbuch Bildungsund Erziehungssoziologie. VS Verlag, Wiesbaden, S. 527 [Hervorh. d. Verf.].

34 Vgl. ebd.

35 Vgl. Haus der Statistik. Online: https://hausderstatistik.org/modellprojekt/ (15.8.20).

36 Vgl. Cooperative City. Online: https://cooperativecity.org/product/ funding-the-cooperative-city/ (15.8.20) [Übers. d. Verf.].

37 Ilona Koglin und Marek Rohde im Interview (2019) Faironomics. Auf dem Weg zu einer neuen Form der Ökonomie. In: Agora42, Nr. 3. Online: https://agora42.de/faironomics/\#more-11070 (1.7.19). 
38 Erik Swyngedouw (2005) Governance Innovation and the Citizen. The Janus Face of Governance-beyond-the-state, S. 1991-2006. In: Urban Studies, Nr. 42/11 zit. nach Misselwitz (2017) Und täglich grüßt das Murmeltier..., S. 23-24.

39 Ein Intellektuellentypus, der eng mit den entscheidenden materiellen und ökonomischen Strukturen der Gesellschaft verbunden ist und aus deren Milieu hervorgeht; vgl. Antonio Gramsci (1930-32) Die Herausbildung des Intellektuellen zit. nach Nick Srnicek, Alex Williams (2016 [Engl. 2015]) Die Zukunft erfinden. Postkapitalismus und eine Welt ohne Arbeit. Bittermann, Berlin, S. 270.

40 Vgl. Peter Streckeisen (2012) Pierre Bourdieu und der kollektive Intellektuelle. In: Debatte, Nr. 20. Online: https://debatte. ch/2014/07/pierre-bourdieu-und-der-kollektive-intellektuelle/ (24.7.19).

41 Die Mitglieder arbeiten meist zusätzlich in anderen Strukturen, z. B. in Büros, Galerien, Universitäten; das Kollektiv ist nicht für alle der Hauptjob, vgl. ON/OFF und DIESE-Studio im Gespräch mit der Zeitschrift Bauwelt (2018) https://www.bauwelt.de/dl/ 1329691/Wasmachen-eigentlich-Kollektive-oeffentliche-interventionen-architektur-on-off-diese-studio-berlin-darmstadt.pdf (23.7.19).

Zur Organisationsökologie (Netzwerke, Partizipation), vgl. Srnicek, Williams (2016 [Engl. 2015]) Die Zukunft erfinden, S. 254, 264, 266; vgl. Jeremy Rifkin (2016 [Engl. 1995]) Das Ende der Arbeit und ihre Zukunft. Fischer, Frankfurt/M.

42 Vgl. Ernesto Laclau (2006) Why Constructing a People Is the Main Task of Radical Politics, S. 646-680. In: Critical Inquiry, Nr. 32/4; vgl. Srnicek, Williams (2016 [Engl. 2015]) Die Zukunft erfinden, S. 258-259.

43 Siehe dazu, z. B. Jesko Fezer (2013) Civic City Cahier 6: Design in and Against the Neoliberal City. Bedford Press, London/UK; Marit Rosol (2017) Gemeinschaftlich gärtnern in der neoliberalen Stadt? In: Sarah Kumnig, Marit Rosol, Andreas Exner (Hrsg.) Umkämpftes Grün. Zwischen neoliberaler Stadtentwicklung und Stadtgestaltung von unten. transcript, Bielefeld, S. 11-32.

Wie verhält es sich mit den kooperativen, kommunikativen Planungsprozessen, Charrette-Verfahren, Runden Tischen, Stakeholder-Prozessen, die in der Planung fast wieder zu einer neuen Orthodoxie geworden sind? Vgl. Swyngedouw (2005) Governance innovation and the Citizen zit. nach Misselwitz (2017) Und täglich grüßt das Murmeltier..., S. 22-24.

Zeit für eine kritische Zwischenbewertung: Ist eine nachhaltige Anpassung von Planung zugunsten akteursorientierter Prozesse festzustellen? Vgl. ebd. 
44 Initiativen postkapitalistischer Praxis, z. B. das großbritannische Netzwerk Incredible Edible Network. Online: https://www.incredibleedible.org.uk (4.8.19); das nordamerikanische Netzwerk Business Alliance for Local Living Economies (BALLE). Online: https://bealocalist.org (15.7.19); Transition-Town-Initiativen im Vereinigten Königreich: https://transitionnetwork.org oder in Deutschland, Österreich und der Schweiz: https://www.transition-initiativen.org (4.8.19); siehe dazu auch Kurt Langbein (2018) Zeit für Utopien. Online: http://www.zeit-fuer-utopien.com (15.7.19).

45 Srnicek, Williams (2016 [Engl. 2015]) Die Zukunft erfinden, S. 10.

46 Siehe dazu Paul Mason (2018 [Engl. 2015]) Postkapitalismus. Grundrisse einer kommenden Ökonomie. Suhrkamp, Berlin.

47 Vgl. Fisher (2013 [Engl. 2009]) Kapitalistischer Realismus ohne Alternative? S. 109.

48 U. a. das Mietshäuser-Syndikat als Vorreiter; siehe zur Einverleibung von außerhalb des Marktes Liegendem vertiefend, z. B. Karl Polanyi (2015 [Engl. 1944]) The Great Transformation. Politische und ökonomische Ursprünge von Gesellschaften und Wirtschaftssystemen. Suhrkamp (Lizenzausgabe) u. Europa Verlag, Wien. In der heutigen Kulturindustrie hat sich der althergebrachte Unterschied zwischen Zweckentfremdung (Subversion) und Vereinnahmung (Inkorporierung) bereits aufgelöst: „Heute haben wir es weniger mit der Inkorporierung, der Einverleibung von Dingen, die angeblich mal subversiv gewesen sind, zu tun, als vielmehr mit ihrer Präkorporierung: dem präventiven Formatieren und Gestalten von Begehren, Ansprüchen und Hoffnungen durch eine kapitalistische Kultur [vorauseilende Marktkonformität]. [...] Begriffe wie ,alternativ' und ,unabhängig' bezeichnen nichts, was außerhalb eines Mainstreams passiert. De facto sind sie die dominanten Stile innerhalb des Mainstreams." Fisher (2013 [Engl. 2009]) Kapitalistischer Realismus ohne Alternative? S. 16.

49 Siehe dazu Greg Sharzer (2012) No Local. Why Small-Scale Alternatives Won't Change The World. Zero Books, Winchester/UK.

50 Vgl. Srnicek, Williams (2016 [Engl. 2015]) Die Zukunft erfinden, S. 256.

51 A. a. O., S. 70.

52 Vgl. a. a. O., S. 115-138.

53 Vgl. a. a. O., S. 139-174.

54 Vgl. a. a. O., S. 175-286.

55 Vgl. Mason (2018 [Engl. 2015]) Postkapitalismus, S. 11-21. 
56 Vgl. Neil Brenner (2017) Is "Tactical Urbanism" an Alternative to Neoliberal Urbanism? Reflections on an Exhibition at the MoMA, S. 113-128. In: Doina Petrescu, Kim Trogal (Hrsg.) The Social (Re) Production of Architecture. Politics, Values and Actions in Contemporary Practice, S. 124-125 [Hervorh. i. O.] [Übers. d. Verf.].

57 Vgl. Matthias Schmelzer, Andrea Vetter (2019) Degrowth/Postwachstum. Zur Einführung. Junius, Hamburg, S. 27-31.

58 Unterschied der Ansätze Degrowth und Postwachstum, vgl. Schmelzer, Vetter (2019) Degrowth/Postwachstum, S. 17.

59 Vgl. Dennis Eversberg, Matthias Schmelzer (2018) The Degrowth Spectrum zit. nach Schmelzer, Vetter (2019) Degrowth/Postwachstum, S. 40-41; siehe dazu vertiefend J. K. Gibson-Graham (2006) A Postcapitalist Politics. University of Minnesota Press, Minneapolis/MN.

60 Niko Paech (seit 2008) Grundzüge einer Postwachstumsökonomie. Online: http://www.postwachstumsoekonomie.de/material/grundzuege/ (30.7.19); siehe zum Thema Konsumkritik und Verzicht auch, z. B. Maja Göpel (2020) Unsere Welt neu denken. Eine Einladung. Ullstein, Berlin, S. 118-135.

61 Vgl. Schmelzer, Vetter (2019) Degrowth/Postwachstum, S. 22, 32.

62 Vgl. Oskar Negt (2016 [zuerst 2012]) Nur noch Utopien sind realistisch. Politische Interventionen. Werkausgabe Bd. 17. Steidl Verlag, Göttingen. S. 19; siehe dazu vertiefend, z. B. Hans Jonas (1984 [zuerst 1979]) Das Prinzip Verantwortung. Versuch einer Ethik für die technologische Zivilisation. Suhrkamp, Frankfurt/M.

63 Siehe dazu Fran Tonkiss (2013) Austerity Urbanism and the Makeshift City. In: City, Nr. 17/3, S. 312-324. Online: https://doi. org/10.1080/13604813.2013. 795332 (4.7.15).

64 Negt (2016 [zuerst 2012]) Nur noch Utopien sind realistisch, S. 19.

65 Das korrespondiert mit der Tatsache, dass auch heute noch dezentrale Diversität gegenüber industrieller Monokultur (in Land- und Energiewirtschaft) vorherrscht: $70 \%$ der weltweiten Nahrungsmittel kommt von Kleinbauern, d. h. aus bäuerlicher und nicht industrieller Landwirtschaft, vgl. Weltagrarbericht. Online: https:// www.weltagrarbericht.de/fileadmin/files/weltagrarbericht/Neuauflage/Weltagrarbericht10Jahre.pdf (27.7.19); und $70 \%$ der Energie kommt von Kleinanbietern; dezentralisiertes Microgridding könnte zukünftig $90 \%$ des Energiebedarfs decken, vgl. die niederländische Studie SIDE-Systems. Online: https://www.metabolic.nl/publications/ side-systems/ (2.8.19).

Siehe dazu ältere Studien aus Politik und Wirtschaft, z. B. Ernst F. Schumacher (1973) Die Rückkehr zum menschlichen Maß. Alterna- 
tiven für Wirtschaft und Technik, "Small is beautiful"; Leopold Kohr (2002 [zuerst 1957]) Das Ende der Großen. Zurück zum menschlichen Maß.

Kreislaufwirtschaft als öko-effektive Alternative, z. B. das Projekt InFarming im Altmarktgarten Oberhausen, Dachgewächshaus mit Garten und geschlossenen Kreisläufen zur urbanen Nahrungsmittelproduktion, Kuehn Malvezzi Architekten / Atelier Le Balto.

Publikationen zu postkapitalistischen Praktiken, z. B. William McDonough, Michael Braungart (2002) Cradle-to-Cradle. Einfach intelligent produzieren; Andrea Baier et al. (Hrsg.) (2016) Die Welt reparieren. Open Source und Selbermachen als postkapitalistische Praxis; Christian Felber (2017) Gemeinwohl-Ökonomie; Ilona Koglin, Marek Rohde (2019) Faironomics. Ökologisch, fair und frei; Silke Helfrich, David Bollier (2019) Frei, fair und lebendig. Die Macht der Commons; Bastian Lange et al. (Hrsg.) (2020) Postwachstumsgeographien. Raumbezüge diverser und alternativer Ökonomien.

66 Siehe dazu auch Marc Augé (2019) Die Zukunft der Erdbewohner. Ein Manifest. Matthes \& Seitz, Berlin; Heinz Bude (2019) Solidarität. Die Zukunft einer großen Idee. Hanser, München.

67 Multilokale Netzwerke sind u. a. CoCoon/Contextual Construction, Cooperative City/Eutropians, European Network of Creative Collectives, Hidden Institute, Netzwerk Urbane Gärten Berlin, Stadt statt Strand, Stadt von Unten, Vernetzungsratschlag Berlin.

Handbücher und Leitfäden zur kritischen Architekturpraxis (als Projektergebnisse kommunaler und staatlicher Förderprogramme), z. B. Umweltbundesamt Dessau (Hrsg.) (2005) Die Zukunft liegt auf Brachflächen; Bundesinstitut für Bau-, Stadt- und Raumforschung (Hrsg.) (2016) Freiraum-Fibel. Wissenswertes über die selbstgemachte Stadt; Initiative Stadt Neudenken mit der Senatsverwaltung für Stadtentwicklung und Wohnen in Berlin (Hrsg.) (2017) Erbbaurechte in Berlin; Reallabor für nachhaltige Mobilitätskultur mit dem Bundesministerium für Umwelt, Naturschutz, Bau und Reaktorsicherheit und dem Umweltbundesamt (Hrsg.) (2017) Die Kultur des Experimentierens. In Reallaboren Nachhaltigkeit gemeinsam schaffen.

68 Vgl. Schmelzer, Vetter (2019) Degrowth/Postwachstum, S. 18-24.

69 Vgl. Zygmunt Bauman (1995 [Engl. 1993]) Postmoderne Ethik, S. 55 [Hervorh. i. O.].

70 Vgl. Paul Virilio (1984) Die Auflösung des Stadtbildes, S. 261-273. In: Jörg Dünne, Stephan Günzel (Hrsg.) (2006) Raumtheorie. Grundlagentexte aus Philosophie und Kulturwissenschaften. Suhrkamp, Frankfurt/M., S. 269 [Hervorh. i. O.]. 
71 Vgl. Virilio (1984) Die Auflösung des Stadtbildes, S. 269 [Hervorh. i. o.].

72 Vgl. Fredric Jameson (2005) Archeologies of the Future, S. 232 zit. nach Benjamin Kunkel (2014 [Engl. 2013]) Fredric Jameson. Die kulturelle Logik des Neoliberalismus, S. 59-85. In: Ders. (Hrsg.) Utopie oder Untergang. Ein Wegweiser für die gegenwärtige Krise. Suhrkamp, Berlin, S. 77.

73 Siehe dazu, z. B. Slavoj Žižek (2008 [zuerst 1989]) The Sublime Object of Ideology; David Harvey (2007 [Engl. 2005]) Kleine Geschichte des Neoliberalismus; Frank Bösch (2019) Zeitenwende 1979. Als die Welt von heute begann.

Dazu architekturgeschichtlich-anekdotisch: Mit der Sprengung der Siedlung Pruitt Igoe in St. Louis/MO, eine Siedlung des japanischamerikanischen Architekten Minoru Yamasaki, erklärt Charles Jencks die Moderne im Juli des Jahres 1972 für beendet; im Jahr darauf werden die Zwillingstürme des New Yorker World Trade Centers fertiggestellt, ebenfalls ein Bauwerk Yamasakis und Symbol postmoderner Kultur; die 28 Jahre später, durch die Anschläge im September 2001 (mutmaßlich durch den Architekturstudenten Mohamed Atta) zerstört wurden und symbolisch für das Ende der Postmoderne steht bzw. als solches interpretiert werden kann.

74 Vgl. Uwe Schimank (2012) Vom "fordistischen" zum "postfordistischen" Kapitalismus. Online: https://www.bpb.de/politik/grundfragen/deutsche-verhaeltniss e-eine-sozialkunde/137994/vomfordistischen-zum-postfordistischen-kapitalismus? $p=$ all [Hervorh. $d$. Verf.] (11.8.19).

75 Konkret festzumachen an der starken Leitzins-Erhöhung (um 20 Punkte) der US-Notenbank; vgl. Christian Marazzis Vortrag „Finance, Attention and Affect" am Goldsmith College London 2005 zit. nach Fisher (2013 [Engl. 2009]) Kapitalistischer Realismus ohne Alternative? S. 43.

Siehe zum Übergang vom Fordismus zum Postfordismus vertiefend, z. B. Christian Marazzi (2011 [Engl. 2009]) Verbranntes Geld. Diaphanes, Zürich.

76 Vgl. Lyotard zit. nach Breitenstein (2013) Die Befreiung der Geschichte, S. 25.

77 Sloterdijk (1983) Kritik der zynischen Vernunft, S. 18.

78 A. a. O., S. 19

79 Audre Lorde (1981) Du kannst nicht das Haus des Herren mit dem Handwerkszeug des Herren abreißen, S. 199-212. In: Dies., Adrienne Rich (1993 [Engl. 1983]) Macht und Sinnlichkeit. Ausgewählte 
Texte. Hrsg. v. Dagmar Schultz, Orlanda Frauenverlag, Berlin, S. 200-201 [Hervorh. d. Verf.].

80 Reckwitz (2017) Die Gesellschaft der Singularitäten, S. 7 [Hervorh. i. O.].

81 A. a. O., S. 8 [Hervorh. i. O.].

82 Achille Mbembe (2018 [Frz. 2013]) Kritik der schwarzen Vernunft. Suhrkamp, Berlin, S. 17-18 [Hervorh. d. Verf.].

83 Siehe dazu Jean-Luc Nancy (2004 [Frz. 1996]) Singulär plural sein. Diaphanes, Berlin.

84 Vgl. Marx, Engels (1844) Manifest der kommunistischen Partei, S. 253-290. In: Gareth Stedman Jones (2012 [Engl. 2002]) Das kommunistische Manifest von Karl Marx und Friedrich Engels. Einführung, Text, Kommentar. C.H.Beck, München, S. 258.

Mikro- und Minor-Theorien in Architektur und Literatur, z. B. Gilles Deleuze, Félix Guattari (1986 [Frz. 1975]) Kafka. Toward a Minor Literature; Bell Hooks (1989) Choosing the Margin as a Space of Radical Openness, S. 15-23. In: Framework. Journal of Cinema and Media, Nr. 36; Ignasi de Solà-Morales (1997 [Span. 1995]) Weak Architecture, S. 57-71. In: Ders. (1999) Differences. Topographies of Contemporary Architecture; Cindi Katz (1996) Towards Minor Theory, S. 487-499. In: Environment and Planning D: Society and Space, Nr. 14; Marianne Schuller, Gunnar Schmidt (2003) Mikrologien. Literarische und philosophische Figuren des Kleinen; Jill Stoner (2012) Toward a Minor Architecture.

85 Siehe dazu auch Alfons Trompenaars, Charles Hamden-Turner (1993) Riding the Waves of Culture. Understanding Cultural Diversity in Business. Random House, New York/NY.

86 Srnicek, Williams (2016 [Engl. 2015]) Die Zukunft erfinden, S. 116.

87 Zygmunt Bauman (2000 [Engl. 1999]) Die Krise der Politik. Fluch und Chance einer neuen Öffentlichkeit, S. 281-282.

Siehe dazu auch Charles Taylor (1993 [Engl. 1992]) Multikulturalismus und die Politik der Anerkennung. Fischer, Frankfurt/M.; Wolfgang Welsch (2009 [seit 1992]) Was ist eigentlich Transkulturalität? S. 39-66. In: Lucyna Darowska, Thomas Lüttenberg, Claudia Machold (Hrsg.) Hochschule als transkultureller Raum? Kultur, Bildung und Differenz in der Universität. transcript, Bielefeld.

88 Bhabha (2007 [Engl. 1994]) Die Verortung der Kultur, S. 241 [Hervorh. d. Verf.].

89 Ebd. [Hervorh. i. O.].

90 Ebd. 
91 Hier ist der Verweis auf Protagonist*innen und Autor*innen post-begrifflicher Konzepte, die nicht explizit im Text besprochen werden oder sich aus dem Zusammenhang selbsterklären, hinreichend, z. B. postheroisch: die Whistleblower Edward Snowden und Chelsea Manning, die Politikerin Alexandria Ocasio-Cortez, die Aktivistinnen Greta Thunberg und Carola Rackete; postmigrantisch: ein Gesellschaftskonzept, das durch die Sozialwissenschaftlerin Naika Foroutan und die Theater-Intendantin Shermin Langhoff bekannt gemacht wurde; postoperaistisch: die Trilogie (Empire-MultitudeCommon Wealth) des Literaturwissenschaftlers Michael Hardt und des Philosophen Antonio Negri; postpolitisch: ein Konzept des Philosophen Jacques Rancière.

92 Vgl. Heinz Dieter Kittsteiner (2006) Wir werden gelebt. Formprobleme der Moderne, S. 15 zit. nach Breitenstein (2013) Die Befreiung der Geschichte, S. 28-31.

93 Siehe dazu vertiefend Colin Crouch (2008 [Ital. 2003, Engl. 2004]) Postdemokratie. Suhrkamp, Frankfurt/M.; und z. B. Ludger Heidbrink (2018) Colin Crouch, Postdemokratie, S. 945-960. In: Manfred Brocker (Hrsg.) Geschichte des politischen Denkens. Das 20. Jahrhundert. Suhrkamp, Berlin.

94 Vgl. Jürgen Klatzer (2019) Selbstkritik an der „Postdemokratie”. Online: https://orf.at/stories/3114272/ (15.7.19).

Siehe dazu vertiefend auch Geoff Eley (2016) Fascism then and now, S. 91-117. In: Socialist Register, Nr. 52; Cornelia Koppetsch (2019) Die Gesellschaft des Zorns. Rechtspopulismus im globalen Zeitalter.

95 Vgl. Fisher (2013 [Engl. 2009]) Kapitalistischer Realismus ohne Alternative? S. 14-15; Fisher aktualisiert Jamesons Ansatz, denn die Prozesse seien chronisch geworden, hätten sich verschärft und verändert. Er übernimmt den Begriff „kapitalistischer Realismus” von zwei künstlerischen Parodien auf den „sozialistischen Realismus" und entgrenzt die Bedeutung: „eine Art alles durchdringender Atmosphäre, die nicht nur die Produktion von Kultur bestimmt, sondern auch die Regulation von Arbeit und Bildung, vgl. a. a. O., S. 24.

96 Vgl. Oliver Marchart (2010) Die politische Differenz. Zum Denken des Politischen bei Nancy, Lefort, Badiou, Laclau und Agamben. Suhrkamp, Frankfurt/M., S. 8-9.

97 Eley (1994) Wie denken wir über Politik? S. 21 [Hervorh. d. Verf.].

98 Marchart (2010) Die politische Differenz, S. 9 [Hervorh. i. O.].

99 Siehe dazu Chantal Mouffe (2014 [Engl. 2013]) Agonistik. Die Welt politisch denken. Suhrkamp, Berlin. 
100 Vgl. Wolfgang Braungart (2012) Ästhetik der Politik, Ästhetik des Politischen. Ein Versuch in Thesen. Wallstein, Göttingen, S. 28-29.

101 A. a. O., S. 29 [Hervorh. d. Verf.].

102 Carl Schmitt (1963 [zuerst 1932]) Der Begriff des Politischen. Text von 1932 mit einem Vorwort und drei Corollarien. Duncker \& Humblot, Berlin, S. 26 [Hervorh. i. O.].

103 Marchart (2010) Die politische Differenz, S. 42.

104 Vgl. Simon Herzhoff (2018) Jean-Luc Nancy und Carl Schmitt über das Politische, S. 81-119. In: Kurt Röttgers (Hrsg.) Plurale SozioOntologie und Staat. Jean-Luc Nancy. Nomos, Baden-Baden, S. 83 [Hervorh. d. Verf.].

105 Marchart (2010) Die politische Differenz, S. 30 [Hervorh. i. O.]; die Begriffsverwendung: Mikropolitik wird als Methode zum Machtaufbau innerhalb von Organisationen verstanden; Minimalpolitik hingegen als Politik des kleinen Eingriffs.

Marchart bezieht sich hier mutmaßlich auf das Buch The Machiavellian Moment: Florentine Political Thought and the Atlantic Republican Tradition des Historikers J. G. A. Pocock von 1975.

106 Vgl. Nolte (2012) Was ist Demokratie? S. 165-167; das Recht auf "informationelle Selbstbestimmung" birgt entscheidende politische Konsequenzen. Die Datengewinnung der Tech-Monopole übt großen Einfluss auf die reale Verhaltensweise der Menschen und infolgedessen auch auf Stadtstrukturen aus; durch verborgene Algorithmen ergeben sich nicht nur ganz neue Grenzräume zwischen privatem und öffentlichem Raum, sondern es entsteht auch eine Hybridisierung des Faktischen mit dem Fiktionalen. Ein digitales Gemeinwohl kann sich nur über unabhängige, alternative, lokal organisierte, dennoch global vernetzte Open-source Plattformen durchsetzen, die stadtpolitische Informationen offenlegen und von Bürger*innen mit Ortskenntnis selbst gestaltet werden, z. B. OpenStreetMaps, siehe dazu die Studien des Internetgeographen Mark Graham am Oxford Internet Institute.

Siehe auch Shoshana Zuboff (2019) Das Zeitalter des Überwachungskapitalismus. Campus, Frankfurt/M.

107 Vgl. Stockinger (1982) Aspekte und Probleme der neueren Utopiediskussion in der deutschen Literaturwissenschaft, S. 120-142. In: Voßkamp (Hrsg.) Utopieforschung, Bd. 1, S. 133-135.

$108 \mathrm{Vgl}$. Peter Sloterdijk (2004) Architekten machen nichts anderes als In-Theorie. Sloterdijk im Gespräch mit Sabine Kraft und Nikolaus Kuhnert. In: Archplus, Nr. 169/170: Architekturen des Schaums, S. 18.

109 Heller (2016) Von der Utopie zur Dystopie, S. 18. 
110 Emil Angehrn (1985) Geschichte und Identität, S. 54 f., 65 zit. nach Breitenstein (2013) Die Befreiung der Geschichte, S. 39 [Hervorh. i. O.].

111 Johann Michel (2019 [Frz. 2016]) Vorwort. Cornelius Castoriadis, Paul Ricoeur. Gespräch über die Geschichte und das gesellschaftlich Imaginäre, 1985. Passagen Verlag, Wien, S. 26-29.

112 Vgl. Didier Eribon (2017 [Frz. 2013]) Gesellschaft als Urteil. Suhrkamp, Frankfurt/M., S. 264-265 [Hervorh. d. Verf.].

113 Denn auch z. B. der „nationale Sozialismus” des Dritten Reichs, der "reale Sozialismus" der UdSSR und die heute globalisierte „neue liberale bzw. neoliberale Marktwirtschaft" haben zu Beginn des 20. Jahrhunderts als subversive Gegenbewegungen (oder partikulare Utopien) an Fahrt aufgenommen, endeten jedoch alle im Totalitarismus, denn sie entbehrten humanistischen Grundüberzeugungen.

\section{Nachwort von Jörg H. Gleiter}

1 Giovanni Pico della Mirandola (2009 [Lat. 1496]) Oratio de hominis dignitate. Rede über die Würde des Menschen. Reclam, Ditzingen, S. 7. 

Literaturverzeichnis 
A

Achleitner Friedrich (1967) Aufforderung zum Vertrauen.

Architektur seit I945. In: Ders. (1987) Aufforderung zum

Vertrauen. Aufsätze zur Architektur. Residenz Verlag, Salzburg u. Wien, S. 48-76

Adorno Theodor W., Horkheimer Max (2013 [zuerst I944/47])

Dialektik der Aufklärung. Philosophische Fragmente. Fischer, Frankfurt/M.

- (2003 [zuerst I95I]) Minima Moralia. Reflexionen aus dem beschädigten Leben. Gesammelte Schriften, Bd. 4. Hrsg. v. Rolf Tiedemann. Suhrkamp, Frankfurt/M.

- (20I4 [zuerst I970]) Ästhetische Theorie. Gesammelte Schriften, Bd. 7. Hrsg. v. Rolf Tiedemann. Suhrkamp, Frankfurt/M.

- (I972) Soziologische Schriften I. Gesammelte Schriften, Bd. 8. Hrsg. v. Rolf Tiedemann. Suhrkamp, Frankfurt/M.

- (2003 [zuerst I977]) Kulturkritik und Gesellschaft I. Prismen. Ohne Leitbild. Gesammelte Schriften, Bd. Io. I. Hrsg. v. Rolf Tiedemann. Suhrkamp, Frankfurt/M.

Agamben Giorgio (2003 [Ital. 200I]) Die kommende Gemeinschaft. Merve, Berlin

Alberti Leon Battista (I99I [Lat. um I450]) Zehn Bücher über die Baukunst. Übers. v. Max Theuer. Wiss. Buchgesellschaft, Darmstadt

Alfaro d'Alençon Paola, Bauerfeind Bettina, Konrad Daniela (2017) Ephemere Stadtentwicklung. Planungshilfe und Handbuch. DOM, Berlin

Althusser Louis (20I0 [Frz. I994]) Materialismus der Begegnung. Späte Schriften. Hrsg. u. übers. v. Franziska Schottmann. Diaphanes, Zürich

Andritzky Michael, Burckhardt Lucius, Hoffmann Ot (Hrsg.) (I98I) Für eine andere Architektur, 2 Bde. Fischer, Frankfurt/M.

Arendt Hannah (20I5 [Engl. I95I]) Elemente und Ursprünge totaler Herrschaft. Antisemitismus, Imperialismus, totale Herrschaft. Piper, München

- (I98 I [Engl. I958]) Vita activa. Oder vom tätigen Leben. Piper, München 
Aristophanes (I970 [39I v. Chr.]) Die Weibervolksversammlung. In: Sämtliche Komödien, Bd. 2. Artemis Verlag, Zürich, S. 58I-635

Aristoteles (20 Io [Altgr. 345-325 v. Chr.]) Politik. Schriften zur Staatstheorie. Bibliographisch erg. Ausgabe I989. Übers. u. hrsg. v. Franz F. Schwarz. Reclam, Stuttgart

Arnstein Sherry P. (I969) A Ladder of Citizen Participation. In: Journal of the American Planning Association, Nr. 35/4, S. 2 I6-224. Online: https://www.tandf online.com/doi/ abs/Io.Io8o/or 944366908977225 (22.8.13)

Augé Marc (20 I5) Die illusorische Gemeinschaft. Matthes \& Seitz, Berlin

- (20I9) Die Zukunft der Erdbewohner. Ein Manifest. Matthes \& Seitz, Berlin

Aureli Pier Vittorio (2008) The Project of Autonomy. Politics and Architecture within and against Capitalism. Princeton Architectural Press, New York/NY

Avermaete Tom (2018) Die Konstruktion von Gemeingütern. Ausblick auf eine andere Architekturtheorie der Stadt. In: Archplus, Nr. 232: An Atlas of Commoning. Orte des Gemeinschaffens, S. 32-43

— im Gespräch mit Jørg Himmelreich (20I9) Rückzug nach innen. In: Archithese, Nr. 2/2019: Rückzug, S. I8-27 Awan Nishat, Schneider Tatjana, Till Jeremy (20 I I) Spatial Agency. Other Ways of Doing Architecture. Routledge, Oxon/ UK

\section{B}

Baier Karl (2003) Offenes Kunstwerk versus Kunst der Offenheit. Umberto Ecos abendländische Werk-Ästhetik und John Cages buddhistische Alternative. In: Polylog. Zeitschrift für interkulturelles Philosophieren, Nr. 9, S. 38-56. Online: http:// www.polylog.net/fileadmin/docs/polylog/o9_thema_baier.pdf (I I.2.I9)

Bauer Hermann (I993) Über einige utopische Topoi und die Anfänge der Kunsttheorie in der Renaissance. In: Georg Jenal (Hrsg.) Gegenwart in Vergangenheit. Beiträge zur Kultur und Geschichte der Neueren und Neuesten Zeit. Oldenbourg Verlag, München, S. I-9 
Bauman Zygmunt (I 995 [Engl. I993]) Postmoderne Ethik.

Hamburger Edition, Hamburg

- (2000 [Engl. I999]) Die Krise der Politik. Fluch und Chance einer neuen Öffentlichkeit. Hamburger Edition, Hamburg

- (2017) Retrotopia. Suhrkamp, Berlin

Beck Ulrich (20I7 [Engl. 20I6]) Die Metamorphose der Welt. Suhrkamp, Berlin

Benjamin Walter (I99I [zuerst I934]) Der Autor als Produzent.

In: Gesammelte Schriften, Bd. II.2. Hrsg. v. Rolf Tiedemann, Hermann Schweppenhäuser. Suhrkamp, Frankfurt/M., S. 683-70I

- (2013 [zuerst 1936]) Das Kunstwerk im Zeitalter seiner technischen Reproduzierbarkeit. Suhrkamp, Berlin

- (20I0 [zuerst I940]) Über den Begriff der Geschichte. Werke und Nachlaß. Kritische Gesamtausgabe, Bd. I9. Suhrkamp, Berlin

Bentin Felix, Brandmeyer Ole, Hipp Johannes (2017) Zwischen Hindernis und Ressource. Was können Planer und Gestalter von ephemeren Stadtentwicklungsinstrumenten lernen? In: Paola Alfaro d'Alençon et al. (Hrsg.) Ephemere Stadtentwicklung. Planungshilfe und Handbuch. DOM, Berlin S. 36-4I Bentmann Reinhard, Müller Michael (I992 [zuerst I970]) Die Villa als Herrschaftsarchitektur. Versuch einer kunst- und sozialgeschichtlichen Analyse. Europäische Verlagsanstalt, Hamburg

Berdet Marc, Ebke Thomas (20I4) Einleitung. In: Dies. (Hrsg.)

Anthropologischer Materialismus und Materialismus der Begegnung. Vermessungen der Gegenwart im Ausgang von Walter Benjamin und Louis Althusser. xenomoi, Berlin,

S. 35-7I

Berger Peter L., Luckmann Thomas (2004 [zuerst I969]) Die gesellschaftliche Konstruktion der Wirklichkeit. Eine Theorie der Wissenssoziologie. Fischer, Frankfurt/M.

Beuys Joseph im Gespräch mit Rainer Rappmann ( I975). In:

Rainer Rappmann, Volker Harlan, Peter Schata (I984 [zuerst I976]) Soziale Plastik. Materialien zu Joseph Beuys. 3. erw. u. erg. Auflage. Achberger Verlag, Achberg

Bhabha Homi K. (2007 [Engl. I994]) Die Verortung der Kultur. Stauffenburg, Tübingen 
Biesterfeld Wolfgang (I982) Die literarische Utopie. Metzler, Stuttgart

Bishop Claire (2004) Antagonism and Relational Aesthetics. In:

October, Nr. I IO, S. 5I-79. Online: http://www.teamgal.com/ production/I 70 I/SSo4 October.pdf (I I.7.I7)

- (2006) The Social Turn. Collaboration and Its Discontents. In: Artforum, Nr. 44/6, S. I78-I83. Online: https://www. artforum.com/print/200602/the-social-turn-collaboration-andits-discontents- I0274 (I I.7.I7)

Björk (2017) Utopia. Embassy of Music/Warner

Bloch Ernst ( I964 [zuerst I9I8/23]) Geist der Utopie. Zweite Fassung. Werkausgabe, Bd. 3. Suhrkamp, Frankfurt/M.

- (i985 [zuerst I930]) Spuren. Werkausgabe, Bd. I. Suhrkamp, Frankfurt/M.

- (I959 [zuerst I938-47, I953]) Das Prinzip Hoffnung, 3 Bde. Suhrkamp, Frankfurt/M.

- ( I977 [zuerst I963]) Tübinger Einleitung in die Philosophie. Suhrkamp, Frankfurt/M.

- (I97I) Utopien des kleinen Mannes und andere Tagträume. Ein Gespräch mit Gerd Ueding. In: Gespräche mit Ernst Bloch. Hrsg. v. Rainer Traub, Harald Wieser, S. 4I-57

- (I975) Experimentum Mundi. Frage, Kategorien des Herausbringens. Suhrkamp, Frankfurt/M.

- (I985 [zuerst I978]) Tendenz-Latenz-Utopie. Werkausgabe, Ergänzungsband. Suhrkamp, Frankfurt/M.

Blüher Rudolf ( I920) Moderne Utopien. Ein Beitrag zur Geschichte des Sozialismus. Kurt Schroder, Bonn u. Leipzig Bohning Ingo ( I98 I ) „Autonome Architektur“ und ,,partizipatorisches Bauen“-Zwei Architekturkonzepte. Dissertation an der ETH Zürich. Birkhäuser, Basel

Bohrer Karl Heinz ( I98 I) Plötzlichkeit. Zum Augenblick des ästhetischen Scheins. Suhrkamp, Frankfurt/M.

Bois Marcel (20I9) „Die Kunst — das ist eine Sache!, wenn sie da ist“. Zur Geschichte des Arbeitsrates für Kunst in der frühen Weimarer Republik. Online: http://www.bauhaus-imaginista. org/articles/3207/the-art-that-s-one-thing-when-it-s-there/de (2.2.19)

Bollerey Franziska ( I 99 I [zuerst I977]) Architekturkonzeptionen der utopischen Sozialisten. Alternative Planung und Architektur für den gesellschaftlichen Prozeß. Ernst \& Sohn, Berlin 
Boltanski Luc, Chiapello Ève (2006 [Frz. I999]) Der neue Geist des Kapitalismus. UVK Verlagsgesellschaft, Konstanz

Bösch Frank (20I9) Zeitenwende I979. Als die Welt von heute begann. C.H.Beck, München

Bourdieu Pierre (I987 [Frz. I979]) Die feinen Unterschiede. Kritik der gesellschaftlichen Urteilskraft. Suhrkamp, Frankfurt/M.

Bourriaud Nicolas (2002 [Frz. I998]) Relational Aesthetics. Les presses du reel, Dijon

Braun Bernhard (I99I) Die Utopie des Geistes. Zur Funktion der Utopie in der politischen Theorie Gustav Landauers. SchulzKirchner, Idstein

Braun Eberhard ( 1983) Antizipation des Seins wie Utopie. Zur Grundlegung der Ontologie des Noch-Nicht-Seins im ,Prinzip Hoffnung'. In: Burghart Schmidt (Hrsg.) Seminar. Zur Philosophie Ernst Blochs. Suhrkamp, Frankfurt/M., S. I23-I50

Braungart Wolfgang (20I2) Ästhetik der Politik, Ästhetik des Politischen. Ein Versuch in Thesen. Wallstein, Göttingen

Brecht Bertolt, Weill Kurt (20I7 [zuerst I929]) Aufstieg und Fall der Stadt Mahagonny. Oper in drei Akten. Suhrkamp, Berlin

Breitenstein Peggy H. (20I3) Die Befreiung der Geschichte.

Geschichtsphilosophie als Gesellschaftskritik nach Adorno und Foucault. Campus, Frankfurt/M.

Brenner Neil (2017) Is "Tactical Urbanism" an Alternative to Neoliberal Urbanism? Reflections on an Exhibition at the MoMA. In: Doina Petrescu, Kim Trogal (Hrsg.) The Social (Re)Production of Architecture. Politics, Values and Actions in Contemporary Practice. Routledge, London/UK, S. I I3-I 28 Bruyn Gerd de (I996) Die Diktatur der Philanthropen. Entwicklung der Stadtplanung aus dem utopischen Denken. Bauwelt Fundamente, Bd. I Io. Vieweg, Braunschweig u. Wiesbaden Buckminster Fuller Richard ( 1998 [Engl. I 967/69]) Bedienungsanleitung für das Raumschiff Erde und andere Schriften.

Verlag der Kunst, Dresden

Budde Gunilla, Freist Dagmar, Günther-Arndt Hilke (Hrsg.) (2008) Geschichte. Studium-Wissenschaft-Beruf. Akademie Verlag, Berlin

Buden Boris (2004) Benjamins „,Der Autor als Produzent“: Eine Re-Lektüre im postkommunistischen Osten. In: transversal / EIPCP multilingual webjournal, Nr. I2/2004. Online: https:// transversal.at/transversal/I 204/buden/de (5.9.20). 
Burckhardt Jacob ( I989 [zuerst I860]) Die Kultur der Renaissance in Italien. Deutscher Klassiker Verlag, Frankfurt/M.

Burke Peter (2005) Was ist Kulturgeschichte? Suhrkamp, Frankfurt/M.

C

Campanella Tommaso ( I602) Sonnenstaat. In: Klaus J. Heinisch (Hrsg.) (20 I I [zuerst I960]) Der utopische Staat. Morus: Utopia, Campanella: Sonnenstaat, Bacon: Neu-Atlantis. 30. Auflage. Rowohlt, Reinbek bei Hamburg, S. I I I-I 69

Castells Manuel (200 I [Engl. I 996]) Das Informationszeitalter, Bd. I. Der Aufstieg der Netzwerkgesellschaft. Leske + Budrich, Opladen

Castoriadis Cornelius, Ricoeur Paul (20I9 [Frz. 20I6/I985])

Gespräch über die Geschichte und das gesellschaftlich Imaginäre. Passagen Verlag, Wien

Castro Varela María do Mar (2004) Utopien. Kitsch, Widerstand und politische Praxis. In: Susanne Kollmann, Kathrin Schödel (Hrsg.) PostModerne De/Konstruktionen. Ethik, Politik und Kultur am Ende einer Epoche. LIT Verlag, Münster,

S. I I I-I 22

-, Dhawan Nikita (20I5) Postkoloniale Theorie. Eine kritische Einführung. transcript, Bielefeld

Certeau Michel de (I988 [Frz. I980]) Kunst des Handelns. Merve, Berlin

Chakrabarty Dipesh (20Io [Engl. 200o]) Europa als Provinz.

Perspektiven postkolonialer Geschichtsschreibung. Campus, Frankfurt/M.

Claeys Gregory, Sargent Lyman Tower, Schaer Roland (2000)

Utopia. The Search for the Ideal Society in the Western World. Oxford University Press, New York/NY

—, Sargent Lyman Tower (Hrsg.) (2017) The Utopia Reader. Second Edition. New York University Press, New York/NY.

Coleman Nathaniel (2005) Utopias and Architecture. Routledge, Oxon/UK

Crouch Colin (2008 [Ital. 2003 / Engl. 2004]) Postdemokratie. Suhrkamp, Frankfurt/M. 


\section{D}

Davis Angela (2018) Vortrag auf dem Symposium Planetarische Utopien. Hoffnung, Sehnsucht, Imagination in einer postkolonialen Welt. Akademie der Künste Berlin, Bundeszentrale für politische Bildung. Online: https://www.youtube. com/ watch?v=cc-nGNo7gnk (25.6. I 8)

Debord Guy, Nieuwenhuys Constant (I953) Erklärung von Amsterdam. In: IS 2, I958. Online: http://www.si-revue.de/ nachrichten-von-der-internationalen-I9582 (I8.6.19)

Defert Daniel (20I7 [Frz. 2004]) Raum zum Hören. In: Michel Foucault. Die Heterotopien. Der utopische Körper. Zwei Radiovorträge. Suhrkamp, Frankfurt/M., S. 67-92 Defila Rico, Di Giulio Antonietta ( 1998 ) Interdisziplinarität und Disziplinarität. In: Jan H. Olbertz (Hrsg.) Zwischen den Fächern - über den Dingen? Universalisierung versus Spezialisierung akademischer Bildung. Springer VS, Wiesbaden, S. I I I-I 37

Demirović Alex (20I8) Bevölkerung und Klassenpolitik. Gramscis hegemonietheoretische Annäherung an die Frage der Migration. Online: https://www.zeit schrift-luxemburg.de/bevoelkerung-und-klassenpolitik-gramscis-hegemonie theoretischeannaeherung-an-die-frage-der-migration/ (I6.8.19)

Dewey John (I988 [Engl. I934]) Kunst als Erfahrung. Suhrkamp, Frankfurt/M.

\section{E}

Eagleton Terry (I994 [Engl. I990]) Ästhetik. Die Geschichte ihrer Ideologie. Metzler, Stuttgart

— (I993 [Engl. I99I]) Ideologie. Eine Einführung. Metzler, Stuttgart

- (20I8 [Engl. 20 I I]) Warum Marx recht hat. Ullstein, Berlin.

Eaton Ruth (200I) Die ideale Stadt. Von der Antike bis zur Gegenwart. Nicolai, Berlin

Eco Umberto (I977 [Ital. I962]) Das offene Kunstwerk. Suhrkamp, Frankfurt/M.

Eley Geoff ( I 994) Wie denken wir über Politik? Alltagsgeschichte und die Kategorie des Politischen. In: Berliner Geschichtswerkstatt (Hrsg.) Alltagskultur, Subjektivität und Geschichte. Zur Theorie und Praxis von Alltagsgeschichte. Westfälisches Dampfboot, Münster, S. I7-36 
Elias Norbert (I982) Thomas Morus' Staatskritik. Mit Überlegungen zur Bestimmung des Begriffs Utopie. In: Wilhelm Voßkamp (Hrsg.) Utopieforschung. Interdisziplinäre Studien zur neuzeitlichen Utopie, Bd. 2. Metzler, Stuttgart, S. IOI-I5O Engels Friedrich ( I 880) Die Entwicklung des Sozialismus von der Utopie zur Wissenschaft. In: Marx-Engels-Werke (MEW), Bd. I9 ( I987). Hrsg. v. Institut für Marxismus-Leninismus beim ZK der SED. Dietz, Berlin, S. I77-228

- (I 845) Die Lage der arbeitenden Klasse in England. In: MEW, Bd. 2 (I962) S. 225-506

- ( I 873) Zur Wohnungsfrage. In: MEW, Bd. I8 (I976)

S. 209-287

Eribon Didier (20I7 [Frz. 20I3]) Gesellschaft als Urteil. Suhrkamp, Frankfurt/M.

Eusterschulte Birgit (20 I 8) Un/Mögliche Funktionalisierungen oder Die Fallen des Ausstellens. In: Juliane Rebentisch (Hrsg.) Das ist Ästhetik! Kongress-Akten, Bd. 4. Deutsche Gesellschaft für Ästhetik. Online: http://www.dgae.de/wp-content/ uploads/20 I 7/o6/Eusterschulte-dgae_20 I 8.pdf (7.6.19)

\section{$\mathbf{F}$}

Fezer Jesko (20I3) Civic City Cahier 6: Design in and Against the Neoliberal City. Bedford Press, London/UK

Fischer Ole W. (20I0) Zur Frage der Postmoderne in der Architektur. Rezension. In: Sehepunkte. Rezensionsjournal für die Geschichtswissenschaften, Ausgabe Io, Nr. I2. Online: http:// www.sehepunkte.de/20 Io/I2/I 8456.html (25.4. I9)

Fisher Mark (20I3 [Engl. 2009]) Kapitalistischer Realismus ohne Alternative? Eine Flugschrift. VSA, Hamburg

Fitz Angelika, Ritter Katharina (Hrsg.) (2017) Assemble. Wie wir bauen. Katalog zur gleichnamigen Ausstellung im Architekturzentrum Wien. Park Books, Zürich

Förster Birte (2018) I9I9. Ein Kontinent erfindet sich neu.

Reclam, Stuttgart

Förster Kim (2013) Das Paradox der Nachhaltigkeit als Modeerscheinung. In: Archithese, Nr. 6/2013: Natur, S. 72-77.

Foster Hal (1983) The Anti-Aesthetic. Essays on Postmodern Culture. Townsend/WA

Foucault Michel (I97 I [Frz. I966]) Die Ordnung der Dinge. Suhrkamp, Frankfurt/M. 
- (20I7 [Frz. I966]) Die Heterotopien. Der utopische Körper. Zwei Radiovorträge. Suhrkamp, Berlin

- (2006 [Frz. I967/I984]) Von anderen Räumen. In: Jörg Dünne, Stephan Günzel (Hrsg.) Raumtheorie. Grundlagentexte aus Philosophie und Kulturwissenschaften. Suhrkamp, Frankfurt/M., S. 317-329

- (20I8 [Frz. I969]) Archäologie des Wissens. Suhrkamp, Frankfurt/M.

- (2002 [Frz. I97 I]) Nietzsche, die Geneaologie, die Historie. In: Ders. Schriften, Bd. 2. Suhrkamp, Frankfurt/M.,

S. I66-I9I

- (I976) Mikrophysik der Macht. Über Strafjustiz, Psychiatrie und Medizin. Texte und Interviews. Merve, Berlin

- (I992 [Frz. I978]) Was ist Kritik? Merve, Berlin

Fourier Charles ( I966 [Frz. I 808]) Theorie der vier Bewegungen und der allgemeinen Bestimmungen. Hrsg. v. Theodor W. Adorno u. eingel. v. Elisabeth Lenk. Europäische Verlagsanstalt, Frankfurt/M.

Freyer Hans ( 1936) Die politische Insel. Eine Geschichte der Utopien von Platon bis zur Gegenwart. Bibliographisches Institut, Leipzig

Frye Northrop ( I970 [Engl. I965]) Spielarten der utopischen Literatur. In: Frank E. Manuel (Hrsg.) Wunschtraum und Experiment. Vom Nutzen und Nachteil utopischen Denkens. Rombach, Freiburg, S. 52-79

G

Geertz Clifford (I973) Thick Description. Toward an Interpretive Theory of Culture. In: Ders. The Interpretation of Cultures. Selected Essays. Basic books, New York/NY, S. 3-30

Gerber Andri (20I4) Metageschichte der Architektur. Ein Lehrbuch für angehende Architekten und Architekturhistoriker. transcript, Bielefeld

Gibson-Graham J. K. (2006) A Postcapitalist Politics. University of Minnesota Press, Minneapolis/MN

Giedion Sigfried (20I5 [Engl. I94I]) Raum Zeit Architektur. Die Entstehung einer neuen Tradition. Birkhäuser, Basel

Ginzburg Carlo, Poni Carlo (I985) Was ist Mikrogeschichte? In: Geschichtswerkstatt Nr. 6. Schwierigkeiten beim Entdecken der Heimat. Hrsg. v. Alf Lüdtke, Hans Medick, Wolfgang 
Schäfer für die Geschichtswerkstatt e.V. Verlag die Werkstatt, Göttingen, S. 48-52

- (I993) Mikro-Historie. Zwei oder drei Dinge, die ich von ihr weiß. In: Historische Anthropologie, Bd. I, Heft 2,

S. I69-I 92

Gleiter Jörg H. (20I0) Urgeschichte der Moderne. transcript, Bielefeld

- (20 I4) Stoff, Form, Hylemorphismus. In: Mario Rinke, Joseph Schwartz (Hrsg.) Holz: Stoff oder Form. Transformation einer Konstruktionslogik. Niggli, Salenstein/CH, S. I 27-I3 I

- (20I9) Architekturtheorie Grundlagen I. Traditionelle Theorie I863-I938. DOM, Berlin

Glissant Édouard (2005 [Frz. I996]) Kultur und Identität. Ansätze zu einer Poetik der Vielheit. Wunderhorn, Heidelberg

Goodwin Barbara, Taylor Keith ( I982) The Politics of Utopia. Hutchinson, London/UK

Göpel Maja (2020) Unsere Welt neu denken. Eine Einladung. Ullstein, Berlin

Graeber David (2002) The New Anarchists. In: New Left Review (NLR), Nr. I3, S. 6I-73. Online: https://newleftreview.org/ II/I3/david-graeber-the-new-anarchists (30.6.I5)

- (20I6 [Engl. 20I5]) Bürokratie. Die Utopie der Regeln. KlettCotta, Stuttgart

Gramsci Antonio (I994 [Ital. I975/I929-35]) Gefängnishefte.

Kritische Gesamtausgabe, Bd. 6 (Hefte Io-I I): Philosophie der Praxis. Hrsg. v. Wolfgang Fritz Haug. Argument, Hamburg Gribat Nina, Meireis Sandra (2017) A Critique of the New, Social Architecture' Debate. Moving Beyond Localism, Developmentalism and Aesthetics. In: CITY 2 I/6: Special Feature:

Designed to Improve? The Makings, Politics and Aesthetics of the ,Social' Architecture and Design. Taylor \& Francis, Oxon/ UK, S. 779-788

Guérot Ulrike (20I9 [zuerst 20I7]) Warum Europa eine Republik werden muss. Eine politische Utopie. 3. Auflage. Piper, München

Günther Hubertus (20I2) Der Architekt in der Renaissance. In: Winfried Nerdinger (Hrsg.) Der Architekt. Geschichte und Gegenwart eines Berufsstandes, Bd. I. Publikation zur gleichnamigen Ausstellung im Architekturmuseum der TU München. Prestel, München, S. 8I-IO3 
H

Habermas Jürgen (I990 [Habil. I962]) Strukturwandel der Öffentlichkeit. Untersuchungen zu einer Kategorie der bürgerlichen Gesellschaft. Suhrkamp, Frankfurt/M.

- (I999 [zuerst I98 I]) Theorie des kommunikativen Handelns. 2 Bde. 3. Auflage. Suhrkamp, Frankfurt/M.

Haffner Sebastian (201 8 [zuerst I969]) Die deutsche Revolution I9I8/I9. Rowohlt, Reinbek bei Hamburg

Hardt Michael, Negri Antonio (2003 [Engl. 2000]) Empire. Die neue Weltordnung. Campus, Frankfurt/M.

Harvey David (2007 [Engl. 2005]) Kleine Geschichte des Neoliberalismus. Rotpunktverlag, Zürich

Hebekus Uwe, Völker Jan (20I2) Neue Philosophien des Politischen. Zur Einführung. Junius, Hamburg

Hegel Georg Wilhelm Friedrich ( 986 [zuerst I 807]) Phänomenologie des Geistes. Werke 3. Neu editierte Ausgabe auf Grundlage der Werke von i 832-45. Suhrkamp, Frankfurt/M.

- (20I3 [zuerst I 820]) Vorrede. Grundlinien der Philosophie des Rechts. Hrsg. v. Horst D. Brandt. Meiner, Hamburg, S. 5-20

- (I994 [zuerst I 822/28]) Vorlesungen über die Philosophie der Weltgeschichte, Bd. I: Die Vernunft in der Geschichte. Hrsg. v. Johannes Hoffmeister. Meiner, Hamburg

Heller Ágnes (20I6) Von der Utopie zur Dystopie. Was können wir uns wünschen? Edition Konturen, Wien u. Hamburg

Herzhoff Simon (20I8) Jean-Luc Nancy und Carl Schmitt über das Politische. In: Kurt Röttgers (Hrsg.) Plurale Sozio-Ontologie und Staat. Jean-Luc Nancy. Nomos, Baden-Baden, S. 8 I-I I9

Heyer Andreas (2006) Die Utopie steht links! Ein Essay. Dietz, Berlin

- (2007) Ursprung und Gehalt des Utopiebegriffs von Karl Mannheim. In: UTOPIE kreativ. Diskussion sozialistischer Alternativen, Nr. I97, S. 24 I-25I. Hrsg. v. Rosa-Luxemburg-Stiftung. Online: https://www.rosalux.de/fileadmin/rls_ uploads/pdfs/Utopie_kreativ/I97/I97Heyer.pdf (20.6.I7)

Höffe Otfried (Hrsg.) (20I6) Politische Utopien der Neuzeit. Thomas Morus, Tommaso Campanella, Francis Bacon. De Gruyter, Berlin

Hofmann Werner ( I998) Die Moderne im Rückspiegel. Hauptwege der Kunstgeschichte. C.H.Beck, München 
Hofmann Wilhelm (I996) Karl Mannheim. Zur Einführung.

Junius, Hamburg

Hoffmann Thomas Sören (2004) Georg Wilhelm Friedrich Hegel.

Eine Propädeutik. Marix, Wiesbaden

Hoffmann-Axthelm Dieter (20I8) Hochhaus und Gemeinschaft.

Zur Erbschaft der Moderne. DOM, Berlin

Hölscher Lucian (2016 [zuerst I999]) Die Entdeckung der

Zukunft. Wallstein, Göttingen

Holz Hans Heinz ( I 975) Logos spermatikos. Ernst Blochs Philosophie der unfertigen Welt. Luchterhand, Darmstadt u. Neuwied

Honeck Thomas (20I5) Zwischennutzung als soziale Innovation.

Von alternativen Lebensentwürfen zu Verfahren der räumli-

chen Planung. In: Informationen zur Raumentwicklung, Heft

3/20 I 5, S. 2 I9-23 I

Honneth Axel (20 I I) Das Recht der Freiheit. Grundriß einer demokratischen Sittlichkeit. Suhrkamp, Berlin

- (2015) Die Idee des Sozialismus. Suhrkamp, Berlin

Horkheimer Max (I97 I [zuerst I930]) Anfänge der bürgerlichen Geschichtsphilosophie. In: Ders. Geschichtsphilosophie / Hegel / Montaigne. Eingel. v. Alfred Schmidt. Fischer, Frankfurt/M., S. 9-83

- (2005 [zuerst I937]) Traditionelle und kritische Theorie. Fünf Aufsätze. Fischer, Frankfurt/M.

- (I98I) Gesellschaft im Übergang. Aufsätze, Reden und Vorträge I942-I970. Hrsg. v. Werner Brede. 2. Auflage. Fischer, Frankfurt/M.

- (I987) Gesammelte Schriften, Bd. 2: Philosophische Frühschriften I922-32. Hrsg. v. Gunzelin Schmid Noerr. Fischer, Frankfurt/M.

Howard Ebenezer ( I968 [Engl. I 898]) Gartenstädte von morgen:

Das Buch und seine Geschichte. Hrsg. v. Julius Posener.

Bauwelt Fundamente, Bd. 2 I. Ullstein, Frankfurt/M. u. Berlin

I

d'Idler Martin (2007) Die Modernisierung der Utopie. Vom

Wandel des Neuen Menschen in der politischen Utopie der

Neuzeit. LIT Verlag, Berlin

Imbusch Peter (I998) Macht und Herrschaft in der Diskussion.

In: Ders. (Hrsg.) Macht und Herrschaft. Sozialwissenschaft- 
liche Konzeptionen und Theorien. Leske + Budrich, Opladen, S. 9-26

Institut für Marxismus-Leninismus beim ZK der SED ( I956/I98 I)

Vorwort. MEW, Bd. I. Dietz, Berlin, S. ix-xxi

J

Jacobs Jane (I992 [zuerst I96I]) The Death and Life of Great American Cities. Vintage Books, New York/NY

Jameson Fredric (I99I) Postmodernism, or, the Cultural Logic of Late Capitalism. Verso, London/UK

- (2005) Archeologies of the Future. The Desire Called Utopia and Other Science Fictions. Verso, London/UK

Jeinic Ana (20I3) Neoliberalism and the Crisis of the Project... in Architecture and Beyond. In: Dies. Anselm Wagner (Hrsg.) Is there (anti-)neoliberal Architecture? Jovis, Berlin, S. 64-77

Jonas Hans ( 984 [zuerst I979]) Das Prinzip Verantwortung.

Versuch einer Ethik für die technologische Zivilisation. Suhrkamp, Frankfurt/M.

K

Kant Immanuel (2009 [zuerst I 790]) Kritik der Urteilskraft. Hrsg. v. Heiner F. Klemme. Meiner, Hamburg

- (20I0 [zuerst I795]) Zum ewigen Frieden. Ein philosophischer Entwurf. Hrsg. v. Rudolf Malter. Reclam, Stuttgart

- (20I3 [zuerst I798]) Der Streit der Fakultäten. Zweiter Abschnitt. Der Streit der philosophischen Fakultät mit der juristischen. In: Ders. Schriften zur Geschichtsphilosophie. Hrsg. v. Manfred Riedel. Reclam, Stuttgart, S. I83-200

Kaufmann Emil ( 1985) Von Ledoux bis Le Corbusier. Ursprung und Entwicklung der autonomen Architektur. Hatje, Stuttgart Kermani Navid (20 I I) Bloch, gegen die Gegenwart gedacht. Eine Rede anlässlich der Verleihung des Ernst-Bloch-Förderpreises im Jahr 200o. In: Julian Nida-Rümelin, Klaus Kufeld (Hrsg.) Die Zeitkritik der Utopie. Zeitkritik und Denkwende. Karl Alber, Freiburg u. München, S. 220-223

Keyvanian Carla (2000) Manfredo Tafuri: From the Critique of Ideology to Microhistories. In: DesignIssues, Nr. I6/ I, S. 3-I 5. Online: https://www.jstor.org/ stable/I 5 I I 926 (I6.7.I8) 
Kilminster Richard ( I982) Zur Utopiediskussion aus soziologischer Sicht. In: Wilhelm Voßkamp (Hrsg.) Utopieforschung. Interdisziplinäre Studien zur neuzeitlichen Utopie, Bd. I. Metzler, Stuttgart, S. 64-96

Koch Andreas (2018) Die Wahrheit 9oer Spezial. In: von hundert, Nr. 3 I, S. I9-2 I. Online: http://vonhundert.de/20I8-03/PDF_ vonhundert3I_03_20I8.pdf (6.6.I9)

Koselleck Reinhart ( 1982) Verzeitlichung der Utopie. In: Wilhelm Voßkamp (Hrsg.) Utopieforschung. Interdisziplinäre Studien zur neuzeitlichen Utopie. Bd. 3. Metzler, Stuttgart, S. I-I4

Kramer Sven (2012) Nachwort. (S. 325-350. In: Walter Benjamin. Der Autor als Produzent. Aufsätze zur Literatur. Reclam, Stuttgart)

Krämer Stefan (2017) Ephemere Stadtentwicklung. Wie geht das? In: Paola Alfaro d'Alençon et al. (Hrsg.) Ephemere Stadtentwicklung. Planungshilfe und Handbuch. DOM, Berlin, S. 6-7 Kreis Christian (2006) Das Verhältnis der „Kritischen Theorie“ von Max Horkheimer und Theodor W. Adorno zum utopischen Denken. Ibidem, Stuttgart

Kruft Hanno-Walter ( I989) Städte in Utopia. Die Idealstadt vom I 5. bis zum I 8. Jahrhundert zwischen Staatsutopie und Wirklichkeit. C.H.Beck, München

Kube Ventura Holger (2002) Politische Kunst Begriffe. In den I990er Jahren im deutschsprachigen Raum. Dissertation an der Universität Kassel. Edition Selene, Wien

Kuhnert Nikolaus (2017) im Gespräch mit Stephan Becker, Kristina Herresthal, Anh-Linh Ngo. In: Archplus, Nr. 229: Am Ende: Architektur / 50 Jahre Archplus: Projekt und Utopie, S. 7-19

Kumnig Sarah, Rosol Marit, Exner Andreas (Hrsg.) (2017)

Umkämpftes Grün. Zwischen neoliberaler Stadtentwicklung und Stadtgestaltung von unten. transcript, Bielefeld

Kunkel Benjamin (20I4 [Engl. 20I3]) Utopie oder Untergang. Ein Wegweiser für die gegenwärtige Krise. Suhrkamp, Berlin

$\mathbf{L}$

Laclau Ernesto, Mouffe Chantal (I99i [Engl. I985]) Hegemonie und radikale Demokratie. Zur Dekonstruktion des Marxismus. Passagen Verlag, Wien 
- (2006) Why Constructing a People Is the Main Task of Radical Politics. In: Critical Inquiry, Nr. 32/4, S. 646-68o. Online: https://www.jstor.org/stable/Io. I086/ 508086 (19.7.19)

Landauer Gustav (I923 [zuerst I905/07]) Die Revolution. Rütten u. Loening, Frankfurt/M.

- ( I967 [zuerst I9I I]) Aufruf zum Sozialismus. Europäische Verlagsanstalt, Frankfurt/M.

Lang Suzanne ( I952) The Ideal City. From Plato to Howard. In:

The Architectural Review, Nr. 868, S. 9I-IO I

Langner Johannes (I986) Bauten in Bildern der Zukunft. Utopische Architektur. In: Der Traum vom Raum. Gemalte Architektur aus 7 Jahrhunderten. Katalog zur gleichnamigen Ausstellung der Albrecht Dürer Gesellschaft in Zusammenarbeit mit der Kunsthalle Nürnberg, Hitzeroth, Marburg,

S. I63-I73

Latour Bruno (2007 [Engl. 2005]) Eine neue Soziologie für eine neue Gesellschaft. Einführung in die Akteur-NetzwerkTheorie. Suhrkamp, Frankfurt/M.

- (20I8) Das terrestrische Manifest. Suhrkamp, Berlin

Le Corbusier (I985 [Frz. I922]) Ausblick auf eine Architektur. Bauwelt Fundamente, Bd. 2. Vieweg, Braunschweig u. Wiesbaden

- (2015 [Frz. I925]) Städtebau. DVA, München

- (200 I [Frz. I929]) Feststellungen zu Architektur und Städtebau. Bauwelt Fundamente, Bd. I2. Birkhäuser, Basel

Lefebvre Henri (I99I [Frz. I974]) The Production of Space. Blackwell Publishing, Malden/MA

Leucht Robert (2016) Dynamiken politischer Imagination. Die deutschsprachige Utopie von Stifter bis Döblin in ihren internationalen Kontexten, I848-I930. De Gruyter, Berlin u. Boston/MA

Levi Giovanni (200 I [zuerst I99I]) On Microhistory. In: Peter Burke (Hrsg.) New Perspectives on Historical Writing. Polity Press, Cambridge/UK, S. 97-I I9

Levitas Ruth (I990) The Concept of Utopia. Peter Lang, Oxford/ UK

- (20I3) Utopia as Method. The Imaginary Reconstitution of Society. Palgrave Macmillan, Hampshire/UK 
Lorde Audre (198I) Du kannst nicht das Haus des Herren mit dem

Handwerkszeug des Herren abreißen. In: Dies., Adrienne Rich ( 993 [Engl. I983]) Macht und Sinnlichkeit. Ausgewählte Texte. Hrsg. v. Dagmar Schultz, Orlanda Frauenverlag, Berlin,

S. I99-2 I 2

Löw Martina (200I) Raumsoziologie. Suhrkamp, Frankfurt/M. Lüdtke Alf (I998) Alltagsgeschichte, Mikro-Historie, historische Anthropologie. In: Hans-Jürgen Goertz (Hrsg.) Geschichte.

Ein Grundkurs. Rowohlt, Reinbek bei Hamburg, S. 557-578

Lukács Georg (I977 [I968/zuerst I923]) Geschichte und Klassen-

bewusstsein. Werke 2, Frühschriften II. 2. Auflage. Luchter-

hand, Darmstadt u. Neuwied

Lüscher Regula (20I4) Vorwort. In: Francesca Ferguson, Urban

Drift Projects (Hrsg.) Make_Shift City. Die Neuverhandlung des Urbanen. Jovis, Berlin, S. 8-9

Luxemburg Rosa (I9I3) Karl Marx. Beitrag zur Leipziger Volkszeitung, Nr. 6o. In: Gesammelte Werke, Bd. 3, S. I78-I 84.

Online: https://www.marx ists.org/deutsch/archiv/luxemburg/I9I3/03/marx2.htm (4.9.19)

Lyotard Jean-François (2009 [Frz. I979]) Das postmoderne

Wissen. Ein Bericht. Passagen Verlag, Wien

M

Machiavelli Niccolò (20 I I [Ital. I5I3]) Der Fürst. Übers. v. August W. Rehberg. Nikol Verlag, Hamburg

Majetschak Stefan (2007) Ästhetik. Zur Einführung. Junius, Hamburg

Manguel Alberto, Guadalupi Gianni (I98I) Von Atlantis bis

Utopia. Ein Führer zu den imaginären Schauplätzen der Weltliteratur. Christian Verlag, München

Mannheim Karl (I969 [zuerst I929]) Ideologie und Utopie. Verlag Schulte-Bulmke, Frankfurt/M.

Manuel Frank E. (I970 [Engl. I965]) Zur psychologischen

Geschichte der Utopien. In: Ders. (Hrsg.) Wunschtraum und

Experiment. Vom Nutzen und Nachteil utopischen Denkens.

Rombach, Freiburg, S. 80-I I4

-, Manuel Fritzie P. (I979) Utopian Thought in the Western

World. Basil Blackwell, Oxford/UK

Marazzi Christian (20I I [Engl. 2009]) Verbranntes Geld.

Diaphanes, Zürich 
Marchart Oliver (20I0) Die politische Differenz. Zum Denken des Politischen bei Nancy, Lefort, Badiou, Laclau und Agamben. Suhrkamp, Frankfurt/M.

Marcuse Herbert (I982 [Engl. I955]) Triebstruktur und Gesellschaft. Ein philosophischer Beitrag zu Sigmund Freud. Suhrkamp, Frankfurt/M.

Marx Karl ( I 843) Brief an den Schriftsteller Arnold Ruge. Nach: Briefe aus den ,Deutsch-Französischen Jahrbüchern“ von I 844. In: MEW Bd. I ( I98 I) Hrsg. v. Institut für MarxismusLeninismus beim ZK der SED. Dietz, Berlin, S. 337-346

- ( I 844) Zur Kritik der Hegelschen Rechtsphilosophie. In: MEW Bd. I (I98I) S. 20I-333

-, Engels Friedrich ( I 844) Manifest der kommunistischen Partei. In: Gareth Stedman Jones (20I2 [Engl. 2002]) Das kommunistische Manifest von Karl Marx und Friedrich Engels. Einführung, Text, Kommentar. C.H.Beck, München, S. 253-290

—, Engels Friedrich ( I 845) Die deutsche Ideologie. In: MEW Bd. 3 (1978)

- (I867) Das Kapital, Bd. I. In: MEW Bd. 23 (I962)

- (I 894) Das Kapital, Bd. 3. In: MEW Bd. 25 (I964)

Mason Paul (20I8 [Engl. 20I5]) Postkapitalismus. Grundrisse einer kommenden Ökonomie. Suhrkamp, Berlin

Mbembe Achill (20I 8 [Frz. 20I3]) Kritik der schwarzen Vernunft. Suhrkamp, Berlin

Medick Hans (I994) Mikro-Historie. In: Winfried Schulze (Hrsg.) Sozialgeschichte, Alltagsgeschichte, Mikro-Historie. Eine Diskussion. Vandenhoeck und Ruprecht, Göttingen, S. 40-53 Meier Christian (20I2 [zuerst I993]) Athen. Ein Neubeginn der Weltgeschichte. Pantheon, Berlin

Meireis Sandra (20I8) Die gentrifizierte Palette. Eine Stilkritik. In: Marlowes, eMagazin in den Bereichen Architektur und Stadt. Online: https://www.marlowes.de/ die-gentrifizierte-palette/ (8.I.I 8)

- (2019) Visionäre Vorstellungen. Der utopische „Augenblickskern-Keim“ des Ästhetischen. In: der Architekt. Zeitschrift des BDA (4/20I9): Orte des Denkens. Architektur als philosophische Praxis, S. 56-59

Menke Christoph im Gespräch mit Alexander Kluge (2017)

Baustelle Revolution. Online: https://magazin.dctp. 
tv/20I7/o3/I9/neu-im-catch-up-service-baustelle-revolution/ (I9.5.19)

Mercier Louis-Sébastien (I989 [Frz. I77I]) Das Jahr 2440.

Ein Traum aller Träume. Hrsg. v. Herbert Jaumann. Insel, Frankfurt/M.

Michel Johann (20I9 [Frz. 20I6]) Vorwort. Cornelius Castoriadis, Paul Ricoeur. Gespräch über die Geschichte und das gesellschaftlich Imaginäre, I985. Passagen Verlag, Wien, S. I I-3 I

Michelis Marco de (20I7) Manfredo Tafuri und der Tod der Architektur. In: Archplus, Nr. 229: Am Ende: Architektur / 50 Jahre Archplus - Projekt und Utopie, S. 36-45

Mick Carola (2012) Das Agency-Paradigma. In: Ullrich Bauer,

Uwe Bittlingmayer, Albert Scherr (Hrsg.) Handbuch

Bildungs- und Erziehungssoziologie. VS Verlag, Wiesbaden,

S. 527-54 I

Mill John Stuart (2009 [Engl. I 859]) Über die Freiheit. Meiner, Hamburg

Misselwitz Philipp (2017) Und täglich grüßt das Murmeltier... In:

Paola Alfaro d'Alençon et al. (Hrsg.) Ephemere Stadtentwicklung. Planungshilfe und Handbuch. DOM, Berlin, S. 20-24

Mitscherlich Alexander (2008 [zuerst I965]) Die Unwirtlichkeit unserer Städte. Anstiftung zum Unfrieden. Suhrkamp, Frankfurt/M.

Mohl Robert von ( I960 [zuerst I 855]) Die Staatsromane. In: Ders. Die Geschichte und Literatur der Staatswissenschaften. In Monographien dargestellt, Bd. I. Akademische Druck- und Verlagsanstalt, Graz, S. I65-2 I4

Moravánszky Ákos, Hopfengärtner Judith (Hrsg.) (20 I I) Aldo Rossi und die Schweiz. Architektonische Wechselwirkungen. gta Verlag/ETH, Zürich

Moritz Karl Philipp ( 968 [zuerst I788]) Über die bildende Nachahmung des Schönen. Kraus Reprint, Nendeln/Liechtenstein Morus Thomas ( I 5 I6) Utopia. In: Klaus J. Heinisch (Hrsg.) (20 I I [zuerst I960]) Der utopische Staat. Morus: Utopia, Campanella: Sonnenstaat, Bacon: Neu-Atlantis. 30. Auflage. Rowohlt, Reinbek bei Hamburg, S. 8-i io

Mouffe Chantal (20I4 [Engl. 20I3]) Agonistik. Die Welt politisch denken. Suhrkamp, Berlin 
Mühl Sebastian (2020) Utopien der Gegenwartskunst. Geschichte und Kritik des utopischen Denkens in der Kunst nach 1989. transcript, Bielefeld

Müller Werner ( I96I) Die heilige Stadt. Roma quadrata, himmlisches Jerusalem und die Mythe vom Weltnabel. Kohlhammer, Stuttgart

Mumford Lewis (2008 [zuerst I922]) The Story of Utopias. Forgotten books

- (I96I) The City in History. Its Origins, Its Transformations, and Its Prospects. Harcourt, Orlando/FL

- (I970 [Engl. I965]) Utopie, Stadt und Maschine. In: Frank E. Manuel (Hrsg.) Wunschtraum und Experiment. Vom Nutzen und Nachteil utopischen Denkens. Rombach, Freiburg,

S. 27-5 I

Musil Robert (2002 [zuerst I978]) Der Mann ohne Eigenschaften. Rowohlt, Reinbek bei Hamburg

\section{N}

Nagel Reiner (2017) Zum Verhältnis von ephemerer Stadtentwicklung und Planung. In: Paola Alfaro d'Alençon et al. (Hrsg.) Ephemere Stadtentwicklung. Planungshilfe und Handbuch.

DOM, Berlin, S. I8-I9

Nancy Jean-Luc (2004 [Frz. I996]) Singulär plural sein.

Diaphanes, Berlin

Negt Oskar (20I6 [zuerst 20I2]) Nur noch Utopien sind realistisch. Politische Interventionen. Werkausgabe Bd. I7. Steidl Verlag, Göttingen

Nerdinger Winfried (Hrsg.) (20I2) L'Architecture engagée.

Manifeste zur Veränderung der Gesellschaft. Publikation zur gleichnamigen Ausstellung im Architekturmuseum der TU München. Detail Verlag, München

Neupert Alexander, Doppler Lisa (20I4) Das Recht auf Stadt als konkrete Utopie? Utopisches Bewusstsein als Gegenstand der Bewegungsforschung. In: Norbert Gestring et al. (Hrsg.) Stadt und soziale Bewegungen. Springer VS, Wiesbaden, S. I63-I 78

Neupert-Doppler Alexander (20 I 5) Utopie. Vom Roman zur Denkfigur. Schmetterling, Stuttgart

Neusüss Arnhelm (Hrsg.) ( I 986) Utopie. Begriff und Phänomen des Utopischen. Campus, Frankfurt/M. 
Nipperdey Thomas ( I962) Die Funktion der Utopie im politischen Denken der Neuzeit. In: Archiv für Kulturgeschichte, Bd. 44, S. 357-378. Online: https://doi.org/I0.7788/akg-I962-jg20 (29.3.17)

Nietzsche Friedrich (2016 [zuerst I874]) Vom Nutzen und Nachtheil der Historie für das Leben (Unzeitgemässe Betrachtungen. Zweites Stück). Hrsg. v. Günter Figal. Reclam, Stuttgart

Nolte Paul (20I2) Was ist Demokratie? Geschichte und Gegenwart. C.H.Beck, München

\section{0}

Ostrom Elinor (20I3 [Engl. I990]) Die Verfassung der Allmende. Jenseits von Staat und Markt. Mohr Siebeck, Tübingen Oswalt Philipp, Overmeyer Klaus, Misselwitz Philipp (2013)

Urban Catalyst. Mit Zwischennutzungen die Stadt entwickeln. DOM, Berlin

Overmeyer Klaus, Lauinger Holger (2007) Urban Pioneers. Berlin, Stadtentwicklung durch Zwischennutzung. Jovis, Berlin

\section{P}

Paech Niko (seit 2008) Grundzüge einer Postwachstumsökonomie. Online: http://www.postwachstumsoekonomie.de/material/ grundzuege/ (30.7.19)

Pasolini Pier Paolo ( I968) Teorema. Geometrie der Liebe. Aetos Produzioni Cinematografiche

Piercy Marge (20I6 [Engl. I99I]) Er, Sie und Es. Argument, Hamburg

Piketty Thomas (2020 [Frz. 20I9]) Kapital und Ideologie.

C.H.Beck, München

Pizan Christine de (I990 [Frz. I405]) Das Buch von der Stadt der Frauen. DTV, München

Platon (20 I6 [Altgr. 4.-5. Jh. v. Chr.]) Sämtliche Werke, Bd. 2:

Lysis, Symposion, Phaidon, Kleitophon, Politeia, Phaidros.

35. Auflage. Übers. v. Friedrich Schleiermacher u. hrsg. v.

Ursula Wolf. Rowohlt, Reinbek bei Hamburg

- (20I4 [Altgr. 4.-5. Jh. v. Chr.]) Sämtliche Werke, Bd. 4: Timaios, Kritias, Minos, Nomoi. 24. Auflage. Übers. v. Friedrich Schleiermacher und hrsg. v. Ursula Wolf. Rowohlt, Reinbek bei Hamburg 
Polanyi Karl (20 I 5 [Engl. I944]) The Great Transformation. Politische und ökonomische Ursprünge von Gesellschaften und Wirtschaftssystemen. Suhrkamp (Lizenzausgabe) u. Europa Verlag, Wien

Poppelreuter Tanja (2007) Das Neue Bauen für den Neuen Menschen. Zur Wandlung und Wirkung des Menschenbildes in der Architektur der I920er Jahre in Deutschland. Olms Verlag, Hildesheim

Posener Julius (20I3 [zuerst I98 I]) Vorlesungen zur Geschichte der Neuen Architektur. In: Archplus, Nr. 2 Io: Julius Posener. Vorlesungen zur Geschichte der Neuen Architektur, 2 Bde. )

$\mathbf{R}$

Rancière Jacques im Gespräch mit Peter Engelmann (2016) Ästhetik und Politik. Passagen Verlag, Wien

Rebentisch Juliane im Gespräch mit PräPosition (2019) Texturen der Gegenwart \#6. Online: https://www.praeposition.com/text/ vorzeichen/juliane-rebentisch (5.6.I9)

Reckwitz Andreas (2017) Die Gesellschaft der Singularitäten. Zum Strukturwandel der Moderne. Suhrkamp, Frankfurt/M. Rehm Michaela (2005) ,Ihr seid verloren, wenn ihr vergeßt, daß die Früchte allen gehören und die Erde niemandem": Rousseaus bedingte Legitimation des Privateigentums. In: Andreas Eckl, Bernd Ludwig (Hrsg.) Was ist Eigentum? Philosophische Eigentumstheorien von Platon bis Habermas. C.H.Beck, München, S. I03-I I 7

Ricoeur Paul (I986) Lectures on Ideology and Utopia. Columbia University Press, New York/NY

Rifkin Jeremy (20I6 [Engl. I995]) Das Ende der Arbeit und ihre Zukunft. Fischer, Frankfurt/M.

Risselada Max, Heuvel Dirk van den (Hrsg.) (2005) Team io. A Utopia of the Present. Katalog zur gleichnamigen Ausstellung im Netherlands Architecture Institute Rotterdam. NAi publishers, Rotterdam/NL

Rollig Stella, Sturm Eva (Hrsg.) (2002) Dürfen die das? Kunst als sozialer Raum. Turia + Kant, Wien

Rosa Hartmut (2016) Resonanz. Eine Soziologie der Weltbeziehung. Suhrkamp, Berlin 
Roskamm Nikolai (2017) Die unbesetzte Stadt. Postfundamentalistisches Denken und das urbanistische Feld. Bauwelt Fundamente, Bd. I58. Birkhäuser, Basel

Rosol Marit (2017) Gemeinschaftlich gärtnern in der neoliberalen Stadt? In: Sarah Kumnig, Marit Rosol, Andreas Exner (Hrsg.) Umkämpftes Grün. Zwischen neoliberaler Stadtentwicklung und Stadtgestaltung von unten. transcript, Bielefeld, S. I I-32

Roß Bettina (I998) Politische Utopien von Frauen. Von Christine de Pizan bis Karin Boye. Edition Ebersbach, Dortmund

Rowe Colin ( 998 [Engl. I959]) Die Architektur Utopias. In: Die Mathematik der idealen Villa und andere Essays. Birkhäuser, Basel, S. 209-226

-, Koetter Fred ( I988 [Engl. I978]) Collage City. Birkhäuser, Basel

Rullmann Marit (Hrsg.) (I998) Philosophinnen. 2 Bde. Suhrkamp, Frankfurt/M.

Russo Manfred (20I6) Projekt Stadt. Eine Geschichte der Urbanität. Birkhäuser, Basel

S

Saage Richard (I99I) Politische Utopien der Neuzeit. Wissenschaftliche Buchgesellschaft, Darmstadt

- (r999) Utopie und Eros. Zu Charles Fouriers ,,neuer sozietärer Ordnung“. In: UTOPIE kreativ. Diskussion sozialistischer Alternativen, Nr. I05, S. 68-80. Hrsg. v. Rosa-Luxemburg-Stiftung. Online: https://www.rosalux.de/fileadmin/ rls_uploads/pdfs/ı05_Saage.pdf ( I6.4.I7)

- (200I-2004) Utopische Profile. 4 Bde. LIT Verlag, Münster

- (2004) Wie zukunftsfähig ist der klassische Utopiebegriff? In: UTOPIE kreativ. Diskussion sozialistischer Alternativen, Nr. I65/I66, S. 6I7-636. Hrsg. v. Rosa-Luxemburg-Stiftung. Online: http://www.rosa-luxemburg-club.de/fileadmin/rls_ uploads/pdfs/I65_i66-saage.pdf (I7.4.I7)

- (2008) Utopieforschung. 2 Bde. LIT Verlag, Berlin

Safranski Rüdiger (2007) Romantik. Eine deutsche Affäre. Hanser, München

Sant'Elia Antonio, Marinetti Filippo Tommaso (I9I4) Futuristische Architektur. In: Ulrich Conrads (Hrsg.) (200 I [zuerst I964]) Programme und Manifeste zur Architektur des 20. 
Jahrhunderts. Bauwelt Fundamente, Bd. I. Vieweg, Braunschweig u. Wiesbaden, S. 30-35

Schaik Martin van, Mácel Otakar (Hrsg.) (2005) Exit Utopia. Architectural Provocations I956-76. Prestel, München Scheppe Wolfgang (20I8) Die Grundrente der Kunst und der Ausschluss aus der Stadt. Das Exemplarische an Venedigs Singularität. In: Archplus, Nr. 23 I: The Property issue, S. I4-3 I

Schick Ludwig (20I0) Der Gottesstaat Augustins. Maßgabe für heutige Staaten? Festrede zur Jahresvollversammlung der Gesellschaft zur Förderung der Augustinus-Forschung e.V. Online: https://de.zenit.org/articles/der-gottesstaat-augustinsmassgabe-fur-heutige-staaten/ (I8.I2.I 8)

Schiller Friedrich (2009 [zuerst I795]) Über die ästhetische Erziehung des Menschen. Suhrkamp, Frankfurt/M.

Schimank Uwe (20I2) Vom ,fordistischen“ zum ,postfordistischen“ Kapitalismus. Online: https://www.bpb.de/politik/ grundfragen/deutsche-verhaeltnisse-eine-sozialkunde/I37994/ vom-fordistischen-zum-postfordistischen-kapitalismus? $\mathrm{p}=$ all ( I I.8.19)

Schloßberger Matthias (20I3) Geschichtsphilosophie. Akademie Verlag, Berlin

Schmelzer Matthias, Vetter Andrea (20I9) Degrowth/Postwachstum. Zur Einführung. Junius, Hamburg

Schmidt Burghart ( I 988) Kritik der reinen Utopie. Eine sozialphilosophische Untersuchung. Metzler, Stuttgart

Schmitt Carl (2015 [zuerst I927/I932]) Der Begriff des Politischen. Text von I932 mit einem Vorwort und drei Corollarien. Duncker \& Humblot, Berlin

Schneider Tatjana, Till Jeremy (2009) Beyond Discourse: Notes on Spatial Agency. In: Footprint, Nr. 4: Agency in Architecture, S. 97-I I I. Online: https://doi.org/ I0.7480/footprint.3. I.702 (30.4.14)

Schölderle Thomas (20I2) Geschichte der Utopie. Eine Einführung. Böhlau, Köln

Schriefers Thomas (2005) Für die Ideen dieser Welt. Temporäres Bauen. In: Temporäre Architektur an besonderen Orten. Blaue Reihe StadtBauKultur NRW, S. IO-I 5. Online: https:// stadtbaukultur-nrw.de/site/assets/files/I 566/ temparchitekur I40205.pdf (4.7.I7) 
Schulte-Bulmke Gerhard ( I952) Vorwort zur dritten Auflage. In: Karl Mannheim ( 1969 [zuerst I929]) Ideologie und Utopie. Verlag Schulte-Bulmke, Frankfurt/M., S. v-vi

Schumacher Patrick (20I 8 [Engl. 20I6]) Acht-Punkte-Manifest. In: Archplus, Nr. 23I: The Property Issue, S. 97

Schumpp Mechthild (1972) Stadtbau-Utopien und Gesellschaft. Der Bedeutungswandel utopischer Stadtmodelle unter sozialem Aspekt. Bauwelt Fundamente, Bd. 32. Bertelsmann, Gütersloh

Schweppenhäuser Gerhard ( I996) Theodor W. Adorno zur Einführung. Junius, Hamburg

- (2007) Ästhetik. Philosophische Grundlagen und Schlüsselbegriffe. Campus, Frankfurt/M.

Sharzer Greg (20I2) No Local. Why Small-Scale Alternatives Won't Change The World. Zero Books, Winchester/UK Shvartzberg Carrió Manuel (20 I8) Verteidigung der Demokratie. Gegen eine anarchokapitalistische Architektur. Erwiderung auf Schumacher. In: Archplus, Nr. 23 I: The Property issue, S. IO2-IO7

Simmel Georg ( I903) Über räumliche Projektionen sozialer Formen. In: Jörg Dünne, Stephan Günzel (Hrsg.) (2006) Raumtheorie. Grundlagentexte aus Philosophie und Kulturwissenschaften. Suhrkamp, Frankfurt/M., S. 304-3 I6

Sloterdijk Peter (I983) Kritik der zynischen Vernunft. Suhrkamp, Frankfurt/M.

- (2014 [zuerst I994]) Die Stadt und ihr Gegenteil: Apolitologie im Umriss. In: Ders. Der ästhetische Imperativ. Schriften zur Kunst. Suhrkamp, Berlin, S. I 84-229

- (2004) Architekten machen nichts anderes als In-Theorie. Sloterdijk im Gespräch mit Sabine Kraft und Nikolaus Kuhnert. In: Archplus, Nr. I69/I70: Architekturen des Schaums, S. I4-2 I

Smith Adam (2009 [1978/Engl. I776]) Der Wohlstand der Nationen. Eine Untersuchung seiner Natur und seiner Ursachen. I 2. Auflage. Übers. u. hrsg. v. Horst Claus Recktenwald. DTV, München

Smith Neil (2008) Uneven Development. Nature, Capital, and the Production of Space. Third Edition. University of Georgia Press, Athens/GA 
Solnit Rebecca (2007) Detroit Arcadia. Exploring the post-

American Landscape. Letter from Michigan. In: Harper's

Magazine (Juli 2007) S. 65-73. Online: https://harpers.org/ archive/2007/07/detroit-arcadia/ (30. I I. I 8)

Sommer Bernd, Welzer Harald (2017) Transformationsdesign. Wege in eine zukunftsfähige Moderne. Oekom Verlag, München

Spivak Gayatri Chakravorty (2008 [Engl. I988]) Can the Subaltern Speak? Postkolonialität und subalterne Artikulation. Turia + Kant, Wien

Srnicek Nick, Williams Alex (20I6 [Engl. 20I5]) Die Zukunft erfinden. Postkapitalismus und eine Welt ohne Arbeit. Bittermann, Berlin

Steets Silke (20 I5) Der sinnhafte Aufbau der gebauten Welt. Eine Architektursoziologie. Suhrkamp, Berlin

Stockinger Ludwig ( I982) Aspekte und Probleme der neueren Utopiediskussion in der deutschen Literaturwissenschaft. In: Wilhelm Voßkamp (Hrsg.) Utopieforschung. Interdisziplinäre Studien zur neuzeitlichen Utopie, Bd. I. Metzler, Stuttgart, S. $\mathrm{I} 20-\mathrm{I} 42$

Szidat Joachim ( I980) Hippodamos von Milet. Seine Rolle in Theorie und Praxis der griechischen Stadtplanung. In: Verein von Altertumsfreunden im Rheinlande (Hrsg.) Bonner Jahrbücher. Jahrbücher des Vereins von Altertumsfreunden im Rheinlande, Bd. I80, S. 3 I-44

$\mathbf{T}$

Tafuri Manfredo (I980 [Ital. I968]) Theories and History of Architecture. Harper \& Row, New York/NY

- (I977 [Ital. I973]) Kapitalismus und Architektur. Von Corbusiers „Utopia“ zur Trabantenstadt VSA, Hamburg u. Westberlin

- (I987 [Ital. I980]) The Sphere and the Labyrinth. AvantGardes and Architecture from Piranesi to the I970s. MIT Press, Cambridge/MA

- (2006 [Ital. I992]) Interpreting the Renaissance. Princes, Cities, Architects. Yale University Press, New Haven/CT Taylor Charles (I993 [Engl. I992]) Multikulturalismus und die Politik der Anerkennung. Fischer, Frankfurt/M. 
Tempest Kate (20I9) The Book of Traps and Lessons. Caroline Records, London/UK

Thierstein Alain (20I8) Das Kind mit dem Bade ausschütten?

Erwiderung auf Schumacher. In: Archplus, Nr. 23I: The

Property issue, S. I08-I09

Thompson Edward P. (1987 [Engl. I963] Die Entstehung der

englischen Arbeiterklasse. Suhrkamp, Frankfurt/M.

Thoreau Henry D. (20I0 [Engl. I 849]) Über die Pflicht zum Unge-

horsam gegen den Staat. 20. Auflage. Diogenes, Zürich

Tod Ian, Wheeler Michael ( I978) Utopia. Orbis, London/UK

Tonkiss Fran (2013) Austerity Urbanism and the Makeshift City.

In: City, Nr. I7/3, S. 3I 2-324. Online: https://doi.org/Io. Io8o/ I36048I3.20 I3.795332 (4.7.I5)

Tönnesmann Andreas (2004) Filarete im Dialog: Der Architekt, der Fürst und die Macht. In: Bodo Guthmüller, Wolfgang G. Müller (Hrsg.) Dialog und Gesprächskultur in der Renaissance. Sonderdruck. Harrassowitz Verlag in Kommission der Herzog August Bibliothek Wolfenbüttel, S. I 53-I63

Trapp Harald (20I8) Kapital Heim. In: Archplus, Nr. 23I: The Property issue, S. 34-39

Triebel-Schubert Charlotte, Muss Ulrike (1983) Hippodamos von Milet. Staatstheoretiker oder Stadtplaner? In: Hephaistos.

Kritische Zeitschrift zu Theorie und Praxis der Archäologie und angrenzender Gebiete, Nr. 5/6, S. 37-6o

Trompenaars Alfons, Hamden-Turner Charles (I993) Riding the Waves of Culture. Understanding Cultural Diversity in Business. Random House, New York/NY

Trousson Raymond ( I982) Utopie, Geschichte, Fortschritt. Das Jahr 2440. In: Wilhelm Voßkamp (Hrsg.) Utopieforschung. Interdisziplinäre Studien zur neuzeitlichen Utopie. Bd. 3. Metzler, Stuttgart, S. I5-23

Turner John F. C. (I978 [Engl. I976]) Verelendung durch Architektur. „Housing by people“. Plädoyer für eine politische Gegenarchitektur in der Dritten Welt. Rowohlt, Reinbek bei Hamburg

U

Ueding Gerd (I982) Ernst Blochs Philosophie der Utopie. In:

Wilhelm Voßkamp (Hrsg.) Utopieforschung. Interdisziplinäre 
Studien zur neuzeitlichen Utopie, Bd. I. Metzler, Stuttgart, S. 293-303

- (2009) Utopie in dürftiger Zeit. Studien über Ernst Bloch.

Königshausen u. Neumann, Würzburg

V

Virilio Paul ( I984) Die Auflösung des Stadtbildes. In: Jörg Dünne,

Stephan Günzel (Hrsg.) (2006) Raumtheorie. Grundlagen-

texte aus Philosophie und Kulturwissenschaften. Suhrkamp,

Frankfurt/M., S. 26I-273

Vitruv ( 964 [Lat. ab 33 v. Chr.]) Zehn Bücher über Architektur.

Übers. u. mit Anmerkungen versehen v. Curt Fensterbusch.

Wiss. Buchgesellschaft, Darmstadt

Vogl Joseph (2010) Das Gespenst des Kapitals. Diaphanes, Zürich

Vollmer Lisa (20 I8) Strategien gegen Gentrifizierung. Schmetter-

ling Verlag, Stuttgart

Vretska Karl (20Io [zuerst I958]) Einleitung. In: Platon (387-

367 v. Chr.) Der Staat (Politeia). Bibliographisch ergänzte

Ausgabe 2000. Übers. u. hrsg. v. Dems. Reclam, Stuttgart,

S. $\mathrm{I}-82$

W

Wachinger Marie, Wallaschek Stefan (2019) Die Zukunft der Solidarität, (keine) zwei Meinungen. Rezension: Heinz Bude (20I9) Solidarität. Die Zukunft einer großen Idee. Online: https://www.theorieblog.de/index.php/20I9/o6/die-zukunftder-solidaritaet-keine-zwei-meinungen/ (2 I.6.19)

Weidermann Volker (20I8) Träumer. Als die Dichter die Macht übernahmen. Kiepenheuer \& Witsch, Köln

Weiss Peter (20I8 [zuerst I975-8I]) Die Ästhetik des Widerstands. 3 Bde. 4 . Auflage. Suhrkamp, Frankfurt/M.

Welsch Wolfgang ( I993) Unsere postmoderne Moderne. Akademie Verlag, Berlin

- (2009 [seit I992]) Was ist eigentlich Transkulturalität? In: Lucyna Darowska, Thomas Lüttenberg, Claudia Machold (Hrsg.) Hochschule als transkultureller Raum? Kultur,

Bildung und Differenz in der Universität. transcript, Bielefeld, S. $39-66$ 
Wiebenson Dora (1960) Utopian Aspects of Tony Garnier's Cité Industrielle. In: Journal of the Society of Architectural Historians (JSAH), Nr. xix, S. I6-24

Willke Helmut (200I) Atopia. Studien zur atopischen Gesellschaft. Suhrkamp, Frankfurt/M.

Wirth Louis ( 1937) Vorwort zur englischen Ausgabe, später ins

Deutsche übertragen. In: Karl Mannheim ( I969 [zuerst I929])

Ideologie und Utopie. Verlag Schulte-Bulmke, Frankfurt/M.,

S. ix-xxvii

Wischhoff Mona (2013) Geäußerte Künstlerkritik der Gegenwart.

Das politische Potenzial einer ,Relationalen Ästhetik“. In:

DIENADEL - Kulturwissenschaftliche Zeitschrift für Kunst und Medien, Nr. I/20I3, S. 60-82

Wolf Frieder Otto (20I4) Was bedeutet der „Materialismus der

Begegnung“ bei Louis Althusser? Versuch, eine neue Perspektive zu eröffnen, S. I97-222. In: Marc Berdet, Thomas Ebke (Hrsg.) Anthropologischer Materialismus und Materialismus der Begegnung. Vermessungen der Gegenwart im Ausgang von Walter Benjamin und Louis Althusser. xenomoi, Berlin Wright Erik Olin (20I7 [Engl. 20Io]) Reale Utopien. Wege aus dem Kapitalismus. Suhrkamp, Berlin

\section{Z}

Zimmermann Margarete (I990) Einleitung. In: Christine de Pizan ( I405) Das Buch von der Stadt der Frauen. DTV, München, S. 9-33

Žižek Slavoj (2008 [zuerst I989]) The Sublime Object of Ideology. Verso, London/UK

Zuboff Shoshana (20I9) Das Zeitalter des Überwachungskapitalismus. Campus, Frankfurt/M.

Zudeick Peter ( 1985) Der Hintern des Teufels. Ernst Bloch. Leben und Werk. Elster, Moos u. Baden-Baden

\section{Nachschlagewerke}

Geschichte der Architekturtheorie. Von der Antike bis zur Gegenwart (2004 [zuerst I985]) Hanno-Walter Kruft. Studienausgabe. 5. Auflage. C.H.Beck, München

Geschichte der Kunst (2016 [Engl. I950]) Ernst H. Gombrich Phaidon, Berlin 
Geschichte des politischen Denkens. 2 Bde (20I 2 [zuerst 2006])

Ein Handbuch; u. (20I8) Das 20. Jahrhundert. Hrsg v.

Manfred Brocker. Suhrkamp, Frankfurt/M. u. Berlin

Hauptwerke der politischen Theorie (2007) hrsg. v. Wilhelm

Hofmann, Giesela Riescher, Theo Stammen. Kröner, Stuttgart

Hauptwerke der Soziologie (2000) hrsg. v. Dirk Kaesler, Ludgera

Vogt. Kröner, Stuttgart

Historisches Wörterbuch der Philosophie. I3 Bde (I97 I-2007)

hrsg. v. Joachim Ritter, Karlfried Gründer, Gottfried Gabriel.

Wiss. Buchgesellschaft, Darmstadt u. Schwabe, Basel

Historisch-kritisches Wörterbuch des Marxismus. I5 Bde (seit

I994) hrsg. v. Berliner Institut für kritische Theorie (InkriT).

Argument, Hamburg

Lexikon der Weltarchitektur (I992 [Engl. I966]) hrsg. v. Nikolaus

Pevsner, John Fleming, Hugh Honour. Prestel, München

Lexikon der Weltliteratur. 4 Bde ( I997) hrsg. v. Gero von Wilpert.

DTV, München

Wörterbuch der philosophischen Begriffe (2005) hrsg v. Arnim

Regenbogen, Uwe Meyer. Meiner, Hamburg 
Abbildungsverzeichnis 
I Stadtanlage Sforzinda, Filarete, I46I-64

Traktatauszug: (C) Ministero per i beni e le attività culturali e per il turismo. Biblioteca Nazionale Centrale di Firenze https://www.bncf.firenze.sbn.it/Bib_digitale/Manoscritti/ II. I40/main.htm (2.4. I9)

2 Gartenstadt-Diagramm Nr. 7, Ebenezer Howard, I 898 https://commons.wikimedia.org/wiki/File:Diagram_No.7_ (Howard,_Ebenezer,_To-morrow.).jpg (25.5.I9)

3 Cité Industrielle, Gesamt- u. Schemaplan, Tony Garnier, I904/I9I 7

Collage: Sandra Meireis

https://www.penccil.com/gallery.php?p=4905044 I 4 I 59 (9.8.20)

Dora Wiebenson (1969) Tony Garnier. The Cité Industrielle. George Braziller, New York/NY, Tafel 8I

4 Gemeinschaften und Eigenbrötler, Zeichnung Nr. Io, Bruno Taut, I920

Bruno Taut (I920) Die Auflösung der Städte oder die Erde eine gute Wohnung oder auch: Der Weg zur Alpinen Architektur. Folkwang Verlag, Hagen

Digitalisat: https://digital.ub.tu-berlin.de/view/work/ BVoI337397I/I/ (28.I2.I8)

5 Città Nuova, Stazione, Antonio Sant'Elia, I9I4 https://upload.wikimedia.org/wikipedia/commons/4/4f/ Stazione_Sant\%27Elia.jpg (24.7.20)

6 Plan Voisin, Le Corbusier, I925 Buchauszug: (C) VG Bild-Kunst Le Corbusier ( 1964 [zuerst I933]) La Ville Radieuse. Éléments d'une doctrine d'urbanisme pour l'equipement de la civilisation machiniste. Vincent, Freal \& Cie Editeurs, Paris, S. I35

7 Monumento Continuo: St. Moritz rivisitata, Superstudio, I 969 Grafik: (C) Gian Piero Frassinelli

Peter Lang, William Menking (Hrsg.) (2003) Superstudio. Life Without Objects. Katalog zu gleichnamigen Ausstellungen in London und New York. Skira Editore, Mailand, S. I44-I 45

8 The Doorn Manifesto, Alison u. Peter Smithson, I954. Manuskript: (C) Collection Het Nieuwe Instituut / TTEN, 9-I

9 Luchtsingel Rotterdam, 20 I I-I4

Foto: Ossip van Duivenbode 
https://www.tagesspiegel.de/wirtschaft/immobilien/make-cityin-rotterdam-ein-laufsteg-als-ausweg/I I 972 I 82.html (2 I.5.I9)

Io Les Grands Voisins Paris, Lageplan-Axonometrie, 2016 Grafik: (C) Yes We Camp http://lavoixdu I4e.blogspirit.com/media/o2/oI/344342739o. jpg (2 I.5.19)

I I Küchenmonument seit 2006, RaumlaborBerlin Foto: (C) RaumlaborBerlin http://raumlabor.net/kuchenmonument/ (I 5.4.I 5)

I 2 Stadtlücken Stuttgart, 20 I 9 Foto: (C) Stadtlücken https://www.oe-platz.de/bildergalerie (I9.5.19)

I3 The Cineroleum, Assemble, London, 2010 Foto: Zander Olsen https://assemblestudio.co.uk/projects/the-cineroleum (I.3.I9)

I4 Holzmarkt 25 Berlin, 2017 Foto: Tom Maelsa ( I 5.5. I7)

I5 Prinzessinnengarten Berlin, Laube seit 2017 Foto: Marco Clausen (I4.6.I7).

I6 Basurama, Gruppenfoto Foto: (C) Basurama http://basurama.org/basurama/ (23.7.I9)

I7 Assemble, Gruppenfoto Foto: (C) Assemble https://assemblestudio.co.uk/about (I3.7.20)

I 8 Himmelbeet, Berlin, 20I3-2 I. Foto: Sandra Meireis (I 8.6.19).

I9 Union Street Urban Orchard, London, 20I0 Foto: Mike Massaro https://www.wayward.co.uk/project/union-street-urbanorchard (I9.5.19)

20 Park Fiction, Hamburg, seit 1995

Foto: (C) ahoihamburg.de https://www.instagram.com/p/BwkKUegHmsR/ (26.8.I9).

2 I b_books, Berlin, seit 1996 Foto: (C) Aisthesis https://bersarin.files.wordpress. com/20i6/o7/I6_07_24_p_5_6985I.jpg (I7.7.20) 
22 Universität Leuven, Lucien Kroll, I976 https://www.domusweb.it/en/architecture/20 Io/o6/30/lucienkroll-utopia-interrupted.html (27.5.19)

23 Picnurbia, Loose Affiliates, Vancouver/BC, 20 I I

Foto: Krista Jahnke

24 Urban Farming, Detroit North End, seit 20 I I

Foto: (C) Nadir Ali/3andathird

https:/www.metrotimes.com/detroit/on-urban-farming-

and-colonialism-in-detroits-north-end-neighborhood/

Content?oid=7950059 (24.7.19)

25 Ex-Rotaprint, Illustration

Grafik: Beatrice Terrmeer

https://stadtvonunten.de/suk/pro/exrotaprint/ (24.7.19)

26 Babel im Park, Hildesheim, On/Off, 2017

Foto: Robert Oppermann

http://www.onoff.cc/projects/babel/ (23.7.r9).

27 Microlibrary Taman Bima, SHAU, 2020

Foto: (C) SHAU Architects

http://www.shau.nl/de/project/84 (I4.8.20)

28 Haus der Statistik, Raumlabor/ZUsammenKUNFT Berlin

e.G., seit 2015

Grafik: RaumlaborBerlin

http://raumlabor.net/haus-der-statistik/ (23.7.I9).

29 Funding the Cooperative City, 2017

Grafik: Cooperative City

https://cooperativecity.org/funding-the-cooperative-city/

(23.7.19)

30 R-Urban Colombes, Île de France, Illustration, Atelier

d'Architecture Autogerée (AAA), 2009-I7

Grafik: AAA

https://agile-city.com/agile-city-research/r-urban-colombesa-sustainable-network-of-agriculture-and-building-processes/ (23.7.19)

3 I Eco-Box, Colombes

Foto: AAA

http://www.urbantactics.org (23.7.19).

32 R-Urban global, Illustration

Grafik: AAA

https://twitter.com/doina_petrescu/

status/52868 I78 I458I32992 (23.7.I9) 


\section{Architektur Denken}

Die Reihe ArchitekturDenken widmet sich der kritischen Reflexion der Architektur im sich wandelnden, heute von den Debatten um Klimawandel, Geschlechtergerechtigkeit, Nachhaltigkeit, Partizipation und Digitalisierung geprägten kulturellen Kräftefeld. Architektur ist jene kulturelle Praxis, mit der der Mensch sich seinen gleichbleibenden wie auch sich ändernden Bedürfnissen eine von der Natur verschiedene, ihm einzig angemessene Lebenswelt schafft. Sie ist ohne Vorbild in der Natur, eine menschliche Erfindung, mit Aristoteles ist sie eine hervorbringende, poietische Kunst und damit immer schon durch Modelle des Denkens mithin Theorie vorstrukturiert. ArchitekturDenken möchte die Modelle des Denkens zur Sprache und zum Bewusstsein bringen, die das Entwerfen (Konzeption), das Bauen (Konstruktion) und die Erfahrung (Perzeption) von Architektur leiten. Da Architektur allein in der Gleichzeitigkeit von Empfindung und Intellekt sowie Denken und Handeln besteht, verfolgt ArchitekturDenken, über das Verständnis als Ideengeschichte hinaus, eine kulturphilosophische Erweiterung der Architekturtheorie. 
1 Architekturtheorie heute. Jörg H. Gleiter, 2008 ISBN 978-3-89942-879-7

2 Die enzyklopädische Architektur. Gerd de Bruyn, 2008 ISBN 978-3-89942-984-8

3 Welten und Gegenwelten. Arata Isozaki, 2011 Übersetzt und herausgegeben von Yoco Fukuda, Jörg H. Gleiter und Jörg R. Noennig; ISBN 978-3-8376-1116-8

4 Urgeschichte der Moderne. Jörg H. Gleiter, 2010 ISBN 978-3-8376-1534-0

5 Das Wissen der Architektur. Gerd de Bruyn, Wolf Reuter, 2011 ISBN 978-3-8376-1553-1

6 Alphabet und Algorithmus. Mario Carpo, 2012 Herausgegeben von Jörg H. Gleiter, aus dem Englischen übersetzt von Jan Bovelet und Jörg H. Gleiter; ISBN 978-3-8376-1355-1

7 Symptom Design. Herausgegeben von Jörg H. Gleiter, 2014 ISBN 978-3-8376-2268-3

8 Architektur und Philosophie. Herausgegeben von Jörg H. Gleiter und Ludger Schwarte, 2015 ISBN 978-3-8376-2464-9

9 Das Diaphane. Herausgegeben von Ulrike Kuch, 2020 ISBN 978-3-8376-4282-7

10 Media Agency. Herausgegeben von Christophe Barlieb und Lidia Gasperoni, 2020 ISBN 978-3-8376-4874-4

11 Betrachtungen der Architektur. Versuche in Ekphrasis Herausgegeben von Tim Kammasch, 2020 ISBN 978-3-8376-4994-9

12 Mikro-Utopien der Architektur. Sandra Meireis, 2021 ISBN 978-3-8376-5197-3

Erhältlich im Buchhandel oder beim transcript Verlag. Portofreie Zustellung bei Bestellung direkt vom Verlag. Fax +49 (521) 393797-34 bestellung@transcript-verlag.de www.transcript-verlag.de 
